UCRL-15673

PSA 1312705

\title{
Human Factors Design Guidelines for Maintainability of Department of Energy Nuclear Facilities
}

James P. Bongarra, Jr., Harold P. VanCott, Richard F. Pain, L. Rolf Peterson, Ronald I. Wallace

June 18,1985

Prepared for:

U.S. Department of Energy Office of Nuclear Safety

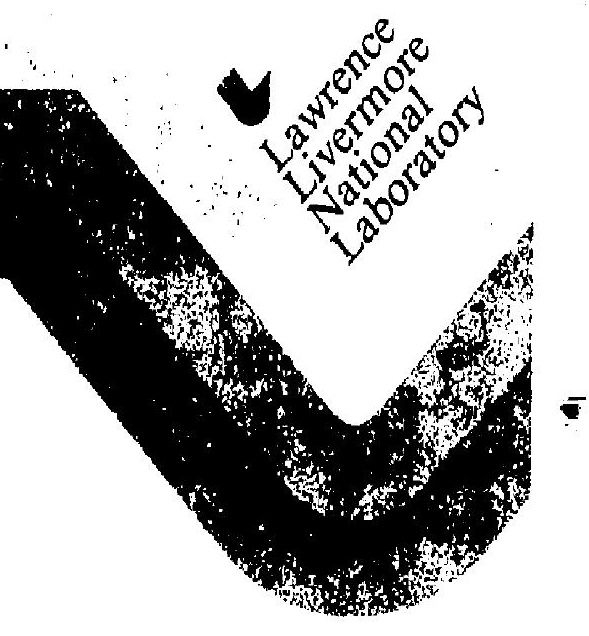




\title{
HUMAN FACTORS DESIGN GUIDELINES FOR MAINTAYNABILITY OF DEPARTMENT OF ENERGY NUCLEAR FACILITIES
}

\author{
James $P$. Bongarra, Jr. \\ Harold P. VanCott \\ Richard F. Pain \\ L. Rolf Peterson \\ Ronald I. Wallace \\ Prepared by: \\ BioTechnology, Inc.
}

Falls Church, Virginia 22042

Contract No. PSA 8096701

\author{
Revised by: \\ Essex Corporation \\ Alexandria, Virginia \\ Contract No. PSA 4312705 \\ Prepared for: \\ U.S. Department of Energy \\ Office of Nuclear Safety \\ Washingtor., J.C. 20585
}

Work performed for:

Lawrence Livermore INational Laboratory

Nuclear Systems Safety Program

June 18, 1985 


\title{
FOREWORD
}

This document, Human Factors Design Guidelines for Maintainability of Department of Energy (DOE) Nuclear Facilities, was prepared by BioTechnology, Iric., Falls Church, VA, under the auspices of the Office ci Nuclear Safety, U.S. Department of Energy. This project was performed as a subcontract to the Nuclear Systems Safely Program, Human Factors Engineering, Lawrence Livermore National Laboratory.

Thanks is also expressed to Dr. Richaro F. Pain, Project Director for BioTechnology, and the following members of the BioTechnology support staff: Kristy L. Donnelly, editing and producticn coordination, Betty J. Price, word processing, and Tammy S. Black, graphics.

Revisions of materials after receipt of comments from the Department of Energy Field Offices were made by Lawrence Livermore National Laboratory and Essex Corporation.

\section{DISCLAIMER}

\begin{abstract}
This report was prepared as an account of work sponsored by an agency of the United States Government. Neither the United States Goverminent nor any agency thereof, nor any of their cmployes, makes any warranty, express or implied, or assumes any legal liability or responsibility for the accuracy, completeness, or usefulness of asy information, apparalus, product, or process disclosed, or represents that its use would not infringe privately ownet rights. Reference berein to any specific commercial product, process, or service by trade name, trademark. manufacturer, or otherwise does not necessarily constitute or imply its endorsement, recom. mendation, or favoring by the United States Government or any agency therenf. The views and opisions of authors expressed berein do not necessarily state or teflect those of the United Stales Gowernment or any agency thereol.
\end{abstract}




\section{PURPOSE AND SCOPE}

The intent of these guidelines is to provide design and design revlew teams of DOE nuclear facilities with human factors principles to enhance the design and aid in the inspection of DOE nuclear facilities, systems, and equipment.

These guidelines are concerned with design features of DOE nuciear facilities which can potentially affect preventive and corrective maintenance of systems within DOE nuclear facilities. Maintenance includes inspecting, checking, troubleshooting, adjusting, replacing, repairing, and servicing activities. Other factors which influence maintainability such as repair and maintenance support facilities, maintenance information, and various aspects of the environment are also addressed. 


\section{CONTENTS}

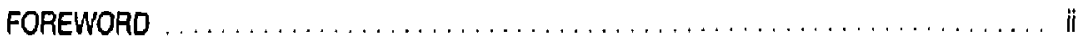

PURPOSE AND SCOPE $\ldots \ldots \ldots \ldots \ldots \ldots \ldots \ldots \ldots \ldots \ldots \ldots \ldots \ldots \ldots \ldots \ldots \ldots \ldots$

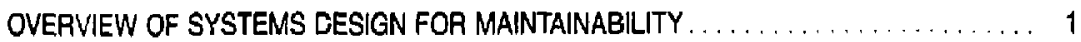

INTRODUCTION TO THE GUIDELINES $\ldots \ldots \ldots \ldots \ldots \ldots \ldots \ldots \ldots \ldots \ldots$

HUMAN FACTORS DESIGN GUIDELINES FOR

MAINTAINABILITY OF DOE NULLEAR FACILITIES $\ldots \ldots \ldots \ldots \ldots \ldots \ldots \ldots$

\subsection{ENGINEERED HARSWAPE}

1.1 Unitization and Modularization for Maintainability ............ $1.1-1$

1.2 Unit Layout, Packaging, and Mounting for Maintainability ......... 1.2-1

1.3 Hardware Identification for Maintainability ................. $1.3-1$

1.4 Equipment Accessibility ............................. 1.4

1.5 Controls and Displays for Maintainability ................. $1.5-1$

1.6 Line and Cable Design for Maintainability ................. $1.6-1$

1.7 Test and Service Point Design for Maintainability ............. $1.7-1$

1.8 Test Equipment Design for Maintainability . . . . . . . . . . . . . . . $\quad \uparrow .8-1$

1.9 Connector Ḋesign for Maintainability . . . . . . . . . . . . . . . . . 1.9-1

1.10 Cover, Case, and Shield Design for Maintainability ............. 1.10-1

1.11 Fastener Design and Application for Maintainability . . . . . . . . . . . 1.11-1

1.12 Drawer and Rack Design for Maintainability . . . . . . . . . . . . . 1.12-1

1.13 Handle Design for Maintainability . . . . . . . . . . . . . . 1.13 !

\subsection{FACILITY SUPPORT}

2.1 Workspace, Storage, and Repair Facility Design for Maintainability . . . 2.1-1

2.2 Maintenance Support Equipment . . . . . . . . . . . . . . . . . . . . 2.2-1

2.3 Hand Tool Design for Maintainability .................... 2.3-1

2.4 Stair, Ladder, and Ramp Design for Maintainability . . . . . . . . . . . 2.4-1

2.5 Platform and Shelter Design for Maintainability ............. 2.5-1

2.6 Design of Computer Systems for Maintainability ................ 2.6-1

\subsection{PERSONNEL}

3.1 Engineering Anthropometry in the Design for Maintainability ........ 3.1-1

3.2 Environmental Conditions and Constraints Affecting Maintainability ... . 3.2-1

3.3 Maintenance Information. ......................... $3.3^{-1} 1$

3.4 Design Plan and Schedule for Maintainability .............. $3.4-1$

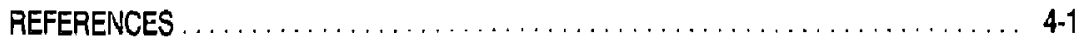

SOURCE REFERENCE DOCUMENT $\ldots \ldots \ldots \ldots \ldots \ldots \ldots \ldots \ldots \ldots \ldots \ldots \ldots \ldots$ 


\section{OVERVIEW OF SYSTEMS DESIGN FOR MAINTAINABILITY}

\section{Reliability vs. Maintainability}

Reliability, that is, whether something is available and able to perform its required function, is a property inherent to the system or piece of equipment. Reliability may be further defined as "the probability that the system or component is available for use when needed." " One measure of reliability is a numerical probability indicating the likelihood of failure-free operation for a specific period of time. Another measure of reliability is mean time between failures (MTBF), which refers to the total system operating time divided by the number of system failures during that time. The reliability of a piece of equipment or a system is predominantly dependent upon the merits (or demerits\} of its design.

Maintainability is that characteristic of design and installatior, which affects the amount of time necessary to repair, test, calibrate, or adjust an item to a specified condition, when using defined procedures and resources. The two classes of maintainability, preventive and corrective, are highly dependent upon the characteristics of the user. Both classes, regardless of how well a piece of equipment is designed, are "intimately bound to the existing knowledge, practices, skills, facilities, environment, and supplies of the user-maintainer." * Each of these factors must be considgred when designing for maintainability. Each will be bound by the limitations of the user. One must additionally consider equipment reliability. If a piece of equipment never fails, corrective maintenance will not be necessary.

\section{Background of Systems Design for Maintainability}

Systems design for maintainability has, as a prime objective, the design of equipment and systems capable of being maintained in the least amount of time, at the lowest cost, and with a minimum expenditure of support resources. Attempts to achieve this objective have evolved into the engineering discipline of maintainability.

Maintainability engineering was a direct result of reliability programs being performed primarily by the military in the late 1940 s and early 1950 s. This research indicated that the goal of designing equipment with $100 \%$ reliability (i.e., equipment that would never fail) was impossible. The concept of maintainability evolved from the increase in complexity, size, and quantity of items that comprise a system, and the associated technical problems, increased support costs, and technological advances. Therefore, the problem of maintenance became a fact of life that had to be effectively managed, The oiscipline of maintainability engineering was established to provide designers with a source of specialized knowledge and skill about the support and maintenance of equipment and systerns.

\section{Application of Systems Design for Maintainability (in an emerging design)}

To realize the goal of maintainability, that is, to restore a system or device that has failed to operational effectiveness easily and cost effectively, requires that maintainability and the associated human factors contributions be considered as part of the total systems design process. Maintainability must be designed into the system and equipment during the beginning stage of development to ensure that costly maintenance and/or redesign are avcided. Systems design for maintainability is an evolutionary process that starts in the equipment concept stage and ends after the equipment has been built and tested,

-Evans, R.A., "Reliability Optimization," in E.J. Henley and J.W. Lynn (Eds.). Genaric Techriques in Systems Reliability Assessment. Leycen, the Netherlands: Noordhoft International Publishing, 1976, 117-131.

"Morgan, C.T., Chapanis, A., Cook, J.S.. II!, \& Lund, M.W. (Eds.) Human engineering guide to equipment design. New York: MeGraw-Hill, 1983. 368. 
Though the process of designing for maintainability will vary to some extent, depending on the level of effort required by the type of system and/or equipment being designed, there are elements which are standard to any systems design for maintainability. As a minimum, designing for maintainability should include the following steps: planning, designing, and testing and revising the design.

During the planning step, requirements and objectives for maintainability are established by defining such parameters as the goal or mission of the system, the availability and dependability required by the system, personnel and support equipment, facilities and resources available, levels of maintenance that will be required (i.e., iield, shop, factory), etc. By the time functional diagrams, specifications, and drawings are being produced, designing for maintainability should be well underway, This second step in a systems design process for maintainability is when the design team determines maintainability design criteria for the system and/or equipment being designed. These criteria will focus on accomplishing objectives such as:

- Reducing the need for and frequency of design-dictated maintenance.

- Reducing system/equipment down-time.

- Reducing desigri-dictated maintenance suppors costs.

- Limiting maintenance personnel requirements.

- Reducing the potential for maintenance error.

- Using standard procedures, equipment, and tools, when possible.

The Human Factors Design Guidelines for Maintainability of DOE Nuclear Facilities has been assembled to provide the design team with generic design principles to help satisfy the abovementioned objectives. It is important to remember that the principles contained in the guidelines which follow are malleable, especially for an emeiging system. It is quite likely that during the application of these guideiines to an emerging design, modification, addition, or elimination of some principles might occur irl favor of alternative criteria for effective maintainability. The "goodness of fit" of the guideline principles can be adequately judied only if the next step of the design program, testing and revising the design, is accomplished.

The testing and revising step is where a developmental model of the equipment le.g., scale model, bench mock-up, or simulator) is tested under conditions that duplicate, as nearly as possible, the actual conditions under which the equipment will be maintained.

For any system design for maintainability to be successful, regardless of the degree of complexisy of the equipment and/or system being designed, there are certain considerations that should be observed in applying the concept of maintainability and in using the guidelines which follow successfully:

1. The concept of maintainability cannot be accomplished by an individual, one specific skill type or level, or by a single organizational en ity. Implementing a successful systems design for maintainability (or retrofit) requires a cooperative effort by a number of professional disciplines.

2. Maintairiability in equipment design can be specified, predicted, measured, and demonstrated. 
3. Planning for maintainability must occur concurrent with equipment design. Lack of consideration for maintainability during the initial stages of design will result in either costly product support throughout the equipment life cycle or the need for costly product design changes.

4. Existing capabilities of facilities, test equipment, personnel, spare parts, etc. should be considered in determining design criteria for maintainability. Theoretical maintainability principles may be waiverd in favor of existing capabilities.

5. During equipment design, the concept of maintainability is applied in conjunction with reliability, human engineering, and other system effectiveness characteristics. A sacrifice of any of these characteristics might be necessary to obtain the best overall design configuration.

6. Equipment or systems that represent the ideal maintainability design characteristics may be prohibitive because of cost. A successtul application of maintainability considers costs incurred during design, development, and production, as well as costs assaciated with equipment support.

7. Maintainability should complement operational requirements of a system.

8. Safety provisions which protect personnel and equipment should receive special consideration in the design for maintainability. If necessary, otherwise desirable design features are rejected to retain safety provisions.

9. Maintenance is a consequence of design. Properly applied maintainability forestalts the requirement of maintenance and alters the course of design to eliminate or reduce the effect.*

"Blanchard, B.S., \& Lowery, E.E, Maintainability: Arinciples and practices. New York: McGraw-Hill, 1969, 11-12. 


\section{INTRODUCTION TO THE GUIDELINES}

\section{Limiletions}

Research in human factors for maintenance has been conducted for over 30 years. The recommendations in this guidelines document are "rules of thumb" or generally accepted practices. However, some principles that are directly related to the nuclear field are not yet adequately supported by empirical research. Therefore, these guidelines do not provide answers to all problems in the design for maintainability of DOE lacillties. It is the author's hope that these guidelines will provide general direction to the design team and facility personnel in the design and/or review of DOE nuclear facilities for effective maintainability practices. The users of these guidelines are encouraged to add their own examples of effective techniques for enhancing the maintainability of systems and equipment. This document is assembled in loose leaf format to facilitate addition of information the user finds helpful.

These guidelines contain human factors principles. Therefore, they emphasize the human element in the design for maintainability of DOE racilities. Prime consideration is given to describing systems and equipment characteristics that will facilitate the technician's performance of required maintenance tasks. These guidelines do not enphasize mainlainability from an engineering science perspective. The methematical techniques used to quantify various parameters such as down time, repair time, costs associated with maintenance, etc. or engineering concepls (e.g., mean time between fallures) that are relevant to equipment reliability or maintainablity ars not the focus of these guidelines. While the principles presented in these guidelines are generally applicable to all systems-military, commer. cial nuclear, or non-nuclear-they are not intended to be applied blindly. $A$ thorough understanding of underlying system design criteria and overall objectives is necessary for these principles to be applied effectively. In some cases, trade-offs in a given design or function of a syslem may require certain design features and/or guidelines to be modified or perhaps replaced by some unique practice.

Though these guidelines do provide general considerations for planning and scheduling for maintainability, no attempt is made to detai! procedures for developing a maintainability program. Designing a maintainability program that will satisty user needs is not within the scope of this present effort. However, source references relevant to maintainability program design are listed in the relerences.

\section{Organization and Content}

The guidelines are organized into three sections, which correspond to major influences on system design for maintainability: engineered hardware, facility support, and personnel. Each section is further divided into guidelines that contain relevant definitions and, in most cases, general and specific human factors design principles for maintainability. These guidelines may be used for designing new facilities; and for evaluating and modifying existing ones. Each section is tabbed for ease of reference. The user may selectively apply a set of principles to a system, subsystem, equipment, or component to ensure conformance to recommended human factors practices for maintainability. To further aid the user, at the beginning of each guideline there is a topical index to the principles contained in the guidelines which directs the user to the specific page on which the principle is identified. 


\section{Application}

These guidelines may be used as a source reference for designers of new facilities and by reviewers of existing facilities concerned with retrofit operations. They are intended for use, as appropriate, with other ralated sources such as applicable industry standards (e.g., ANSI standards), NUREGs (e.g., NJREG-0700, Guidelines for Control Room Design Reviews), Military Sta.1dards (e.g., MIL-STD 1472C), facility-specific procedures, and manufacturer's spricifications.

During the design of a new system and/or equipment, the guidelines may be used by the design team to establish maintenance requiremenis and devalop hypotheses on how maintenance will be provided. The guidelines will aid the design team in establishing parameters such as types and lavels of maintenance that will be required, and kinds, numbers, and levels of training and organization of personriel that will be needed to support the engineering cesign. Application of these guidalines during the initial stage of design (i.e., the "hypothetical design phase" ") will also faclltate allocating functions to humans or automation. Hypothesizing the engineering and human factors requirements for maintenance of a system or equipment is essential for answering the crucial question of which system and task responsibilities are best assigned to humans, which to machine, and which to some combination of the two components.

As part of a retrofit operations, these guidelines may be used by the design review team to determine the existence of human engineering discrepancies (HEOs) in the design of systems and/or equipment for maintainability. An HED, as applied to systums design for maintainability, may be considered as a deviation from some benchmark, such as a standard of human engineering practice or convention, a technician preference or neegd, or an instrumentjequipment characteristic implicitly or ey "sitly required for a maintenance task." The review team may use these guidelines as a source for de. uning detailed checklists for surveying systems and equipmant to identify deficiencies which may affect maintenance tasks.

\section{Source Credits}

These guidelines represont a compilation of information from a wide variety of sources whicn has been selected for application to the design for maintainability and/or retrofit operation: of Deparment of Energy nuclear facilities. While the presentation format and selection of metgriais is original, the material itself is not new. The sources of information used for thiese guidelines are listed in the references and the source reference document.

- Pulliam, R., Price, H.E., Bongarra, J.P., Jr., Sawyer, C.R., \& Kisner, R.A. A methodology for allocating nuclear power plant control functions to human or automatic control (NURGE/CR-3331). U.2. Nuclear Regulatory Commission, Washington, D.C., 1983, 70.

*- This definition has been adapted from Guidelines fo: Coutrol Room Desigan Reviews (NUi-EG-J700), U.:. Nuclear Regulatory Curimission, Washington, D.C., 1981, 1-4. 


\section{HUMAN FACTORS DESIGN GUIDELINES FOR MAINT, AINABIY,ITY OF DOE NUCLEAR FACILITIES}

This section contains human factors guidance for Jesigning systerns and equipment to be maintained with ease and cost effectiveness. The organization of this section follows. As an aid to the user, each guideline is alan, preceded by a topical index.

\subsection{ENGINEERED HARDWARE}

1.1 Unitization and Modularizaiion for Maintainability

1.2 Unit Layout, Packaging, and Mounting for Maintainability

1.3 Hardware Identification For Mair,tainability

1,4 Equipment Accessibilitio

1.5 Contrals and Displays for Maintainability

1.6 Line and Cable Design for Maintainability

1.7 Test and Service Point Design for Maintainability

1.8 Test Equipment Design For Maintainability

1.9 Ccnnector Design for Maintainability

1.10 Cover, Case, and Shield Design for Maintainability

1.11 Fastener Design and Application for Maintainability

1.12 Drawer and Rack Design for Maintainability

1.13 Haindla Design f.JP Maintainability

\subsection{FACILITY SUPPORT}

$\therefore .1$ Workspace, Strrage, and Rapgir Facility Desigrı for Waintainability

2.2 Maintenance Support Equipment

2.3 Hand Tool Design for Maintairabilit,

2.4 Stair, Ladder, and Ramp Design for Maintainability

2.5 Platform and Shelter Design for Maintainahility

2.5 Design of Computer Systems for Muntainability

\subsection{PERSONNEL}

3.1 Engineering Anthropometry in the Design for Maintainability

3.2 Environmental Conditions and Constrair,ts Affecting Maintainability

3.3 Maintenance Information

3.4 Design Plan and Schedule for Maintainability 
1.0 ENGINEERED HARDWARE

1.1 Unitization and Modularization for Maintainability 


\section{ENGINEERED HARDWARE 1.0 \\ UNITIZATION AND MODULARIZATION FOR MAINTAINABILITY 1.1}

\subsubsection{INDEX}

Page

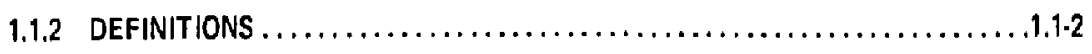

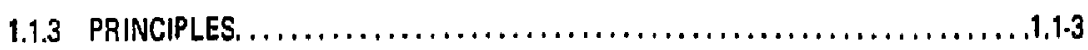

1.1.3.1 Unitization/Modularization...............................

1.1.3.2 Disposable Modules....................................... 
ENGINEERED HAGDWARE 1.0

UNITIZATION AND MODULAFIZATION FOR MAINTAINABILITY $\$ .1$

\subsubsection{DEFINITIONS}

Unitization refers to separating equipment into physically and functionally distinct units to allow for easy removal and replasement. This type of equipment separaition will permit division of maintenance responsibility, especially troubleshooting, among various maintenance levels. Specifically, unit design of equipment will:

a. Maximize the efficiency and accuracy of on-line replacement of system components.

b. Facilitate and minimize troubleshooting time at esch level of maintenance activity.

c. Minimize duplication of maintenance efforts between levels of maintenance activity.

d. Permit production line repair at the higher maincenance level.

e. Permit use of automatic or semi-automatic techniques where practicable.

f. Allow test, checkout, troubleshooting, and repair procedures to be unit specific and structured to aid in identification of faulty units, then subunits, etc.

g. Reduce downtime.

Unitization will also:

a. Provide easy access to malfunctioning components.

b. Allow for high degree of stivi Jardization.

c. Minimize time and cost of maintenance training.

d. Simplity new equipment design and shorten design time by using previously developec standard "building blocks."

Modularization refers to the range of complete interconnected functional units or unitized equipment built on a single structure, down to the smailest printed circuit insert.

Disposable module refers to any module designed to be thrown away rather than repaired after its first failure, assuming that the original diagnosis of failure is validated before disposal. 


\section{$1,1.3$ PRINCIPLES}

\subsubsection{UNITIZATION/MODULARIZATION}

a. Equipment should be divided into as many modules as are electrically and mechanically teasible in keepin! with efficient uss of pace and overall equipment reliability.

b. An integrated approach to design should be used, conșidering simultaneoussly the problems of materials, component design, and application of the modular concept.

c. All modules and component parts stould be approximately unifom in basic size and shape for the best packaging.

d. A module should contain components that contribute to a single, common function rather than providing multiple, divergent functions.

e. Madules and units should be designed to permit operational testing when removed and requirs little or no calibration after replacement.

f. Testing should accept or reject each module wr unit on a go-no-go bosis.

g. The physical separation of equipment into replacesble units should be matched with the functional design of the equipment to maximize the functional independence of units and ininimize interaction between units.

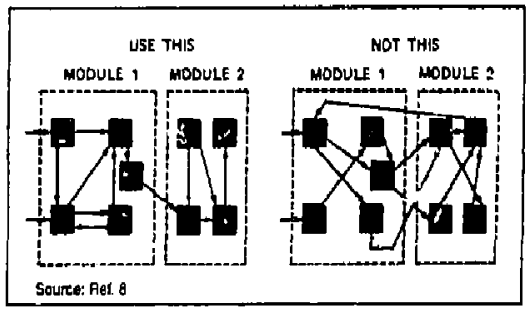

Exhibir 1.1.1 A Hypothetical Equipment Dosign Incarpstating Modularization and Functional Unltization

h. Where an assemply can be made af two or more subasemblies, the major assembly should be designed $x$ that it consists of subassemblies which can be removed independently, without removal of the other subassemblies. This is particularly valuable when the various subassemblies have widely varying life expectancies.

i. All equipment should be designed so that rapid and easy removal and replacement of maffunctioning com. ponents can be accomplished by one technician, unloss this is structurally or funetionally not feasible.

j. Where possible, modules and units should be smell and light enough for one person to handle or carry. The weight of removable units should not exceed 45 lbs. Units weighing more than $10 \mathrm{lbs}$, should have handles.

k. Where possible, each madule should be capable of being checked independently. If adjustment is required, design for adjustment separate from other modules.

1. Control levels and linkages should be designed so they can be easily disconnected from components to permit easy removal and replacement.

$m$, Modularization for forward levels of maintenance should be emphasized to enhance operational capability. Modularization versus parts replacement for shop mainterance can be determisied to a considerable extent by cost factors.

n. Unitizing the module with the urireliable components removable fram the exterior of the pacikage should be considered if all components of a madule except for one or two a re refiable.

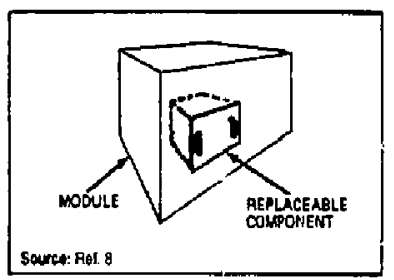

Exhibit 1.1.2 Unitiznion of a Module for Eey Replacament of Law Religbility Componsuts

\subsubsection{DISPOSABLE MODULES}

a. All decisions and requirements for disposable modules should be concurred on by the purthasing activity and should be based on exhaustive and clearly decisive analyses which prove that:

(1!) Maintenance is either impractical or costs more than replacement.

(2) The edventeges of disposable modules outweigh the disadvantages.

\begin{tabular}{|c|c|}
\hline Advantapet & Disadvantoget \\
\hline 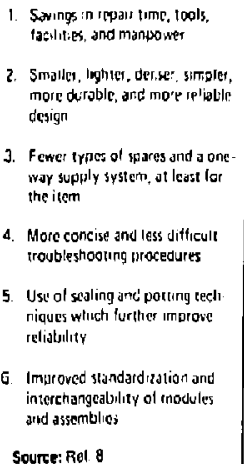 & 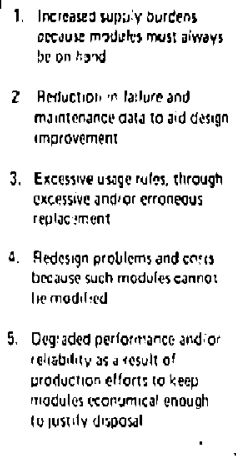 \\
\hline
\end{tabular}

Exhibit 1.1.3 Adrantages and Disadvantayes of Disposable Modules

(3) Significant and favorable differen es exist between the values of:

- End costs of the disposable versus the maintainable module.

- Man-time, materials, tools, etc. necessary to maintain each.

- Supply, storage, handling, and procuring costs and problems.

- Other costs and problems as determinable and appliceble. 
b. Disposable modules should be designed, manufac. tured, and installed to meat the following criteria:

(1) Excencive parts are not thrown away for tailure of inexpensive parts.

(2) Long-ifte pars are not discarded for failure of short life parts.

(3) Low-çost and non-critical items are, in general, made disposable.

(4) Throw-away modules are encapsulated wherever practica.

(5) All encapsulated modules are designed for disposalat fáilure.
(6) Modules costing $\$ 50$ of les ure disposable wherever practical.

(7) Modules costing more then $\$ 50$ are ercopulated as necessary to meet serformence and reliability requirements.

(8) The maintenance level of throw-away modules is cleariy identified.

(9) Test procedures to be applied before disposal are clearly specified and provide clear and unequivocal results.

(10) The identification plate or marking contains the statement: "Dispose of st Failure." 


\subsection{ENGINEERED HARDWARE}

1.2 Unit Layout, Packaging, and Mounting for Maintainability 
1.2.1 INDEX

Page

$1,2,2$ DEFINITIONS $\ldots \ldots \ldots \ldots \ldots \ldots \ldots \ldots \ldots \ldots \ldots \ldots \ldots \ldots, \ldots \ldots \ldots, 2.2$

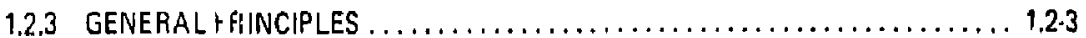

1.2.3.1 Layout of Units and Compznents.......................... 1,2-3

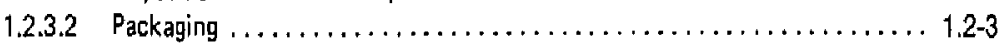

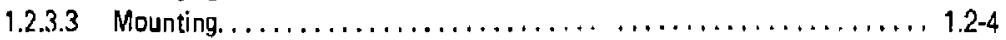

1.2 .4 SPECIFIC PRINCIPLES $\ldots \ldots \ldots \ldots \ldots \ldots \ldots \ldots \ldots \ldots \ldots \ldots \ldots, \ldots \ldots \ldots, 1.2-5$

1.2 .4 .1 Packaging $\ldots \ldots \ldots \ldots \ldots \ldots \ldots \ldots \ldots \ldots \ldots \ldots \ldots \ldots \ldots, 2-5$

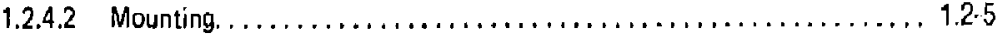




\section{ENGINEERED HARDWARE 1.0}

UNIT LAYOUT, PACKAGING, AND MOUNTING $\mathbf{1 . 2}$

\subsubsection{DEFINITIONS}

Layost refers to the general arrangement and placement of units and components within a system.

Packaging refers to the particular method used to systematically configure units or components.

Mounting refers to a means of attaching and positioning components emphasizing accessibility for maintenance technicians.

Effective layout, packaging, and mounting should:

a. Satisfy unitization and modularization objectives.

b. Minimize place-to-place movement of the technician during servicing, check-out, and troubleshooting.

c. Be organized according to maintenance specialties so that maintenance perforimed by one specialist does not require removal or handling of equipment maintained by another specialist, especially where the equipment is so critica! that it requires highly specialized skills. 


\section{1,2.3 GENERAL PRINCIPLES}

\subsubsection{LAYOUT OF UNITS AND COMPONENTS}

a. Equipment components should be located to minimize the possibility af equipmnnt darnage and personnel injury.

b. Delicate components should be located where they will not be damaged while equipment is being worked on.

c. Comporients stould be positioned so that oil, other fluids, and dirt are not likely to contaminate them.

d. High temperature parts should be guarded or locaied such that personnel tontact will not occur dtrirg operation or maintenance. Heat.producing equipriert should be shielded so that technicians are not made uncomiortable.

e. High-current switching devices should be enclosed to protect personnel.

f. Internal controls should be located away from dangerous volzages.

g. Check points, adjustment points, cable end connections, labels, and 1001 required shous 'se placed in full view and ranch of the tecthician.

h. Smiul, hinge-mounted units, which must have access from the back, should be free to open their full distance and remain open without being held.

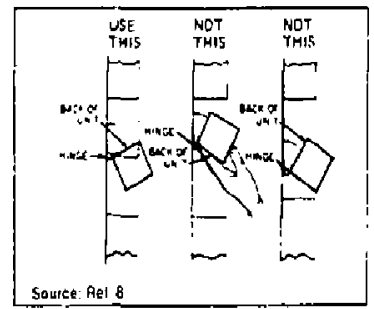

Exhibit 9.2.1 Design of Hinged Units

i. Components and systems which require frequent in spactions should be as easily accessible as possibls.

j. Units should be located so other equipment does not heve to be removed to ga in access.

$k$. Units should not be stzcked. If necessary, place the less frequently accessed unit in the rear or bottom.

1. Frames or structural member's shuuld not intertere with maintenance activities.

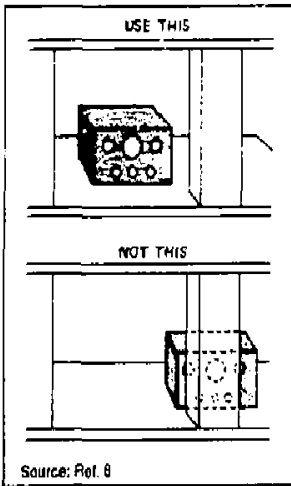

Exhibit 1.22 Proper Pisctmont of Components $\mathrm{m}$. Components that require trequent visual inspection should be installed in positions where they can be easily seen without removing panels, covers, or other units.

ก. Components to be serviced or repaired in position should be at the most favorable working level, i.e. between hip and shoulder height.

\subsubsection{PACKAGING}

a. Labels and codes should be provided on and within the packaging arrangement, as required to;

(1) Outline and identify functional groups of equip ment.

(2) Identify each item or part by name of common 5ymbol.

(3) Identify each test or service point, and the sequence in which used.

(4) Identify the value and tolerances of parts such as resistors; this identification should be direet rather than in color code where possible.

(5) Indicate the direction of current or flow to aid systematic elimination of possibilities without continuous cross reference to schematics.

(6) Provide "maintenance highways" to guide the tech. nician through routine piocess. The following code has proven useful:

- Black for line inaintenance

- Green for shor maintenarce

- Red for clf sit: maintenance

- Other codes as necessary.

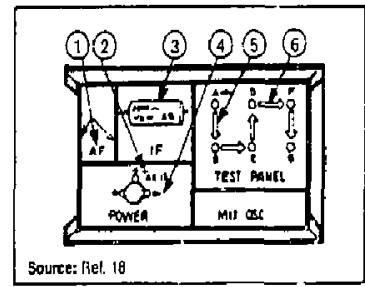

Exhibıt 1.2.3 Labeling and Coding a Packaging Arrangement

b. Provisions should be made for the Iollowing instructions to appear on packaging arrangements when appropriate:

(1) The weight of uniss over 45 lbs. should be prominently labeled.

(2) Warning and caution labels should be provided as necessary.

(3) Instruction plates should be provided to outline procedures not made obvious by design and to supply whatever information is necessary for troubleşhooting and maintenence.

(4) The presendition and/or recording of historica data where practicable, particularly to:

- Oisplay periodic readings at test points to allow development of trends where these are fundamental 10 maintenance decisions.

- Allow recording of replacement dates or other data necessary to replenishing or preventive maintenance.

c. Labels and codes used in packaging arrangements should be compatible with principles establishlıd under "Identification," and should be: 
(1) Consistintly and unambiguously used throughout the system.

(2) Of such a nature as to be easily read and inter. preted.

(j) Durable enough to withstend expected wear and environmental conditions.

(4) Coordinated and compatible with

- Codes and labels on related test and service equipment

- Other coding and labeling within the system

- Related job aids, instruetions, handbooks, and manuals.

\subsubsection{MOUNTING}

a. Mounting of components is influenced by:

(1) How othen components will be removed for maintenance or replacement.

(2) The accesșibility of other components which may be affected.

(3) The size and weight of components to be mounted.

(4) How much space will be required for access, removal, and feplacement of the component or for using test equipment, tools, etc.

(5) The required preventive maintenance for an instalied component.

b. Mounting fixtures, e.g., rollers, brackets, slide rails, should be designed so that:

(1) Only interconnecting wire and structural members are permanently attached to units. All othe fixtures should be removable.

(2) Built-in fixtures to the chassis are either strong enough to withstand use over the life of the system or are removable.

(3) Mounting is compatible with the size and weight of the part to prevent breakege or damage from fatigue, under vibration, handling stress, elc. c. Design for mounting of components, modules, and parts should be such as to prevent their being inadvertently reversed, mis-mated, or misaligned during installation or replacement.

d. Design should make errons physically impossible, by:

(1) Coding, labeling, or keying symmetrical com ponents to indicate the oroper orientation for mounting or installation.

(2) Providing mounting brackets which are asym metrical, to prevent incorrect mounting, as below.

(3) Providing side alignment brackets which permit mounting in oniy one position, as below.

(4) Providing asymmetrical mounting hales, studs, or alignnment pins, as below.

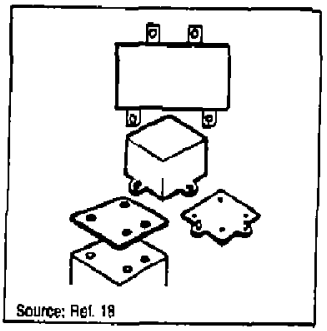

Extibit 1.2.4 Error.Free Mounting Desions

c. Components of the same form, function, and walue should be completely interchangesble throughout the system or related svstems.

t. Components of the same or similar form, but of dif ferent functional properties, should be:

(1) Mounted with standard orientation throughout :! unit.

(2) Readily identifiable, distinguishable, and not physically interchangeable. 


\subsubsection{SPECIFIL PAINCIPLES}

1.2.4.1 PACKAGING. The packaging of equipment, assamblies, and/or components should follow one or a combination of the following methods fin order of proferencel:

a. LOGICAL. FLOW PACKAGING. This mothod requires that:

(1) Circuits, parts, and components should be pack aged and located in an arrangement parallel to their functional relationships.

12) Methods and subassemblies be selected so that only single input and ouput rhecks are necessary to isolate a fault within an item.

(3) The unidirectional signal flow within a given piece of equipment is clearly indicated.

b. CIRCUIT PACKAGING. This method uses the following lechniques:

11) A.ll parts of a given circuit, or of logically or

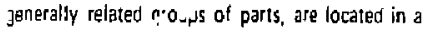
common volume.

(2) Each circuit should be placed in a separate module. If a tube is associated with the circuit, place it on top of the module.

(3) The circuit should consist of a single terminal board or plugi.in type module when possible.

(4) Plug:n printed circuit boards should be structurally rigut and easy to remove and replate.

c. COMPONENT PACKAGING. This method should incorporate the following:

11) All similar components sheuld be found in one place on the equipment.

(2) Relays should be located in a single or small number of relay panels.

(3) Resistors, capacitors, tube sockets, etc, should be segregated in a minimum number of locations on subassemblies or terminal boards.

(4) Inexpensive components should be placed on separate, plug-in type bo ards mounted beneath the chassis to facilitate disposal at failure.

(5) Multiples of similat parts le.g., tubes, transistors) that are likely to require replacement about the same time should be grouped rogether.

i6) Components should be segregated based on signiticant variations in the maintenance tasks which are required. For example, items which must be cleaned by different methods (steam, gunk, solvent, etc.) should be pack zyed so cleaning is possible with minimal masking,

1.2.4.2 MOUNTING. The mounting of equipinent, as. semblies, and/or components should use one or a combination of the following tectiniques:

a. FOLD.OUT CONSTRUCTION. This methed of con. structing subarsemblies should be used whenever feasible. The parts and wiring should be positioned to prevent damage to them when opening and closing this assembly.

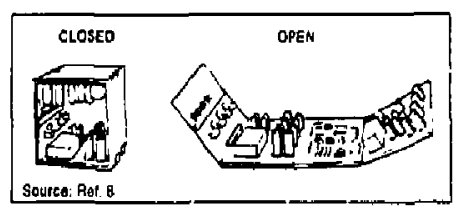

Exhibit 1.2.5 Example of fold.Out Construction

b. BRACES. Braces or similar items should be provided to hold hinged assemblies in the "out" position while they are being worked on. Fests or stands should be provided to prevent damage to delicate parts. If feasible, the rests or stands should be a part of the basic chassis.

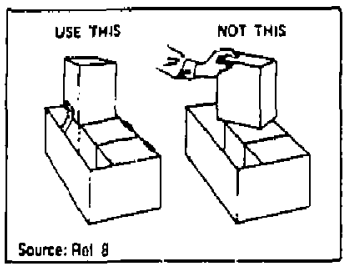

Exhibit 1.2.6 Bracing of Hinged Assemblies

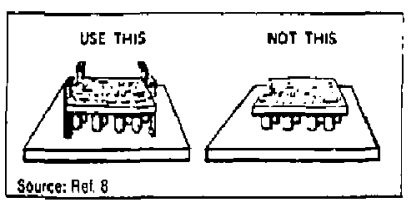

Exhibil 1.2.7 Use of Stands for Component Maintenance

c. STRAPS AND BRACKETS. Straps and brackets should be used:

(1) As necessary for tying down large components.

(2) Particularly to support iteris mounted on the underside of assemblies.

(3) Instead of cantilever brackets for mounting parts.

(4) As necessary to prevent the mounted item from sliding or jumping out of position. "U" straps should only be used to "tie-down" components, not to secure or support them.

(5) Which ere thick or rounded enough so they have no sharp adges.

(6) Which are shorter than mounted units to provide a clamiping action.

(7) Which are twist- or push to lock mounting types for small components. Such brackets should be designed so that locking studs are visible when the component is in place, and locking serews or dimples are provided as necessary to ensure security of the mount. 


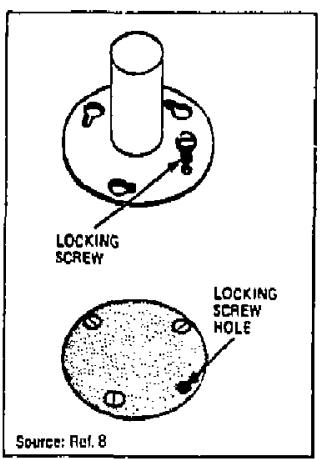

Exhibit 1.2.8 Twistro-Lock Type Mounting Bracket

d. SHOCK MOUNTS, Shock maunts should be used. as necessary, to:

(1) Eliminate vibrational fluctuations in displays, markings, etc.

(2) Protect fragile or vibration-sensitive components and instruments.

(3) Control sourcess of high or dangerous noise and vibration.

e. Other methods to be considered in the mounting of components are as follows:

(1) Hinged bars are useful for tying down and pur. mitting axcess to a number of small components at ons time. Such bars should be podded or provided with springs as necessary to prevent damage to the items secured.
(2) Where rigid mounting may result in damage $10 \mathrm{com}$. panents, a device which permits some flexivility should be used. For example, a frequent cause of thread-stripping of " $T$ " fietings is the rigid mounting of the fittings.

(3) Where blind mounting is required, the inaccessible side should be secured with mounts which will allow exceptionally easy mating and do not require acaess (such as friction lugs, tongue and groove fittings, etc.).

(4) Spring clamps should be used to mount tubing, pipes, or wiring which may require frequent removal and replacement. For overhead mounting, a spring clemp similar to that used for floor mounting should be used, but a hinged locking latch should be provided over the opent side of the clamp to prevent accidents.

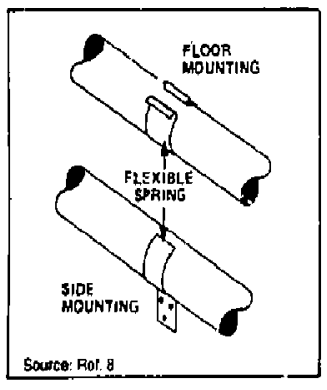

Extibin 1.2.0 the of Spring Clamp Mounn 


\subsection{ENGINEERED HARDWARE}

1.3 Hardware Identification for Maintsinability 
1.3.1 INDEX

Page

1.3.2 DEFINITION $\ldots \ldots \ldots \ldots \ldots \ldots \ldots, \ldots \ldots \ldots \ldots \ldots \ldots \ldots, \mathbf{1 , 3 \cdot 2}$

1.3 .3 GENERAL PRINCIPLES $\ldots \ldots \ldots \ldots \ldots \ldots \ldots \ldots \ldots \ldots \ldots \ldots \ldots, 1.3,3$

1,3.4 SPECIFIC PRINCIPI.ES $\ldots \ldots \ldots \ldots \ldots \ldots \ldots \ldots \ldots \ldots \ldots \ldots \ldots \ldots, \$, 3.4$

1.3.4.1 Instruction Plates $\ldots \ldots \ldots \ldots \ldots \ldots \ldots \ldots \ldots \ldots \ldots \ldots \ldots \ldots \ldots \ldots \ldots \ldots \ldots, 1.3 .4$

1.3.4.2 Parts., $1 d$ Reference Designatioris .............................. $1.3-4$

1.3 .4 .3 Labels $\ldots \ldots \ldots \ldots \ldots \ldots \ldots \ldots \ldots \ldots \ldots \ldots \ldots \ldots \ldots \ldots, \ldots, 3.4$

1.3.4.4 Warning Labels and Plo:ards............................ 1.3-7 


\section{ENGINEERED HARDWARE $\quad 1.0$ \\ HARDWARE IDENTIFICATION FOR MAINTAINABILITY 1.3}

\subsubsection{DEFIN'TION}

Hardware identification refers to the adequate marking or coding of parts, components, controls, and test points to facilitate repair and replacement during maintenance operations. Hardware identification is used to:

a. Identify the purpose or function of specific units, parts, controls, displays, test points, etc.

b. Present critical information for equipment maintenance procedures.

2. Present safety information, i.e., cautions and warnings which lead to prevention or avoidance of hazards to maintenance personnel or damage to equipment.

Proper labeling or coding is present if the component is readily identified for repair, replacement, or service with minimum effort by the technician. 


\subsubsection{GENERAL PRINCIPLES}

1,3,3.1 Hardware identification (labels, legends, placards, signs, markings, codes, or combinations of these) should be provided whenever peisonnel must identify, interpret, follow procedures, or avoid haz grds.

1.3.3.2 Identification characteristics should be consistent with factors such as:

a. Accuracy of identification required.

b. Time arailable for recognition or other responses.

c. Location and distance at which identification must be read.

d. Level and color of illumination.

e. Criticality of the function identifios.

f. Consistency of the identilying information within and between systems.

1,3,3.3 Label-making devices should be readily available for cresting new labals to replace missing, damaged, or deficient identifiers.

1.3.3.4 Identifiers used in multi-unit facilities should be sufficiently distinctive to prevent confusing one unit with another.

13.3.5 Periodic facility-wide surveillance checks should be made to erisure that all equipment and facilities are properly identified, and that informal labels added by operators and maintenance technicians are systematically replaced with accurate, easily read, high-contrast, permanent labels and togs.

13.3.6 Maintenance procedures should inciude a step to check for the availability of identification tags and labels as part of the system restoration process.

13.3.7 Quality control inspection procedures should include measures to ensure that identification tags and labels are replaced when necessary subsequent to maintenance tasks.

1.33.8 Equipment (except detailed essembliss and parts) should be identified with a securely attached, permanent, non.fading, oil-, gasoline, and corrosion-ressistant name plate. The name plate hould be permanently and legibly marked with the following information:

a. Contract order or task ne.

b. Item name (noun first).

c. Specification number.

d. Manufacturer's part no. for Govemment Standard Part No,l.

e. Serial no. (when uvailable).

f. Stock no. (when wailable).

9. Manufacturer's name and addrtss. Manufacturers' lopos should be eliminated or removed if they interfere with identifying os interpreting equipment functions.

133.9 Equipment identification should include perinent information about its function, capacity, capobilities, limits, ranges, frequency, and current requirements, Weight, rpen, horsepower, and other basic information should be included.

13.3.10 Electrical assembly connections should be markad according to MIL-STD.195, or comperable industry standards.

13.3.11 Insulated wire should be color of numbercoded per MiL-STD-681, or comperable industry standards.

1.3.3.12 for color coding, no more than nine easily distinguishable colors should be used for color-normel and color-defirient observers.

\begin{tabular}{|c|c|}
\hline Spec. No.* & Spec. No. \\
\hline Fed $\ldots \ldots \ldots \ldots+1110$ & Gray ...........1625 \\
\hline Orange $, \ldots \ldots \ldots, 210$ & Buff $\ldots$ \\
\hline Yellow $\ldots \ldots \ldots \ldots, 1310$ & White ....... \\
\hline Blut $\ldots \ldots \ldots \ldots 1087 / 6$ & Black ..........1770 \\
\hline Purple...... & \\
\hline
\end{tabular}

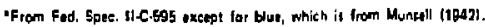

Sourte: Rat. 25

Exhlbit 1,3.1 Surtace Colors tor Calor-Normal and Color.Deticient Persons 


\subsection{SPECIFIC PAINGIPLES}

\section{1,3.4.1 INSTRUCTION PLATES}

a. Instruction plate: should describe or illustrate, as necessary:

(1) Basic operating instructions.

(2) Calibration data and adjusiment instruction.

(3) Simple wiring or fluid flow diagrams.

(4) Warning and safety precautions.

(5) Test point locations.

(6) Transistor and other pertinent electronic equip ment.

(7) Volve settings.

(8) Type of fuels, oils, or greases applicable.

i9) Other similar data for routine preventive mainte. nance.

b. Permanent instruction plates should be attachnd in an easily visible and suitable location.

c. Where required, o permanent pocket or similar device should be atteched for containing various maintenance aids such as signal flow diagrams, diagnostic procedures, pictorial presentations, and maintenance records.

\subsubsection{PARTS AND REFERENCE DESIGNATIONS}

a. MILSTD-16 or comparable industry standards should be used in the formation and application of alphanumeric pars and reference designations. The unit numbering method should be used for all new equipment.

\section{b. COLOA AND STYLE}

(1) Designations should be clear and easily distinguished in subdured light at a distance of 28 inches.

(2) Black markings should be used on light backgrounds such as lightgray painted surtaces, unfinished brass, aluminum, and all bright, plated surfaces, White markings should be usd on dark back. grounds such as medium-gray surfaces.

(3) Recommended letter and numeral heights for viewing distance of 28 inches are given. For other viewing distances, multiply given values by the distance in inches divided by 28.

\begin{tabular}{|c|c|c|}
\hline Nature of Markings & $\begin{array}{l}\text { Low Brightness } \\
\text { down lo } 0.03 \\
\text { tt.lambert (in.) }\end{array}$ & $\begin{array}{l}\text { High Brightress } \\
\text { down to } 1.0 \\
\text { st.lumbert fin. }\end{array}$ \\
\hline $\begin{array}{l}\text { Critical markings-position variable } \\
\text { (numerals on counters and wethable } \\
\text { of moring scates! }\end{array}$ & 0.20 to 0.30 & 0.12100 .20 \\
\hline $\begin{array}{l}\text { Critical markings-position fixed } \\
\text { (numerals on fixed scalas. con usal } \\
\text { and switch markings, amergenz } \\
\text { instruetionst }\end{array}$ & 0.15 to 0.30 & 0.10 to. 0.20 \\
\hline $\begin{array}{l}\text { Noncritical markings finstrument } \\
\text { identification labels, foutine } \\
\text { instructions, any markings } \\
\text { required for initial familiarization } \\
\text { only) } \\
\text { Source Rat. } 8\end{array}$ & 0.05 to 0.20 & 0.05 to 0.20 \\
\hline
\end{tabular}

Sxhibit 1.3 .2 Rucommended Loxter ind Numeral Heights (for 28-inch viewing distente)

\section{c. LOCATIONOF DESIGNATIONS}

(1) Designation markings on equipment should be placed on or immediately adjecent to the part to which it pertains in a consistent manner.

(2) Small electrical parts $\left(0 g_{1}\right.$, resistors, capacitors, terminals) affixed to mounting boards should be identified by marking on the boards.

(3) Multiple terminals should be identified by markings on the component or adjacent chassis.

(4) Parts which protrude from an electronic chassis should be marked on the wiring side.

(5) Terminals of transformers, relays, capacitors, and all socket-mounted items, except standard vacuum tubes, should be marked adjacent to each termingl.

(6) Receptacles for plugs, modules and units, and similar parts that are accessible from the top side should hase both bontom and top sivis identification.

(7) Markings should be placed so that they are visible without removisg parts.

(8) Markings should be oriented $x$ that they can be read with the unit in the namal, installed position.

\section{d. MARKING PARTS}

(1) Parts should be identified by designations which refer to parts descriptions .;; a drawing or she matic.

(2) Wires, sockets, pluts, receptacles, and similar parts should carry designations from wiring diagrams prepared in accordance with the xhematic diagrams.

(3) Replaceable mechanical parts should have standard designations.

14) Semi-fiked electrical iterns (0.g., fuses, ferruloclip-mounted resistors) should carry the elecirical rating in addition to the standard designation.

(5) Critical polarity and impedance ratings should be shown on items having these ratings.

(6) If an assembly is compiex, a concise wiring diagram should be affixed to the unit.

(7) Markings should be accurate and sufficient to identify the referenced pert.

(B) Markings stould be permanent enough to last the life of the equipment.

(9) Stacked parts and modules should be marked so that they can be individually recognized.

(10) Individually enclosed or shielded parts should be identitied on the outside of the enclosure.

(11) Fixed and removable parts of a plugin assembly should be marked identically.

(12) Individual sections of dual parts should be clearly identifted.

\subsubsection{LABELS}

a. Labels are lettered indications of the name, identifying number, and function of equipment which are affixed on or negr the relevant equipment.

b. It is usually better to over-label than under.label, ospecially in cases where equipr ant is separated from operation and instruction manuals. 


\section{c. COLOR AND SIZE}

(1) Color combinations of printing and background should be provided which will maximize legibiliry. Best calor cambinations for labels, in descending order, are:
- Blue on white
- Black on yellow
- Green on whise
- Black on white
- Green on red
2 Red on yellow.

(2) If color coding of iabels is neceessary, colors should be selected on the basis of recognizable differences. he following coiors are suitable for surface coding uecause they are easily recognizable by both normal and color defictelent per sons.

$\begin{array}{ll}\text { Calor } & \text { FED.STD.595 } \\ \text { Black } & 1770 \\ \text { White } & 1755 \\ \text { Yellow } & 1310 \\ \text { Blue } & 10 \text { (1) } 7 / 6\end{array}$

(3) Labels should be printed in capitals. Periods should not be used after abbreviations.

(4) The width of letters should be $3 / 5$ of the height, except for " $M$ " and " $W$ " which should be $4 / 5$ of the height and " $\mathrm{l}$ " which should be one stroke wide,

(5) The width of numerals should be $3 / 5$ of the height, except for "a" which should be one stroke width wider and " 1 " which should be one stroke wide.

(6) When conditions demand the use of wider characters (e,g, on curved surfeces), basic height-to width ratios may be increased to 1:1.

(7) When black chardeters are used on a white for lightl background, the strake width should be 1/6 to $1 / 7$ of the height.

(8) Where areas are dimly illuminated or legibility at night is critical, and white sharacters are specified on a biack background, the stroke width of the chataters should be from $1 / 7$ to 1/8 of the height (j,e, narrower than for daytime vision). The stroke width should be the same for all letters and numerals of equal height.

(9) Minimum spacing between characters used in labels should be one stroke width.

(10) Minimum spacing between words should be the width of one character.

(11) Minimum spacing between lines should be one-half the character height.

(12) Recommended numeral and legter heights or a viewing distence of 28 inches ane the same as for parts idantification and reference designations, Exhibit 1,3.2, Other viewing distance and character height values are given below.

\begin{tabular}{|c|c|}
\hline Viewing vistance & Minimpm Hoipht \\
\hline 1. Lass than $500 \mathrm{~mm}$ (196.7 in.) & $2.3 \mathrm{~mm} 10.09 \mathrm{in} .1$ \\
\hline b. $0.5-1.0 \mathrm{~m}(19.7-39.4 \mathrm{in.})$ & $4.7 \mathrm{~mm} 10.18 \mathrm{in})$ \\
\hline c. $\quad 1.0-2.0 \mathrm{~m}(39.4-78.7$ in. 1 & $9.4 \mathrm{~mm}\{0.37$ in. \\
\hline d. $\quad 2.0-4.0 \mathrm{~m}(78.7-157.5 \mathrm{in}, 1$ & $19 \mathrm{~mm}(0.75 \mathrm{in.})$ \\
\hline $\begin{array}{l}\text { e. } 4.0-9.0 \mathrm{~m}(157.4-3.5 .5 \mathrm{in} .1 \\
\text { Sounce: } \text { A }_{1.11} 11\end{array}$ & $38 \mathrm{~mm}$ । $\$ .50 \mathrm{in}\}$. \\
\hline
\end{tabular}

Exhibit 1.3.3 Vitwing Distunçe and Character Height Volues

\section{d. COMPOSITION}

(1) Labels should be brief yat explanatory, Brief, familiar words should be used. Abbravietions should be used only when known to all personnel. Key artion words should be used instead of abbreviations when possible.

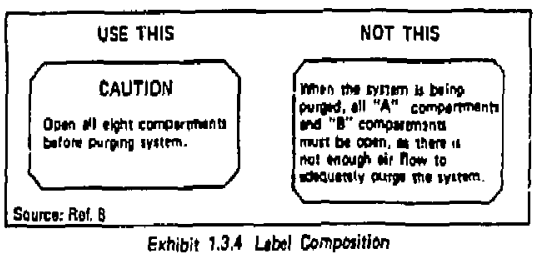

(2) Labels containing a number of steps in be performed sequentially should itemize the steps rather than present them in parzgraph form.

\begin{tabular}{|c|c|}
\hline USE THIS & NOT THIS \\
\hline $\begin{array}{l}\text { ASSENBLING INJECTOR } \\
\text { TAPPING TOOL }\end{array}$ & $\begin{array}{l}\text { ASSEHBLING INJECTOR } \\
\text { TAPPING TOOL }\end{array}$ \\
\hline 1. Replace defective part. & $\begin{array}{l}\text { First roplace the defective part } \\
\text { from fupply, Instail nut and } \\
\text { wacher on hand tao shank. }\end{array}$ \\
\hline C. hand tep shenk. & Next, Dlace the Rollpin in the \\
\hline 3. Install Rollpin in nut. & $\begin{array}{l}\text { nut. Upon etompletion, dheck } \\
\text { the tapping tool tor praper }\end{array}$ \\
\hline $\begin{array}{l}\text { 4. Chect tapping iool for } \\
\text { proper operation. }\end{array}$ & performance. \\
\hline Source Rot a & \\
\hline
\end{tabular}

Exhibit 1,3.5 1,abel Contaning Sequence of Steps

(3) Codes and labels on equipment should be consistent with instruction manuals and equipment parts catalogs.

(4) Labels should read horizontaily rather than vertically.

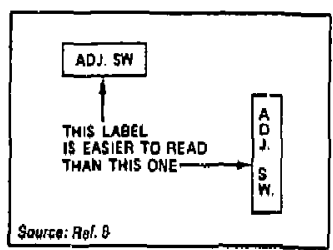

Exhibit 1.3.6 Une of Horizontal Rather Then Vurtical Labeling 
(5) Arrows used in labels should bo clearly recog. nizable and assily identifiable when read from a distance, it : $;$ easier to interpret the direction of arrows with sharp ongles and clean lines from a distance than arrows which use wide angles and broader overall width to-length ratios.

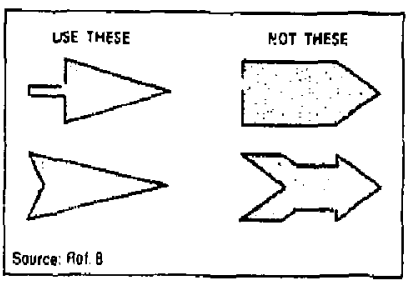

Exhibin 1.3.J Use of Arrows Whith Nartow Width-lo-Lnggh Ratios

(6) Wording of labels should be thosen besed on the operator's familiarity with the in when possible, Common lechnical terms, if familiar to the main tenance technician, may be usad as necensary. Abstrict symbols (e,g., squares and Greek letterșl should be used only if they are understood by all intenderi readers.

\section{e. LOCATION OF LABELS}

11) Labels should be located so they will not be obscured by grease, tilings, dirt, ar moisture. Whese a label may be particularly susceptible to being covered by material droppings from above, it should be mounted vertically.

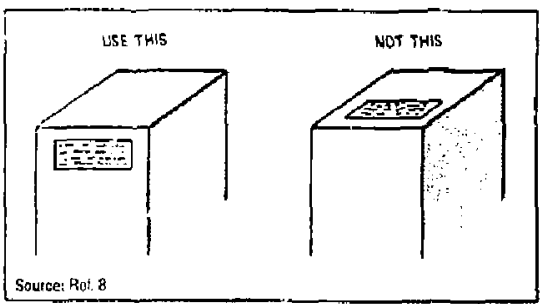

Exhibit 1,3.8 Label Pơsitioning

(2) Labels used on similar pieces of equipment should be placed in relatively the same position.

(3) Labels should not be hidder from view, crowd each other, or obscure other useful information.

(4) Parts that look similar but are not ptysically interchangeable and cannot be physically keyed should be labeled. Labels should be lacated on several sides of the part, if possible, with precautions about interchangeability or use-distinctive markings that correspond with markings on the assembly in which the pert will be placed.

(5) Labels or other markings should be provided to indicate control positions. A rider may be attached to the shat of a valve to indicate position. Labels may' also include calibration dats where applicable.

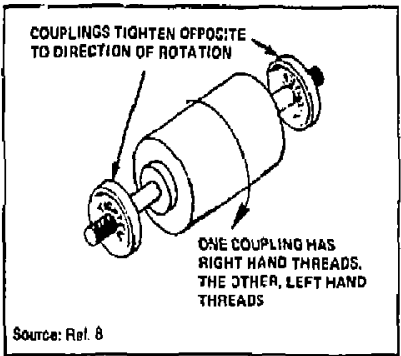

Exhboh 1,3.9 Camponene Cabulion to Precisdu Oparating Errar

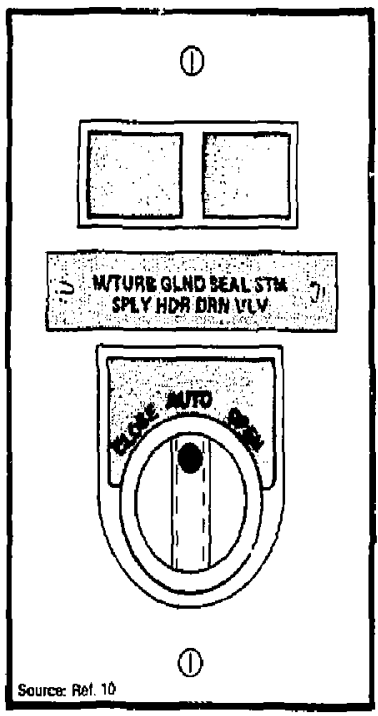

Exhlbit 1.3.10 Labal Indiating Control Positions

(6) Labels should be placed consistently in the same place in relation to the instrumentation on a panel. Labels normally should be placed above the controls and displays thay describe. If a panel is above eye level, labels may be located helow if the visibility is entanced.

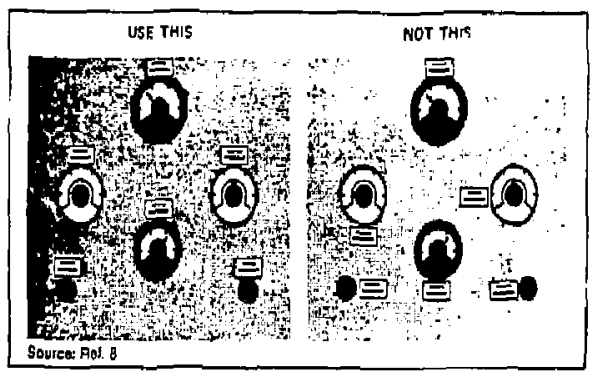

Exhibit 13.11 Relating Lobels to Controh and Disolays 
17) Functianally grouped controls and displays should be identified by labels located above the functional groups which they identify. If a functional greup is demarcated by a line, the label should be centered at the top of the group either in a break in the line, or just below the line, When colored pads are used, the label should be centered at the top within the pad area.

\section{3,4,4 WARNING LABELS AND PLACARDS}

a. Warning labels should be installed whenever a maintenance technisian or mechanic must consult a technical manual before working on the equipment.

b. Warning labels shouls be as informative as possible given space constraints present (sea examples below).

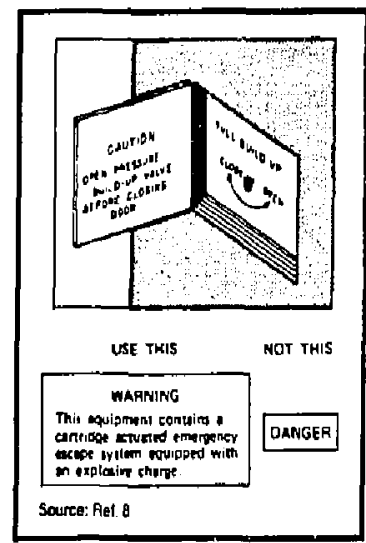

Exhibit 1.3.12 Examples of Waming Labels

c. Though content of warning labels will yary, they should inform the technician of.

(1) Why a dangerous condition exists.

(2) Places to arvid.

(3) Behavior to avoid.

(f) Sequence to follow to obviate the danger,

(5) Where to refer for more inlormation.
(6) Radiation protection precautions or procedures.

(7) What to do in case of injury.

d. High visibility warnings should be erected when personnel may be subjecied to harmful naise or a sudden increase or decrease in pressure or exposure to radietion,

e. Tolerance or safety load limits of an apparaius should be permanently displayed.

f. The following are examples of specific applications of warning labels and placards:

(i) WARNING PLACARDS-Warning placards should be mounted adjecent to eny equiprnent which presents a hazard to personnel (e.g., from high voltage, heat, toxic vapors, explosion, ionizing radiation).

(2) CENTER OF GRAVITY AND HEIGHT-Where applicable, the center of gravity and tine weight of equipment should be marked.

13) WEIGHT CAPACITY-The weight capacity should be indicated on stands, hoists, lifts, jacks, and similar weightbearing equipment to prevent overloading.

(4) IDENTIFICATION OF PROTECTIVE ITEMSOperation and maintenance areas requiring special clothing, tools, or equipment le.g., insulated shoes, gloves, suits, respirators) should be specifically and conspicuously identified.

(5) "NOSTEP" MARKINGS-These markings should be provided, when necessary, io prevent injury to oersonnel or damsge to equipment.

(6) ELECTAICAL LABELS-All receptacles should be marked with theil voltage, phase, and frequency characteristics as appropriate.

(7) HAND GRASP AREAS-Hand grasp areas should be conspicuously and unambiguously identified on equipment.

(8) PIPE, hOSE, AND tUBE LINE IDENTIFICA. TION-Pipe, hose, and tube lines for liquids, gas, steam, etc. should be clearly and unambiguously coded for contents, pressure, hest, cold, or other specific hazardous properties. MIL.STD-1247 or comparable industry stindards should be used for further guidance.

(9) LONG RUN CABLES, PLUMBING LUNES, AND CONDUITS-These should be clearly identified or coded, not only at the termi.lal ends but also at periodic distances between ends to facilitate accurate iracing of lines. 
1.0 ENGINEERED HARDWARE

1.4 Equipment Accessibility 
ENGINEERED HARDWARE 1.0

EQUIPMENT ACCESSIBILITY 1.4

1.4.1 INDEX

Page

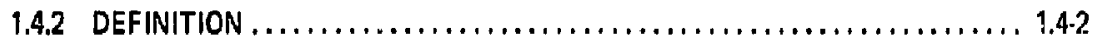

1.4 .3 GENERALPRINCIPLES $\ldots \ldots \ldots \ldots \ldots \ldots \ldots \ldots \ldots \ldots \ldots \ldots \ldots, 1,4,3$

1.4.4 SPECIFIC PRINCIPLES $\ldots \ldots \ldots \ldots \ldots \ldots \ldots \ldots \ldots \ldots \ldots \ldots, 1.4-4$

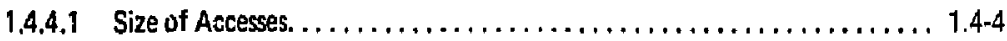

1.4 .4 .2 Shape of Accesses $\ldots \ldots \ldots \ldots \ldots \ldots \ldots \ldots \ldots \ldots \ldots \ldots \ldots, 1.4-5$

1.4.4.3 Location of Accesses................................... 1.4-5

1.4.4.4 Access Safety Requirements............................. 1.4-6 


\subsubsection{DEFINITION}

Equipment accessibility refers to the relative ease with which an assembly or component can be approached for repair, replacement, or servicing. If the steps required are few and simple, then the component is accessible; the component is inaccessible if the steps are many or difficult to perform. Accesses include entrance doors; inspection windows; and lubrication, pneumatic, and hydraulic servicing points. Accesses should provide:

a. Sufficient clearance to use the tools needed to complete the task.

b. Adequate space to permit convenient removal and replacement of components.

c. Adequate visual exposure to the task area. 


\subsubsection{GENERAL PRINCIPLES}

1.4.3.1 Access must be provided to all points, items, units, and components which require or may require testing, sevicing, adjusting, removal, replacement, or repair.

14,3.2 The type, shape, location, and size of accesses should be determined by thoroughly understanding:

a. Operationst location, setting, and environment of the unit.

b. Frequency with which the access must te entered,

c. Maintenance functions to be performed through the access.

d. Time requirements for the performance of these functions.

e. Types of tools and accessories required by these functions.

f. Work clearances required for performance of these functions.

g. Type of clathing likely to be worn by the technician.

h. Distance to which the technician must reach within the access.

i. Visual requirements of the technician in performing the task.

$j$. Packaging of items and elements, etc. behind the access.

$k$. Mounting of items, units, and elements behind the access.

I. Hazards involved in or related to use of the access.

$m$. Size, shape, weight, and clearance raquirements of logical combinations of human appendages, tools, units, etc. that must enter the act 'ss.

1.4.3.3 An access should be designed to make the repsir or servicing operation as simple as possible.

14.3.4 Where possible and feasible, accessibility should be designed for on a grand seate by:

8. Using hinged or removable chassis.

D. Designing major units and assemblies fespecially engines, turtines, etc.] with removable housings to allow for complete inspections

c. Correlating the design of unit accessibility features with the accessibility requirements of the overall system.

1.4.3.5 Accesses shruld be designed, located, covered, and fastenes to avoid the need for removing components, wires, etc. to reach tha item requiring maintenance.

1.43.6 Accesses should be designed so that the removal of any replaceable unit requires opening of only one access, unless the accesses are of the latched or hinged door tyge.

1.4.3.7 Items that require visual inspection (e.g., hydraulic reservoirs, gaugesl should be located so they can be ob. sened without the removal of panels or other components.

1.4.3.8 All access covers that are not completely removable should be self-supparting in the open position.

1.4.3.9 When access covers must serve as stressbearing structural members, large serews should be used rather than small ones,
1.4.3.10 On hinged access doors, the hinge should be placed on the bottom or a prop should be provided so that the door will stay apen without heing held if unfastened.

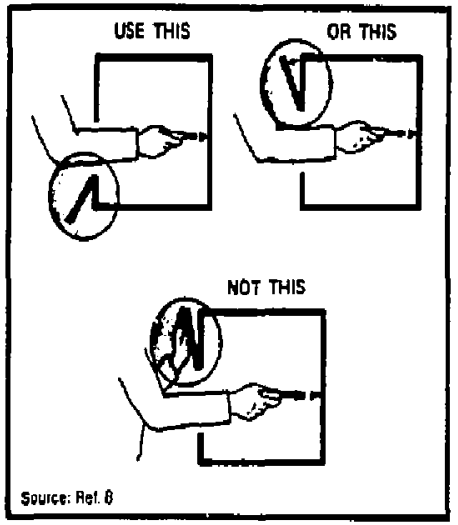

Exhibin 1.4.1 Aetets Door Hinge

1.4.3.11 If the manner in which a cover is opened is not obvious from its structure, it should be labeled with appro. priate instructions.

1.4.3.12 When a tube or plug has to be put through a small tole, a conspievous label can be used to show how the pins on the tube or plug will line up with the holes in the sockst.

1.4.3.13 An access should be labeled with a number, letter, or other symbol that identifies it in the mbintenance instructions.

1.43.14 Labels thould be used to indicote items thet can be reached through an acess and the service equipment, if any, to be used there.

1.4.3.15 Equipment should be left exposed (without coverings 0 : housings\} for maintenance whenever permitted by structural, environmental, operational, and safety conditions. This pertains especially to test and service points, maintenance controls and displays, and rack. mounted units.

1.4.3.16 The table following provides guidange for selecting equipment accesses:

\begin{tabular}{|c|c|c|c|}
\hline 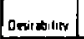 & $\begin{array}{c}\text { For Phries] } \\
\text { Aeens }\end{array}$ & $\begin{array}{c}\text { For Visual } \\
\text { Inspaction Only }\end{array}$ & $\begin{array}{l}\text { Fort Tout ond } \\
\text { Servide Equipsent }\end{array}$ \\
\hline 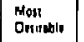 & 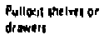 & $\begin{array}{l}\text { Opening with no } \\
\text { exvil }\end{array}$ & $\begin{array}{l}\text { Oponing witt no } \\
\text { contr }\end{array}$ \\
\hline Deniflolt & 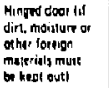 & 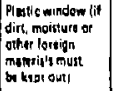 & 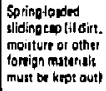 \\
\hline $\begin{array}{l}\text { Lnu } \\
\text { Desiedsle }\end{array}$ & 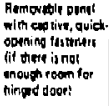 & 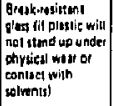 & \\
\hline $\begin{array}{l}\text { Lersi } \\
\text { Deursula }\end{array}$ & 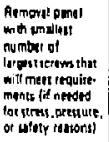 & 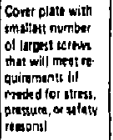 & 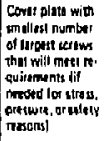 \\
\hline 14. Apt & & & \\
\hline
\end{tabular}

Exhibit 1,4,2 Equipment Access Selection Criteris 


\subsubsection{SPECIFIC PRIHCIPLES}

\subsubsection{SIZE OF ACCESSES}

a. Size of stould be determined by what the muintenance technician will have to do and should depend on factors such as:

(1) Size and shape of the part, component, or assembly to which access is dessired.

(2) Whether or not the object must be removed and replaced through the openings.

(3) Movements of the human body member or members required once acress is gained luming, pulling, pushing, ett.).

(4) The size of the body member or members required to enter through the access.

b. Generally, one large access is preferred to two or more smill ones. Where thare are structural $; i$ other require. ments, visual and phyiciegl precsis may be provided separately.

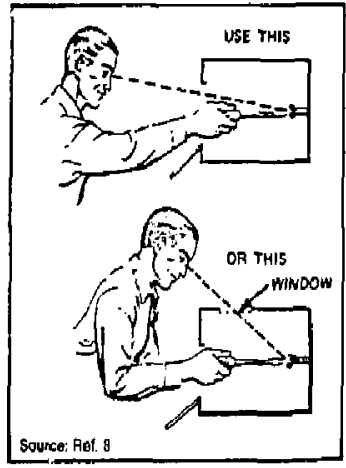

Exhibit 1.4.3 Proper Visual Acces

c. The following are recommended minimum standards standards for one-hand access apenings without visual access.

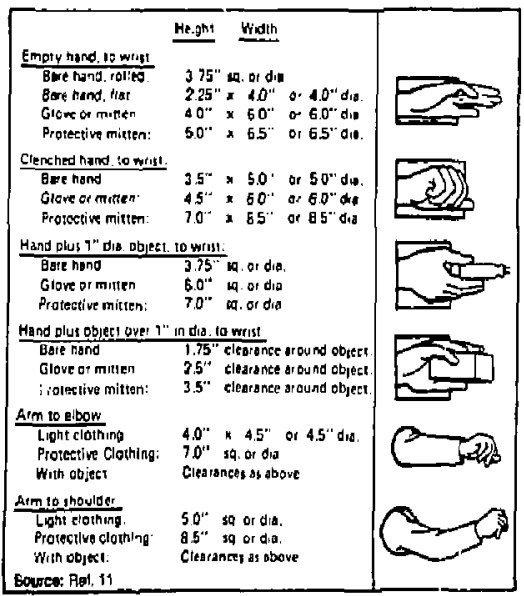

Exhibis 1.4.4 Srandards tor One , Hand Accesset Without Visual Access d. The following are recimmendid dimensions for two. hand actess openings without visual access.

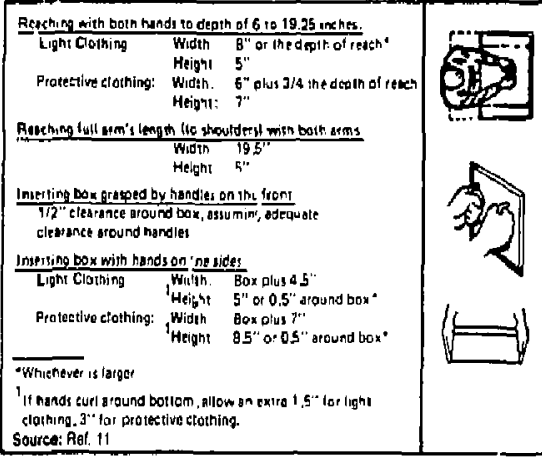

Source: Pal, 1

Exhibit 1.4.5 Standards for Two Hond Accesses Without Visual Aceess Note: Special consideration (larger access) must be given when user may be wearing protective clothing while performing a task.

e. The following are dimensions for various types of hand coverings during specified functions. These dimensions are generalizable to any situation which requires a definable hand clearance, or to similar types of protective hand coverings.

\begin{tabular}{|c|c|c|c|c|}
\hline \multirow[b]{2}{*}{ Hand Altitude } & $\begin{array}{c}\text { Anticontact } \\
\text { Glove } \\
\end{array}$ & $\begin{array}{l}\text { Wer Cond } \\
\text { Glove }\end{array}$ & $\begin{array}{c}\text { Wel. Cold } \\
\text { Mitten }\end{array}$ & $\begin{array}{l}\text { Protective } \\
\text { Miteen }\end{array}$ \\
\hline & $\begin{array}{lll}X & Y \\
\end{array}$ & $\begin{array}{lll}x & y & z \\
\end{array}$ & $\begin{array}{lll}X & Y & Z \\
\end{array}$ & $X Y Z$ \\
\hline Extended flat: & 10.34 .52 .5 & 10.55 .53 .0 & 14.05 .83 .2 & $16.45 .2 \quad 3.6$ \\
\hline Closed as fist: & $70 \underline{50} 3.3$ & $7,3 \underline{5.93 .2}$ & 11.55 .83 .8 & 14.35 .25 .4 \\
\hline Graspoing handle & & & & \\
\hline $\begin{array}{l}25 " \text { diameter: } \\
1,0^{\prime \prime} \text { diameter: } \\
2.0^{\prime \prime} \text { diannter: }\end{array}$ & $\begin{array}{llll}7.0 & 5.0 & 3.5 \\
7.0 & 5.0 & 3.5 \\
7.5 & 4.5 & 4.2\end{array}$ & $\begin{array}{l}735.53 .5 \\
7.35 .74 .0 \\
8.0474 .0\end{array}$ & $\begin{array}{l}3.05 .7 \quad 4.2 \\
11.050 .24 .5 \\
12.05 .2 \quad 4.7\end{array}$ & $\begin{array}{l}14.05 .5 \\
14.75 .5 \\
15.05 .5 \\
5.0\end{array}$ \\
\hline Grasping knob: & & & & \\
\hline $\begin{array}{l}25 \text { "diameter: } \\
1.0^{\prime \prime} \text { diameter: } \\
20^{\prime \prime} \text { diameter: }\end{array}$ & $\begin{array}{llll}8.0 & 3.8 & 4.3 \\
9.0 & 3.5 & 4.0 \\
9.5 & 3.7 & 3.7\end{array}$ & 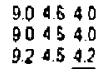 & $\begin{array}{l}11.55 .04 .2 \\
12.050 .04 .0 \\
12.54 .64 .4\end{array}$ & 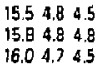 \\
\hline
\end{tabular}

f. The following are design guides for minimal finger access to first joint dimensions.

\begin{tabular}{|c|c|c|}
\hline Pust boundoceess & $\begin{array}{l}\text { Gore hand } \\
\text { Gloved hand }\end{array}$ & 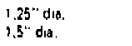 \\
\hline $\begin{array}{l}\text { Twp linger fwist accless } \\
\text { Source: Ret. } 18\end{array}$ & $\begin{array}{l}\text { Barehend } \\
\text { Glaved hatind }\end{array}$ & $\begin{array}{l}\text { Objact ol us } 2.0^{\prime \prime} \text { dia. } \\
\text { object alus } 25^{\prime \prime} \text { dia. }\end{array}$ \\
\hline
\end{tabular}

Exhibit 1.4.7 Standards tor Finger Access to First Joint

\subsubsection{SIZE OF ACCESSES (Cont'd)}

g. The following are recommended whale body dimensions for passing through limited accesses in various configurations. 


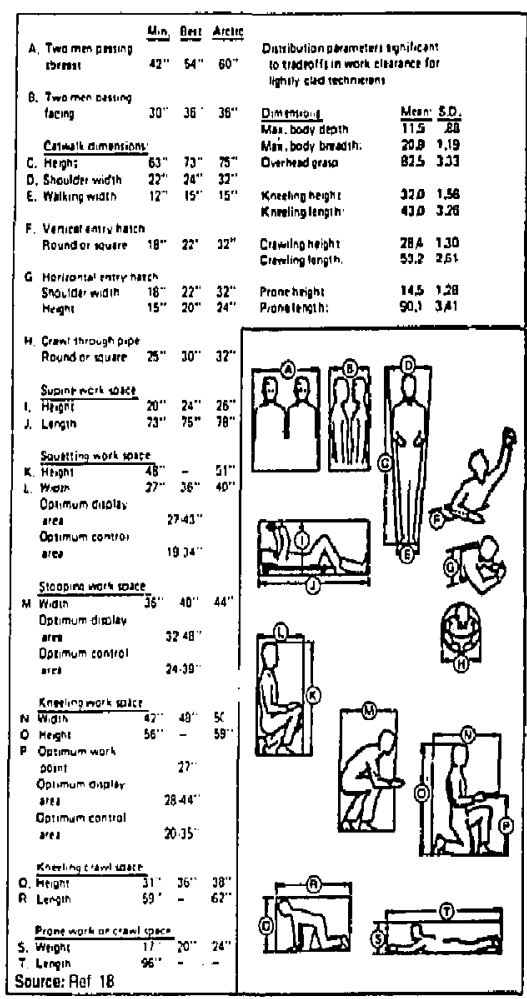

Exhibit 1.4.8 Recominended Whole Body Dimensions for Various Accesses "OSHA Standard 1910.23 (C) (2) requires an 18 " width for catwalks/runways.

\section{h. SPACING REOUIREMENTS FOR HAND TOOLS}

(1) Nuts and bolts should be spaced with enough clearance to allow a wrench to be used.

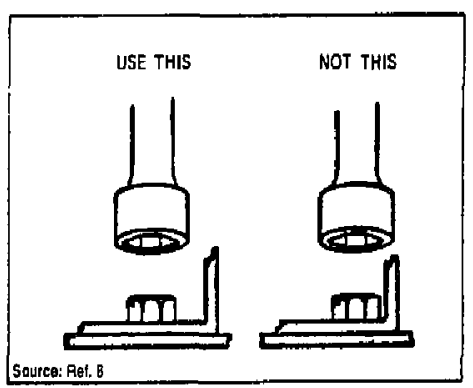

Exhibit 1.4.9 Nut snd Bolt Spxcing Cle arances

(2) Screwdriver-type tools should have an overhead clearance of nc less than the full length of the tool itself, plus the length of the fastener and at least 3 inches for the technician's hand. A minimum size (stubby) screwdriver labout 3 inches longl would require an overhead clearance of at least 6 inches. An off-set screwdriver would reguire less overhead clearance, but would require additional space for iadiel mcvement.

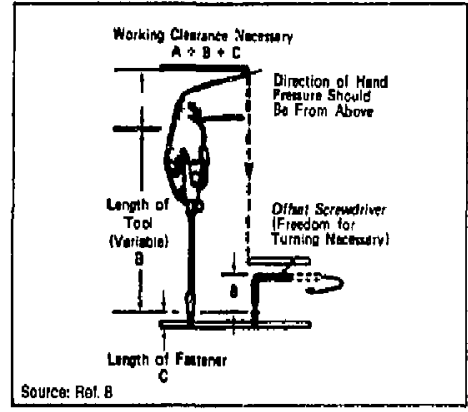

Exhibit 1.4.10 Hand Toal Working Space Clearences

\subsubsection{SHAPE OF ACCESSES}

a. Accesses may be of regular geometric shapes or any irregular shape, as long as the shape satisfies both structural and accessibility requirements, Shape of the access should permit easy passage of required iterns, body appendeges, implements, etc., and should consider:

(1) Dimensions of the various units that must be repleced through the access.

(2) Protuberances, attachments, handles, etc. on thrse units.

(3) Methods of grasping units during removal, and the required clearances.

(4) Requirements for work clearance for work within the compartment.

(5) Requiremenz for visual control of functionts performed within the compartment.

b. If a removable access plate must be attached in a certain way, i.e., to prevent damage to equipment mounted on the back of the plate, shape code the access plate to prevent incorrect attachment, or use asymmetric mounting holes.

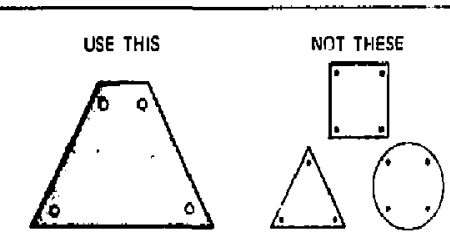

(A) Shape Code Aecess Plater

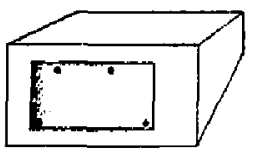

(B) Code Acoess Plates by

Asynimetrle Mounting Holes

Sous: Bet: Be

Exhibit 1.4.11 Costing Removable Access Plates

\subsubsection{LOCATION OF ACCESSES}

a. Accesses should be located

(1) Only on unit faces that will be accessible to normal installation, 
(2) To permit direct access and maximum convenience for job procedures.

(3) On the same face of the equipment as the related displays, controls, test points, cables, etc.

(4) Away from high voltages or dangerous moving parts, or provide adequate insulation, shielding. etc. around such parts to prevent injury to per. sonnel.

(5) So that heavy units can be pulled cut rather than lifted a.je.

(6) So that the bottom edige of a limited access is no lower than 24 inches or the top edge no higher than 60 inches from the floor or work platform.

(7) To conform to heights of work stands and carts related to use of the access.

\subsubsection{ACCESS S.AFETY REQUIREMENTS}

a. Edges of accesses that might injure the ecrnicien's hands or arms should be protected with internal fillers or other protection. b. To minimize the possibility of injuries and equipment damage, access. covers, cases, and handles should have rounded corners and edges.

c. Accesses that lead to equipment with high voltages should be equipped with safety interlocks so that electrical circuits will be opened when the access cover is removed. If the technician must work on the equipment with the power on, provide a "cheater" switch that automatically resets to its safery-protection position when the access cover is replaced.

d. Conspicuous warning lebels should be provided on all accesses leading to high voltages, rotating machinery. or other hazards.

e. Positive indications should be designed to show that access covers are unsecured, even when they are in place.

f. Screwdriver guides should be provided to adjustment points which must be operated near high voltages.

g. Visual access should be provided the technician for all maintenance operations which require visual control, especially where hazerds are present within the access. The technicien should not be required to work blindly. 


\subsection{ENGINEERED HARDWARE}

1.5 Controls and Displarys for Maintainsbility 


\subsubsection{INDEX}

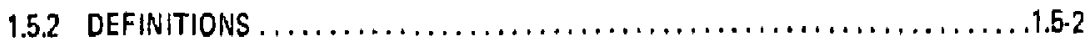

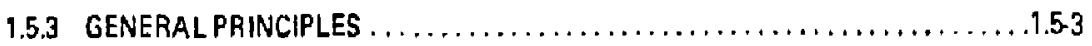

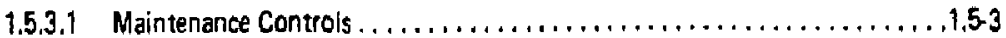

1.5.3.2 Maintenance Displays ...................................

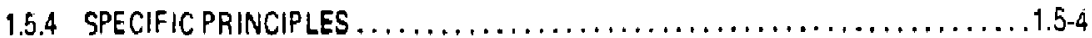

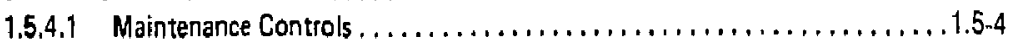

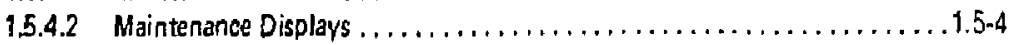


ENGINEERED HARDWARE 1.0

CONTROLS AND DISPLAYS FOR MAINTAINABILITY $\mathbf{1 . 5}$

\subsubsection{DEFINITIONS}

Controls are the means by which a maintenance technician inputs information/instruction into the equipment. Many of the same controls may je used by both the technician and the operator. Some controls may be built into the equipment and used strictly for maintenance purposes. Maintenance controls include not only knobs and switches, but tool-operated controls such as screwdriver adjustment points, setscrews, and lockouts.

Displays provide the technician with information about whether or not the total system and its various units are operating within tolerance.

\section{NOTE}

The design of $\mathrm{r}$. ntrols and displays is not a function which is specific to maintainability. Control and display design has been more extensively covered under operator activities. In particular, NUREG-0700, "Guidelines for Control Room Design Reviews," Division of Human Factors Safaty, Office of Nuclear Reactor Regulation, U.S. Nuclear Regulatory Commission, is a principal source for control and display design criteria for the nuclear power industry. In addition, MIL-STD-1472C, "Military Standard: Human Engineering Design Criteria for Military Systems, Equipment and Facilities provides data concerning general human engineering criteria, principles, and practices to be applied in designing s\}'stems, equipment, and facilities. Therefore, only considerations which have been determined pertinent to maintainability are presented. 


\subsubsection{GENERAL PRINCIPLES}

\subsubsection{MAINTENANCE CONTROLS}

a. Internal controls should be lacated so the technician will be able to manipulate the control while at the same time observe its rejated display. This will eliminate the need for two technicians-one to operate the control, the other to provide/interpret feedbook from tiie display.

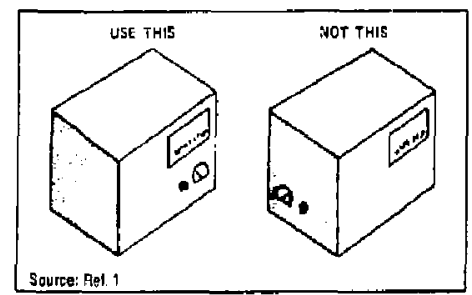

Exhibil 1.5.1 Locating Intemal Controls

NOTE: This design should be used only when the access, as shown, does not interfere with normal operation of the equipment.

b. If it is impractical to provide an access to an internally located to remotely located control, a remote control should be provided.

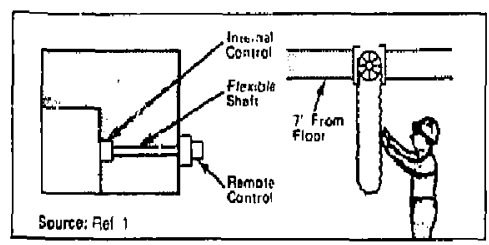

Exhibit 1.5.2 Ręmole Cônitols

c. Emergency controls should be located so that they may be activatad from any position in the mainenance area. If the work area is especially larin and acress tc a singie emergency control is difficult, dupticate controls should be provided.

d. Maintenance controls located on operators" panels should be shielded with removable covers so as not to intertere with the operator's performance while remaining accessible to the ritaintenoncc wishnician.

e. Tooloperated controls strould be designed to be operated with hand tools from the technician's standard tool kit. If a special tool is required, it should be artached near the control which it operates.

t. If the maintenance task is one of selecting and calibrating several functionally related variables, a single control and a switching mechanism should be provided to allow simultanecus or sequential operation of each yariable as desired.

\section{1,5.3.2 MAINTENANCE DISPLAYS}

a. Displays should be located so thev are easily visible to the technician.

b. Front panel access stould be provided for chanģing indicator lights when possible.

c. Instrumentation should be designed for mounting and removal from a front panel.

d. All maintenance displaws which sre relevant to a particular task shovid be grouped together and observable to the technician while performing the task.

e. If maintenance and operator displays must be located on the operator's panel, maintenance displays should be separated and grouped away from opera to displays.

I. Auditory as well as visual warnings should be provided to indicate malfunctions when maintenance must be performed in an area with a high degree of ambient illumination. Visual and auditory displays should operate on separate circuits,

9. instrument amplifiers should be located as close as possible to their indicators: which will require only one technicias to make the needed calibrations. 


\subsubsection{SPECIFIC PAINCIPLES}

1.5.4.1 MAINTENANCE CONTROLS

$a_{*}$ Tank and reservoir drain valves should be locabed so they may be removed from outside the tank af reservoir.

b. Labels or other marking devices should be provided to clearly designate the position of a value control. A rider may be attacheo to the shaft with marks to indicate the fully opened and fully closed positions.

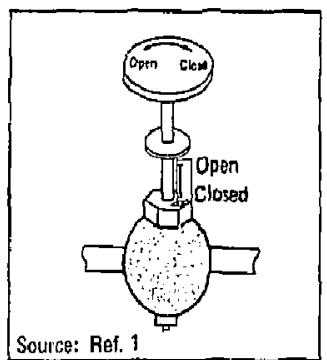

Extribit 1.5,3 Valve Control Lobels c. Valves should be color-coded by content of the substance which they control,

\begin{tabular}{|c|c|}
\hline Contonis & USAF Color \\
\hline $\begin{array}{l}\text { Futl } \\
\text { Water Injection } \\
\text { Lubrication } \\
\text { Hydraulic } \\
\text { Pneumatic } \\
\text { Instrument Air } \\
\text { Coolent } \\
\text { Ereathing Oxygen } \\
\text { Air Conditioning } \\
\text { Fite Protection } \\
\text { De-icing } \\
\text { Compressed Gasses } \\
\text { Electrical Conduit }\end{array}$ & $\begin{array}{l}\text { Red } \\
\text { Red-Gray-fied } \\
\text { Yellow } \\
\text { Blue \& Yellow } \\
\text { Orange \& Blue } \\
\text { Orange \& Gray } \\
\text { Blue } \\
\text { Green } \\
\text { Brawn \& Gray } \\
\text { Brown } \\
\text { Gray } \\
\text { Orange } \\
\text { Brown \& Orange }\end{array}$ \\
\hline Souce: Ra!. 1 & \\
\hline
\end{tabular}

\begin{tabular}{|c|c|c|c|}
\hline Contents & $\begin{array}{l}\text { Navy Color for } \\
\text { Value Hantwheels } \\
\text { \& Operating Levers }\end{array}$ & $\begin{array}{l}\text { Fet. Std. } 595 \text { Coipr } \\
\text { Number and Chip }\end{array}$ & $\begin{array}{l}\text { Nayy Standard for } \\
\text { Interior Pipe } \\
\text { Lines" }\end{array}$ \\
\hline Steam & Whitg & 17886 & $A$ and $B$ \\
\hline $\begin{array}{l}\text { Potable- } \\
\text { Water }\end{array}$ & Dark Blue & 15044 & $A$ and $B$ \\
\hline Nitrogen & Light Gray & 16375 & A \\
\hline H.P. Aitr & Dark Gray & 16001 & A \\
\hline L.P.Air & $\operatorname{Tan}$ & 10324 & A \\
\hline Oxygen & Light Green & 14449 & Light Giatn \\
\hline Salt Water & Dark Green & 14062 & $A$ and $B$ \\
\hline Furel Oil & Yellaw & 13538 & A \\
\hline Lube Oil & Yellow & 13538 & A \\
\hline Fire Protection & Red & 11105 & A \\
\hline $\begin{array}{l}\text { Foam } \\
\text { Discharge }\end{array}$ & Striped Red/Green & $11105 / 14062$ & A \\
\hline Garolinę & Yellow & 13538 & Yẹllow \\
\hline Fredwater & Light Blue & 15200 & $A$ and $B$. \\
\hline Hydraulic & Orange & 12245 & A \\
\hline Freon & Dark Purcle & 17100 & A \\
\hline Hydrogen & Chartreuse & 23814 & $A$ \\
\hline Sowage & Gold & 17043 & $A$ \\
\hline
\end{tabular}

Exhibit 1.5.4 Examples of Value Color-Coding Schane

\subsubsection{MAINTENANCE DISPLAY'S}

a. Liquid level indicators should be located so that a minimum $x$ visual parallax is present.

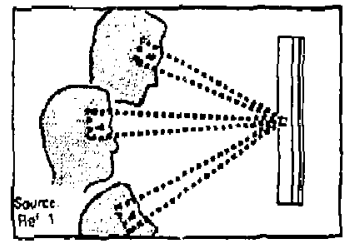

Exhibit 1.5.5 Minimizing Visusl Parallax b. Liquid level indicators should be used for oil tanks or similar reservoirs so that maintenance technicians can tell whether the reservoirs are filled properly.

c. Liquid level indicators should have adequate contrast between the background of the indicator and the color of the liquid it contains.

d. Markings should be etched or painted on the glass of a liquid level indicator to eliminate the need for looking through the liquid to the scale.

e. Plug-in meters/displays should be designed in such a way that they are visually accessible while pertorming a maintenance task.

1. Means of indicating a "trippes circuit breaker" should be provided. 
g. Where possible, direct-reading type indicators should be used for hydraulic and other fluid tanks. For example, to tacilitate quick visual in oection of the presence of ail in gear cases, eil level sight plugs may be used. This eliminates the need for dipgticks or fluid level gauges.

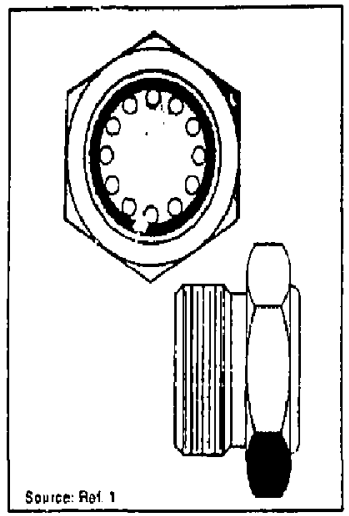

Exhibil 1.5.5 Oil Level Sight Plug h. To avoid computational errors in weight and balence from a volumetric figure for hel, a gauge thould be provided which measures the welght of fuel in pounds.

i. The lubrication system of an assembly should be pro. vided with gauges necessery to keep the maintenence technicien fully informed about the condition of the equipment, $i_{1}, \theta_{\text {, }}$ oil temperature, inlet, and outlet pressure gauges should be provi: jed,

j. Oil dipsticks should bo designed to:

(1) Provide contrast between the finish of the dipstick gauge and clear thin oil.

(2) Make interpolation of liquid level observations un. necessary by graduating the of stick in increments.

k. Magnetic chip detectors should be provided in lube systems rather than electrical detectors since the lattes create maintenance problems. 
1.0 ENGINEEAED HARDWARE

1.6 Line and Cable Dusign for Maintainability 
ENGINEERED HAHOWATY 1.0

LINE AND CABLE DESIGN FOR MAINTAINABILITY 1.5

1.6.1 INDEX

P:Lis'

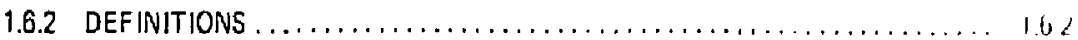

1.6.3 GENERAL PRINCIPLES $\ldots \ldots \ldots \ldots \ldots \ldots \ldots \ldots \ldots \ldots \ldots \ldots \ldots \ldots \ldots \ldots$

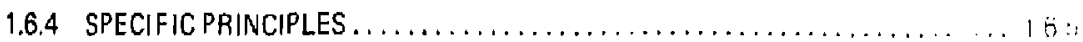

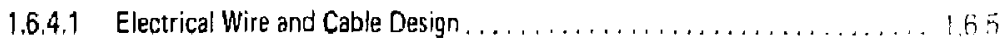

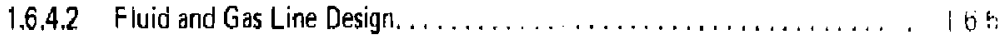


ENGINEERED HARDWARE 1.0

LINE AND CABLE DESIGN FOR MAINTAINABILITY 1.6

\subsubsection{DEFINITIONS}

Lines refer to any single length of pipe, wire, or tubing.

Cables refer to a number of lines bound together within a single, permanent sheath. 


\subsubsection{GENERAL PRINCIPLES}

1.6.3.1 Lines and cables stould be selected, designed, bound, mounted, and routed to:

a. Preclude wearout, brtakage, or damage.

b. Facilitate logical and efficient divisions of maintenance responşibilitiess.

c. Allow for quick and easy:

(1) Troubleshooting, testing, checking and isolation of maltunctions.

(2) Tracing, removal, repair, and replacement.

(3) Connecting and disconnecting.

1.6.3.2 Lines and cables should be designed to minimize the number oi:

3. Types and varieties of lines and cables.

b. Difierent lengths of identical lines or cables.

c. Reiăted çonnectors, fittings, and fixtures.

1.6.3.3 Lines and cables should be routed and mounted to be accessible:

d. With minimum disassembly required or remoual of other equipment or items.

b. Especially at connect, test, mount, and splice points.

c. For compiete removal and replacernent in case of damage.

1.6.3.4 Lines and cable; should be routed over the shortest runs allowable by lead, mourting, and other requirements.

1.6.3.5 High pressure or high voltage lines and cables should be routed away from sensitive equipment, high temperature sources, work areas, controls, etc, where personnel may require access.

1,6.3.6 Lines and cables should not be routed through remote switches or valves which may be inadvertently used while work is being performed on equipment.

1.6.3.7 Lines and cables should be rauted so they will not be:

a. Used for inand./footholds.

b. Bent or sharply twisted.

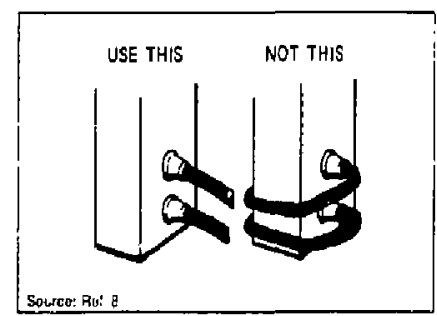

Exhubl 1,5 I Proser Routing of Cabte to Audid Sharp Bends

o. Walked on or rolled over by heavy traffic.

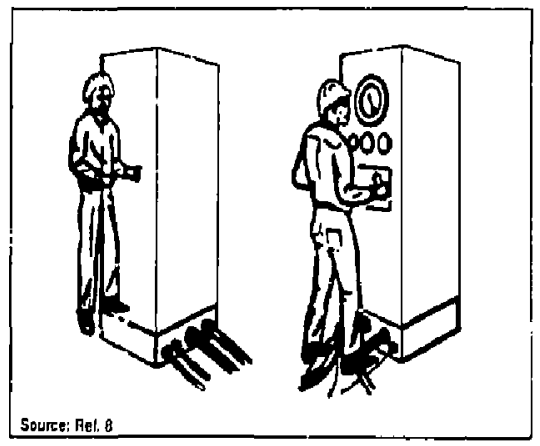

Exhibit 1,6.2 Proptr Routing of Colle to Avoid Walking On

d Pinched or stressed by loose objects, doors, lids, covers, sliding drawers, or roll-out racks.

1.6.3.8 Lines and cables should be mounted so that:

a. They will not interfere with other maintenance operations.

b. They will not chafe or flex excessively under predicted conditions of use.

c. Protection from metal edges is provided by grommets or pads.

d. They are securely anchored to the chassis by clamps or plates.

e. They are not terminated or mounted on the front of ;abinęts or control-display panets (test cables excepted).

1.6.3.9 Clamps or mounting plates used for mounting should:

a. Fit snug without deforming or erimping the line or cable.

b. Bespaced nc more than $\mathbf{2 4}$ inches apart.

c. Be put at both ends of bends where the bending radius is 3 inches or less.

d. Be lined with heat resistant material if the line is likely to become extremely hot.

e. Be non-conductive or properly insulated if they are securing a conductor.

f. Require only one-handed operation with common hand tools.

9. Be of a quick release, hinged, or spring type if the line or cable must be frequently removed. Hinged clamps are preferred; they suppurt the weight of the line during maintenance, freeing the techniciari's hands for other tasks.

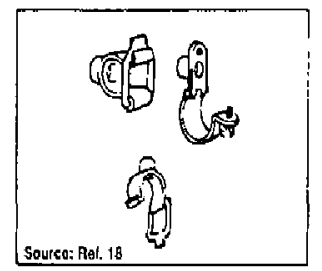

Exhibit 1,6.3 Ouick Release, Hinged and Spring Type Cl amps 


\section{T.O ENGINEERED HARDWARE}

h. For overhead mounting, be of a spring clamp type with a hinged locking latch over the open side of the clamp to prevent accidents.

1.6.3.10 Adequate storage and handling provisions should be mede for excension.type lines and cables such as:

a. Covered storage spece in grourd support equipment for storing lines and cables.

b. Suitable racks, hooks, or cable winders within the storage place to hold lines and cables conveniently.

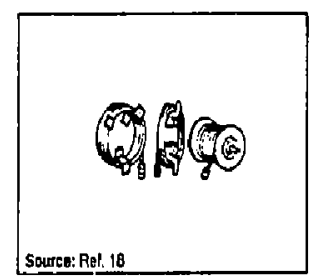

Exhbit 1.6.4 Line and Cob/o Rack, Winder, ans Hook

c. Recis or reel carts for handling large, he wy, or long lines ar cables. Automatic rewind should be wailatic, where possible, to minimize damage and kinking.

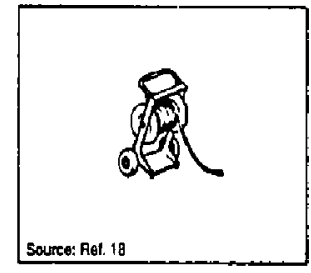

Exhibit 1.6.5 Line and Cable Reel Can

4. Wheets or othe' mobile supports for especially large lines or cables that must be frequently moved.

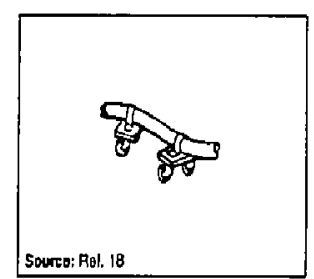

Exhibit 1,6.6 Line and Cable Mobile Support 


\subsubsection{SPECIFIC PAINCIPLES}

\subsubsection{ELECTRICAL WIAE ANO CABLE DESIGN}

a. The layout and routing of wires and cables should be predetermined and made as simple and functionally logical as possible by:

(1) Combining conductors into cable wherever practical.

(2) Combining conductors into harnesses wherever cables are not used.

(3) Segregating conductors into and within cables or harnesses according to their functions and relation. ships to replaceable equipment.

(4) Using preformed cables wherever possible to minimize wiring errors and to allow more flexible and efficient arsembly meihods, Provide spare leats in cables to allow for growth and to speed wiring time.

(5) Where possible, use physical measures, such as cable length, to prevent interchanging units or components with the same or similar form, that are not, in fact, functionally ir,terchangable (MIL-STD-1472C pg. $179,5.9 .1 .93$ \}.

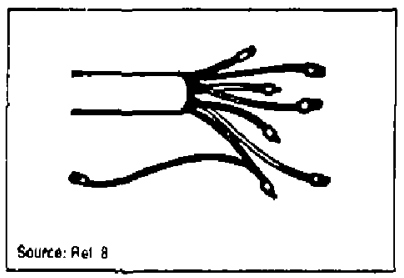

Exhibil 1.6.7 Pretormed Cables

b. Wire connections should contorm to the tollowing recommendations:

(1) For easy maintenance, plug-in contacts are better than serew terminals and screw terminals are better than solder connections.

(2) The end of a wire oldered to a terminal stould be left out of the solder so that the wire will be easy to remove.

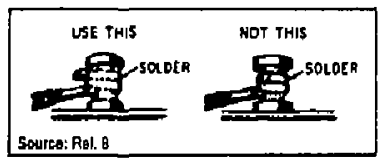

Exhibit 1.6.8 Proper Soldering of Elsctrical Wire

(3) U.lugs should be used rather than O.Iugs whenever practicable.

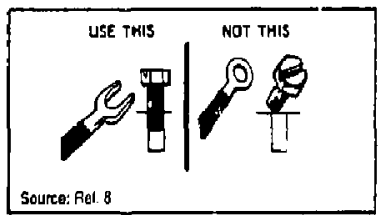

Exhibit 1.6.9 U.Type Lug
(4) Separate terminals to which wires are to be soldered should be separated far enough apart so that work on one terminal does not damage neighboring ones.

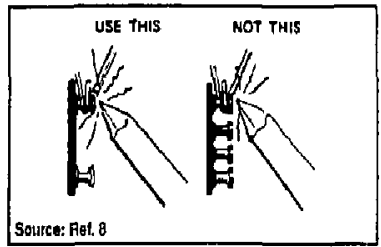

Exhibit 1.6.10 Proper Specing of Wire Leads

(5) Terminals or other connęctions to which wires are soldered should be made long enough so that insulation and other materials are not burned by the hot soldering iron.

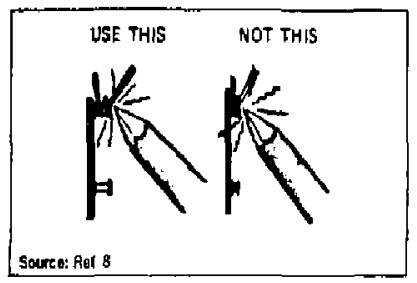

Exhibit 1.6.11 Propet Lengh of Tetminals and Connectionn

c. Harnesses should:

(1) Be designed, fabricated, and insta!led as units.

(2) Be held securely with lacing twine or other means acceptable to the user.

(3) Keep the individual conductors essentially paraltel, so they do not intertwine, though twisted pairs may be used when required.

d. Lead lengths should be as short as is consistent with the task to be performed, but long enough to allow:

(1) Easy connection and disconnection, with enough slack to back the wire away from the poinl of attachment to facilitate removal of the unit.

(2) Sufficient slack for at least two (preferably six) replacements of terminal fittings, electrical con. siderations permitting.

(3) Movements of moving parts to which they may be attached (doors, covers, etc.) without undue stress or bending.

(4) Connection, disconnection, or movement without requiring a bending radius of less than six imes the diameter of the lead.

(5) Movement of the units which are difficult to handle in their mounted position to a morc convenient position for connection or disconnection,

e. Extension cables should be planned, designed, and provided to:

(1) Increase the efficiency and ease of maintenance,

(2) Avoid removal of assemblies or opmponents for testing.

(3) Allow each functioning unit to be checked in a convenient place. 
(4) Allow support equipment to be parked or set in o convenient place.

(5) Serve as many related functions as possible, yet waid the possibility of misuse or misconnection.

f. Mounting of wires and cables, in addition to satislying the General Principles previousiy listed, should:

(1) Ensure that lightly insulated wires clear parts normally at ground potential by at least 0.75 inches under operating conditions.

(2) Employ receways, stulfing tubes, conduit, junction boxes, and insulation as necessary to obtain the required degree of protection, security of mounting, and ease of maintenence.

(3) Ensure that adequate accessibility is provided to racewsys, stuffing tubes, etc.

(4) Allow checking of the signal flow through each conductor by arrengement, location, and mounting of leads; provide test points where leads are un. available for testing; and provide test points in connectors.

9. Leads should be mounted so they:

(1) Do not bear the weight of the cable, harness, or other components.

(2) Are provided with support at splices and points of connection.

(3) Are "fannet out" to provide adequate clearance for the technician's haind and/or any tool required for checking or connection.

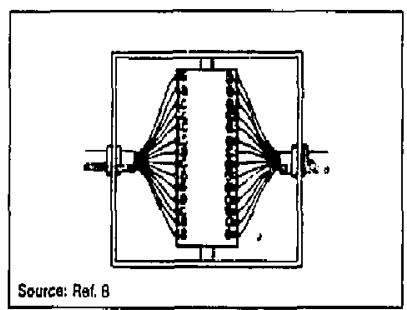

Exhibit 1.6.12 Coble "f inning" tor Eaxe of Maintenance

(4) Are oriented, where possible, in such a manner as to prevent erroneous connection or "crossing."

(5) Do not allow flexing ot weak ereas, e.g, at splices, solder points, or where the conductor is bare or crimped, or strands are tinned together.

h. Leads or cables to moving parts, doors, covers, etc, should have adequate slack and protection \$o they:

(1) Allow movement of the part (door, etc.) without their disconnection,

12) Fold out of the way jutomatically when the part is moved,

(3) Do not chafe or break under the repeated floxing required.

(4) Are not pinched or otherwise damaged by movement of the part

i. When determining materials to be used for wire and cable applications, the following should be considered.

(1) Clear plastic insulation aliows rapid detection of internal breaks.
(2) When polyvinyl wire is used, care should be taken so there will be no cold flow of insulation due to tightness of lacing or mounting.

(3) Neoprene-covered rather than aluminum-sheathed cable should be used in areas where intense vibration or corrosive substances may cause failures,

(4) High-temperature wire should be used when wires are routed near ducts carrying pressures over $50 \mathrm{psi}$ and/or temperatures abovn $200^{\circ} \mathrm{C}\left(382^{\circ} \mathrm{F}\right)$

(5) Metallic shieidirig unprotected ty outer insulation should be secured to prevent the shielding from contacting exposed terminals or cunductors.

$j$. Wire and cable insulation should be protcated from termite destruction by coating them with compounds of creosote, antimony, or other mixtures acceptable to the user.

k. Insulated wire or cable should be color- or number coded in accordance with standards ecceptable to the user (e.g., MILSTD-185; MILSTD-681).

\subsubsection{FLUID AND GAS LINE DESIGN}

(a) Lines for fluids and gases should be designed and routed to prevent:

(1) Misconnection during serviching or maintenence operations.

- Firtings should be standardized so it is impossible to intercharige lines that differ in content.

- Employ arrangement, size, shape, and color coding as necessary to prevent interchange of adjacent lines.

- All fluid carrying lines should be identified by color bands.

(2) Spraying or draining on personnel or equipment during disconnections.

- Connections should be located away from work areas and sensitive components.

- Shielding should be provided for sensitive components where required.

- Drains and bleed fittings should be provided to allow draining or reduction of pressure prior to disconnection.

- High visibility warning signs stould be pravided at disconnect areas of where pressures or the content of lines could injure personnel.

(3) Drainage problems.

- Lines should be designed to be completely emptied when requires.

- Avoid low points or dips in lines that are difficult to drain'.

- Make bends, where possible, in the horizontal rather than the vertical plane, to avoid fluid traps.

- Low point drains should be provided where required to drain such traps.

b. Lines for fluids and gases should be mounted and installed.

(1) Rigid lines should be installed with fittings that do not require the line to be bicked-olt for disconnection. 
(3) Tubing should be used instead of rigid lines, because it allows more flexibility in handling. can be backedoff easily, and is easier to ihreac through equipment when replacement is required.

(3) Flexible hose should be used rather then pipss or tubing where minimuln space is wailable for removing, handlirn? or replacing lines.

(4) Aclequate supports should be provided for lines which run from external service or test equipment, of where extensions will be attached for ather purposes. These supports must withstand:

- The initial surges of pressure through the line.

- The weight of the exterizal extersions.
- The rigor of handling and repeated connection and disconnection.

(5) Lines should be moui $d$ and installed in such a way as to preclude kinkung by:

- Emploving sufticięnt mounts and supports to prevent kinking.

- Emjloying quick-disconnect fittings to reduce manhandling of lines during conn_ition or disconnection.

- Eliminating work space restrictions around mounts and connections that may cause the technician to bend the line in installation, disconnestion, or mavoval. 
1.0 ENGINEERED HARDWARE

1.7 Test and Service roint Design for Maintainability 
ENGINEERED HARDWARE 1.0 TEST AND SERVICE POINT DESIGN FOR MAINTAINABILITY 1.7

\subsubsection{INDEX}

Pije

1.7 .2 DEFINITIONS $\ldots \ldots \ldots \ldots \ldots \ldots \ldots \ldots \ldots \ldots \ldots \ldots \ldots \ldots, 1.7 .2$

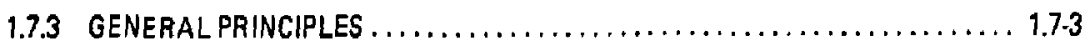

1.7 .4 SPECIFIC PRINCIPLES $\ldots \ldots \ldots \ldots \ldots \ldots \ldots \ldots \ldots \ldots \ldots \ldots \ldots, 1.7-4$

1.7.4.1 Test Points $\ldots \ldots \ldots \ldots \ldots \ldots \ldots \ldots \ldots \ldots \ldots \ldots \ldots \ldots \ldots, 1.7-4$

1.7.4.2 Service Paints $\ldots \ldots \ldots \ldots \ldots \ldots \ldots \ldots \ldots \ldots \ldots \ldots \ldots \ldots \ldots, 1.7-5$ 


\subsubsection{DEFINITIONS}

Test points are means for conveniently and safely determining the operational status of equipment and isolating malfunctions. Test points, strategically placed, make signals available to the techrician for checking, adjusting, or troubleshooting.

Service points are means for lubricating, filling, draining, charging, and similar service function. Service points allow adequate adjustment, lubrication, filling, changing, charging, and other services to be provided on all equipment and components requiring such service between overhauls. 


\subsubsection{GENERAL PRINCIPLES}

1.7.3.1 Aequirements for periodic or repetitive 1esting and servicing of enmponents should be avoided when possible by using sealed bearings, oil impregnated bushings, highly feliable components, etc.

1.7.3.2 To seduce tho number of test and service points required, built in indicators, pressure gauges, direct reading fluid level gauges, etc. should be used for quick checks without the need of auxiliary equipment.

1.7.3.3 Test and service points should be designed for compatibility with checking, troubleshooting, and servicing procedures and test/service equipment.

1.7.3.4 Different types of the following items should be minimized:

a. Test and service equipment and pacressories required.

b. Fixtures required lfittings, connectors, etc.l.

1,7,3,5 Distinetively different connectors or fittings should be provided for each type of test or service equipment. probe, grease, oil, etc. to minimize the lik elihood of error or misuse,

1.7.3.6 Test and service points should be located so they are:

a. hecessed, guarded, or otherwise protected from damage by persornel, moving cargo or equipment, dust, moisture, etc

b. Within each funstional reaching and/or seeing distance of related or corresponding controls, displays, fittings. switches, etc.

c. Convenient to related maintenance support equipment and compatible, iา terms of work space and clearance requirements, with the various features and characteristics of such equipment.

d. Away from dangerous electrical, mechanical, or other hazards. More than a hand's width $\left(4.5^{\prime \prime}\right)$ separation trom the nearest hazard should be provided, and guards and shields should be provided as necessary to prevent injury.

e. Not concealed or abstructed by buikheads, brackets, other units, etc., and so it is not necessary to disassemble, remove, or support other units, wires, etc. to test, senvice, or troubleshoot.

1.7.3.7 Locations of internally located points should be indicated on the access plate or adiacent surface of the equipment.
1.73.8 Safety valves should be located where they are readily accessible, but where popaft action will not injure personnel or damage equipment.

1.7.3.9 Fluid fill areas for combustible materials (luel, oil, etc.) should be located away from sources of heat, sparking, or potential voltage shorts.

1.7.3.10 Fluid fill areas should be located so there is little chance of spillage during servicing, expecially on personnel or easily damaged equipment.

1.7.3.11 Connectors or fasteners for test and service points should:

a. Use direct insertion of quick disconnects except on pressurized systems.

b. Key the connectors on pressurized systems so they are properly seated before an opening occurs, to prevent loss of gases or fluids and reduce the hazards involved.

c. Require only hand operation by common hand tools. Special tools shauld not be required for the connection of test and service equipment.

d. Incorporate holding devices, clamps, and auxiliary shelves to support test probes, test sets, etc., and free the technician's hands for other tasks, such as making adjustments.

e. Incorporate guards and shipids to protect personnel and test or service equipment, particularly if the equipment must be serviced while running.

f. Employ self-sealing elastomers or similar devicess to allow probing into hermetically sealed units. Such devices should be providad with tool guides to ensure that proper contact is made.

1.7.3.12 Test and service points should be designed so they are easily distinguisirable, Color coding with a distinctive color may make then mor? easily located by the technician. Color for tast points should be clearly different from the color used for service points.

17.3.13 Luminescent markings for test and service points should be used if they must be used in low illumination.

1.7.3.14 When a test or service point is internally located, its location should be indicated on the access plate on the surface of the equipment.

1.73.15 Dangerous test and service points should be labeled as such. The labeling should be clearly visible, using capital letters. 


\subsection{SPECIFIC PRINCIPLES}

\subsubsection{TEST POINTS}

\section{a. DESIGN OF TEST POINTS}

(1) If internal probing of hermetically sealed units is required, accesses should be covered with self. sealing elastorners, and needle probes should be used

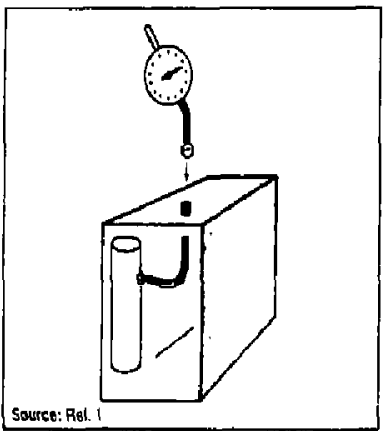

Exhibit 1.7.1 Internal Noedle Probe und Self-Sesling Elastomer

(2) High pressure test indicators should be built wherever possible to avoid some of the dangers in remporary high pressure onnnections.

(3) A special "ground" point should be provided if a good grounding point is not available and connection to ground should be made during tests of a given unit. Technicians may heve difficulty if only painted surfaces are available for ground connections.

(4) Suitable guides for test probes should be provided when test points are located internally.

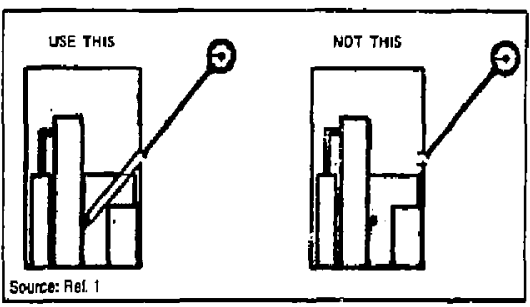

Exhibit 1.7.2 Test Probe Guider

\section{b. LOCATION AND GROUPING OF TEST POINTS}

(1) The functional location of test points should be fixed by determining from maintenance procedures the signals that must be available to the technician and at whot points they must be available.

(2) Generally, test points should be concentrated in one place, but practical limitations do no: always make this possible.

(3) Highly accessible test points should be provided for checking and troubleshooting.

(4) Accessible test points should be provided on fuel, hydraulic, and pressure systems that will eliminte the need for:

- Removing fittings to attach test equipment.

- Rernoving components such as fuel purnps and actuators during troubleshooting.

(5) Test accesses should be provided for mechanical components likely to wear. For example, brake assemblies should le provided with an inspection opening to permit insertion of a gauge for deter. mining the clearance between the brake lining and drum.

(6) On electrical equipment, cables should be fanned out on terninal strips if special test points are not pravided.

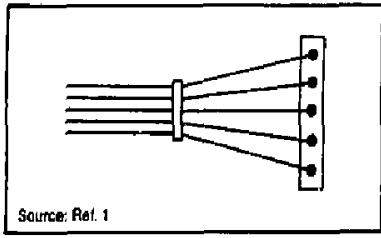

Exhibit 1.7.3 Fun Out Cables tor Tht Paint

(7) When possible, test points should be grouped on a central panel to facilitato checking and troubleshooti.ig.

(8) Test points should be located so they are in a convenient arrangernent for sequential checking.

(9) When test points are located on one central test panel, they should be grouped $a$. rding to the units which are bsed for testing

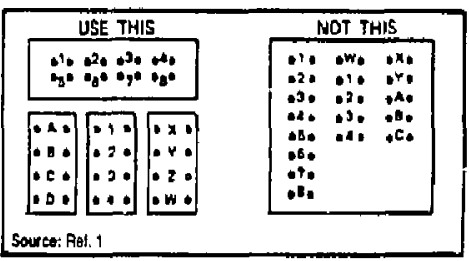

Exhibit 1.7.4 Proper Test Pount Grouping

(10) Test points should be locsted clase to the controls and displays which are used in the checking operation. The technician should be able to activate the conttol and see the display at the same time.

\section{c. ALTERNATE TEST POINT ARRANGEMENTS}

(1) A EUILT.NN TEST UNIT. An arrangement built in as part of the installation is most desirabla for effieient maintenance and troubleshooting. If voltage; and wave shapes must be checked, for example, the test unit might consist of a meter, an oseilloscope, and a rotary switch for selecting circuits. The meter and oscilloscope should have fixed, preset circuits so that the meter always reads center scale and the oxilloxcope needs no adjustment. Either an in-tolerance meter reading or an in-tolerance waveform on the oxcilloscope should be coded for each position of the rotary switch. If more test points are needed than can be handled by a single switch, multiple switches could be used. 


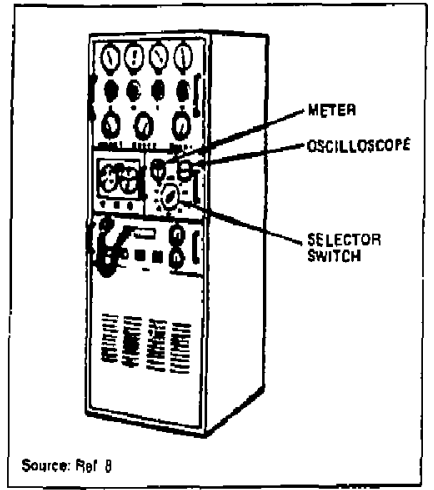

Exhibil 9.7 .5 Built:In Test Unit

(2) A PARTIALLY BUILT-IN TEST UNIT. Because some oscilloscopes are large, heavy, and expensive. it may not be practical to design a test unit such as that recommended in (1) above for each major component of a system. An acceptable compromise is to mount a center reading meter on each major component that can be checked by meter and then provide a set of test jacks as an outlet for signals requiring an oscilloscope. The selector switch and circuits for this arrangement should be designed as before.

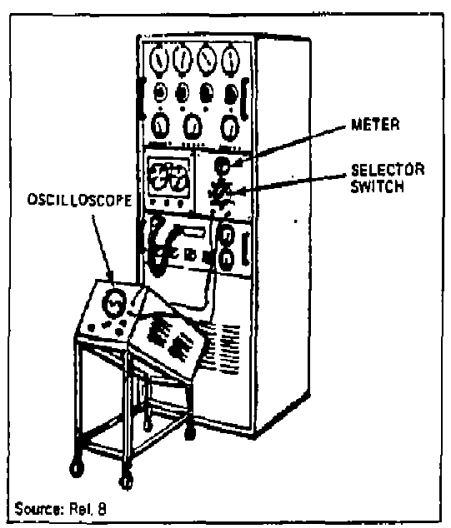

Exhibit 17.6 Panisally Buite-In Ten Unit

(3) A PORTABLE TEST UNIT. If neither of the two built-in test arrangements is practical because of space or weight limitations, an integrated ponable test unit resembling the built-in unit may be used. A single, multiprong contact on the end of a cable can be used to attach the test unit.

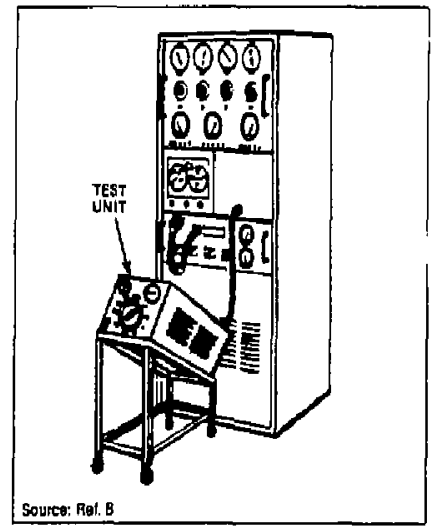

Exhibi: 1.7.7 Portable Test Unit

(4) A BUILT.IN TEST PANEL. If, for some reason, none of the alternatives described previously is practical, a test panel should be provided on the equipment. With this arrangement, the outpues of each test point should be designed for checking with standard test equipment, and the points should be planned to provide a miniature block diagram of the system, with each block repre. senting a line replaceable unit. Overlays for the test panel should direct the technician to test points he should check and the order in which he should check them, In-tolerance signals should be shown on the overlays, and test points should be coded on the panel with full instructions provided in the maintenance manual in the event the overlay is lost.

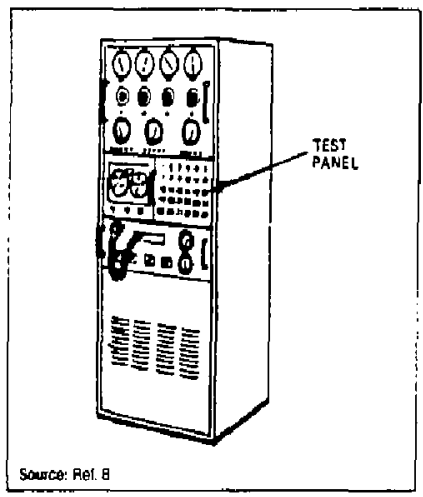

Exhibit 1.7.8 Buslt:in Test Panel

(5) TEST POINTS ON REPLACEABLE UNITS. If none of these arrongements is practical, test points should be provided for the inputs and outpuss on each replexeable unit, if possible, components 
should be mounted an one side of the board or chassis and wiring on the other side. Even if the wiring is mounted on the same side as the parts, test leads should be brought through to the back. An advantage in having test points on the back is that full identifying intormation for each test point can be marked on the back without being obscured by parts.

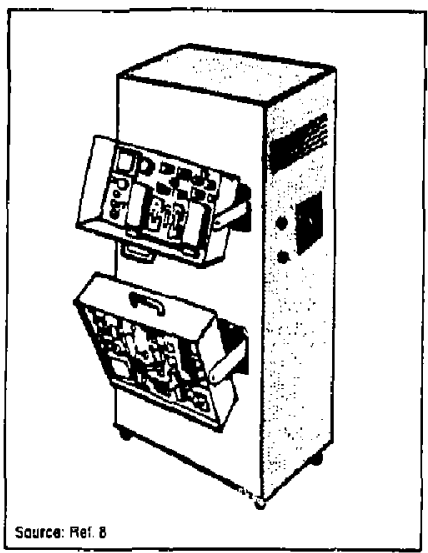

Exhibit 1.i.9 Test Points on Replacesble Units

\section{d. LABE LING AND CODING}

(1) Test points should be labeled with the name of what is heing tested. If it is nor possible to include the name on the test point, it should be coded with a symbol. Explanations for symbols used should be in tables placed near the equipment or in job instructions.

(2) Test point labels should be locatted consistently throughout the system and should be consistent with identifiers used in maintenance instructions.

(3) Test points should be labeled with in-tolerance indications or colerance limits of the signal being measured there.

(4) Color coding of test points should be considered for easy locition.

(5) Phosphorescent or chemoluminescent markings should be used on test points, selector swirches, and meters that require reading in low light conditions.

\subsubsection{SERVICE POINTS}

\section{a. DESIGN OF SERVICE POINTS}

(1) Lubrication points should be designed with a reservoir to reduce the trequency of required lubrication.

(2) Service fittings should be designed to be hand operable or to requira on'y common hand tools. Petcocks and valves are preferred to drain plugs.

(3) Guards should be provided around lube points which may be serviced while equipment is cuer. ating.

(4) Grease fittings should be standardized for a given lubricant so that the number of different grease gun tips required is minimized.

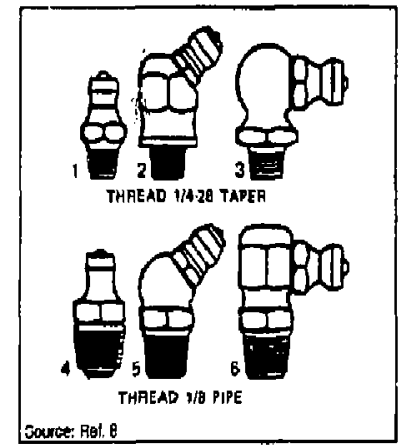

Exhibit 1.7.10 Exumple of Typiea l lubrication Fintings

(5) Oil filler caps should be designed so they:

- Snap and remiin open and closed.

- Provide a large round opening for oil filling.

- Permit application of breather vents, dipsticks, and strainers.

- Use hinges rather than chains for attaching the lid.

- Look different when opened or closed.

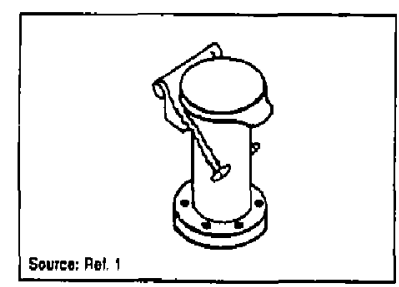

Exhibit 1.7.11 Example of Well.Dnigned Oil Filler Cap

(6) Pressure fittings should be provided for applying grease to bearings which are shielded from oil.

(7) The game fuels and lubricents should be used in auxiliary or mounted equipment, as in the prime unit, when possible.

(8) Lubrication requirements should be reduced to two types, if possible; one for engine and another for gear lubrication.

(9) If lubrication is reguired, lubrication goints rother than equipment disassembly should be provided.

(10) If lubrication points are not feasible, easy access to equipment should be provided.

b. FLUID LEVEL INDICATORS

(1) Direct reading gsidges are preferable to dipsticks of uther methods of indicating fluid levels, because they allow rapid, immediate, and continuous inspection, and thus remove requirements for inspection tables.

(2) If used, gauges or dipsticks should be calibrated in terms of functional units (quars, pounds, galions, atc.), rathar than in general terms such as dry, low, add, atc.

(3) If used, gauges or dipsticks should be immediately accessible and quickly and essily read, i.e., there 
should be gooo contrast between the finish of the gauge and the fluid.

\section{c. DRAIN POINTS/BLEED FITTINGS}

(1) Provide drains on all fluid tanks and systems, fluid filled coses or pans, filter systems, float chambers, and other items which are designed or likely to contain fluid that would otherwise be difficult to remove.

(2) Use drain fittings of a few types and sizes, and standardize these according to appliaztion throughout the system.

(3) Use valves ar petcocks in preference to drain plugs. Where drain plugs are used, they should require only common hand tools for operation, end design must engure pdequate too' and work clearance for operstion.

(d) Drain cocks or valves should be clearly labeled to indicate ogen and closed positions, and the direction of movement required to open.

(5) Drain cocks should always close with clockwise motion and open with counterclockwise motion.

(6) Provide instruction plates as necessary to ensure that the system is properly prepared prior to draining.

(7) Design, locate, and install drain points

- Where they are readily reachable and operable by the technician.

- So fluid will not drain or spil, on equipment or personnel.

- At the lowest point in the systerm when com plete draining is required or when separation of fluids is desired.

- At other points in the system as required to permil selective draining of bleeding to facilitate maintenance procedures.

- To permit drainage directly in to a wasta container without use of separate adapters or piping.

- So fuel or other combustible fluids cannot run down to or collect in the starter, exhaust, or other hazardous areas.

\section{d. LOCATION AND GROUPING}

(1) Lubrication points should be located so that they are easily accessible, Lead tubes of extended fittings should be provided if required to avoid equipment disassembly or locating a lubrication point in a hard to reach areag.

(2) Removing cesses, covers, or other pieces of equip. ment should be avoided to obtain access to lubrication points by:

- Locating oil dipsticks and other such level indicators so that they may be fully with. drawn without touching other pieces of equipment.

- Locating lubrication test points close to corresponding lubrication add points, if possible.

(3) When possible, a central lubrication point or grouping of points should be provided tor applying lubricant to all areas which require lubrication within a system, subsystem, or major component.

(4) The oil quantity dipsticks should be placeo in an accessible lacation.

\section{e. LABELING AND CODING}

(1) Lubrication, fuel, and other filling points should be labeled with the type of lubricant or other material which is being replaced or replenished. A log and instructinns for lubrication schedule should be included where possible,

(2) Servicing instruction plates should be provided adjacent to servicing points.

13) Cautions (or overflow mechanisms] should be provided adjacent to lubrication points where excess lubrication is unwanted.

(4) Drain systems should be labeled to indicate proper position of equipment for draining.

(5) Service points should be clearly distinguighed from other fittings or breathing holes not to be lubricated or otherwise services. 
1.0 ENGINEERED HARDWARE

1.8 Test Equipment Design for Maintainability 
ENGINEERED HARDWARE 1.0

FEST EQUIPMENT DES. $.3 N$ FOR MAINTAINABILITY 1.8

\subsubsection{INDEX}

Page

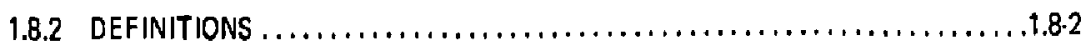

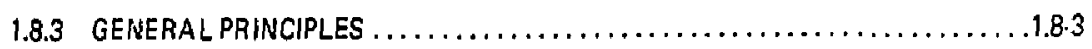

1.8.3.1 Selection of Test Equipment. ...........................

1.8.3.2 Characteristics of Test Equipment. ........................

1.8.4 SPECIFIC PRINCIPLES $\ldots \ldots \ldots \ldots \ldots \ldots \ldots \ldots \ldots \ldots \ldots \ldots \ldots \ldots, \ldots \ldots \ldots, 1.8,4$

1.8.4.1 Electrical Connections. ............................

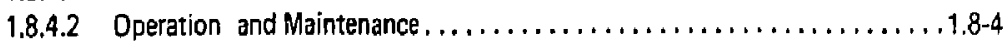

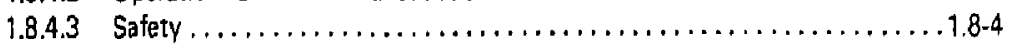




\section{ENGINEERED HARDWARE 1.0 \\ TEST EOUIPMENT DESIGN FOR MAINTAINABILITY 1.8}

\subsubsection{DEFINITIONS}

Four general types of test equipment are used in maintenance tasks:

a. Built-in test equipment is an integral part of the prime equipment. It may be a complex automatic checker or a simple voltmeter with external leads.

b. Go, no-go test equipment provides only one of two alternative answers to any question. It tells only whether a given signal is in or out of tolerance.

c. Automatic test equipment checks two or more signals in sequence without the intervention of a technician. The test usually stops when the first out-of-tolerance signal is detected.

d. Collating test equipment presents the results of two or more checks as a single display. For example, a light may come on only if a number of different signals are in tolerance.

All test equipment should be designed to satisfy the following functions:

a. Simplify the job of the on-line maintenance technician.

b. Reduce the preparation or tum-around time for systems.

c. Reduce total maintenance costs. 


\subsubsection{GENERAL PAINCIPLES}

\subsubsection{SELECTION OF TEST EOUIPMENT}

a. Test equipment should be designed and selected so that it is easy, fast, and safa to use.

b. The type of tert equipment to be used should be decided upon in the early stages of prime equipment design and should be firm by the system/subsystem stage of development.

c. Selecting test equipment depends on:

(1) The mission and opcrational characteristics of the equipment.

(2) The anticipated reliability of the er virment.

(3) The inaintenance structure,

(4) Personnel available.

(5) Operational envifonment.

(6) Logistics support requirements.

(7) Development time and costs.

d. Advantages and disadvantages of various types of test equipment

Builtin Tast Equipment

\section{Advantugas}

Less likely than portable test equipment to be lost or damaged.

- Avoilable when nceded.

- No special storage facilities are required.

- Transportation so the prime equipmens for use in mainte nance is not reguired.

\section{Diadvantege}

- Likely to add to the weight and spare sequirements of the prime equipment.

- More buistin test equipont mav be required because soparote item is usually required for each prim equipment.

- Transportation of buirtin test equip ment to a joint for convenient calibration may be mote difficult than transoorta tipn ol portable test tquipment.

- Permanent installation of the test equipment m. $y$ incresse the complexily of wiring for the system and mav even incre ase the amount of required maintenance for the prime equipment.

Ga, No-Go Tast Equipment

\section{Adventuges}

- Presents intormation tha is clear and unambiguous.

- Usually easy 10 read

- Cen simplify difficult takss such a balancing circuits or checking complex woveshapes.

\section{Dizadrantanga}

- Uniqua cirevitry usuah required for each signal value to be tested. Sometimes, howe eves, ondinary displays can be converted to go, nogo by epptopiriate uxe of reference scoles wich as a colored naction on a metor dial.

- The incragas in the number and complexity of circuits usually required adds to initial cos! and development time; it is also likely to increase the rate o test equipment breakdown.

- Except in long, tasl check sequencas 60 , nogo equipment is of relatively little help to the technician in checking common vo! tages or simple waveshapes.
- Liliedy to requise modifceation when prime equipme it is modified. A special inode may be requited for asch mode of prime equipment

Adruntuse Disedvantage

- Can make a rapid squence of - Cost, size, waight, end mainte the sks with little or no chance nence raquirements are relatively of ominting any steps. hight.

- This type of equipment is relatively sotecialized, with Jittle versalility.

- Must almost necessarily have self-checking features to detect tost equipment malfunctioniting. This adds to cost and to problems of maintaining the tost equipment.

- More likely to require modifica tion when prime equipment is modified. A special model may be required for each model of prime agujpmenl.

Collating Tast Equipment

\section{Adrontegr} Diendranteres

- Reduce the number of displays - Similar to tiose for 50, no-go the techrician must read theroby redusing shed time and probably redueing errors.

Collating test equipment should indieate hot only that ail signals are of ate not in tolerance; it should also provide an indication of which signal, if any, is out of tolerance. If only the collated display is prosented, the equipment will not be an aid to troubleshooting.

\subsubsection{CHAAACTERISTICS OF TEST EOJIPMENT}

a. Controls and displays required on test equipment should be kept to a minimum.

b. The number and complexity of steps required to operate the test equipment should be minimal. This may be accomplished by "ganging" certain controls or by making cer ain operations automatic.

c. Operating instructions for the test equipment should be availatle to the echnician, clearly written, and easily understandable. A complete set of instructions should be stored with the equipment, and/or a checklist for operating the equipment should be printed on a plate attached to it.

d. Test equipment should be designed either to prevent the technician from making errors or warn him tf his errors.

e. Circuit breakers should be grounded an al! ters enuipment to safeguard against damage if the wrong w tch or jack position is used.

1. Fail-sate features should be incorporated into the test equipment to minimize the danger to the technician and equipment in case of equipment failure.

g. Test equipment should be built to withstand the rigors of the job.

h. When required to support operations or maintenance functions, rests or stands should be provided on which units can be placed. These stands should include space for test equipment, tools, technical orders and manuals. When permitred by design requirements, such rests or stands shall be part of the basic unit, rack, or console chasiis. 


\subsubsection{SPECIFIC PRINCIPLES}

\subsubsection{ELECTRICAL CONNECTIONS}

a. Selector switches should be used on test equipment instead of inany plug in connections lif the effects of switching will not degrade information desired).

b. Test points, adjustment points, cable end connections, and labels should bo in full view of the technician making connections or adjustments at that point.

c. The technician should not be required to assume an awkward positicn to make connections.

\section{1,8.4.2 OPERATIDN AND MAINTENANCE}

a Equiprient should be simplo to operate and have self-checking and calibrating feztures.

b. Test equipment should be designesd for operation by one technician.

c. Test equipment should be easily calibrated or equipped with a go, nogo indicato or simp le check to determine whether the instrumen! requires calibration or is mal. functioning.

d. A warm-up indicator should be provided if applicable, Required warm-up time should be shown clearly near the display if no visual signal is provided.

e. A simple check for testing the accuracy of resuits should be incorpurated in to the test equipment.

f. Conversion tables should be attacthed to test equipment when they are required. Standards and tolerances should be explicit.

g. Adjus:'ments required by techniciang should be limited to only those that are essential. They should be made by means of "lowroghigh" type indicators. Feedback information to the technician should be by qualitative, positive signafing means, such as colorcode signals and zero-center meters.

$h$. Controls and displays should be designed to permit misalignment which may be caused by vibration, senvice use, or accidsntal cantact.

i. Automatic shut-off capability should he built into the test equipment to insure the equipment is tumed off when not in use.

j. rower switches should shut off automatically when instrument's lid is closed.

\subsubsection{SAFETY}

a. Test equipment should be designed so that all exposed moving and cutting parts are shielded.

b. Protrusions, rails, comers etc. that technicians might come into contact with sn the test equipment should be covered with rubber or other appropriate materials.

c. Internal controls should be located away from denger. ous voltages.

d. High voltage areas should be insulated or guarded.

e. Wherever a potential hazard exists, adequate warning should be provided. 
1.0 ENGINEERED HARDWARE

1.9 Connector Design for Maintainability 
1.9.1 INDEX

$\underline{\text { Page }}$

1.9 .2 DEFINITION $\ldots \ldots \ldots \ldots \ldots \ldots \ldots \ldots \ldots \ldots \ldots \ldots \ldots \ldots \ldots \ldots, 1.9-2$

1.9.3 GENERAL PRINCIPLES $\ldots \ldots \ldots \ldots \ldots \ldots \ldots \ldots \ldots \ldots \ldots \ldots \ldots \ldots, \ldots \ldots .9 \ldots \ldots$

1.9.3.1 Selection, Design, and Use of Connectors . . . . . . . . . . . . . . . . 1.9-3

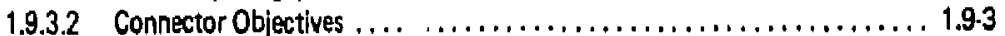

1.9.3.3 Types of Connectors. ................................ 1.9.3

1.9 .4 SPECIFIC PRINCIPLES $\ldots \ldots \ldots \ldots \ldots \ldots \ldots \ldots \ldots \ldots \ldots \ldots \ldots \ldots \ldots \ldots, 1.9 .5$

1.9.4.1 Electrical Connections................................... 1.9.5

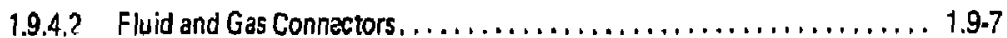


ENGINEERED HARDWARE 1.0

CONNECTOR DESIGN FOR MAINTAINABILITY 1.9

\subsubsection{DEFINITION}

A connector is any fixture designed and intended to join or connect lines lany single length of pipe, hose, wire, or tubing) or cable (number of lines, bound together within a single, permanent sheath\}. 


\subsubsection{GENERALPRINCIrLES}

\subsubsection{SELECTION, DESIEN, AND USE OF}

CONNECTORS. Decisions affeeting the selection, design, and use of connectors should be compatible and $\mathrm{CO}$. ordinated with:

a. Line and cable principles.

b. Fastener principles,

c. Mounting and packaging principles.

d. Environmentel factors to be endured.

e. Maintenance routines in which connectors will bo involved.

1. Reliability of the system in which connectors will be used. Connectors are sources of unreliability and should be considered as such in system design.

9. Reliability of ecmponents whose connection they affect. Components of low reliability should be easiest and fastest in disconnect.

1.9.9.2 CONNECTOR OBJECTIVES. COnnectors should be selected, designed, anid mounted to:

a. Maximize the rapidity and ease of maintenance oper. ations.

b. Facilitate the removal and replacement of components and units

c. Minimize sotup time of test and service equipment.

d. Ensure compatibitity between prime and ground support or auxiliary systems.

e. Minimize dangers to personnel and equipments from pressures, contents, or voltages of lines during the relezse of connectors.

1. Be operated by hand where possible, or with cominon hand toois. Requirements for special tools to effect connection, disconnection, or removal of connectors thould be avoided.

\subsubsection{TYPES OF CONNECTORS}

8. PLUG-IN CONNECTORS. These are the fastest and easjest to use, e.g., simply push in or putl out, but they have low holding power. Plug-in connestors:

(1) Should not be used where stresses or pressures will overcome holding power.

(2) Should not be used where holding power is such that lines are likely to be damaged or connectors loosened by the pulling required to disconnect.

(3) Should be used where possible for all connections that will not be seriously stressed and particularly for those that must be frequently disconnected.

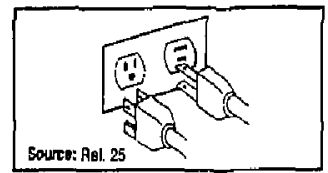

Exhibit 1.8.1 Exumple of Plug in Connecter

b. QUICK.DISCONNECT DEVICES, These are very fast and easy to usa. They exist in a veriety of forms and include any type of connector that can be released by snap action, twisting up to a full turn, triggering a latch or spring device, of removing an extamal pin. Ouick. disconnect devices should be:
(1) Designed for hand operation, while catches, pins, etc. should bo designed for operation with gloved hands.

(2) Designed to prevent loosening which allows leakage or overheating from pressures or voltages involved.

(3) Previded with self-locking cetches, as necessary, to prevent loosening, resist stress, and onwre secure connection.

(4) Used for all connections of:

- Auxiliary, test, or suppart equipment to other major units,

- Units which require frequent disconnection of replacement.

- Units which require replacement within critical readiness times.

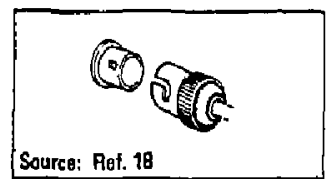

Exhlbit 1.9.2 Exumple of Ouick.Dixeonnect Connector

a. LUGS AND CRIMP-ON DEVICES. These are most useful to connect or splice single wires, Both can be used, and are próerab'e to soldering, at elevated temperatures.

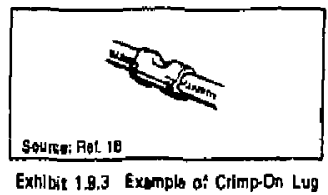

(1) Lugs must be compatible with the terminal post requirements.

(2) Where lugs and crimp-on devices are used, slack should be provided for at least six replacements of those devices which must be cut off.

(3) Lugs and crimpon devices should clamp the insulation as well as the conductor, to provide support for the line and preclude flexing of the conductor against the end of the connector.

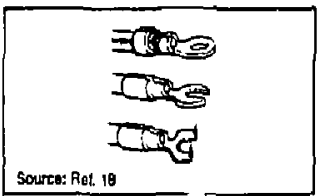

Exhibit 1.9.4 Example of Proper Aruchment of Crimp. On Devises

(4) "U-lugs" should be used tather than "eyelugs:" U-lugs:

- Are easier and tbser to connece and discon. nect. 
- Do not require complete removal of the con. nerting fastener.

- Are more likely to disconnect rather than allow the line to break under extreme stress.

d. BOLT OR SCrEW ASSEMBLIES. These provide very secure consection, but also require time-consuming handling and operation of bolts or screws. They are particularly useful for connecting large or high pressure lines.

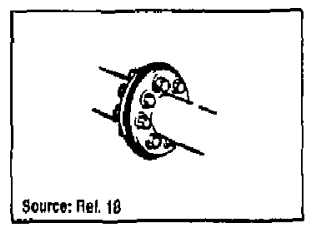

Exhibit 1.9.5 Example of Bolt Ausembly

Bolt or screw connector assemblies must:

(1) Satisfy fastener preferences and requirements.

(2) Ensure adequate work and tool clearances aboul these fasteners.

(3) Employ the minimum possible number of separate parts.

(4) Sutisfy gasket and seal requirements.

g. THAEADED CONNECTORS. These provide very secure sonnection, particularly when locked into place by set screws, retainers, or safety wires. They require more time to operate, depending upon the ease of operation, number of turns required, and types of tools required. Connectors should be right-hand threaded.

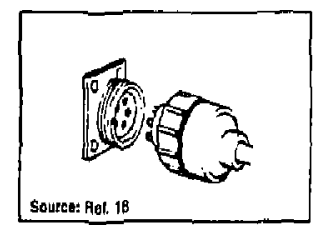

Exhibit 1.8.6 Exomple of Threaded Connector
Threaded connectors should:

(1) Require as tew tums as are consistent with holding requirement.

(2) Be operable by hand when used for electrical connection.

(3) Require only common hand tools or special tools which are immediataly accessible.

(4) Be so designed that the line need not be backed-off to etfect connection or disconnection, especially in the case of rigid lines.

(5) Be designed and arranged to reduce the danger of loosening other connectors while working on one. This is a major problem with threaded fasteners on continuous pipe or tube systems.

(6) Be designed so that aligning guides and cornector pins are easy to engage and start efficiently to ensure accurate engagement before the threaded section makes contact,

f. SOLDERING, BRAZING, OR WELDING. Such methods provide the securest connection, and are often the most efficient way of securing small connection points or maintaining herrneticseals. But such connections require considerable maintenance time for connection or disconnection.

(1) Soldering should satisfy terminal post requirements.

(2) Welding and brazing should be used only for connections that are very unlikely to require disconnection,

(3) These methods should never be used to effect con. nection of lines or assemblies that may require disconnection by line maintenance personnel.

9. WIRE-WRAPPIYG OR PIG-TAILING. Such methods are only useful for electrical connections and should be avoided because they require more maintenance time, damage conductors, and do not provide reliable contact.

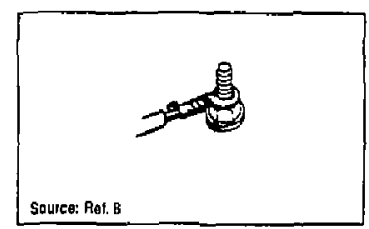

Exhibit 1.9.7 Example of a Wire-Wrap Connection 
1,9,4 SPECIFIC PAINCIPLES

\subsubsection{ELECTRICAL CONNECTIONS}

a. CONTACT. Inadequate electrical contact is an everpresent source of internittent faults. To acfiese adequate electrical contact:

(1) Whenever possible, superior Insulating materials, corrosion-proof platings, and moistureproof con. nectors should be used. If maisture-proof conneclars cannot be used, the connector case should contain a drain hole. Vertical mounting of cennectors should be avoided.

(2) To protect against corrosion, all parts and mating surfaces of connectors should be coated with on electrical lubricating compound. Metal parts of all medium-, very-high, and ultra-high frequescy (MF, VHF, and UHFI connactors should be silverplated inside and out

(3) Insertion forces should be kept low to minimize the possibility of damaging contact surfaces on connector parts.

(4) Contacts should be avoided which depend on wires, lugs, terminals, etc. clamped between metol and insulation. These contacts should be clemped botween metal members.

(5) Hoth ends of static discharge lines and grouned wires should be sacurely fastened. Alligator clips sould be used only for temporary grounding or testing because they gre fast and easy to use, They should not be used for permanent grounding because they may become induertently decached.

(6) Spring contacts should be used which are:

- Relatively long to avoid concentrating stress and permit contact surfaces to wipe each other clean as contact is made.

- Made of beryllium copper where contact is to be frequintly stressed-copper is adequate for most other purposes.

- Not stamped from flat metal-these tend to resume flat shape after a number of flexings.

(7) Contact surfaces should be plated with non ta:'nishing materia/s such as:

- Gold-a perfect plating material but very costly,

- Cadmium-satisfactory for most purposes.

- Silver-may be used wherever its 1endency to $r$ igrate in humid environments does not inter. tere with circuit operation.

\section{b. TERMINAL POSTS}

(1) rose or poorly arrarged tepminal posts require auout three times as long to solder or connect than adequately eacured ones, Therefore, posts should be located, constructed, and arranged so that:

- They are accessible.

- A maximum of three wires will be attached to a single post.

- Good electrical contact is assured.

- Posts will not loosen, rotate, or break with re. peated usage.
- Wites tan be rapeatedly removed and replaced disconnected, and/or soldered without damaging of loosening the posts.

- Aokyuate hand and tool clearances are provided for connection and disconnection.

- Posts are far etr.tugh apert so work (particularly soldering) on ons terminal does not damage neighboring connections, insulations, or other parts.

(2) So'der type posts should, in addition, be designes and mounted so that:

- They are completely plated with tin or silver.

- They are notched or provided with other means for mechanically securing the wire prior to soldering.

- The free end of the wire sticks out of the rolder and thus can be essily grasoed with pliers to facilitate disconnection,

- Suppors are provided, where stranded copper wire is $10 \mathrm{be}$ soldered, to prevent flexing where the strands are tinned together.

c. Electrical PLUGS, Plugs should he designed, mounted, and installed so that:

(1) It is impossible to insert the wrong plug into a recoptacle or insert a plug the wrong way into a recestacle. For example, pluas of different sizes msy be used for neaby connections; different keys or alignment pins, and/or oslar-toded paint may also be used on the plug receptacle to which it belongs.

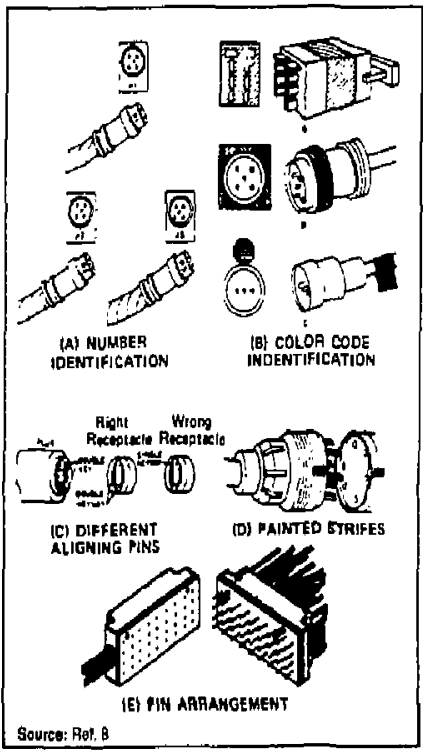

Exhibir 10.8 Plug and Recopteds Identifichion Methods

(2) Each pin on each plug should be clearly identified, e. 9, number and/or letter identification.

(3) Cuck.disconnect plugs or plugs that can be discon. nected with usually no more than one turn should 
be used rather than plugs with fine threads that require numerous turns.

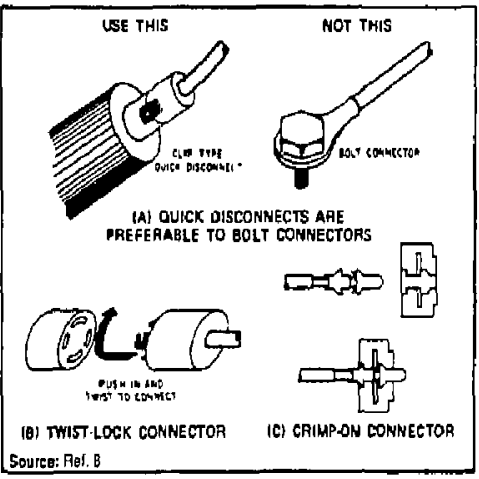

Exhibit 1.9.9 Examplet of Duist-Ditconnet Plugs

(4) Fluggs should be used in which the aligning pins or keys extend beyond the electrical pins. This arrangement protects the electrical pins from damage through poor alignment or twisting of the plug when it is partially inserted.

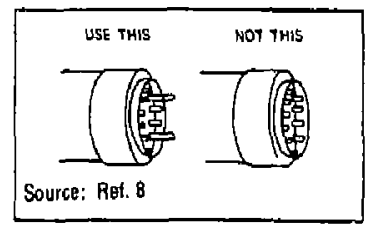

Exhibic 1.9.10 Example al Extended Alignment Guides

(5) Symmetrical arrangements of aligning pins or keys should be avoided so that plugs cannot be inserted $180^{\circ}$ from the correct position.

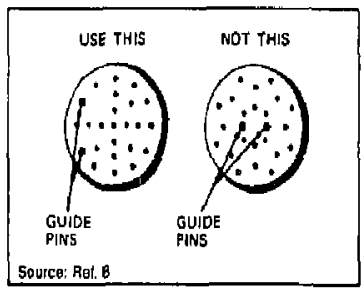

Exhibit 1.9.11 Example of Asymmetrical Aligning Pin Arrangement

(6) Cannectars should be located far enough apart so they can be gripped firmly for connecting and disconnecing. The actual space required will vary with the size of the plug, with 2-5 inches between plugs being minimum separation.

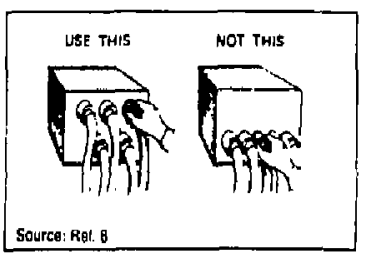

Exhibit 1.8.12 Proper Axtensament of Electrical Connectors
(7) When a part can be removed for maintenance, cables connecting the removable part with the rest of the machine or system should have plugs and receptacles that will disconnect before the cables will bręak, particularly if non-electronics personnel do the removing. A jerk. Jpen plug will separate belore any damage is dont; a screw plug will not.

(8) Plugs and receptacles should be used for connecting cabies to equipment instead of pig-tailing them, Pigtailed connections are more difficult to replace.

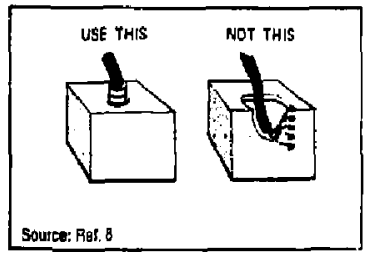

Exhibit 1.9.13 Plug ws Pig-Triling Connections

(9) Plugs should be used with integral test points for each ingut and output that cannot be easily checked. Otherwise, an integra! sliding cover for the test points in the plug should be provided if dust or moisture is a problem. As an altemative, a test point adapter may be providec for insertion between plugs and reseptacles.

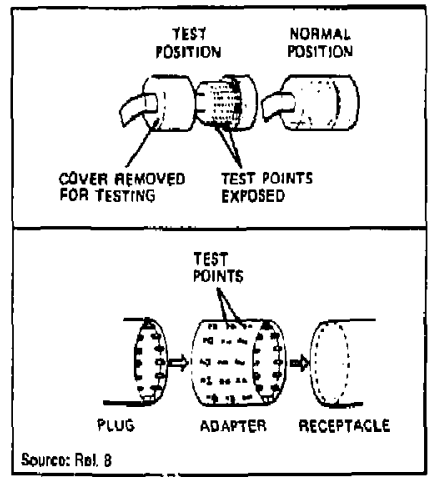

Exhibit 1.9.14 Examples of Plua With Integral Tent Point or Test Point Adapter

(10) Fewer plugs with many pins should be used rather than meny plugs with few pins. It wakes about the ame amount of time to connect a plug with many pins as it does one with few pins.

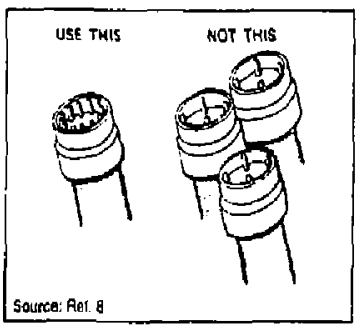

Exhibil 1.9.15 Example of Preper Use of Plugs With Masy Pins 
(11) Connectors should be used in which electrical contacts cannot be shorted by extemal objects.

(12) Recoptacles should be "hat" and plugs "cold."

(13) Plugs should have a self-locking safety cotch rather then require safety wiring. If salety wiring is required, holes and sloss should be designed for most efficient and rapid attachment of safety wire.

(14) Plugs and leads should be ensured not to transmit stored charges when being disconnected.

(15) Lead pins and plugs should be designed strong enough to withstand rough use.

(16) Individual power disconnects shoulc be used ti permit power to be wrned off in one part of the system without disconnecting the entire system.

(17) Power receptacles should be cieariy labeled for primary, secondary, of utility systems to prevent injury to personnel or damage to equipment.

\subsubsection{FLUID AND GAS CONNECTORS}

a. Fluid and gas connectors should be located and installed so that:

(1) Backing-off of the line or removal of other components is not required to effect disconnection or remova' 'f related items.

(2) Draining, filling, or other maintenance involving the connectors can be accomplished without jecking up the equipment.

(3) Leakage tests tan be performed easily and without endangering the zechnician. Tess should be planned so the technician does not have to insert his head into areas of extreme noise, vibration, or other danger while the equipment is running.

b. Gaskets and seals used in connections of fluid and gas lines should be selected and installed to:

(i) Be replaceable or have renewable wearing surfaces, rather than require throw.away of the connector when the sal is damaged or worn.
(2) Be easily replaceable without comoval of other con. nector parts or disassembly of other equipment.

(3) Be identifiable with part numbers so they can be easily ordered and handled logistically; the job instructions should specify the life of seals and gaskets and recommend when they should be changed.

(4) Contain or provide teatures, where required, which:

- Permit lubricant escape under conditions of hight pressures.

- Prevent leakage of lluid when disconnect is made.

- Prevent air from entering disconnected lines where such gir would create maintenance problems, as in hydraulie lines.

- Allow tightening to offset shrinkage, particularly of rubber seals and gaskets.

c. Gaskets and seals should be used which:

(1) Are visible externally after they are installed, to reduce the common failure to replace seals during assembly or repair.

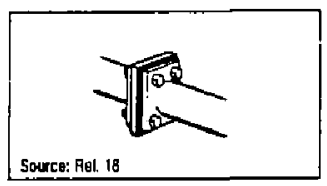

Exhibit 1,0.16 Example of Entermally Visible Gasket

(2) Do nor protrude or extrude beyond the coupling. Protruding seals are chipped and shredded by vibration or contact and the damage spreads internally to destroy sealing power and deposit pieces in the line. Tapered nylor or teflon washers of appropriate size can be emploved to prevent extrusion, 


\subsection{ENGINEERED HARDWARE}

1.10 Cover, Case, and Shiold Design for Maintainability 


\subsubsection{INDEX}

1.10 .2 DEFINITION $\ldots \ldots \ldots \ldots \ldots \ldots \ldots \ldots \ldots \ldots \ldots \ldots \ldots \ldots \ldots \ldots \ldots, 1.10-2$

1.10 .3 GENERALPRINCIPLES $\ldots \ldots \ldots \ldots \ldots \ldots \ldots \ldots \ldots \ldots \ldots \ldots \ldots, 1.10-3$

1.10.3.1 General Design Requirements......................... 1.10-3

1.10.3.2 Size Requirements. . . . . . . . . .

1.10.3.3 Shape Requirements.................................. 1.10-3

1.10.3.4 Mounting Requirements $\ldots \ldots \ldots \ldots \ldots \ldots \ldots \ldots \ldots \ldots \ldots \ldots, 1.10-3$

1.10.3.5 Fastener Requirements ., . . . . . . . . . .

1.10.3.6 Labeling Requirements................................. 1.10-3

1.10.3.7 Types of Covers, Cases, and Shields. . . . . . . . . . . . . . . . . . . . . $\quad 1.10-4$

1.10 .4 SPECIFIC PRINCIPLES $\ldots \ldots \ldots \ldots \ldots \ldots \ldots \ldots \ldots \ldots \ldots \ldots \ldots, 1.10-5$

1.10.4.1 Hinged Doors, Hoods, and Caps ........................... 1.10-5

1.10 .4 .2 Sliding Doors and Caps ................................ 1.10-5

$1,10,4,3$ Removable Doors, Plates, and Caps........................ 1.10-5

1.10.4.4 Removable Panels or Sections ............................ 1.10-5

1.10 .4 .5 Cases $\ldots \ldots \ldots \ldots \ldots \ldots \ldots \ldots \ldots \ldots \ldots \ldots \ldots \ldots \ldots \ldots \ldots \ldots \ldots \ldots, 1.10-5$

1.10 .4 .6 Shields......................................... $1.10-5$ 


\subsubsection{DEFINITION}

Covers, cases, and shields refer to all protective and packaging devices which guard equipment from damage during shipping or during operation and maintenance on the job site. When necessary to use, covers, crses, and shields should:

a. Maintain the degree of enclosure required by structural, operational, or environmental protection or contol.

b. Divide enclosures into sections which differ because of temperature or ventilation control, types of cleaning methods to be used, etc.

c. Protect personnel from coming into contact with dangerous electrical or mechanical parts.

d. Protect moving parts, fuels, lubricants, etc. from dust, dirt, moisture, etc.

e. Protect delicate or sensitive equipment from damage by movements of personnel, shifring of cargo of loose objects, or actions involved in the installation and maintenance of nearby assemblies. 


\subsubsection{GENERAL PRINCIPLES}

1.10.3.1 GENERAL DESIGN REOUIREMENTS. Covers, cases, and shields should bi designed and evaluated based on:

a. The degree to which they contribute to or detract from the soeed and ease with which required maintenance is pertormed. (fiefer to Guidelines for Equipment Accessibility, 1.4.)

b. The manner in which they are fastened. ffefer to Guidelines for Fastener Design, 1.11.)

c. Their size, weight, and ease of handling. fhefer to Guidelines for Engineering Anthropometry, 3.11

d. Provisions for handles or tool grips. (Refer to Guidelines for Handle Uesign, 1.13, and Tool Design, 2.3.)

$\therefore$ W, sk space and clearance around them. RRefer to Guidelines for Workspace Design, 2.1.)

f. The frequency with which they must be opened or removed fin terms of the refiability and maintenance requirements of the enclosed components).

1.10.32 SIZE REOUIREMENTS. Covers, cases, and shields should:

a. Be lightweight, if possible, but allow the degree of accessibility required.

b. Be openable, removable, and transportable by one hand, one individual, or, at most, two individuals, in that order of preference.

c. Be provided with lifting eves and plenned for crane handling if more then 100 lbs.

d. Be provided with hendles or tool grips if heavy or difficult to open or move.

e. Allow sufficipnt clearance around enclosed components to minimize damage to these components and to aroid requirements for extremely fine of nareful positioning and handling.

f. Be designed and located so that bulkneads, brackets, or other units will not interfere with operation of the cover or cose and so the cover or case, when opened. will not interfere with other maintenance operations.

9. Be designed for ease of use, in terms of equipment accessibility for maintenance (Quick release and connection covers, cases and sheilds, shoulo be used with equipment that is frequentiv tested or adjusted.)

1.10.3.3 SHAPE REQUIREMENTS, Covers, cases, and shields should:

a. Be whatever shape is necessary to accomplish the degree of enclosure, allow the degree of accessibility, and provide the clearances required.

b. Make obvious, if possible, the manner in which the item must be positioned or mounted.

c. Make obvious, if possible, the orientation of encloseo delicate components, to minimize damage to these during removal.

d. Be tree from shap edges or protrusions which could injure pursonnel or damage lines and wires.

e. Be free of indentations or settling areas on top surfaces, to reduce rust, corrosion, and the accumulation of ditt and grease.
1,10.3.4 MOUNTING REQUIREMENTS. Covers, cases, and shields should be designed, located, and mounted so they:

a. Do not bear any part of the structural load. It should not be necessary to support, dowaload, or disasemble any equipment to remove the item.

b. Are completely removable and replaceabla in of damage. Irregular extensions and accessories shoutd be readily removable.

c. Can be opened of semoved as necessary when the equipment system is completely asembled and auxiliary equipment has been installed.

d. Do not cause the equipment to become unbalanced when opened. Props, retainers, or other support should be provided where required to prevent this.

e. Do not obscure or interfere with controbs, displays, ters points, or connections related to work within the access or enclosure, when in the open position.

f. Are provided with s.'.quate stops and retainers to prevent them from swinging into or being dropped on ' ras:" ${ }^{\prime \prime}$ eguipment or persannel.

g. Are provided with locking devices or retsiner bars to lock them in the open position if they might otherwise fall or shut and cause camage, injury, or inconvenience. This is particularly necesary for daors, covers, and shields which may be used in strang wind conditions.

1.10.3.5 FASTENER REQUIREMENTS. Fasteners for covers, casss, and shields should be stlected, applied, and mounted so that:

a. They optimally satisly the applicable Guidelines for Fastener Design for Maintainability, 1.11, requirements.

b. Maximum use is made of hinges and latches or catches to minimize the number of tasteners and requirements for han dling and stowing covers and casers.

c. Fasteners for a given item or identical items are inter. changeable, i.e., are the same type, size, diameter, and pitch of thread,

d. Fasteners align themselves with their retaining catches, nuts, blocks, or inserts without sticking and without damage to their threads or latches.

e. The cover or case will not open or loosen automatically under whatever stress, vibration, or other conditions are expectable.

f. It is obvious when a cover or case is not in place or securely fastened. Where possible, fasteners should be spring-loaded so they stand out or the cover itself stays ajar when not secure.

1.10.3.6 LABELING REQUIREMENTS. Labels and mark. ings on covers and cases should be provided which:

a. Provide opening, removal, of positioning instructions, if methods for accomplishing these are not obvious from the design,

b. Provide stock references so that covers, cases, and shiali can be replaced when damaged.

c. Adequately reveal the functions of units behind the anclosure and/or the functions which are to be per. formed through the access, such as "Battery," "Fual Purnp," "Oil Here," etc. 
d. Adequately warn against dangers or hazards involved in removing the cover or case or working within the enclosure.

e. Provide the proper orientation or connection of units, service equipments, etc. to go through the opening, if this is not clear or visible.

f. Oo not provide instructions, such as preventive maintenance instructions, which are subject to revision or change.

9. Oo not provide instructions which will be required but will not be vistble when the cover, door, or case is open. Such instructions should be placed in a visible location on the structure behind of to the side of the access.

1.103.7 TYPES OF COVERS, CASES, AND SHIELDS

a. HINGED DOORS, HOODS, AND CAPS. The use of hinges allows the lastest and easiest access, reduces the number of fasteners required, supports the cover so the technician does not have to handle it, and makes it un. necessary to disconnect wires or components mounted on the cover belore entering the accass. This type of cover, however, requires "swinging space," and may interfere with other operations or components.

b. SLIDING DOORS OR CAPS. Large sliding donrs may create structural design problems but are particulerly useful where "swinging space" is limited. Small, sliding caps are particularly useful for small accesses that do not require a close seal.

c. REMOVABLE DOORS, PLATES, OR CAPS. These require little space for opening and, once removed, do not interfere with work space; however, their handling requires time and effort (searching, bending, reaching. etc.).

d. REMOVABLE PANELS OH SECTIONS. These are useful to allow access to whole sides of a cabinet or equipment. They discourage non-maintenance personnel from opening the access, Ther do not require "swinging space." However, they may be damaged easily and may be awkward to handle. They may also interfere with maintenance activities. 


\subsubsection{SPECIFIC PRINCIPLES}

\subsubsection{HINGED DOORS, HOODS, AND CAPS}

a. Double-hinged or split doors should be used if opening space is a problem.

b. Hinges should be piaced on the bottom; biased; or a prop, catch, or latch should be provided if the door is to stay open without being held.

c. Adjacent hinged doors should open in opposite directions to maximize accessibility. and cabinets should be arranged so that functionally related cabinets are adjacent and open in opposite directions.

d. Hinged caps over service or test points should be de. signed not to interfere with the insertion or attachment of service or test equipment.

e. Stops, retainers, etc. should be provided when needed to prevent the door from swinging into adjacent displays, controls, or fregile companents, and to prevent springing the hinges.

\subsubsection{SLIDING DOORS AND CAPS}

a. Sliding doors and caps should lock positively.

b. They should be designed to avoid jamming or sticking.

c. They should be easy to use and should not require tools for operation lunless limited or restricted access is intended).

d. Their movement should not interfere with, damage, or have the potential for harmful contact with wires or other equipment items.

\subsubsection{REMOVABLE DOORS, PLATES, AND CAPS}

a. Maximum use stould be made of tongue and siot or similar catchis for small plates, coors, and caps to minimize the number of fasteners needed.

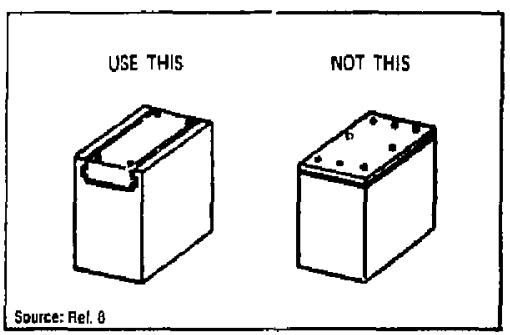

Exhibut 1.10.1 Example of Tongue and Slot Cover

b. Small plates and caps that are likely to be misplaced or damaged should be secured with retainer chains.

c. If a removable plate must be attached in a certain way, it should be designed so that incorrect attachment is impossible, e.g, an asymmetric plate shape should be used, mounting holes shouid be located asymmetrically, or aligning labels should be lised.

\subsubsection{REMOVABLE PANELS OR SECTIONS}

a. Panels intended for removal should be held with a minimum number of combination-head captive fasteners; spring-loaded, quarter.turn fasteners are recommended,

D. These fasteners should show positicn when thay are released, i.e., release should be clear before panel is moved. c. Panels and sections should be removable, carriable, and installabie by ane technician using common hand tools.

d. Panels and sections should be provided with handles to facilitare removal, handling, and replacement.

e. It should not be necessary to disconnect wires, components, etc. from panels before they can be removed, If such items are attached to the panel, they should be hinged to make removal unnecessary.

1.10.4.5 CASES. Cases should be designed, selecte-1, and mounted so that

a. They are lifted off units, rather than units lifted out of cases, particularly when heavy units are involved.

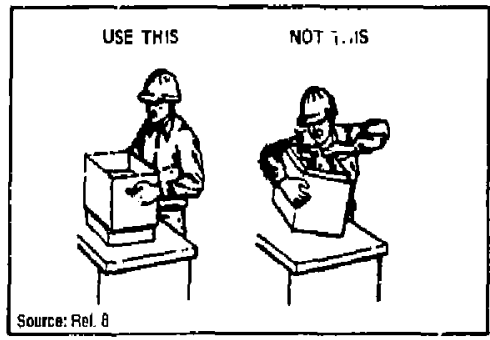

Exhibit 1,10.2 Example of Litt.OH Case

b. They are sufficiently larger than the units they cover to expedite n!moval and replacement and prevent damage to wires or other components during removal or replace. ment.

c. Guidepins and tracks are provided as necessary to help align the case, prevent it from cocking or binding, and prevent damage to deticate or sensitive components dul ing movement of the case.

d. Access is provided, whare teasible, to frequently used adjustment, test, or sevice points, so that the case need not be removed in routine maintenance.

e. All maintenance-significant aspects and portions of the unit are fully exposed when the case is removed

f. Adequate mounting or locking devices are provided and the unit is secure while the case is being moved, particularly if the unit is to be detached from the b.ottom of the case.

9. Rubber stripping or other sealing material is selected and mounted so it will not be damaged or jam when the vase is moved.

1.10.4.6 SHIELOS. Shieids should:

a. Employ light-weight material.

b. Allow rupid and easy installation, removal, transportation, and storage.

c. Provide handles and tool grips as necessary to facilitate handling.

d. Minimize the possipility of damage to the equipment during installation, removal, or other operations related to the shield.

e. Avoir or minimize permanent fixtures on the equjpment as a consequence of the shield, e.g., mounts, safety features.

4. Permit performance of maintenance functions without removal of the chield; for instance, radial engine shields should permis cranking while the shield is in position.

g. Be mounted in a manner that does not interfere with the operating characteristics of the equipment. 
1.0 ENGINEERED HARDWARE

1.11 Fastener Design and Application for Maintainability 
ENGINEERED HARDWARE 1.0 FASTENER DESIGN AND APPLICATION FOR MAINTAINABI!.ITY 1.11

1.11.1 INDEX

Page

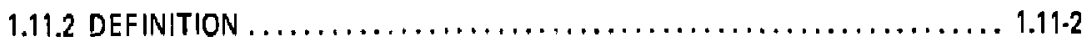

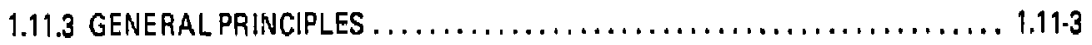

1.11 .4 SPECIFIC PRINCIPLES . . . . . . . . . . . . . . . . . . . . . . . $1.11-5$

1.11.4.1 Quick Release Fasteners (Cowl or Panel Fasteners) .............. 1.11-5

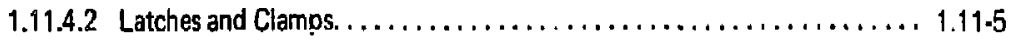

1.11 .4 .3 Captive Fasteners $\ldots \ldots \ldots \ldots \ldots \ldots \ldots \ldots \ldots \ldots \ldots \ldots \ldots \ldots, 1.11-5$

1.11.4.4 Combination Head-Bolts and Screws. . . . . . . . . . . . . . . . . . $1.11-6$

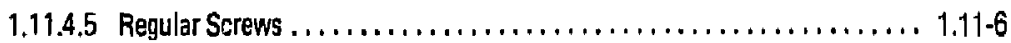

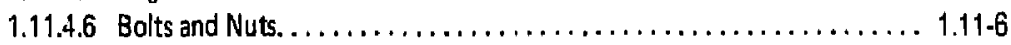

1.11.4.7 Internal Wrenching Screws and Bolts. ..................... 11-7

1.11 .4 .8 Rivets $\ldots \ldots \ldots \ldots \ldots \ldots \ldots \ldots \ldots \ldots \ldots \ldots \ldots \ldots \ldots \ldots \ldots \ldots \ldots \ldots \ldots .1 .11 .7$

1.11.4.9 Fastener Accessories $\ldots \ldots \ldots \ldots \ldots \ldots \ldots \ldots \ldots \ldots \ldots \ldots \ldots \ldots \ldots \ldots$ 
ENGINEEREO HARDWARE 1.0

FASTENER DESIGN AND APPLICATION FOR MAINTA:S: BBILITY 1.11

\subsubsection{DEFINITION}

Fastener refers to a device used to join two or more parts, components, or units together. Fasteners include:
a. Quick disconnects.
b. Latches and catches.
c. Captive fasteners.
d. Combination head-bolts and screws.
e. Regular screws.
f. Internal wrenching screws and bolts.
g. Rivets.

Each device has certain advantages for particular applications. 


\subsubsection{GENEAAL PAINCIPLES}

1.11.3.1 Fasteners should be selected and evaluated based on:

a. Durability.

b. Ease of operation.

c. Speed,

d. Ease of replacement.

1,11,3,2 Design, selection, and application of fasteners should consider the following:

a. Stress and environmental factors the fasteners must withstand.

b. Work spoce, tool clear ance, and wrenching space around the fastener.

c. Types of tools required for operation of the fastener, as a fu! ion of fastener type, application, and location,

d. Types and varieties of fasteners boing used elsewhere in the sytcm, or commonly used by the using utility.

e The trequency with which the festeners will be operates.

f. The time requirements of tasks involving operation of the fasteners.

1.11 .3 .3 The number of types and sizes of fasteners ured within a system should be minimized.

d. The same type and size of fastener should be used for the same spplicstion le.g., all mounting bolts for a given type of iteml.

b. Screws, bolts, and units oi different thread sizes should be clearly different in physical size or shape of the head to preclude being interchanged.

c. Requirements for special or close tolerance fasteners should be avoided.

d. The number of different torque requirements used within a system should be minimized,

11) Only a few basic values should be used.

(2) These values should be keyed to claarly differing types, sizes, or coded fasteners.

13) Where precise rorquing is required, clearance should be provided for wrenches or sockets with variable torque settings.

e. ihe rumber of tool types and sizes that are needed for far:ener operation shouid be minimized.

f. The ease of use, in terms of equipment accessibility for maintenance. JQuick release and connection fasteners should be used with equipment that is trequently tested or adjusted.

1.11.3.4 Fateners should be fabricated of specific materials.

a. Fasteners should be made of corrosion-resistent materials (e.g., stainless, galyanized, cadmium-coated, non-ferrous).

b. Fasteners should not use aluminum alloy threaded into aluminum alloy parts.

c. Fagteners should not be the cause of galvanic action le.g. a titanium fastener used with matgnesium would cause galvanic corrosioril).

d. Fasteners should be metallic where high tensile or shear strength is required
1.11.3.5 Ease of replacing stripped, worn, or damaged fasteners should be a design consideration. Fasteners which are pert of a unit's housing should be avoided.

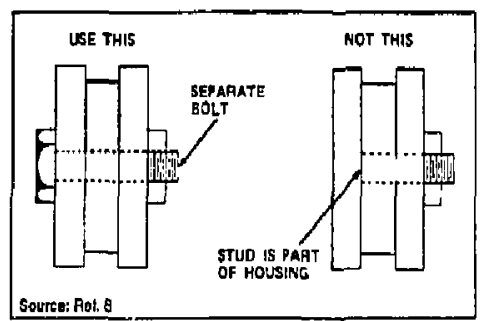

Exhible 1.11.1 Exumple al Proper ind Improper Denlpn of Bolt Fetener

1.11.3.6 The number of fasteners and tastener parts should be minimized.

1.11.3.7 The use of hinges, catches, latches, and quick disconnect festeners should be maximized to reduce the number of fasteners required.

1.113.8 A few large fasteners should be used rather than many smaller ones (except where many ore needed to main. tain a fluid or air-tight seal)

1.11.3.9 No more than four fasteners should be used to mount a unit. (A common fault is to use 'oo many fasteners when a more rigid construction is prefeited.)

\subsubsection{Fasteners should be mounied so that:}

a. Fastener mounting holes or other solerances are large enough to allow "starting" of fasteners without perfect olignment.

b. Hinges, catches, latches, lacks, and other quick disconnect devices are attached by means of smal boits or screws, not rivets.

c. Bolts are mounted with the head up so they will stay in position if the nut falls off.

d. Nuts and bolts (perticularly those which are frequently operated or poorly accessible) ane mounted so they can be operated with one hand or one tool by:

(1) Providing receses to hold either the nut or bolt

(2) Semi-permanently artaching either the nut or bolt.

(3) Using double nuts on terminal bourds and similar applications.

(4) Using nut plates, gang-chärnelisig, or floating nuts.

1.11.3.11 Fasteners should be located so they:

a. Can be operated without priot removal of other parts or units.

b. Can be operated with minimum interterence from other structures.

c. Do not interfere with each other or other components,

d. Do not corstitute a hazard to personnel, wires, or hoses,

e. Are surrounde.' by adequate hand or tool clearance for easy operation.

\subsection{1,3,12 Fasteners should be coded so that:}

a. All external tasteners which are manipulatad during normal maintenanes provide strong color contrast with the color of the surlace on which they appear.

b. All other external farteners and asembly screws are of the same color as the surface on which they appear. 
c. The heads of "specigl" bolts and screws are color- or stampcaded to ensure that they are properly handed and are replaced by identical fastenars.

d. Only markings which designate the size, type, or 10rque value of the fastener are used, Manufacturers' names or trademarks should be omitted. e. Fastener markings are eiched or inbossed to withstand exposure to chemicals, fuels, weather, or other cperationel conditions.

f. One fastener marking code is used throughout the system, This code should be determined and standardized ahead of time, and it should contorm to prevailing standard practices. 


\section{1,11.4 SPECIFIC PRINCIPLES}

1.11.4.1 QUICK RELEASE FASTENEAS (C.OWL OR PANEL FASTENERS). These gre fast and aasy to use, require no tools, may be opersted with one hand, and ire very good for securing plug-in components, small com. ponents, and covers. However, their holding power is low and they cannot be used where a smooth surface is required. These fasteners:

a. Shauld be corefully evaluated on the basis of type and eqplication.

b. Should be used wherever possible for components that must be frequently dismantled or removed.

c. Should fasten and release easily, without the use of tools.

d. Should fasten or unfasten in a maximum of one com. ptete turn.

e. Should be obvious when they are not correctly engaged.

f. Should be located, shaped, sized, or coded so that only the correct male section mav be anxhed.

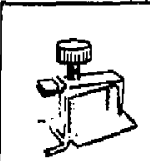

Bist Latew rabsert suber tatem

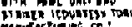
merustive of of

SLIOE ACTIOH

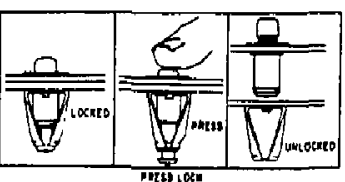

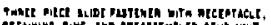

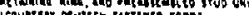

PUSHEUTTON OPERATION

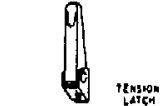

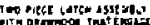

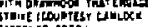

GEVER ACTUATEO

Source: Rat. 8

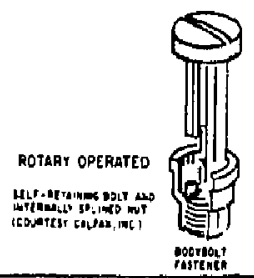

Exhibit 1.11.2 Examples of Quick-Rdesse Type Fusteners

1,11,4,2 LATCHES AND CLAMPS. These are very fast and easy to use, require no tools, have good holding power, and ure especially good for large units, panels, covers, and cases. They cannot be used where a smooth surface is required.

a. Long latch catches should be provided so that accidental springing is minimized.

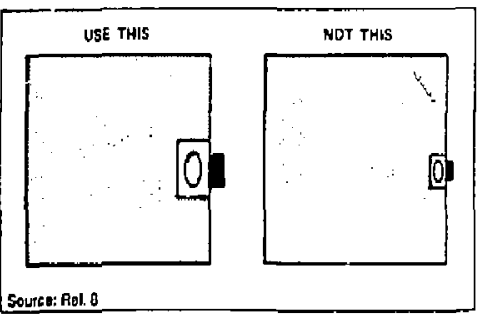

Exhibit 1.11.3 Example of Ellectivg Lotch Satch Fastenet

b. Latches and catches shou'iu be located and prositioned so they vill not open actiden tally undef usual operating conditions.

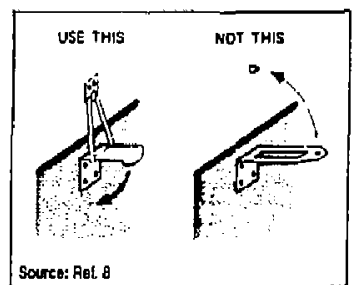

Exhibit t.11.4 Example of Effective Positioning of Lnches

c. Cotches should be spring-loaded so they do not require positive locking, but lock on contect.

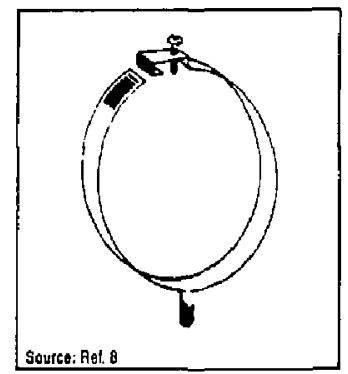

Exhlbit 1.11.5 Example of Ouick-Pelene Clemp

d. A latch loop and locking action should be ustd it positive locking is necessary to meet structural or stress requirements.

e. If a handle is used in conjunction with the latch, the latch release should be located on or near the handle so that only one hand is needed for operation.

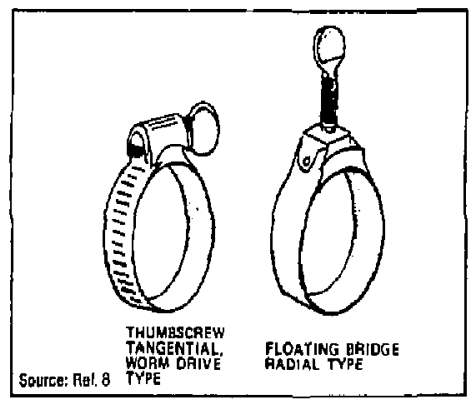

Exhibin 9.11.6 Example of Clamp Fequirng One Hand Operation

$1,11,4,3$ CAPTIVE FASTENERS. These are slower and more difficult to use (depending upon type), and require use of common (usally) handiools; but they star in place, save the time spent handling and looking for bolts and screws, and require only one.handed operation.

a. Captive fastenters should be used wherever fost jerews, bolts, of nuts might cause a malfunction or excessive mointenance time.

o. Only fasteners which may be operated by hand or common hand topls should be used.

c. Only fastener's which may be easily replaced in case of damage should be used.

d. Self-locking, springloaded action thould be provitied on captive fasteners of the quarter-turn tvpe. 


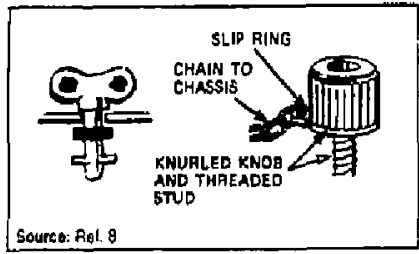

Exhibil 1.11.7 Exomple of Coptive Fatenert

1.11.4.4 COMEINATION HEAD-BOLTS AND SCAEWS. These should bo used in preference: to other screws of bolts simply because they may be operated more rapidly with either a wrench or a screwdriver. This allows use of the more convenient toot and reduces the possibility of slot damage and stuck fasteners. In general, slotted, hexagonal heads are preferable to knurled and silotted heads.

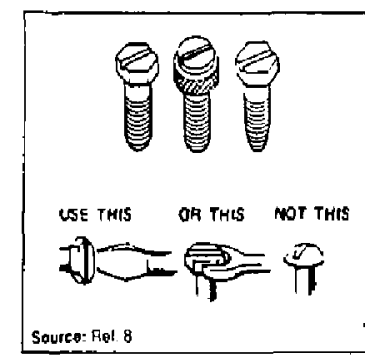

Exhitar 1.11.8 Exanales of Combination Head Bols and Screws and Slotred Hexagon Screws

1.11.4.5 REGULAR SCREWS. Round, squate, or flatheaded serews require more time and are mon! subject to loss, stot damage, stripping. and misapplication than the above; but they require less wrenching space, only one. handed action to operate, and do not involve a number of extra parss. Square-headed screws are generally preferable to round or flat since they provide better tool contact, are less subject to slot demage, and may be removed with pliers.

a. Ti number of surns required to tighten or loosen a screw should be less than 10 .

b. When tightened, the screw must fully engage to a distance at least equal to its diameter.

c. Deep slats should be provided on screw heads to minimize slot dama!ye and tool slippage.

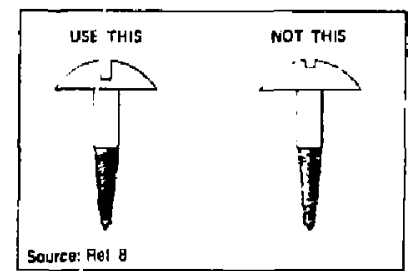

Exhibit 1.11.9 Exumple of Deep-SJatred Serew Heads

d. Screws should be used only when screwdivers may be used in a straigint in fashion,

e. Use of offset screwdrivers should not be required. f. If a screw must be operated blindly, a tool guide should be provided in the assembly.

g. Fine thraad screws are recommended for pressurized units,

b. Countersunk screws should be used only where necessary to provide a smooth surface.

j. Round-head rather than flathead screws shoukd be used on panals less than $3 / 32$ inch thick, to prevent screws from ripping through the panel.

j. Self-tapping screws should have one type of head and be of one size, where feasible, or a minimum number of sizes.

1.11.4.6 BOLTS AND NUTS. Boits are usually slow and ditficult to usa. They require two-handed operation, access to both ends of tha bolt, and often use of wo tools. They also require precise movements in starting nuts and have many loose parts to handle and lose (nuts, washers, etc.l.

a. BOLTS.

(1) Bolt length should not be more than required for a given purpose.

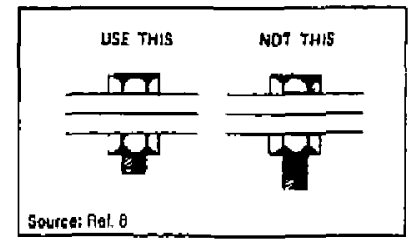

Exhibit 1.11.10 Exumple of Apdropratt Bolt Length

(2) Bolt threads should be no finer than strength requirements dictate.

(3) The number of turns to tighten a boir should be less than 10.

(4) When tightened, the bolt shauld extend a minimum of two threads beyond the nut

(5) Hexagonal-head bolis should be used generally. and especially for high torque usages.

(6) Left-hand threads should be used only when stress conditions require; and both bolts and nuts should be clearly identifiable by marking. shape, or color.

(7) Self-locking bolts (in tapped holest should be used only when ot te surlace must be smooth or is inaccessible and temperatures will be below $250^{\circ} \mathrm{F}$.

b. NUTS

11) Regulas hexagonal nuts are preferred, in a few easily distinguishable sizes.

(2) Different sizes of nuts should be used for different thread requiremerits.

(3) Wing or knurled nuts, which require no tools, should be used for low tension applications. Wing nuts are the easjer to use.

(4) Sell-sealing nuts should be used for fastening equipment to fluid tanks to prevent leaking around fastener. 


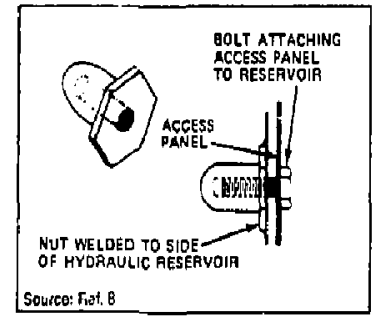

Exhibit 1.11.11 Example of Selt:Seating Nut

(5) Lock nuts may be used for mounting light components; but they must withssand heat requirements, and cannot be used where fallen nuts could damage equipment.

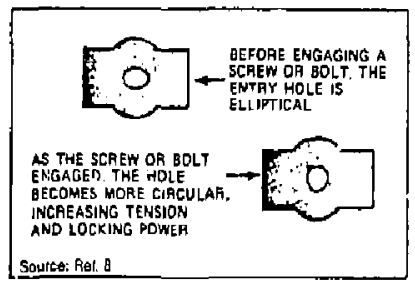

Exhibit 1.11.12 Example of Lock Nut

(i) Clinch nuts should be incapable of rotating or mcving with respect to the surface on which they are mounted.

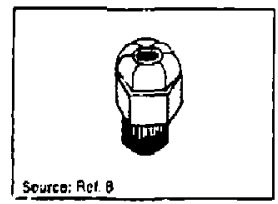

Exhibit 1.11.13 Exmpte of a Clinch Nut

(7) Floating nuts should have an allowable shift of only plus or minus $1 / 16$ inch.

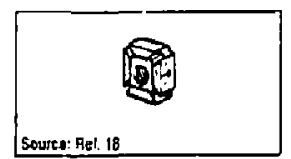

Exhibit 1.11.14 Exemple of Flozting Nur

1.11.4.7 INTEANAL WAENCHING SCREWS AND BOLTS. These allow higher torque, better tool grip, and less wrenching space. However, they are easily damaged, difficult to remove when damaged, and require special tools.

a. The number of different sizes should be minimized tc require only one, ar as few as possible, tools.

b. Slots should be deep, to eliminate damage to the fasteners. c. Design should allow and plen for the removai of damaged internal wrenching fasteners in terms of clearances. power outlets, etc.

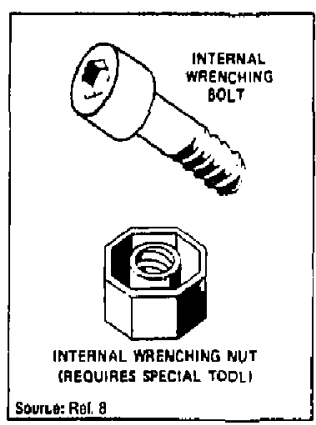

Exhibit 1.11.15 Example of inţeiral Wrenching Bolt and thut

1.11.4.8 RIVETS. Permanent fasteners are hard and slow to rernove and replace; they should not be used on any part which may require removal. Wire stapling or metal stitching is generaily preterable to rivels for maintenance purposes.

a, Rivets should not be used on latches, hinges, or retainers.

b. Rivets should be of softer material than the pieces they iasten.

c. The heads of countersunk rivers should be larger than the thinnest of the pieces they fasten, to prevent them from ripping through.

d. Shear rivets to not expand to fill the hole, so toles must be drilled to close tolerances. Maintenance instructions should specify these tolerences and the sizes of plug yaugcs and reame is to is: used.

e. For minor maintenance of light components, rivets which expand by chemical charge rather than by peening should be used. These rivets expand when heat is applied to a chen izal charge contained within the rivet. Pirrets are especially useful in blind applications.

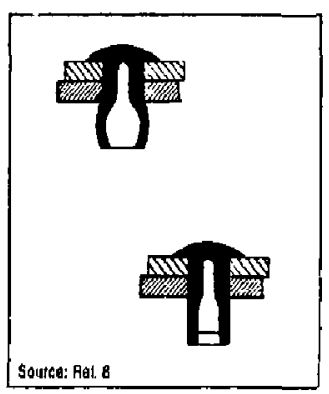

Erribit 1.11.16 Example of Chamical Oyrge River

\subsubsection{FASTENER ACCESSORIES}

a. WASHERS.

(1) Washers should fit tightly against the underside of the fastener head.

(2) Washers should fit the shaft snugly, but should be easy to remove.

(3) Splis.ring lock washers should be used vith static loods as :xess of $20 z$. 
(4) Lock washers should be used with lock nuts, for maximum locking action.

b. METALLIC INSERTS AND BLOCKS. These should be secured so that tightening of the screw or bolt will not Isosen or move the insert or block.

(1) Gang channeling of nuts can save time in hardling many nuts when they are in a straight line. Only channels should be used in which nuts can be replaced individually.

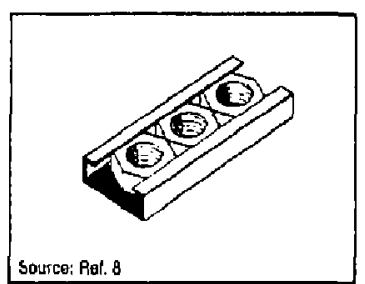

Exhibit 1.11.17 Example of GandChanneled Nuts

(2) Nut-plates are heavy and expensive to replace when a hole is stripped, but :ticy may be used when several bolts are to be fastened on one surfacs and alignment is not problem.

\section{c. COTTER PINS AND KEYS.}

(1) Keys and pins should fit snugly, but should not require driving in or out.

(2) Heads of cotter keys should be large, to facilitate remoral and prevent the keys from slipping through.

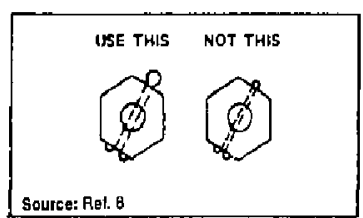

Exhibit 1.11.18 Exwmple of Adequate Size Cotter Key Heod

\section{d. SAFETY WIRE.}

(1) Saiety wire should be used only when self-locking fasteners or cotter pins are not adequate to withstand the expected vibration or stress.

(2) Safety wire should be attached so it can be easily removed and replaced.

(3) Safey wire should be used where visible means of detection is required to determine if a fastenter has become loosened or has changed position.

\section{e. RETAINER RINGS.}

(1) Only rings which may be removed and replaced easily when worn should be used.
(2) Rings which hold with a positive snap action should be used when possible.

(3) Spring tension should be used to prevent loosening or unlocking of twist-to-lock rings.

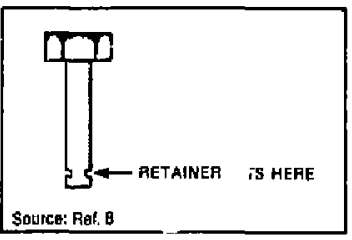

Exhibit 1.11.19 Example of Ratainer Ring

\section{f. Retainer chaINS}

(1) Only link, sash, or woven-mesh type chains should be used. Bead-link chain is not recommended because it breaks more easily than other types.

(2) Chains should be attached with screws of bolts; attachment should be strong and positive, but easily disconnected when required.

(3) Evelets should be provided at both ends of the chain for the attaching fasteners.

(4) Chains to filler caps should be attached extemally rather than internally to facilitate replacement and prevent broken parts from damaging equip ment.

(5) Chains should not be used wierever they might interfere with moving parts.

(6) Chain covers, where required to prevent chains from becoming tangled, should be flexible, durable, and easy to bend.

(7) Retainer chains or locking bars should be used to:

- Keep hatches or doors from opening too far and springing their hinges.

- Turn doors or covers into useful shelves for the technician.

- Prevent \$mall covers, plates, or caps from being misplaced.

- Secure small, special tools to the location in which they will be used.

- Secure objects which might otherwise fall and cause personnel injury.

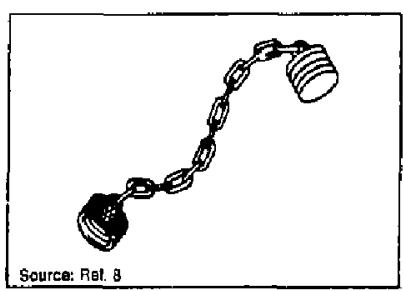

Exhibit 1.11.2. Example of Retainer Chain 
1.0 ENGINEERED HARDWARE

1.12 Drawer and Rack Design for Maintainability 
ENGINEERED HARDWARE 1.0

DRAWER AND RACK DESIGN FOR MAINTAINABILITY 1.12

1.12.1 INDEX

Page

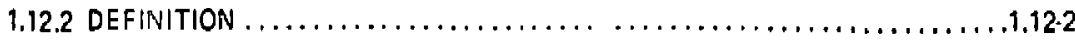

1.12.3 PRINCIPLES $\ldots \ldots \ldots \ldots \ldots \ldots \ldots \ldots \ldots \ldots \ldots \ldots \ldots \ldots \ldots, 1,12.3$ 


\section{DRAWER AND RACK DESIGN FOR MAIN TAINABILITY 1.12}

\subsubsection{DEFINITION}

Drawers and racks refer to pullout, roll-out, slide-out, or hinged equipment assemblies designed to:

a. Optimize work space, tool clearance, and accessibility.

b. Reduce the need for the technician to handle fragile or sensitive items.

c. Facilitate the handling and/or positioning of heavy or awkward iterns.

d. Facilitate the maintenance of items which, must be frequently moved from their installed positions for cnecking, servicing, or repair. 


\subsubsection{PAINCIPLES}

1.12.3.1 Drawers and rarks should require a minimum number of operations to open or release them.

1.12.3.2 A force of less then $\mathbf{4 0} \mathrm{lbs}$, should be required to open and release drawers and racks.

1.12.3.3 A smooth operating bearing assembly should be used, as neepded.

1,12.3.4 Drawers and racks should lock automatically in both serviciıg and operating modes.

1,12.3.5 Handles should be provided on drawers and recks, when necessary, to facilitate operation and handling.

1.1\%.3.6 Assemblies shouid be accessible without breaking internal co'rnections which are necessary for required maintenanct.

1.i2.3.7 To prevent possible damage to fragile or sensitive parts during movement of the assembly, drawers and racks should be provided with guards and shields as necessary.

1,12.3.8 Rests, limit stops, guards, and/or retaining devices should be provided as feart of the basse chassis. They _ 'ould:

a. Prevent the assembly from being dropped.

b. Prevent heavy assemblies from tipping the equipment.

c. Ailow complete and convenient removal of the assembly.

d. Allow the assembly to open to its full distance and remain oper without being heid.

1.12.3.9 If internal cannection is not required for mainte nsnce, connectors to the drawer ar rack may be artached to the assembly so that closing the assembly establishes connection. This requiress:

a. Connector parts to be mounted on the assembly's retar wall.

b. Locks to ensure that the connectors renain engiged.

c. Guides to ensure proper orientation of the assembly prior to pin engagement.

d. Insulation to the connectors, as needed, for safety.

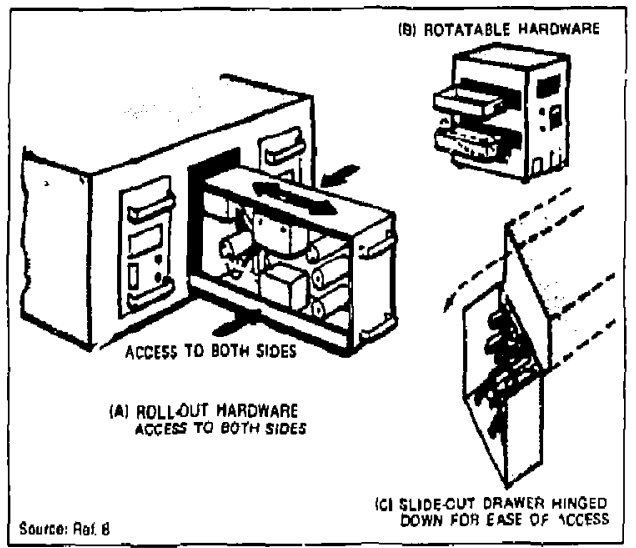

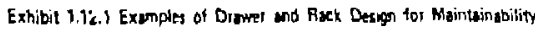




\subsection{ENGINEERED HARDWARE}

1.13 Handle Design for Maintainabiitty 
ENGINEERED HAROWARE 1.0

HANDLE DESIGN FOR MAINTAINABILITY 1.13

\subsubsection{INDEX}

$\underline{\text { Page }}$

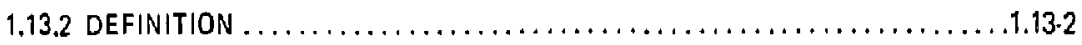

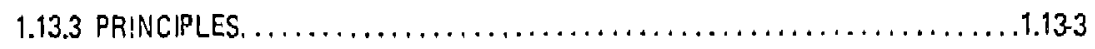

1.13.3.1 Factors Influencing Handle Design $\ldots \ldots \ldots \ldots \ldots \ldots \ldots \ldots \ldots \ldots \ldots .13 .3$

1.13.3.2 Types of Hanciles with their Dimensions. . . . . . . . . . . . . . . . . 13.3

1.13.3.3 Handle Design Recommendations....................... 


\section{ENGINEERED HARDWARE 1.0}

\section{HANDLE DESIGN FOR MAINTAINABILITY 1.13}

\subsubsection{DEFINITION}

Handles refer to means for grasping removable or replaceable units. Handles should be provided on all packages, units, components, and covers whenever these items are handled frequently, difficult to carry, hold fragile components, or weigh over $10 \mathrm{lbs}$. 


\subsubsection{PRINCIPLES}

1.13.3.1 FACTORS INFLUENCING HANDLE DESIGN The size, location, and positioning of handles depends upon:

a. Weight and center of gravity of the item or unit.

b. Number of persons, or hands, required to lift of carry the izerm.

c. Type of clothing and gloves wom.

J. Operational position of the item retative to other items. e. Manner in which the item is to be handled or po. sitioned.

1. Distance over which the item must be cartied.

8. Frequency with which the iterm must be handed or corried.

h. Additional uses the handles could tenve.

1.13.3.2 TYPES OF HANDLES WITH THEIR DIMENSIONS

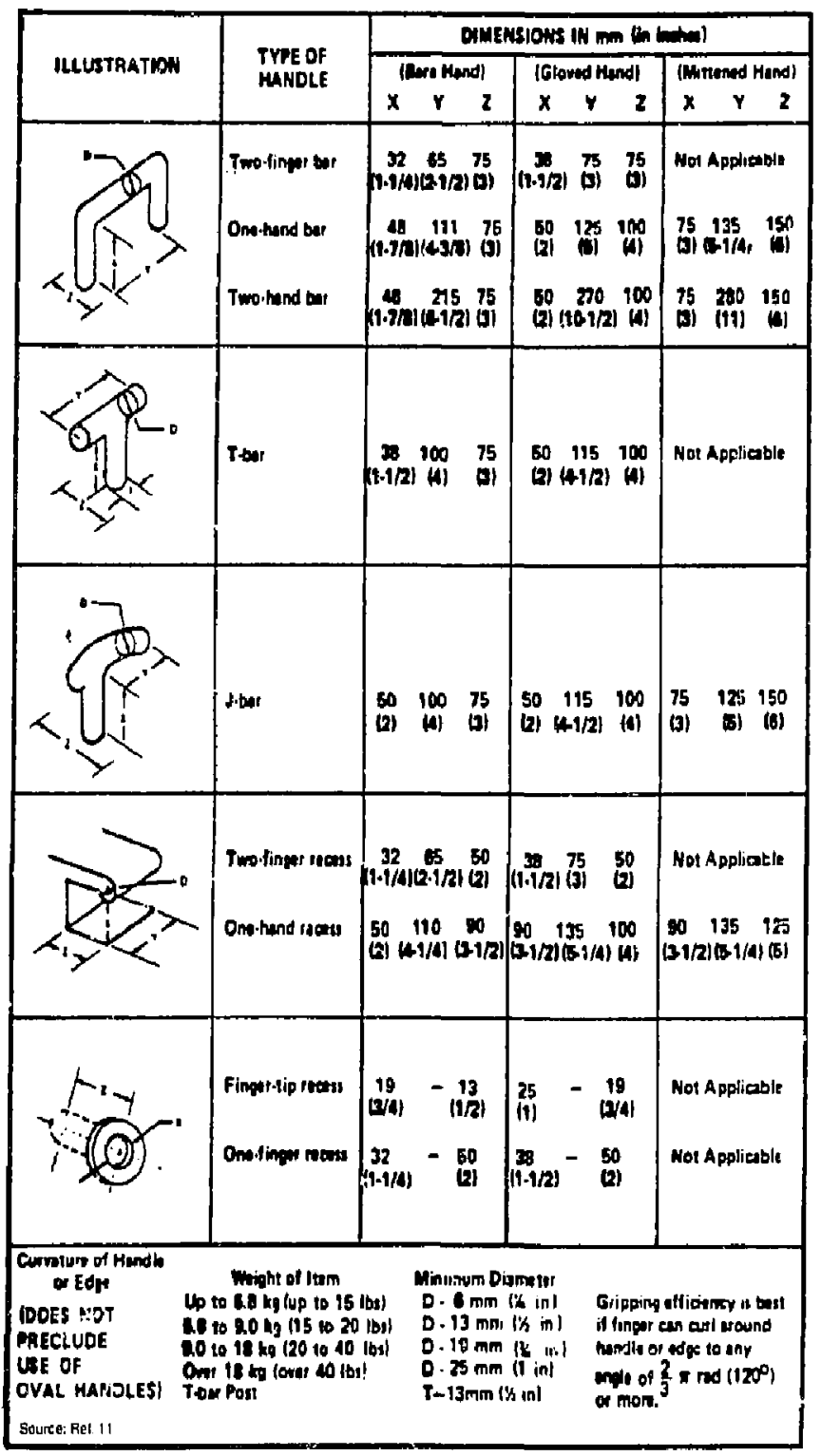

Exhible 1.13.1 Minimum Dimensions for Various Hundle Dejigns 


\subsubsection{HANDLE DESIGN RECOMMENDATIONS}

a. Handles that must be gripped firmly should be at least 4.5 inches wide and 2.0 inches deep.

b. Single handles should be located over the center of gravity of the unit. When two or four handles are required, they should be placed at equal distances from the center of gravity.

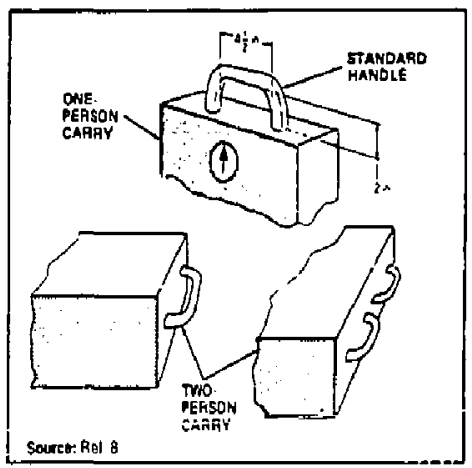

Exhipit 1.13.2 Handle Loention for Easy Curvying

c. Covers should be provided with handles to tacilitate removing them and also for carrying the unit.

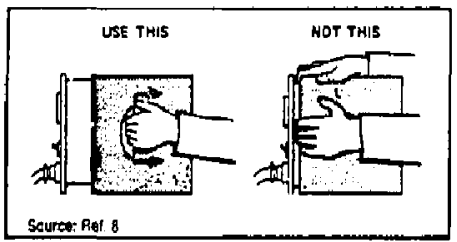

Exhibit t.13.3 Handle Locrtion for Coven end Corrving Linits

d. Handles should meet the following lifting criteria:

\begin{tabular}{|c|c|c|c|}
\hline $\begin{array}{l}\text { Wright } \\
\text { To bs } \\
\text { liles }\end{array}$ & $\begin{array}{l}\text { Mande } \\
\text { Oimentur } \\
\text { (in,) }\end{array}$ & $\begin{array}{l}\text { finpert } \\
\text { clumesces } \\
\text { find }\end{array}$ & $\begin{array}{l}\text { Mandit } \\
\text { Weath } \\
\text { tin. }\end{array}$ \\
\hline $\begin{array}{l}\text { Undet } 25 \text { te } \\
\text { Oner } 25 \text { is } \\
\text { Lind by } \\
\text { Glond Hind } \\
\text { Sourca: Raf. B }\end{array}$ & $\begin{array}{l}0.25 \cdot 0.5 \\
0.5 \cdot 0.75\end{array}$ & $\begin{array}{c}2 \\
2 \\
2.5\end{array}$ & $\begin{array}{c}4.5 \\
4.5 \\
6\end{array}$ \\
\hline
\end{tabular}

Exhibit 1.13 A Lifting Grittria ior Handles

e. Units weighing more than about 25 to $40 \mathrm{lbs}$, idepending on the size and bulkiness of unit) should be provided with handles for two-pssson catrying. for units weighing more than 100 to 150 lbs, (depending on size and bulkiness of unit), suitably labeled hoist eyes should be provided.

f. Handles should be comfortable and easy to gasp. When units must be frequently carried for long periods of time, a molded harndle should be uned to petevent size pressure on the fingers.

9. Recassed grips should be provided near the back of heavy units to tacilitate handling. Receased, concealed, or folding hondles may be used to consone space, but they must be actessible without tools and folding handies must remain securely folved when not in use.

h. Handles should be equipped with quick-releas pins to make them easier to insert and remove,

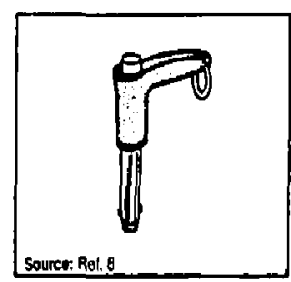

Exhibit 1,13.5 Hendit Equinpwed With Ouick-Reluese Pins

i. Mandles may be used for the withdrawal and handling of printed circuit boards.

j. Handles may be used to fulfill a variety of supplemental functions. 


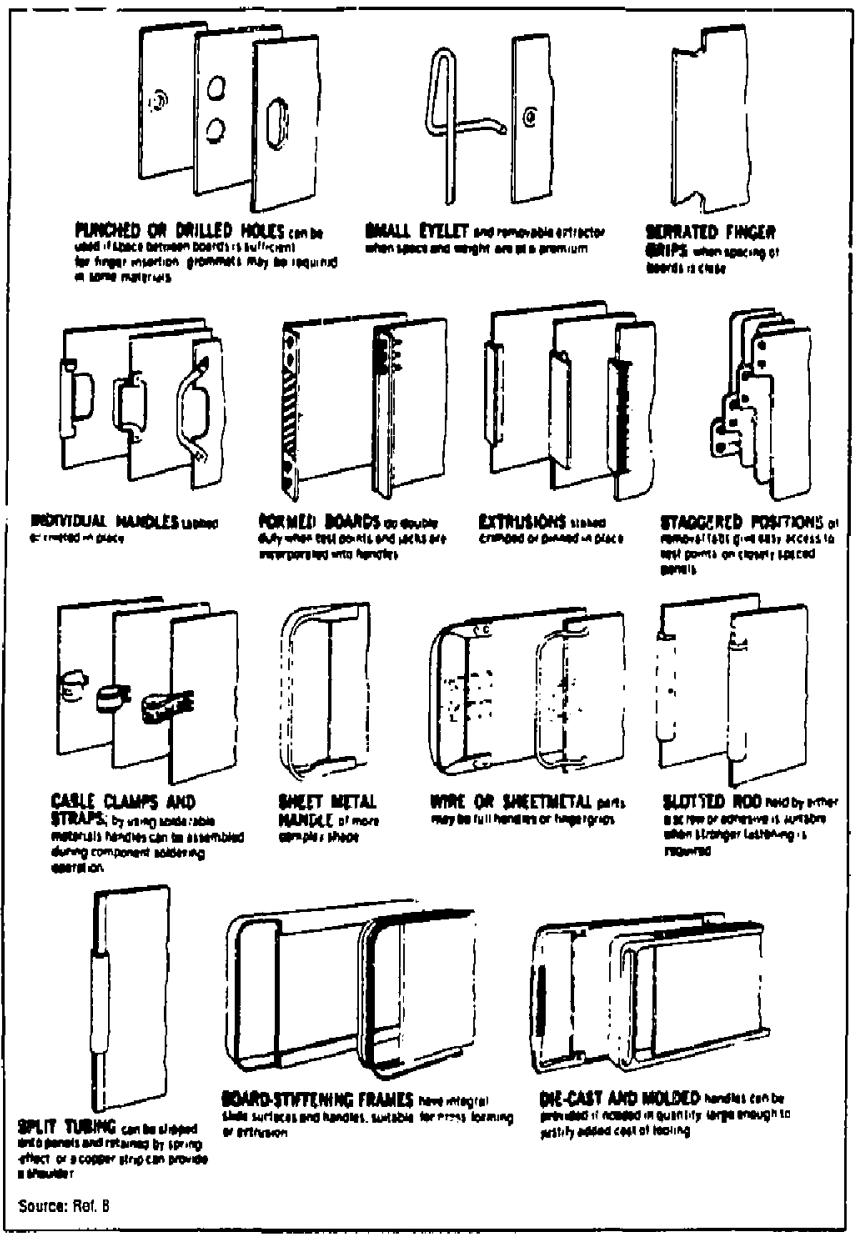

Eahibit t.13.6 Eximplas of Hanulas tar Witherawing Printod Cireult Boudi

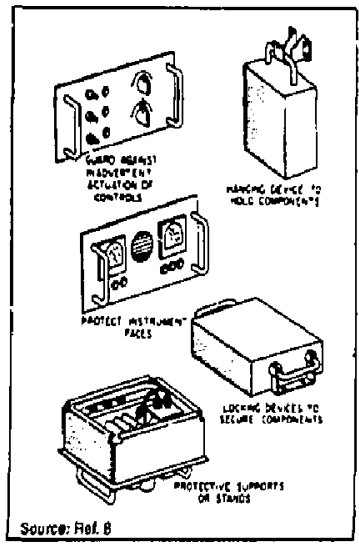

Exhible 1.13.7 Exmples of Milsollaneous thas for Hendles 


\subsection{FACILITY SUPPORT}

2.1 Workspact, Storage, and Repair Facility Design for Maintainability 


\subsubsection{INDEX}

2.1.4 SPECIFIC PRINCIPLES

2.1.4.1 Requirements for Standing Workspace and Clearance ............ 2.1.4

2.1.4.2 Requirements for Seating Workspace and Clearance .............. 2.1.4

2.1.4.3 Requirements for Mabile Workspace........................ 2.1-4

2.1.4.4 Requirements for Workshops $\ldots \ldots \ldots \ldots \ldots \ldots \ldots \ldots \ldots \ldots \ldots, 2.1-5$

2.1.4.5 Requirements for Storage Areas ......................... 2.1 .7

2.1.4.6 Miscellaneous Workspace Requirements $\ldots \ldots \ldots \ldots \ldots \ldots \ldots \ldots \ldots, 2.1-7$ 
FACILITY SUPPORT 2.0

WORKSPACE, STORAGE, AND REPAIR

FACILITY DESIGN FOR MAINTAINABILITY 2.1

\subsubsection{DEFINITION}

Workspace, as usad in these guidelines, refers to the locations within a DOE nuclear facility where maintenance, storage, and repair operations are performed. 


\subsubsection{GENERAL PRINCIPLES}

2.13.1 Workspace stould allow the technician to change posture if the maintenance task being performed requires prolonged kneeling, crawling, or crowehing.

2.13.2 To assi-i the technician in performing the required maintenance, the following should be provided th the workplace whentever practical:

a. Auxiliary hooks, hoiders, lights, outlets, etc. b. Auxiliary stands/shelves built in to equipment to suppori test equipment, removable units, or items to be repaired.

c. Lestice work, low cabinets, mirrors, open space, etc. as necessary io allow observation of reiatad displays, moving parts, fasteners, test points, etc.

d. Communication aids.

2.13.3 Non-skid treads, expanded metal flooring, or abrasive coatings should be provided on all surfaces which may be used for walking, climbing, or foothelds. 


\subsubsection{SPECIFIC PRINCIPLES}

2.1.4.1 PEQUUIAEMENTS FOR STANDING WORKSPACE AND CLEAfAANCE, Whenever possible, workspace design should allow routine, frequent, and/or short-term mainte. nance to be performed from a standing position. The specific requirements which follow are keyed to the illus. tration below, and others âs indicated.

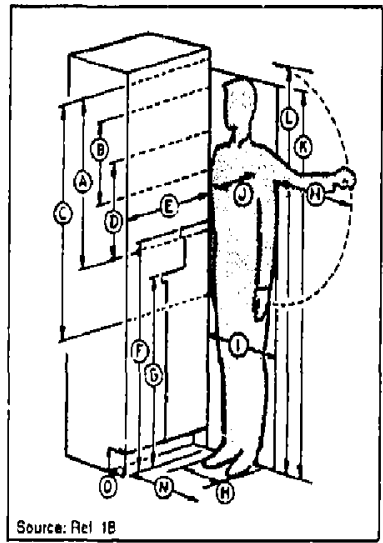

Exhibit 2.1.1 Stunding Workspuce Dimenuions

\section{a. VISUAL AND MANIPULATION WORKSPACE REQUIREMENTS}

(i) Displays, markings, etc. which must be read from the randing position should be within the following distances from the floor:

(A) Maximum limits: 40-70" for all visual displays on vẹrtiçal paneis.

(B) Optimum limits: $40-55^{\prime \prime}$ for critical or highforce controls.

(2) Controls, test points, fasteners, etc, which require manipulaticn from a sanding position should be within the following distances from the floor:
(C) Maximum limits: 30-70" tor all controls.
(D) Optimum limits: 40-55" for critical or high. force controls or tastenters.

(3) Work area length (E) for standing work is limited by time to move between point and/or require. ments for resching of visual contact between points. For work nerformed at a given pnsition, Uistances from the center line should be:

- $22.5^{\prime \prime}$ for all related work points.

- $17.0^{\prime \prime}$ for critical manipulation points.

- $11.5^{\prime \prime}$ for critical visual work points.

\section{b. WORK CLEARANCESFOR STANDING OPERATIONS}

\begin{tabular}{|c|c|c|c|}
\hline & & Minimum & Best \\
\hline 1) & Walking space width: & $12^{\prime \prime}$ & $15^{\prime \prime}$ \\
\hline 21 & Passing body width: & $20^{\prime \prime}$ & $32^{\prime \prime}$ \\
\hline 3) & Pasting body depth: & $13 "$ & $15^{\prime \prime}$ \\
\hline (4) & Overhead clearance: & $73^{\prime \prime}$ & BO" \\
\hline & Maximum overhead reach: & & $7 \mathrm{~B}^{\prime \prime}$ \\
\hline & Maximum depth of reach: & & $23^{\prime \prime}$ \\
\hline
\end{tabular}

(7) Standing space (N) of at least 30", and preferably $36^{*}$. should be provided before all work surfaces where appropriate.

(8) Kick-space (0), 4" high by 4" deep, should be provided wherever personnel stand or sit close to catbinets, benches, or ather work surfaces.

2.1.4.2 REQUIREMENTS FOR SEATING WOAKSPACE AND CLEARANCE. Whenever personnel are required to perform in the sirting position for more than one hour at a time or more than 20 s. of the time, chairs should be provided, Stools or benches will suffice for other sitting operations. For further detail regarding sazing workspace and clearance, refer to NUREG-0700, Section 6.1.2.3.

2.1.4.3 REQU: 9EMENTS FOR MOBILE WORKSPACE. When technicians are required to work in or pass through limited spaces, appropriate values to determine clearances should be selected from those provided below. 


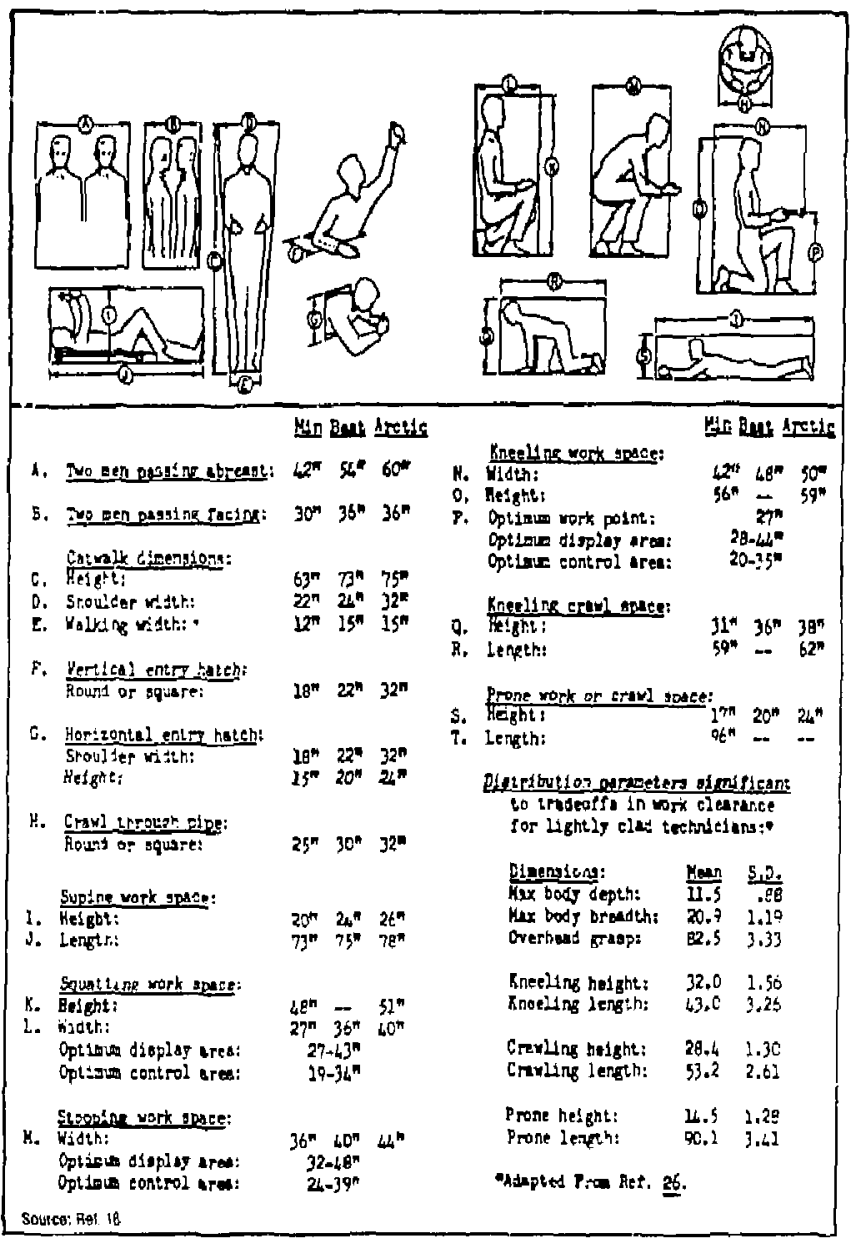

Exhibit 2.1.2 Mobile Workspace Dimensions, Note: OSHA Standard 1910.23(C)(2) :equires using a 18 " minimum width for catwalk/ruriways. Special consideration (larget decass) muș be given when users may be wearing bulky or protective clothing when performing a task.

\section{2,1.4,4 REQUIREMENTS FOR WORKSHDPS}

a. Maintenance workshops should be located and integrated into the overall facility layout in a manner that minimizes the time required for maintenance parsonnel to go back and forth between the shops and work areas within the facility.

b. In multiunir facilities, where units contain different major systems, separate maintenance organizations and workshops should be available for each unit.

c. The facility should offer convenient spaces and support facilities for temporary or permanent outside contractor personnel.

d. Lockers or cabinets should be available for personal slorage so that workbenches and seats stay free of clutter.

e. Entry and exit routes through the maintenance work. shops should be maint sined free of impediments 10 the passage of personnel, carts, vehicles, and moving and lifting dovices. f. Workshop areas should not be used as major thoroughfares for all facility personnel.

g. Maintenance xtivities that gerierate heat, smoke. parks, or noxious odors should be conducted in separated, screened-in, and well-ventilated areas.

h. Appropriate crenes, monorails, fork lifts, carts, and other movement aids should be avaiiable with in the workshop to allow for moving of heavy equipment and haroware.

i. The toal room should be integrated within the maintenance shop area or be in proximity to the shop area.

j. The warehouse should be located close to the maintenance workshop.

k. Maintenance workshops should be properly shielded from plant noise.

1. Workshops should be designed to be tree of drats that may cause discomtort or affect the availability of majntenance technicians to maintain close tolerances in operating plant machinery. 
$m$. The therma//humidity environment with in the workshop should be maintained at a comfortable level year round.

n. Saparate "ho: shops" should be availao'e in normally contaminateJ areas to prawent the necessity for working on conterninated hardware in normally "clean" shops. Expedients such as tents, portable walls, plastic, fabric, or wood barrints may he used. Bounjaries of contaminated "hot" areas should be clearly morked and labeled.

o. Workbench surfaces for standing positions should conform to the following dimensions:

(1) Standard workbenches (gee iflustration below, also):

- Height: $36-40^{\prime \prime}$ above the tioor

- Width: 30" maximum

- Length: As recuired,

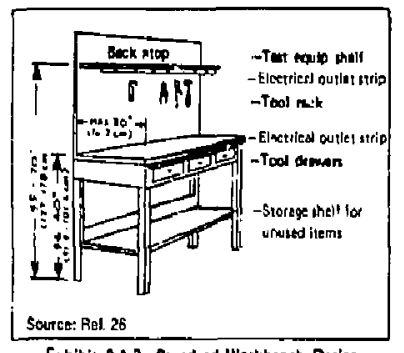

Exhibit 2.1.13 Sundand Workbend: Detign

(2) Podium Noe workbenches or high orecision surfaces (sae illustrations below, also):

- Height: 30-40" above floor

- Width: 36" maximum

- Length: 44" maximum,

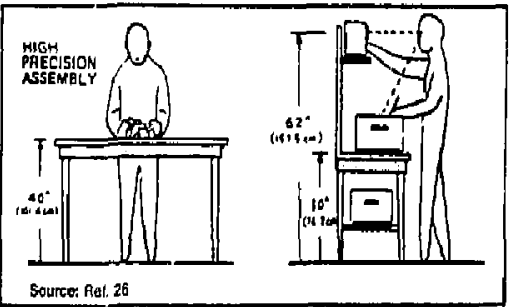

Exnitit 2.1.4 Podlum Type Workbench Desilgn
(3) Double-sided workbench and workbench acces sories configuration (see ill!nstratiens belewh:

p. Workbenches should offer illumination aids; space and supports for accommodating procedures, prints, and menuals; eccess to power sources; magnifiers as required; and built-in kete equigment as needed.

q. "Hot" shops thould be fulty Enclosed or glove boxes provided to aroid spreading conteminated particles that may result when maintenence machines are used to repair contaminated components.

r. Work surtaces for supporting job instruction manuals, worksheets, etc., should be $36^{\prime \prime}$ above the floor.

5. For tasks requiring force, it is recommer ded that work surfaces be 36 " above the fioor.

t. It is recorimended that tesks requiring precision be done on surfaces $40^{\prime \prime}$ above the flor.

u. Fators to be considered when determining workbench height and design:

- Characteristics of the equipment that will be placed on the surface.

- How technicians will perform takks.

- Lifting problems (size or weighil for equipment to be placed on surface.

- Uniqueness of tasks to be completed.

v. For sitting/standing work stations, provide adjustabls seats to accomodate techniciens of various heights and hody dimensions.

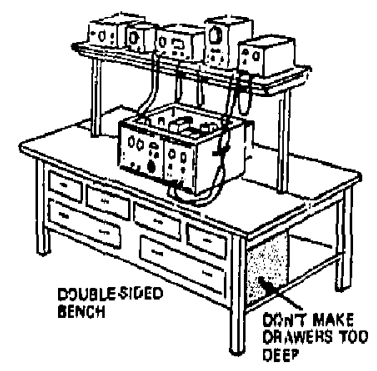

Seurce: Aegl. 20
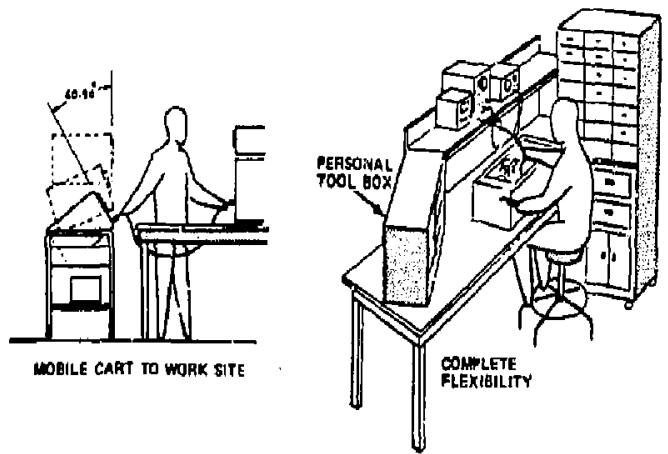


\subsubsection{REQUIREMENTS FOR STORAGE AREAS}

a. Organized stcrage facilitits should be available for sassonelly ysed items such as fans and heaters.

b. Adequate storage should be provided for materials and spares used on a recurrent basis that are not keot in a warehouse.

c. Special storage should be provided for tools and special equipment used during overhauls of outages.

d. Special storage should ba provided for contaminaied equipment that is used during outages.

e. Items stored in special lecations should be controlled and inventoried.

f. Seasonally or infrequently used items should be stored so as hat to interiere with normal entrance and exit pathways, vehicular traffic puths, and emergency escape routes.

\subsubsection{MISCELLANEOUS WORKSPACE REQUIREMENTS}

a. Instrument and control facilities shauld be located near the contral room.

b. Maintenance technicians should have easy access to a wetll-organized and contralled technical library which includes procedures, vendors' manuals, plant schernatics, atc.

c. Health Physics facilities should be located as ionveniently as posible for maintenance teshnicians si delays in making transitions frum "clean" to "hot" areas and vice versa can be avoided. 
2.0 FACILITY SUPPORT

2.2 Maintenance Support Equipment 
FACILITY SUPPORT 2.0

MAINTENANCE SUPPORT EQUIPMENT 2.2

\subsubsection{INDEX}

2.2.2 DEFINITION $\ldots \ldots \ldots \ldots \ldots \ldots \ldots \ldots \ldots \ldots \ldots \ldots \ldots \ldots \ldots \ldots, 2.2 .2$

2.2 .3 GENERAL PRINCIPLES $\ldots \ldots \ldots \ldots \ldots \ldots \ldots \ldots \ldots \ldots \ldots \ldots \ldots \ldots \ldots, \ldots \ldots \ldots$

2.2.4 SPECIFIC PRINCIPLES $\ldots \ldots \ldots, \ldots \ldots, \ldots \ldots \ldots \ldots \ldots \ldots \ldots, \ldots, 2.2-4$

2.2.4.1 Design Principles for Jacks . . . . . . . . . . . . . . . . . . . . . . . . . . . . . . . 2.4

2.2.4.2 Design Principles for Cradles.............................. 2.2.4

2.2.4.3 Design Principles for Cranes ................................ 2.2-4

2.2.4.4 Design Principles for Hoists............................. 2.2-4

2.2.4.5 Design Principles for Elevators .......................... 2.25

2.2.4.6 Design Principles for Remote Handling Equipment. . . . . . . . . . . . 2.2 .5 


\subsubsection{DEFINITION}

Maintenance Support Equipment (MSE), as used in these guidelines, refers to apparatus which are used for handling, lifting, positioning, towing, fueling, and lubricating tasks in the performance of maintenance. Specific apparatus included are jacks, cradles, eranes, hoists, elevators, and various remote handling equipment. Excluded from this definition are tools and test and service equipment. 


\subsubsection{GENERAL PRINCIPLES}

All MSE should be selected and designed so that it:

2.2,3.1 Is as simple es possibla to operate, use, and main tain.
2.2.3.2 is compatible with the maintainability features built into related equipment, and with the maintenance environment in which it will be used.

2.2.3.3 Provides maximum protection for components and working parts 10 minimize the need for repair. 


\section{2 .4 SPECIFIC PRINGIPLES}

\subsubsection{DESIGN PRINCIPLES FOR JACKS}

a. Jacks should be designed so they can be trantsorted, handlet, and stored eașily.

(1) Small jacks that must be lifted and cerried by ont person should not exceed 40 los.

(2) Larger jacks should be mounted on whegled carts that have locking wheels, Repositioning and accurate centering can be accomplished using 3 cart with swivel wheels,

(3) Large hydraulic jacks may be designed with whels that may be retracted or folded into the base of the cart, thus allowing the Ram base to touch the ground for added stability.

b. Jack handles should be removable or folding, If a jack handle is left protruding during maintenance, there is a possibility that personnel or equipment may strike ogainst the handle, knocking the jack from under the load.

c. Jacks should be labeled to show direction of trenk rotation for raising or lowering as well as the load they are designed to handle.

d. On hydraulic jacks, one or more access plates, at least 6 inches in diameter, should be permitted to allow inspection and cleaning of the hydraulic fluid reservoir.

e. Mechanical afety.locking devices should be provided to prevent accidental lowering of the load in the event of hydraulic system failute.

\subsubsection{DESIGN PRINCIPLES FOR CRADLES}

a. Cradles should be designed so that a load can be quickhy. effectively, and safely positioned on siem.

b. When a cradle is desigried to carry a specific losd, guidelines should be marked on the equipment and cradle so that when it is loaded into the cradle, perfect positioning will occur simply by matching guidelines.

c. Cradles should be shaped to fit the equipment to be carried. Cradkes may be adjustable or fitted with adapters to handle various sizes of equipment.

d. The cradle should have sufficient bad-bearing area to support the load when the equipment must remain on the cradle without support bands ai hoists.

e. Metal straps should be provided for attaching equipment to the cradle during positioning procedures.

f. If cradles are designed as integrat parts of other equip. ment, basic equipment with controls for positioning the cradle siould be provided.

9. When practical, a platform should be attached to the lift cradle to allow a technician standing on the platform to directly observe positioning of the component.

h. Mechanical safety dicvices should be provided to prevent inedvertent dropping of the load becauge af hydraulic failure. Check valves or ratchet devices are acceptable safety provis', ons.

\section{2,4,3 DESIGN PAINCIPLES FOR CRANES}

6. "Through" type bolis with convertional nuts and lock washers or lock nuts should be used for assembling structured members.

b. Hook eyes should be provided on boom sactions at the centers of gravity for gasy boom assembly and disassembly. c. Provisions for adjusting the boom length to axcom. modate operational requirements and to make the equipment more versatile should be provided when possible.

d. Two identical and interchangeable winch asemblies thould be provided to aperate the cables of the crane, one for hoisting the load and the other for controlling the boom height.

e. Heary mainterance support equipment such as portable electric winches and cranes should be mounted for ease of movement.

f. An operator's cab should be designed that will ptate with the crane to allow contunuous surveillence of the work opeiation.

9. The crane operator's gat should be located to allow optimum view of the laad, ground, and equipment in the vicinity, and at the same time permit easy operation of the crang's controls.

h. Lights should be mounted on cranes used outroors so that movement of the laad carried by the crane can be followed during night operation.

i. Control direction labels. Use absolute directions (North, South, Eost, West) instead of relative directions (Forward, Reverse, Leit, Right).

\subsubsection{DESIGN PRINCIPLES FOR HOISTS}

a. Hoist contrals should be incorporated into a portable, lightweight, hand-held control box. The box should kave the following design featuress (retier also to the illustrationl:

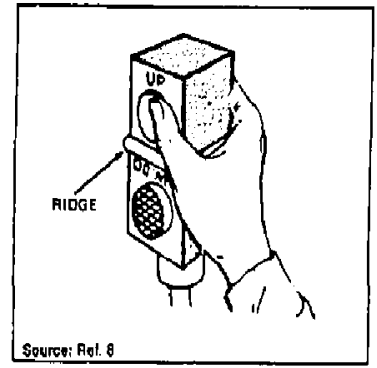

Exhibit 22.1 Hond.Hald Holal Control Box

(1) Two spring.load, recessed pushbuttons, one above the other.

(2) The top button should be "green" and labelet "Up." the bottom button should be "red" and labeled "Dawn." Where possible, color code functions: up should be green, and down should be ręd.

(3) Each oushbutton should have a flat for slightly concave) surface, large enough to be pustied repeatedly, without discomfort.

(4) Pressure to activate either button should be 10 to 4002 .

(5) A 2-inch clearance should be provided between each pushbutton to further prevent accidental activation of the wrong button. Riviging between the buttons should be provided.

(6) The sontrol box should be manageable tnough so the techniclan can reach both control buttons while holding the box securely and comiortobly in one riand. 
b. Maving parts such as belts, chains, gears, and linkages should be placed where operations and maintenance personnel ara least likely to come into contact with them. Guards should be provided if danger from contect exists.

c. Sulficient clearance for lugs used for attaching hoist bearns to equipment structures should be provided so the attachment can be made easily and quickly.

d. Pins should be urnd that have outomatic locking features and do not require the insertion of cotter pins for iocking. The pins should be attached to the hoist by a vire or chain. Matching luge: should be provided on the component or cradle so that the noist beam lugs can be set into the matching lugs to facilitate insertion.

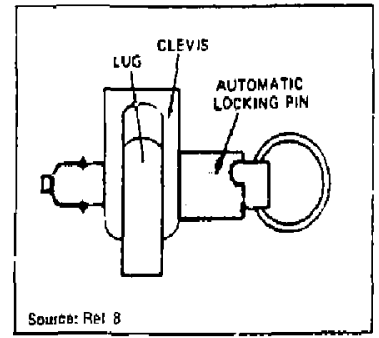

Exhibit 2.2.i Enample of Hoist Lug and Lock Pin

e. Hoist capaxity should be indic:ted on the side of the hoist closest to the operator to prevent rossible over. loading.

f. Posia to locking devices to hold hoist beams in the raised poition in case of power fa se should be provided.

\subsubsection{DESIGN PRINCIPLES FOR ELLVATORS}

a. Elevator coverage should antend to each level of the facility that maintenance persinnel $r_{1}$ lst reach to service heavy equipment

b. Elevators that are :vailable to maintenance technicians should be capable of accommodating personnel, hard. ware, and joo aids.

c. Elevators shov $\mathrm{J}$ be designed for reliable service in their intended environments, e., humidity, padiation.

d. Elevators should provide straight-line coverage from the lowest to the highest elevations in the facility, avoiding the need to transter personnel end materials from one elevator to anothet $\alpha$ some mid-point alevation.

e. Where possible, elevator arive nachinery which requires access for preyentive and corrective maintenanc: shouls be locatiod in nonconeminated arest although the elavator may provide service within contaminated areas of the facility.

f. Elevators that are used to tiansport tardware should be padded or otherwise protected to witt *ind potential damage.

9. Elevatch trat are located in potenticuip hazardous areas should have emerşency escape and/or communication deviccs h. The top button should be green and labeled up; the bottom button should be red and labeled down.

i. When possible, provide directional cues (such as pointing arrowheads) for up and Jown.

j. An automatic fail-sale brake, nr other self-locking device should be provided in case the lift mechanism tails.

$k$. Guards should be provided to grevent the accidental operation of the lift. IFor examule, consider guarding the "Emergency Stop" swixch.

\subsection{4,6 EESIGN PHIINCIPLES FOR REMOTE HANDLING EQUIPMENT}

a. Operator performanee should be optimized by organ izing consecutive tasks and subtasks to be performed by the equipment.

b. Equipment which must be remotely handled should be designed so that it can be broken down completely by the remote manipulator.

c. Components to be handled remotely should be tested for compatibility with the remote handling svsten that is being used before being included in system design.

d. Genera! purpose manipulations linsluding master-slave and rectilinear afm manipulators) should be provided with the following capabilities:

(1) A minimum of seven degrees of freedom of movement.

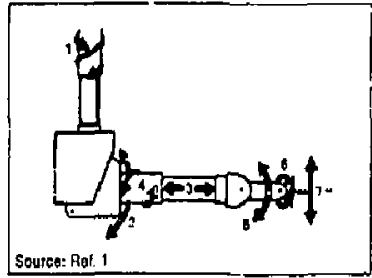

Extigis 223 Degres of Fitedom of Mourtient for hanipularor Arm and lijrise Atumbly

(2) Ability to grasp and manipulate tools. The slave ands provided must be designed to produc: the appropriate inovement, grip, thrust, and torque required by the task.

(3) A bilaterat drive system to reflect force to the tachnician's arm in a natural and meaningful way. The system must be completely rey i. sible so that a lore or movemient of the outpus will give a corrosponding force or movemeni of the input member (k.nob or handls).

(4) Optimal shape of the manipuiator arm. The wrist joint and lower portion ot the arm shrould be as small as possible to permit unobseructed vision by the technician as well as to permit remote inanipulation of equipment in close quarters.

a. Aectilinear arm manipulators should have the following capabilities:

(1) Grip farce indicarion, visual and/or euditory.

(2) Horizontal movement ic permit hendling at any Iccation in the "hat" area.

(3) Portable control console to "follow" the amm to various locations in the "hot" area. 
(4) Provide positive stops to preclude denger to the objerts being handled and/or "hot" area if one of the servo-ioops should fail.

f. Master-slave manipulators should have the following functions and eapabilities:

(1) Manipulator design to utilize the natural characteristics of the operator, with conformity of the control and effector portions with regard to spaxial orientation and position, Errors greater than $20^{\mathbf{0}}$ or $30^{\circ}$ in the synehronous errangement of slave jows and master control handle are detrimental to operator performance.

(2) High mecharical efficiency, low inertia, and low friction.

g. Electronic master-slave manipulators should have the following functions and capabilities:

(1) Variable ratios of control.effector movement.

(2) Variable retios of forct reflection (kinesthetic \{ẹedback\}.

(3) Positive stops to preclude danger to the objects being handled and/or "hot" area if cne of the servo-loops shouid tail.

h. Manipulator haidds should permit a wide range of lifting, holding, and clamping capacities, Several ithusarations of useful hand configurations for maintenance tasks are shown:

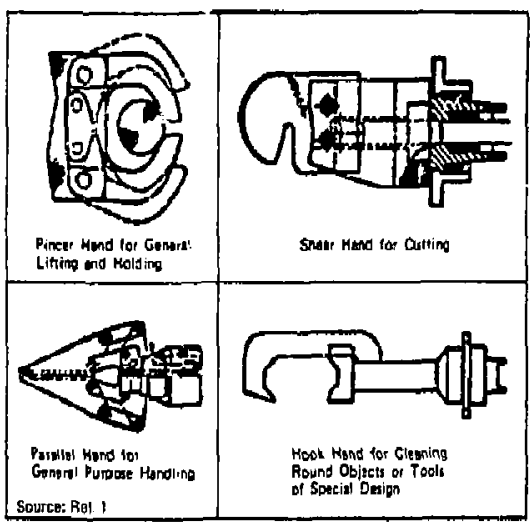

Exhibit 2.2.4 Exımplen of Manipulater $H$ ad Configurations

i. Handling controls should be designed to provide kinesthetic and tactile feedback to the maintenance technician so that o sense of "leel" is provided as to the amount of torque or force being applied or the direction of movement being taken.

(1) Where passible, the arm on which the control handle is attached should have a shape similar to the manipulator arm to maximize che similarity of motions.

(2) For precise measurement and feedback of torque, grip torce, or thrust force, calibrated instrume:its on the control console should be provided. For example, a hano grip force display should be provided which indicates a force reflection over a range from a few ounces to several hundred pounds. j. A means of direct vision should be provided through shielding windows where possible. A means of achieving this is by using turntables designed to rotate the equipment so that any side can be shown to the main tanance techrician. Direct vision is proletred because it provides little or no distortion of dimensions, clarity, and color discrimination.

$k$. Where direct vision is not possible or en adjunct to it is needtat, an optical ng item should be provided such as binocular, or stereoscoptic periscopes or microxopes where three-dimensiongl viewing is essential.

1. Where dizect vision and optical systems are not possible, closed circuis televisur systems should be provided for visibility.

(1) The usefulness of closed circuit talevision as a means to provide visual feedback for o remote performance fie!d appears to be seriously limited when the visual field is displaced from the rormal line of sight.

(2) Two cameros oriented at right angles to one another with a separate monitoring sereen for each are frequently substituted Ior stereo television,

(3) Color enharices the sensation of depth but black and white TV is ordinarily praferred because of its betzer resolution.

(4) Visibility is more dependent upon strong contrasts and shades than on stereoscopic effect.

m. Special windows should be provided to shield mainte. nance technicians from radiation while providing maximum visibility, Liquid.filled windaws must provide the following:

\begin{tabular}{|c|c|}
\hline $\begin{array}{l}\text { Shidding offectivan wa } \\
\text { The same thielding per } \\
\text { unit of thickness as } \\
\text { atlorded by tre remainder } \\
\text { of the biological shiold. }\end{array}$ & $\begin{array}{l}\text { Opdlal officlency } \\
\text { (High iranenission of a } \\
\text { I rrge partion of the visible } \\
\text { spectrum, minimum haze } \\
\text { high ral raction index, } \\
\text { large engle of vigw through } \\
\text { small window aperturs.) }\end{array}$ \\
\hline $\begin{array}{l}\text { Subility of color ond } \\
\text { clorty (Agoinst both } \\
\text { time and radiation.) }\end{array}$ & $\begin{array}{l}\text { Nontoxictiy of window } \\
\text { moterial tin case of } \\
\text { breakage.f }\end{array}$ \\
\hline
\end{tabular}

n. In order to preserve the contrast effect which is importont in discriminating detail, care should be taken to control fastors such as haze in liquid windows. cleanliness of glass surtaces, and multiple surface refliretions.

o. To minimize distortion, objects should not be viewed near the window or with an angle of incidence for the line of sight which is greater than $60^{\circ}$.

p. Sufficient light should be provitted for remote handling operations:

(1) Auxiliary lighting should be provided for visually inaccessible locations in the equipment being handled. For example, lights should be provided on tools, 1est probes, and servicing adapters that are insertea into dark recesses of equipment.

(2) To increase visibility, higher intensities of achro. matic lighting is just as efficient as monocinromatic lighting. 
(3) Monochromatic light should be used only where white light would actually interfere with ob. servation, as with very small components in which the parts would not be distingulshable under white light.

a. If possible, symbol coding rather than color codes should be used when codes must be recognized by the maintenance technician both under conditions of direst viewing and color television use. Symbol coding may not be epplicable for very complex equip- ment. However, any adaptation of color codes to correct for distortion by culor television will confuse the technician who is viewing the code directly. Therefore, another method of coding other than color should be used when both direct and television viewing ere required.

r. Tools and support equipment that are user: in con. junction with remote handling equipment should be designed so that they are exsily atessible to the manipulator hand and easily decuntaminated. 


\subsection{FAC!LITY SUPPORT}

2.3 Hand Tool Design for Maintainsbility 


\subsubsection{INDEX}

Page

2.3 .2 DEFINITION $\ldots \ldots \ldots \ldots \ldots \ldots \ldots \ldots \ldots \ldots \ldots \ldots \ldots \ldots \ldots \ldots \ldots \ldots, 2.3-2$

2.3 .3 GENERAL PAINCIPLES $\ldots \ldots \ldots \ldots \ldots \ldots \ldots \ldots \ldots \ldots \ldots \ldots \ldots \ldots, \ldots \ldots \ldots$

2.3.4 SPECIFIC PRINCIPLES $\ldots \ldots \ldots \ldots \ldots \ldots \ldots \ldots \ldots \ldots \ldots \ldots \ldots \ldots, 2.4$ 


\subsubsection{DEFINITION}

Hand tools, as referred to in these guideiines, include only those which are commonly used in maintenance work for inspesting, adjusting, servicing, removing, or replacing components.

Though tool design is accomplished separate from system design, it is important to ensure that equipment is designed to be maintained (in order of priority):

a. Without tools, where possible.

b. With the :inimum number of tools for the system.

c. With the minimum number of tools for the maintenance task.

d. With common hand tools, where possible.

e. With specialized tools only when absolutely required. 


\section{3,3 GENERAL PRINCIPLES}

23.3.1 Tools should be designed for maximum simplicity, practicality, and 'universality.

2.3.3.2 Requirements for tools should be derived directly from the maintenance takks to be performed and the design characteristics of the equipment involyed.

2.3.3.3 Each equipment system should be accompanied by a comprehensive list of tools required for all mainte. nance tajks.

2.3.3.4 Tools should be used during developmental testing of the system/equipment to find diplications and omissions, and to determine if the equipment requires additional tools.

2.3.3.5 Only those cools usually found in the maintenonce eechnician's tool kit should to required for maintenance operations.

2.3.3.6 Spred or power tooks sucn as ratchets, speed serew. drivers, or power wrenches should be provided the technician when they are required because of torque dernands or space limitations.
2.3,3.7 Femotely controlled tools should be provided where fessible and where such toois will reduce maintenance time and labor hours.

23.3.8 Holding tocls such as pliers or clamps should be designed so that they are skid.proof and do not mar or scratch holding surfaces.

2.3.3.9 Adequate gripping surlaces should be provided on the handles of tools. Knurling, grooving, or shaping the handle to tit the hand ate desirable.

2.3.3.10 In evaluating the finish to be applied to tools, consider that tools having a dull finish, prevent reflecter glare in areag of high illumination, However, dull-finished tools are ofen overlooked when closing assemblies, etc., causing loss of tools and possible damage to the equip. ment. The designer should theretore carefully consider the advantages and disadvantages of this type of finish in relation to th: potential application of the tool.

2.3.3.11 Using plastic, heat- or cold-resistant handles on tools which are to be used in ex tremely hot or cold climates should be specified. The use of metal hendles is indesirable, particularly for cold climates and for electricians' tools. 


\subsubsection{SPECIFIC PRINCIPLES}

2.3.4.t Serewdrivers for small-size adjustment screws should be provided with a funnel-like guide that will ald placement of the screwdriver on the adjustment point.

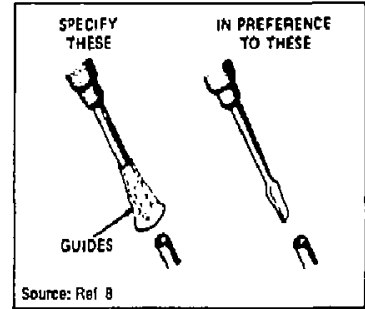

Eanibit 2.3.1 Sctewdtivet for Smull-Sited Adjustments

2.3.4.2 Magnetized serewdrivers, if they will not adversely affect electronic circuits, should bo provided to hold free screws that cannot be held easily with the fingers. If megne. tized screwdrivers are not desirable, screwdrivers should have clips. Design the clip so that it can be slid up the screwdriver shaft when not in use.

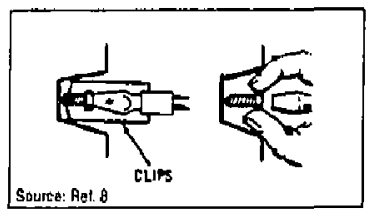

Exhiblt 2.3.2 Exumple of Clip Seroudtiver

2.3.4.3 Push-type tools should be provided wherever serews must be roteted through many revolations, provided the attendant resultant force on the equipment will not be harmful.

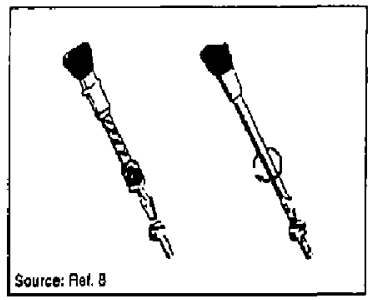

Exhibit 2.3.3 Example of Push.Tyos Tool

2.3.4.4 Tools should be specitied which are compatible with the design of the equipment dii which they will be uced as well as with the job to be pertormed. For example, a toal size should be specified whith is consistent with the size of the prime equipment. Lever handles should be specified rather then screwdriver handles when high torque is to ie applied, and tools should be provided which are consistent with working space avgilable on the prime equipment.
23.4.5 Positive snap.locking action should be used for connecting sockets to the verious components of a sucket set. Oesign them so they can be easily connected and disconnected.

2.3.4.6. Ratchet screwdrivers should be provided where torque requirements are low and soace is limited. They require only one-handed operation and usually require less clearence.

2.3.4.7 Equipment should be designed so thet only straight type sercwdrivers can be used, Offset screwdrivers are not satisfactory because there is a lack of normal force on the screw head stots and the slots become damagod exily. However, the use of offset screwdrivers reduces the amount of space required to turn a serew and tecesuse of space limitations may be the only solution. The overtead space requirement for offset tools and two special type offset tools for removing fasteners are illustrated below.

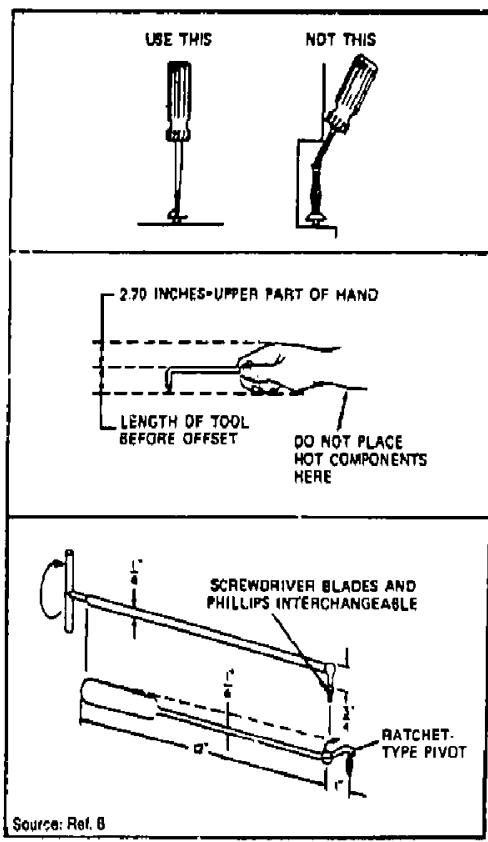

Exhibit 2.3.4 Uat of Stright and Off.Set Selowdriver

2.3,3.8 Drills with floating chucks for drilling fastener holes for rivets should be used. These will insure that the hole is drilled at the proper right angle so that maximum fix tolerances are reached,

2.3.4.9 Spanner wrenches should be designed to be operable from various angles to avoid obstructions in operations.

2.3.4.10 The technician should bo provided with tamplates for making surface control adjustments (rigging) or for mounting links, arms, rods, or other such parts on a flat surface. Markings strould be provided on the templates to show the desired senting or placement of the control or part. 
2.3.4.19 High-speed soldering devices should be provided to melt connections being serviced without damaging adjacent element.

2.3.4.12 Clamping devires should be providied to remove small, closely packed plug-in devices.

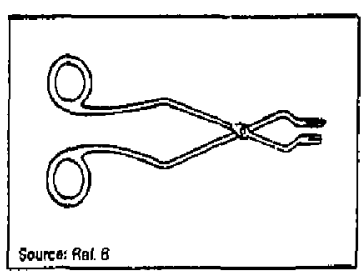

Exhibit 2.3.5 Exomple of Clumping Deviox

2.3.4.13 Long-nosed hemostat.type pliers should be pro. vided which tan lock, hold their grip, and be used as heat sinks.
2.3.4.14 Printed circuit card extenders ond card extractors should be available to the technician for use with com puterized units.

\subsubsection{SAFETY SJGGESTIONS}

8. Adequate insulation should be provided on handles or other parts of tools which the technician is likely to touch whils doing maintenance wotk neat vohages if: excess of 50 volts.

b. Spark.resistant tools should be provided if they are to be used in areas where tire or explosion hazard's are present.

c. Adequate storage for tools should be provided so they cannot fall and causo nersonal injury or be easily misplaced or last.

d. Sharp corners and edges on tool chests shculd be eliminated.

e. Trol filests which are too large to be easily haridled by one person should have oasters of a sufficient number of handles to facilitate moving. Harriles should be locoted so the chest will be balanced when it is b.ing moved. 


\subsection{FACILITY SUPPORT}

2.4 Stair, Lacider, and Ramp Design for Maintainability 


\subsubsection{INDEX}

2.4.4 SPECIFIC PRINCIPLES

$2.4-4$

2.4.4.1 Design Requirements for Stairs. . . . . . . . . . . . . . . . . . . . . . 2.4-4

2.4.4.2 Design Requirements for Stair Ladders......................... 2.4-4

2.4.4.3 Design Requirements for Fixed Ladders...................... 2.4.4

2.4.4.4 Design Requirements for Portable Ladders . .................... 2.4-5

2,4.4.5 Special Requirements for Fixed and Portable Ladders . . . . . . . . . . . . 2.4-6

2.4.4.6 Design Requirements for Ramps.......................... 


\subsubsection{DEFINITIONS}

Stairs, ladders, and ramps refers to structures which allow personnel to abruptly change eleva. tions by more than 12 inches. Stairs (stiles) and ramps may be used to allow for safe and easy passage over low objects (e.g., pipes, lines) in corridors and passageways. Types of structures (in order of preference) are:

a. Stairs allow the fastest, safest, and easiest passage of personnel, especially when they are carrying loads.

b. Stair ladders are preferred to ladders because they provide better footing and faster, safer passage. However, sure balance and fast movement require the use of both hands on the handrails. Carrying loads up stair ladders is also hazardous.

c. Ladders are not desirable for frequent passage. They are comparatively unsafe, difficult to climb, and difficult to work from. Only loads which are strapped to personnel can be carried up ladders. Fixed ladders are preferable to semi-permanent or movable ladders; the former are more stable, less subject to clearance problems, and can be affixed with guardrails and other safety features. Portable ladders should be required and provided only for emergency functions or for use during infrequent maintenance tasks. Permanent ladders or maintenance stands are preferable.

d. In ganeral, ramps are of value only when rolling stock must be moved between different levels and this same space can be used for pedestrian traffic. Long ramps are undesirable except for self-propelled vehicles. Requir in ints for personnel to push or pull rolling stock up ramps should be carefully evaluated in cerms of safety and human strength. 


\section{4 .3 GENERAL PRINCIPLES}

2.4.3.1 Layout and design of stairs, ladders, and ramps should consider:

a. Limitations in the amount of space and clearance available.

b. Predictable environmental conditions that will affect the structure (particularly if it will become wet or covered with ice, snow, or mud).

c. Type, direction, and frequency of traffic over the structure.

d. Relative efficiency of alternate traffic potterns.

e. Loads or other encumberances to be carried by personnel over the strudtures.

$f$. Size and weight of other equipment that may heve to be moved over the route.

9. Need for decontemination and clean up.

2.4.3.2 The type of structure chosen to be used should be based or the angle of the structure's inclination in relation to t'le available space and structural constraints. The illustration shows the preferred and critical angles of ineline suitable for these structures.

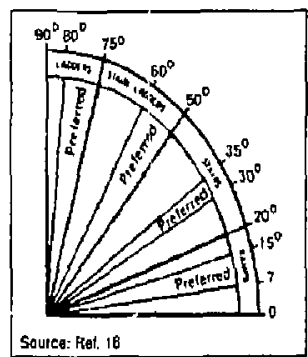

Exhibit 74.1 Preterred end Critical Angles for Ladders. Stair Ledder. Sisirs, and Ramps

\subsubsection{Stairs, ladders, and ramps should be:}

a. Lesigned, installed, or arovided to effect the most inmediate and efficient access to and betrieen worki placess and arós.s.

b. Constructed of materials which are lightweight, non. conductive, splinter-proof, waterpro of, weatherproot, hur.iditity-resistant, and resistant to chemical action.

c. Designed to withstand the combined weights and strengths of the largest number of personnel likely to be on them at one time, multiplied by a safety factor of at least two. Two hundred and fifteen pounds per person should be used to celculate weight.

d. Provided with nonskid suriaces on all areas where personnel are expected to step, walk, or stand.

e. Free of obstruction, edges, notehes, or burrs which could injure personnel or damage hoses or cables.

$f$. Designed to be de-iced, when necessary, by using hot water or steam.

g. Adequately lighted.

h. Adequately marked against harards in their use, 8,g, against low overhead, possible shock.

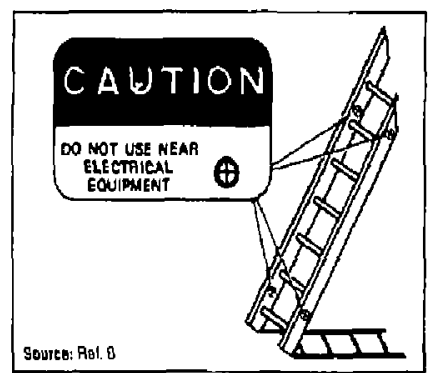

Exhlbit 2.4.2 Exemple of Huzud Marking on Ledder 


\subsubsection{SPECIFIC PFINCIPLES}

\subsubsection{DESIGN REAUIREMENTS FOR STAIRS}

a. Critical dimensions for stair design toliow:

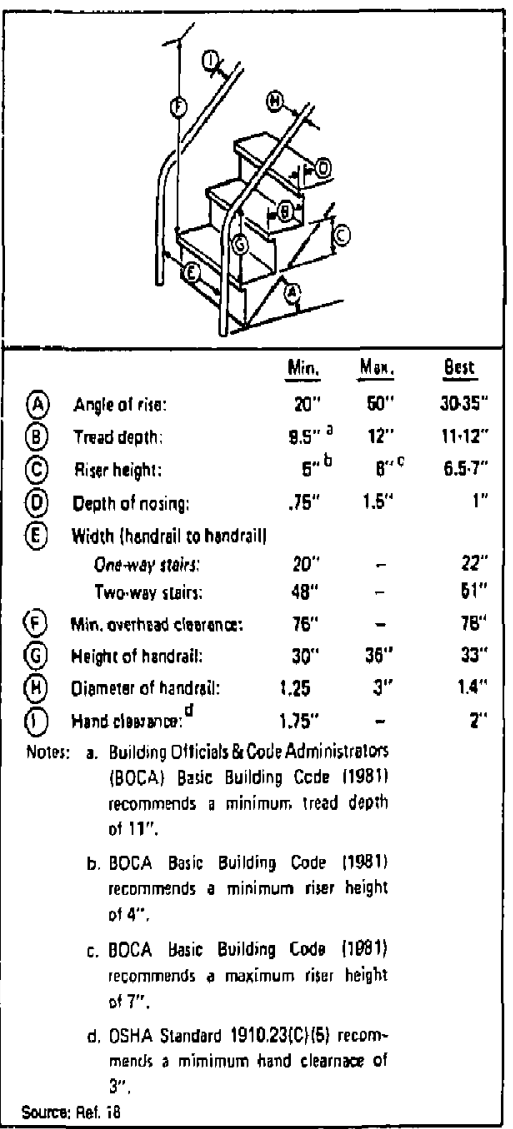

Exhibit 2.4.3 Citten Dimensions for Stairs

b. Tread depth and riser height may vary with the angle of inclination according to the graph below. But loads carried and length of the stairs should also be considered. In general, deep treads ( $\left(12^{\prime \prime}\right)$ and low risers $\left(5^{\prime \prime}\right)$ should be used when loads over 20 pounds are to be crrried or steirs are over two stories high.

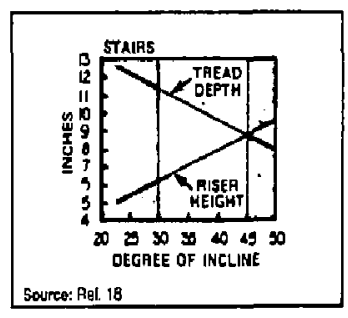

Extibit 24.4 Jread Depth n. Fisst Height
Avoid long flights of stairs. Landings are recommended every 10.12 treads and must be provided for every story (8.12 ft. elevation).

\section{2,4.4.2 DESIGN REOUIREMENTS FOR STAIR LADDERS}

a. Critical dimensions for s:Bir ladder design follow:

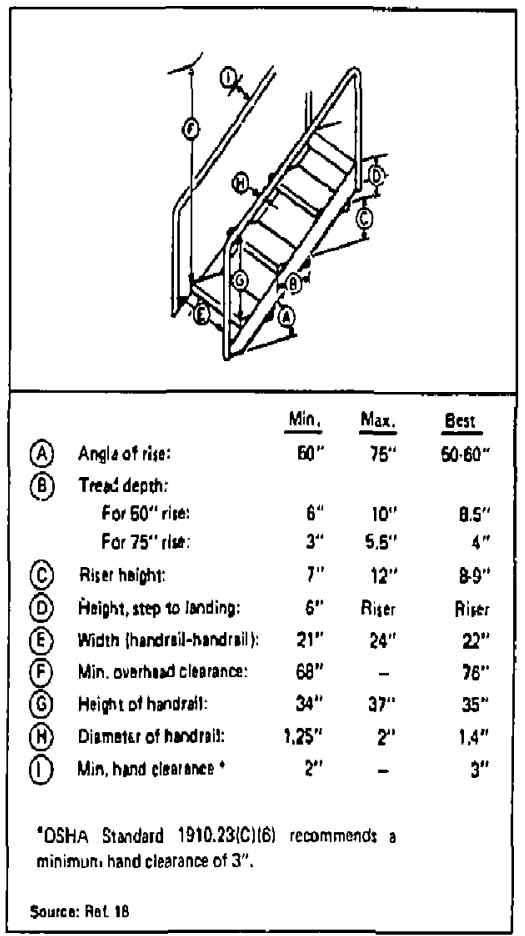

Exhibit 2.4.5 Critien Dimensions for Suir Ladden

b. Clearance on stair ladders should be sutficient for one person only. If simultaneous two-way traffic is desired, ueparate up sond down lasders should be pro. yided. If these are located side by side, a double center hendrail thould be provided with a minimum of 6 " between rails (8" recommended).

c. Treads should be open (without risers'). But metal ereening (or kick plates) should be fastened to the underside where required to prevent injury to personnel or damage to equipment.

\subsubsection{DESIGN REQUIREMENTS FOR FIXED LADDERS}

a. Critical dimensions for fixed ladder design follow: 


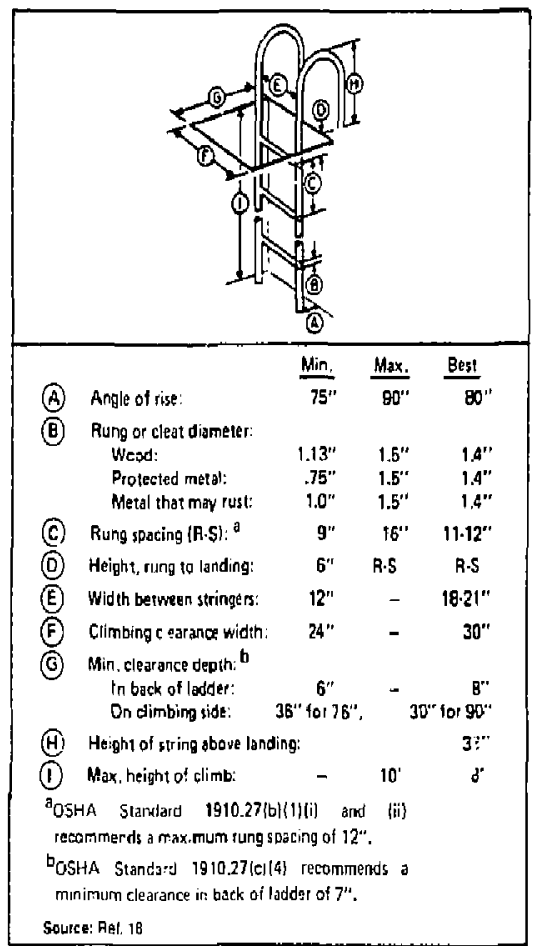

Exhibif 2.4.6 Critice: Dimensions lor Fixed Ledden

b. If ladders are used between several floors, they should be offset and guarded landings should be providad at every floor.

c. Guardrails should F: provided at the top entrance to Jadders, if the ladder well is open.

d. Ladder cages should be provided for fixed ladders over 20 teet long. Dimensions of cage should be as follows:

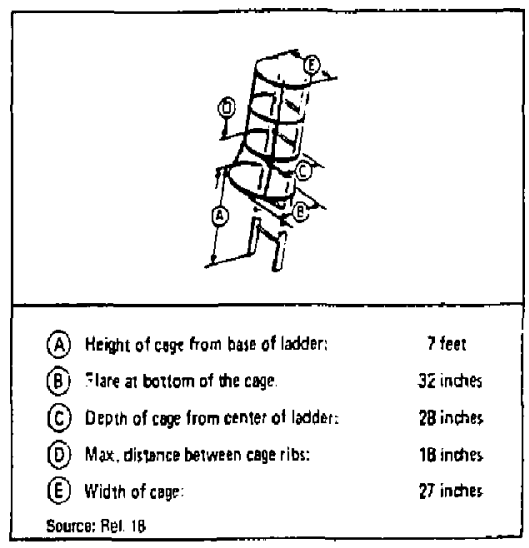

Exhibit 2.4.7 Ledter Come Dimensions e. The insive of the cspe must be clear of obstructions,

f. Round rungs provida better hand holds, but level steps, 3-4" wide, may be used if hendrails are provided on both sides of the ladoer.

\subsubsection{DESIGN REQUIREMENTS FOA PORTABLE LADDERS}

a. Critical dimensions for portable ladder design tollow:

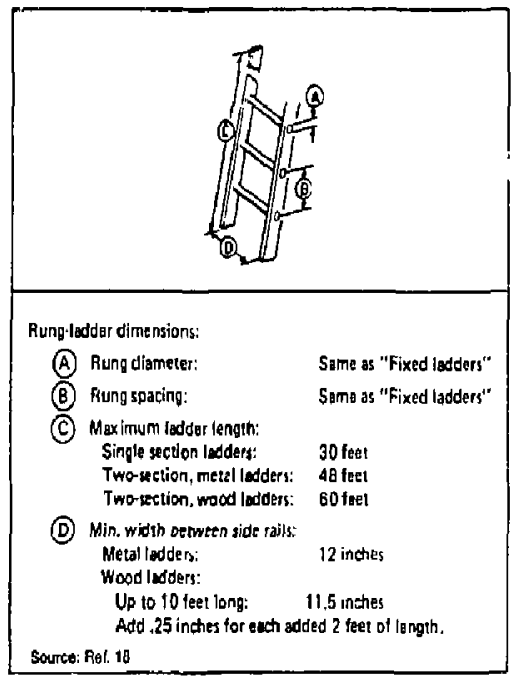

Exhibit 2,4.8 Critical Dimenslons for Portable Ladders

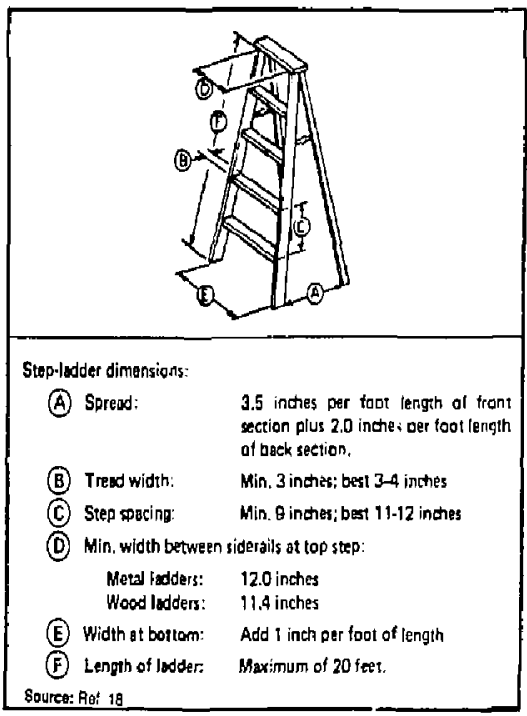

Exhltit 2.4 .9 Critical D/mansions for Step Ladders

b. Ladders should be provided with rubber-cleated, pivoted feet for use in nonfreezing weather, and sleel cleats for use in ice or snow.

c. Permanent hinges and locks should be used in prefer. ence to bolts and nuts for assembly of two-section extension ladders. 


\section{2,4.4.5 SPECIAL REQUIREMENTS FOR FIXED AND PORTABLE LADDERS}

a. Safety devices should be provided on either fixed or portable ledders whenever length, use, of operating conditions require. For instance, pole leshing devices should be provided for ladders to be used against poles, or carrier rails and safety belts should be provided for long ladders to be used in aciverse weather or under emergency conditions.

b. Kick plates shoule be installed behind ladders for special applications where faet may damage the surface of the equipment.

c. Metal ladders should be marked with signs or decals warning ageinst the danger of shock. These should be plated inside the stringers, on both sides, and 3 feet from both ends and read: "CAUTION, Do not use or store near tlectrical equipment."

\subsubsection{DESIGN REQUIREMENTS FOR RAMPS}

a. Critical dimensions for ramp design follow:

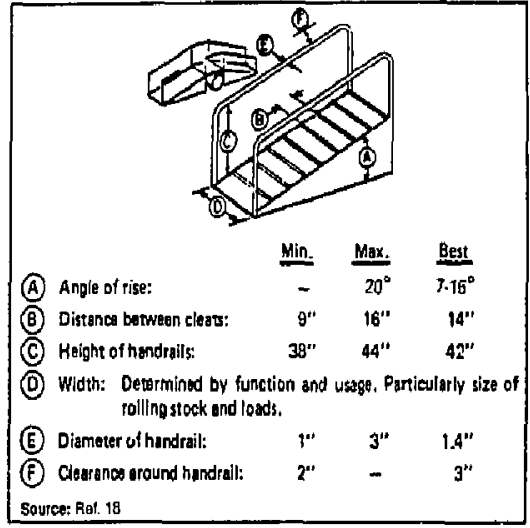

Exhlbit 2.4.10 Critical Dimensions for Ramps

b. Where a smooth surface or runway for wheeled vehicles is needed, it thould be located in the center or to one side of the ramp, with cleated portions on the outside below the hendrails. A combination of ramp and stairway is praferred, however, especially for slopes graater then 7 degrees. 


\subsection{FACILITY SUPPORT}

2.5 Platform and Shelter Design for Maintainability 


\subsubsection{INDEX}

Page

2.5.2 DEFINITIONS $2.5-2$

$2,5,3$ GENERAL PRINCIPLES $\ldots \ldots \ldots \ldots \ldots \ldots \ldots \ldots \ldots \ldots \ldots \ldots \ldots \ldots, 2,5-3$

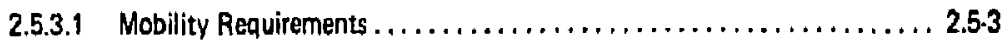

2.5.3.2 Stability Requirements . . . . . . . . . . . . . . . . .

2.5.3.3 Fixture Requirements................................ 2.5

2.5.3.4 Size and Configuration Requirements. $\ldots \ldots \ldots \ldots \ldots \ldots \ldots \ldots \ldots, 2.5-3$

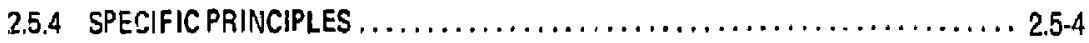

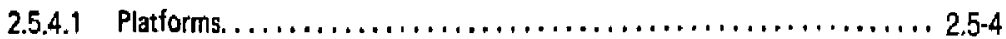

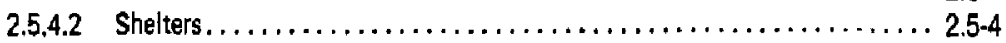

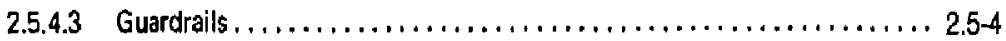


PLATFORM AND SHELTER DESIGN FOR MAINTAINABILITY 2.5

\subsubsection{DEFINITIONS}

Platforms refer to supports which are used to provide maintenance technicians with support at a tolerable working distance to equipment.

Shelters are used to provide enclosure and protection of maintenance technicians and equip. ment during maintenance tasks. 


\subsubsection{GENERAL PRINCIPLES}

2.5.3.1 MOQILITY REQUIREMENTS, Platforms and shelters should be permanently installed whsinever possible. Where they must be mobile, they should be:

a. Lightweight enough for no more then two people to handle, erect, and inștall,

b. Collapsible of adjustable for easy handling and trens. porting,

c. Provided with self-locking devices for all attachments, adjustments, and collapsible supports.

d. Provided with wheels, as necessary, that should:

(1) Hove wheel locks ar brakes to insure stability.

(2) Be large enough to allow easy passage over ridges up to 0.75 inches high or higher.

(3) Provide firm grip and adequate support on slippery surfaces, snow, ice, and sand.

2.5.3.2 STABILITY REOUIREMENTS. Platforms and shelters should be:

a. Provided with low centers of gravity, wide wheel bases, anchors, and/or autriggers as needed 20 achiove stability.

b. Properly balanced and supported to allow using without tipping when the weight of personnel and/or components is applied to any one side.

2.5.3.3 FIXTURE REQUIREMENTS. Where practical and feasible, platforms and sheiters should have:

a. Electrical outlets and fixtures to provide adequate lighting ond facilitate use of test equipment and powered tools b. Shelves or other places for resting test equipment, tools, or components at a convenient operating or working level.

c. Hooks, eyes, clip fasteners, supports, atc. to facilitate the support and connection of associated wiring, hoses, block-and-tackle srrangements, etc.

d. Storage space, cable winders, supports, clainps, etc, to provide storage for assaciated manuals, slings, special tools, extension cables, etc.

\subsubsection{SIZE ANO CONFIGURATION REOUIREMENTS}

Platforms and sheiters should provide:

a. Easy passage of personnial when access doors, cowl flaps, etc. are upen.

b. Adequate work space and work clearances for the maximum number of personnel end range of tasks required in these operations.

c. Etay access to all equipment, mounts, and features integrally related to the maintenance opesations they support; eg., to an engine and all its associated parts, acessories, and points of connection.

d. Safe and easy handling in these operations of all related:

(1) Components that ere likely to be removed.

(2) Spare garts, tools, etc. that must be handlad.

(3) Slings, hoses, lines, and other supports to be handled,

(4) Cowls, pands, or ather major items that must be handled within the shelter or from the platform or stand. 


\section{5,4 SPECIFIC PRINCIPLES}

2.5.4.1 PLATFORMS. Platiorms should be dexigned to:

A. Satisfy the preceding "General Principles."

b. Provide a minimum of 6 square feet of workspace.

c. Permit the technician to have both hands free for work.

d. Provide a mntinuing work surface around or between related portions of the work area, e.g., the engine.

e. Have a capacity in excess of the herviest combination of persons and/or equipment to be suppored at any one time. Use 215 lbs, per person to calculate weight. A minimal capecity of one ton in recommended.

f. Conform closily to the work surface.

(1) General conformition should be within 2 inches.

(2) Gaps greater then 6 incter are nomally objection. able.

(3) Contact plates, cushions, bumpers, or pads should be provided as necessary to protect equipment suriaces.

2.5.4.2 SHELTERS. Shalters should be designed so that:

a. They setisty the preceding "General Principles."

b. Time to instalı and enclose is minimal and does not exceed one hour.

c. Maximurin practical enclosure and protection gre provided in terms of the environment in which the shelter is to be used.

d. Ventilation and environmental control are within tolerable limits, considering the sype of clothing to be worn. e. Allowances are mode for variations in corrifigurations of the sheltered equipment,

f. They can be used side by side where appropriate.

9. Covered openings are provided as necessary to facilitate removal of major components such es complate engines.

h. Thay are compatible with, provide openings for, and allow employment of associated support equipments such as cranes, stands, slings, etce.

i. Their design does nol prevent operations estential to related maintenance.

2.5.4.3 GUARDRAILS. G Jardrails should:

a. Satisfy the requirements : hown below.

b. Hove scr eening or lattice work.

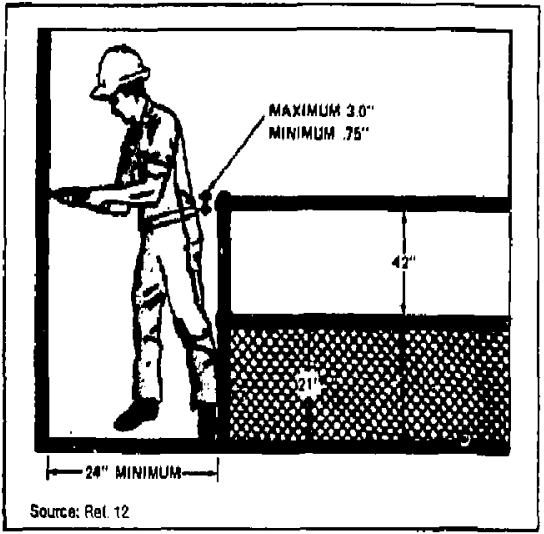

Exhlbit 2.5.1 Critical Dimansions for Guerdrails 
2.0 FACILITY SUPPORT

2.6 Design of Computer Systems for Maintainability 


\subsubsection{INDEX}

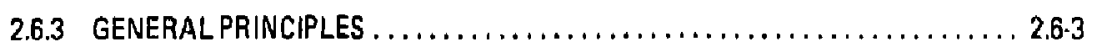

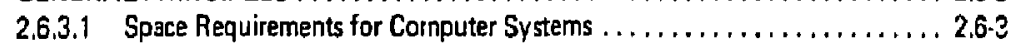

2.6.3.2 Environmental Requirements for Computer Systems ............... $2.6-3$

2.6.3.3 Electrical Power Requirements for Computer Systems ........... 2.6.3

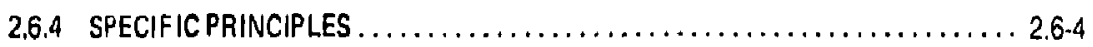

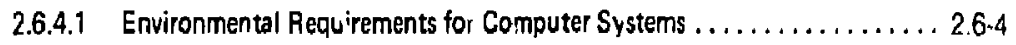

2.6.4.2 Electric Power Requirements for Computer Systerns ............... 2.6.4 
FACILITY SUPFORT 2.0

DESIGN OF COMPUTER SYSTEMS FOR MAINTAINABILITY 2.6

\subsubsection{DEFINITIONS}

a. COMPUTER SYSTEM. A computer systern consists of computer hardware components and other electronic components which are connected together dild operate under control of computer sofiware.

b. UNIOUE INTERFACES. These are electronic in :erfaces of unique design which interface the computer to sensors and other electronic and electrical devices. These interfaces will ve used most often in control and monitoring device applications. Exemples are analog to digital converters (ADCs) and digitai to analog converters (DACs).

c. INPUT DEVICES. These devices provide input information to the computer, Typical devices are keyboards, numeric key pads, disk drives, magnetic tape d-ives, and punched cards and paper tape readers.

d. OUTPUT DEVICES. Computer information is sent as output to these devices either as stored data or as a direct response to computer operator commands. Typical devices are video disilays, printers, plotters, magnetic tape drives, disk drives, and paper tape punches.

e. INPI!T/OUTPUT DEVICES. These are devices which can sern both as input arid output devices. Typical examples are video display terminals with keyboards, magnetic tape drives, and disk drives.

f. COMPUTER SOFTWARE. Software normally means mo'e than one computer program which functions to control operation of a computer and aliow computer system users to perform specific tasks. These tasks may be computational, data-hancling, control, monitoring; analysis, graphics, editing, and other, Typical software storaze devices are computer memory, magnetic tape, disks, paper tape, and punched cards.

g. ENVIRONMENT (Equipment). Environment refers to all conditions which surround a computer :ystem or one of its system components and which directly affect operation of equipmeri. These conditions take into account air, electromagnetic interference (EMII, electrostatic discharges, and power line noise. Factors which affect air conditions are humidity, trmperature, cleanliness of the air, and air flow distribution.

h. ENVIRONMENT (Personnel). Environment refers to air, acoustic noise, electrostatic discharges, and room lighting.

i. POWER FACTOR (PF). This factor numerically gives the phase relationship between a.c. voltage and current when a system or component is connected to an electrical powe: scurce. It is defined using watts consumed and the products of voltage times current.

$$
P F=\frac{\text { watts }}{\text { voltage } x \text { amperes }}
$$

j. POWER DISTURF ANCES. These are changes in the electrical power source which might produce an undes: ble response in the comrjer system or one of its components. Com. puter equipment inanifacturers often specify allowable power line disturbances. 


\subsubsection{GENERAL PRINCIPLES}

\subsubsection{SPACE REOUIREMENTS FOR COMPUTER}

SYSTEMS. Maintainability of a computer system and all its components largely depends on the system operating in properly designed facilities. The design of the facilities incluodes establishing criteria for space. Many tactors directly

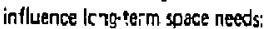

- Equipmer:

- Work areas

- Furniture

- Storage

- Expansion.

Initial design considerations for space should include room struetural requirements for walls, floors, and ceiling. These may require acoustic properties to reduce noise levels gener. ated by equipment. Fleors which are of the raised type can accommodate cables and jir flows for equipment cooling. Suspended ceilings can incorporate acoustic properties, lighting, and fire control systerns. Each computer system site is different and consequently each will have different requirements for space. The following points should be considered at each site:

a. SPACE FOR EOUIPMENT. Adequate spare should be allowed for system coinponents. Generally, at least three (3) feat of space should be allowed between equipment components in rows and equipment com. penents and walls, This will provide a minimum amount of work area to service equipment.

b. SPACE FOR WORK AREAS. Adequate space should be allowed for work areas around equipment. Furniture used by personnel, such as tables and chairs, and areas used for storage, should be taken into account.

c. WORK.FLOW PATTERNS. Space requirements should be considered to allow sufficient work-flow pattems between work areas. Input/output devices usually require ease of visual observation from more than one location.

d. STORAGE SPACE. Storage space should be provided for supplies necessary for system operation.

e. ELECTRICAL POWER. Electrical power requires space for isolation transformers and line veltage regulators if used. Electrical panal boxes require space to allow access by personnel. Overhead space is required for lighting and wall space and/or raised floor space for power outlets.

f. CABLES. Power cables and equipment cebies should accupy floor or ovethead space if raised floors are not used.

g. ENVIRONMENTAL _ QUIPMENT. Air conditioning and/ or humidifying equipment may require both flocr space and duct space.

h. FIRE EOUIPMENT AND HARDWARE. Space requirements should be considered for spinkler systerns, fire extinguishers, and alarm systems.

i. FUTURE SYSTEM EXPANSION. Space consideratio:'. should be given for future expansion of the system.

\subsubsection{ENVIRONMENTAL REQUIREMENTS FOR}

COMPUTER SYSTEMS. Reliability of computer systems and their components dexends largely on operation of equipment in a controlled environment. This requires temperature and humidity levels to te mainteined within specified ranges. The control of air flow and gond distribution prevents equipment from overheating. It is desirable to consider separation of some types of equipment. Printers can contribute to air contamination, whereas disk drivk systems demend a clean air environment for long-term reliability, Both EMI and power line noise can interfere with operation of electronic cireuits. Potential EMI problems may require shialded equipment rooms. Power line noise usually requires line isolation and may requirf special filtering and/or line regulation, Noise levels for system component may need 10 be determined and site designs should take into account ecoustic shielding techniques, Control over lighting and proper placement of light fixtures in a room can minimize problems of reflections and glare from video display sereens.

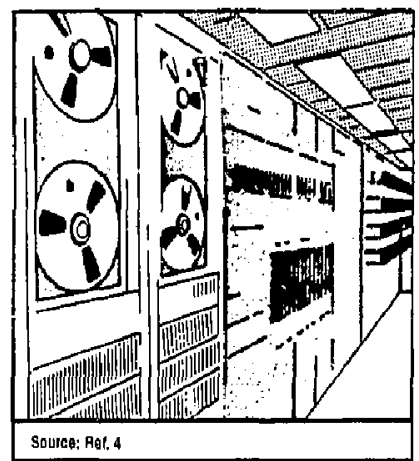

Exhibit 2,6.1 1.1ustration of Computer System in Controlled Envirommant, Highlighting Elfective Plscement of Light Fixtures, and Sound.Deadening ceiling Tiles

2.6.3.3 ELECTRICAL POWER REOUIREMENTS FOR COMPUTER SYSTEMS. Electricslly powered computers end their components are designed to operate from a clean, conslant supply of a.c. power. This a.c. power must be kept within manufacturer-specified tolsrances in order for equip. ment to opetate properly and sately. Power disturbances are a cominon oceurrence at computer sitas and are a major causs of malfunctions in computers. These distutbances fall in to five categories:

a. DECAYING OSCILLATORY TRANSIENTS, These are caused by the switching of power factor correctio, cepacitors and from other network load switching.

b. VOLTAGE SPIKES. These are caused by power network switchi' 19 , user equipment operation, and lightning.

c. UNDERVGLTAGES AND OVERVOLTAGES. These conditions of duration greater than $1 / 2$ cycle are caused by the application of heavy loads to the power line, by faults, and by the subsequent lag time of faulteclearing devices.

d. POWER OUTAGES. These conoivions of duration greater than one cycle are caused by fauls within the user netwerk of by a breakdown of utility powe; transmissicn mquipment,

e. NOISE. This noisp comes from sources external to the system and is injected into tho power lire. These sources include welding equipment, $X$-ray machines, and other sources which may gener the radio frequency (RF).

The effects of these disturbances must ba kept to a minimum within electrical wiring and prounaling designed for the computer system. Grounding systems silould incorporate the connept of a single point ground to minimize their affects. 


\subsubsection{SPECIFIC PRINCIPLES}

\subsubsection{ENVIRONMENTAL REOUIREMENTS FOR} COMPUTER SYSTEMS. Sice design for meintsinability and relliability of a computar system requires that reasonable control be maintained over the system's cperating environmant. The follawing points should by considered;

a. OPERATING TEMPERATURE. 65 to $75^{\circ} \mathrm{F} 118$ to $24^{\circ} \mathrm{C}$; temperature rate of change-3.6 $6^{\circ} \mathrm{F} / \mathrm{hr}$. $\left(2^{\circ} \mathrm{C} / \mathrm{hr}\right.$ ).

b. RELATIVE HUMIDITY. 40 to $60 \%$ non.condensing; humidity rate of change- $2 \% / h$.

c. AIR. An air distribution system should provide cool, well.filtered, humidified air with room air pressure kept higher than the oressure of adjacent areas to prevent dust infiltration. Windows and doors should be weather tight. Slowsoperating door closers should be suoided, Double glass is recommended for large window areas. Sorne equipment generates more heat than others and requires more cooling air. It is desirable to have atn efficient method for distributing and balancing the flow of air.

d. AIR FILTERS. Air clirculating through on air conditioning system and air entering a computer room should be filtered. Permbnent filters or combinetions of replaceable and permanent fiiters stould be used. Permonent fitters should be easily washable and in compljante with fire code standards. Other filter eansiderations include:

- High efficiency at low pressure drop.

- Trouble-free pperation.

- Elimination of downstream dirt during replacement.

- Minimum mairtenance.

- Simple installation.

- Particle.free air at min ínum cost.

Special air filtration is necesseary only where installations are exposed to corrosive gases, salt bir, or unusual dirt or dust conditions. If these conditions exist, an air filcration speciolist should be consulted. The recommented operating environment should filter ure air to 10 microns.

e. STATIC ELECTRICITY. Static electricity cen affect the aperationai characteristics of computer system cam. ponerts. Floor covering ingterial can confribute to the buildup of high static electrical charges which result from the motion of people, carts, furniture, etc. in contact with the floor material, Static buildaup on the floor can be minimized by taking the following precautions:

(1) Use floor tile or otfier floor surface material which has a surface resistance of $0.5 \mathrm{megohm}$ (minimum to 20,000 megohms (maximum) at operating limits of 20 to $80 \%$ relative humidity and temperatures of 60 to $90^{\circ} \mathrm{F}\left[15\right.$ to $25^{\circ} \mathrm{C}$, measired between floor surface and building ground.

(2) Use carpeting of the type designed to minimize the effects of static electricity. Carpeting may have a bras mesh woven throughout the becking or be issigned to prevent build-up of static through special ionized nyion filaments.

(3) Adequately ground flooring consisting of metal panels or flooring with metal edges.

f. ELECTROMAGNETIC INTERFERENGE IERII. Sources of radiation, such os highpower radio frequency
(RF) or pulse transminers, which are in proximity to a computer system or its component;, mey affect system operation. The effect of these emissions can be mini. minimized through tacility designs and equipment installations which incorporate good shledding prectices. Design and installation practices should include:

- Grounding window screens and other large metal surfaces.

- Using Interconnection cables with a grounded shisld,

- Using additional grounding within system cabinatschassis to cabinet.

- Building a screened room or EMI enclosure.

- Posting signs stating that use of EMI generators (e.g., radio transmitters) is prohibited within a designated area,

g. ACOUSTIC NOISE. Facility dasigns should minimize acoustic noise which may interfere with maintenance opetations by:

- Grouping high level noisa devices (disk and magnetic tape drives and isolating them in acoustically damped rooms.

- Designing walls and i eilings using acoustic materials and allowing for use of sound-absorbing partitions.

- Using double windowis (wwo panet of glass) where offices or other personnal work areas are adjacent to the computer system installation.

h. LIGHTING. Vides display serminals and sand-sione computers utilize cathode ray tubes as autput viewing devices. To enable a technician to visw a display, sur. rounding room illumination may need to be reduced or controlled, In particular, reflections and glare from overhesd light stould be considered in room designs.

\section{2,6 4,2 ELECTRIC POWER REOUIREMENTS FOR}

COMPUTER SYSTEMS. Electrical power stability in terms of voltage and frequency and a well-designed distribution system employing proper grounding techniques contribute to the maintainabifity of a camputer system and its com. ponents.

a. VOLTAGE AND FREQUENCY. Line voltage disurbances greater than $\pm 10 \%$ from nominal and a duration areater than $y$ crcle at the input to an operating compyler system may cause systen molfunctions or 6rrors. Alesepted tolerances are $\pm 10 \%$ for a.c. voltages and $\pm 2 \%$ for feequency at $60 \mathrm{OHz}$.

b. SYSTEM POWER REOUIREMENTS. The available supply of a.c. power should bc atequate to handle power loads of the contemplated inmputer system and any loads which are likely to be in Josed by future expansion.

c. POWEA tRANSFORMER. A separale power trans former is advisable for the computer svstem. Transformers specifically designed for computer systems offer noise suppression through the use of an electroslatic shieit.

d. POWER FACTOH. A power factor of greater than 0.85 is desirable for : fully operational computer system.

e. MAINLINE CIRCUIT BREAKER, The feeder lines supplying power to the computer system should be protected by a mainline circuit breaker and be accessibie to operating peroonnel. A light should indicate when power is "DN." 
t. POWER RECEPTACLES. Power ling should terminate, where possible, in National Electric Manufacturers Association (NEMA) receptacles. To minimize the effects of ground loops and other forms of nolse induction, receptacles should not heve the salety ground connected to the conduit tabs internal to the socket. If safety ground is not isolated from conduit by a constent volsage isolation transformer, efforts should be made to isolate ground from conduit and neutral throughout the power distribution system. Required grounding s hould be made at the service entrence.

g. PHOTECTIVE OR SAFETY GROUND, The protective or safeiy equipment ground is a green covered conductor in a multi-conductor cable and is used to prevent the build-up of dangerous voltages on equipment and provides protection for per:onnel. It assures that any short circuit between a power phase and the cabinet will draw enough current to trip the circuit's protective device immediately, rather than raise the potential of the equipment to a dangerous level, A single-point ground system should be used and all "gretn.wire" grounds tied together at the circuit treaker load center. The load center panel should have a copper ground bus to which all equipment grounds can be attached.

5. CONDUIT AND PROTECTIVE GROUND. Conduit and protective ground are often connected together by the NEMAA receptacles or at the circuit breaker neutral bus bar. Attempts should be made to isolate conduit ground from protective ground and a,c. neytral. Idaally, the equipment frame ground should isolated from the protective ground and a.c. neutral all the way baek to the building's main ground stake.

i. A.C. NEUTRAL. A.C. neutral must not be confused with protective ground and never be connected to it except at the building's main electrical service en trance. A.C. neutral must not be connected to equipment on conduit ground. A.C. neutral must be isolated from all building structures, equipment frames, cabinets, panels, and grounds if it is to prevent unwanted signals and noise from being introduced in the computer system.

j. CABINET OR RACK GROUNDS. Cabinets or racks bolted together should have their frames electrically tied togsther using \#4AWG $\{5 \mathrm{~mm}, 0.2$ in. $\}$ copper eonductor or silver copper mesh straps.

$k$. EARTH CONNECTIONS (Groundl. The resistance between the site grounding structure and the actwal earth must be maintained at less than 10 ohms. A copper ground rod of greater than 0.626 -inch diame ter should be driven at least 12 feet into the soil or deeper if subsequent measurements indicate that the impedance axceeds 10 ohms. Chemicals (e.g., common sale, mag. resium sulphate) and petiodic watering may need to be added to the soil surrounding the rod within a thres-foot dismetry and to a depth of two teet. A maintenance schedule to measure ground inpedance should be mointained. 


\subsection{PERSONNEL}

3.1 Engineering Anthropometry in ths Desigr for. Maintainability 
PERSONNEL 3.0

\subsubsection{INDEX}

3.1.2 DEFINITION

3.1.3 PRINCIPLES. $\ldots \ldots \ldots \ldots \ldots \ldots \ldots \ldots \ldots \ldots \ldots \ldots \ldots \ldots \ldots \ldots \ldots, 3.1,3$

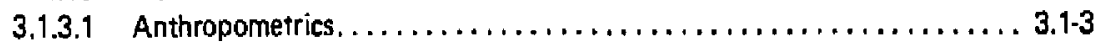

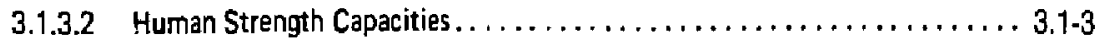


PERSONNEL 3.0

ENGINEERING ANTHROPOMETRY IN

THE DESIGN FOR MAINTAINABILITY 3.1

\subsubsection{DEFINITION}

Enginuering anthropometry, as used in these guidelines, refers to the application of physical measurement methods to human subjects with respect to such characteristics as size, mobility, and streigth.

\section{NOTE}

The dimensions presented in this section will directly impact workspace design for maintainability (Section 2.1) and should be used in conjunction with those principles. 


\subsection{PAINCIPLES}

3.1. ANTHROPOMETRICS. Plant systerris and facilities should be designed to aciommodate the 5th to the 95th percentile technician, Mijor bady-size dimensions are presented below:

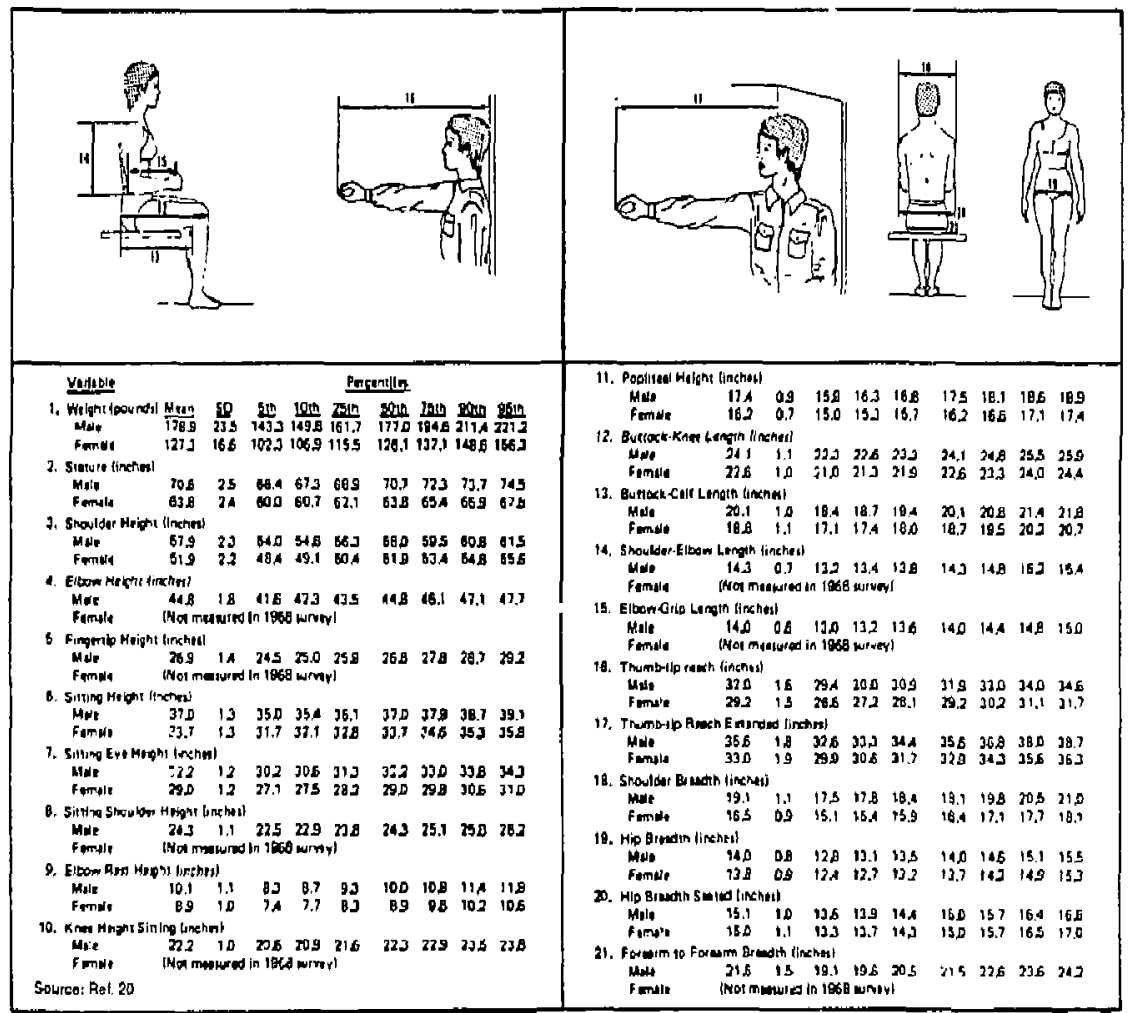

Exhibit 3.1.1 Power Plant Anthropometric Data Base

\subsubsection{HUMAN STFENGTH CAPACITIES}

3. Equipment systems and facilities should be designed so that excessive strength demands are not made on the technician.

b. Maintenance tasks should not require weigh::" fting yalues which excend the following values:

\begin{tabular}{|c|c|}
\hline $\begin{array}{l}\text { Height of Lift } \\
\text { From Ground }\end{array}$ & $\begin{array}{l}\text { Maximum Weight } \\
\text { of Item }\end{array}$ \\
\hline $1 \mathrm{tt}$. & $65 \mathrm{lths.}$ \\
\hline $2 \mathrm{tt}$. & Qu lbs. \\
\hline $3 \mathrm{tt}$ & ủ lós. \\
\hline $4 \mathrm{ft}$. & 50 lbs. \\
\hline $5 \mathrm{th}$. & 35 lbs. \\
\hline stt. & 29 lbs. \\
\hline \multicolumn{2}{|c|}{$\begin{array}{l}\text { NOTE. The above values assume that the item } \\
\text { to be lifted is of convenient configuration (not } \\
\text { more than } 15 \text { inches long or } 12 \text { inches nigh, and } \\
\text { with acceptable handles or grasp areas). For a } \\
\text { wwo-person lift, the values providgd above can be } \\
\text { daubled. } \\
\text { source: Ret } 20\end{array}$} \\
\hline
\end{tabular}

Exhibit 3.1.2 Maximum Weignt-Lifting Values 
c. Push and pull torces required by technicions should be within the following limit:

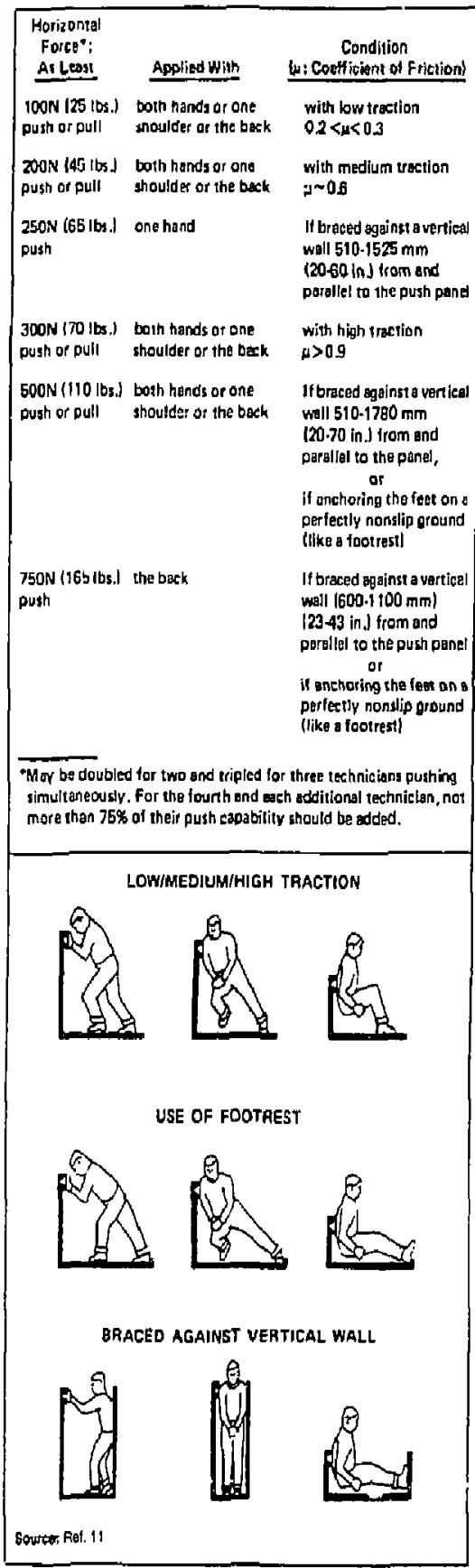

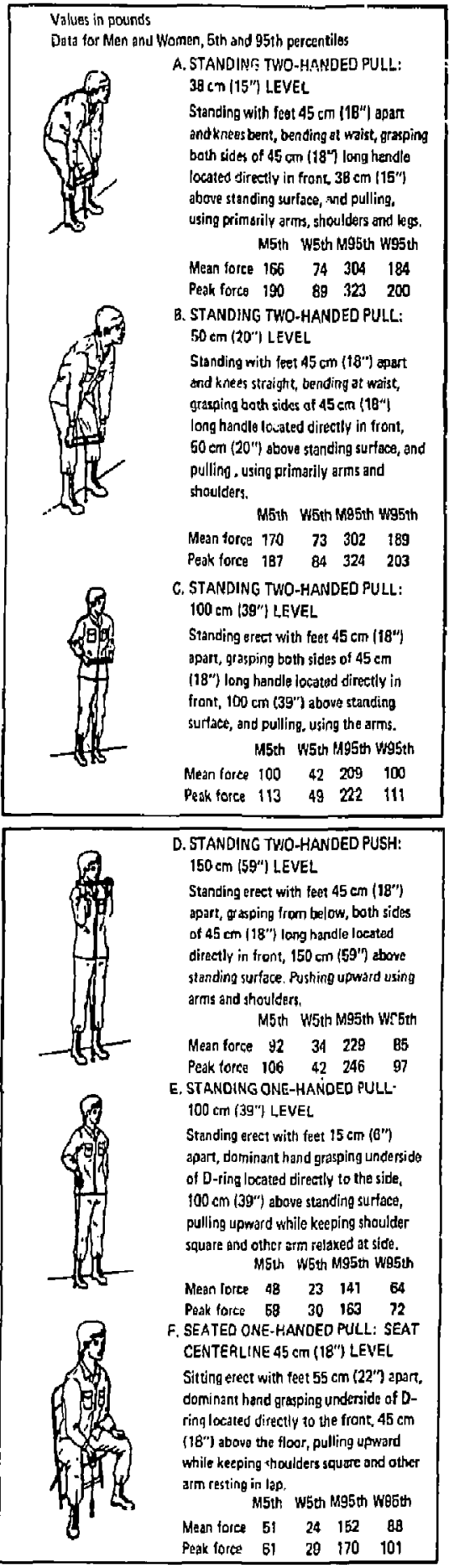

(Exhlbit 3.1.4 Conlinued on naxt pagge) 


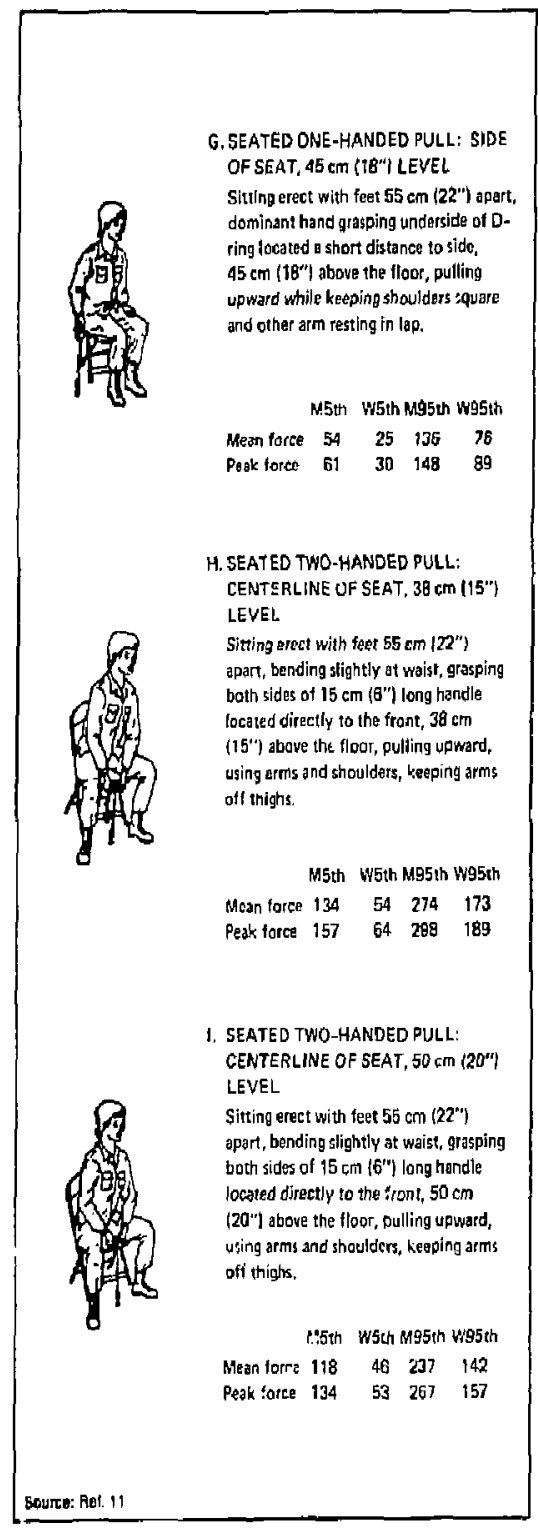

Exhlbit 3.1.4 Maximum Pull Forces tor Men and Women (5th and 95th Peicentiles)

d. Alm, hand, and thumb-finger strengths required of uchnicians should be within the following limits:

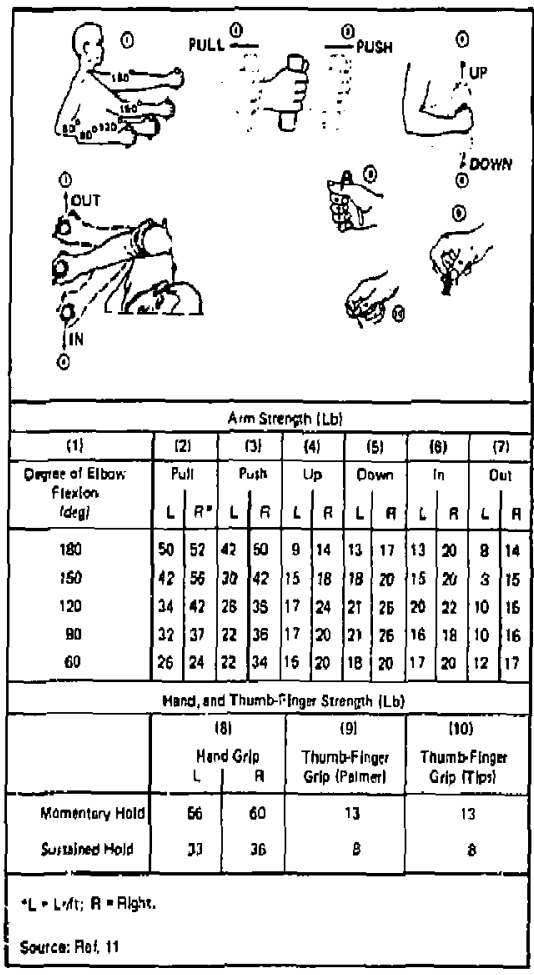

Exhibit 3.1.5 Arm, Hiand, and Thumb Finger Strength [Sth Percentile, Mals]

e. Log strengths requined of technicians should be within the following limits:

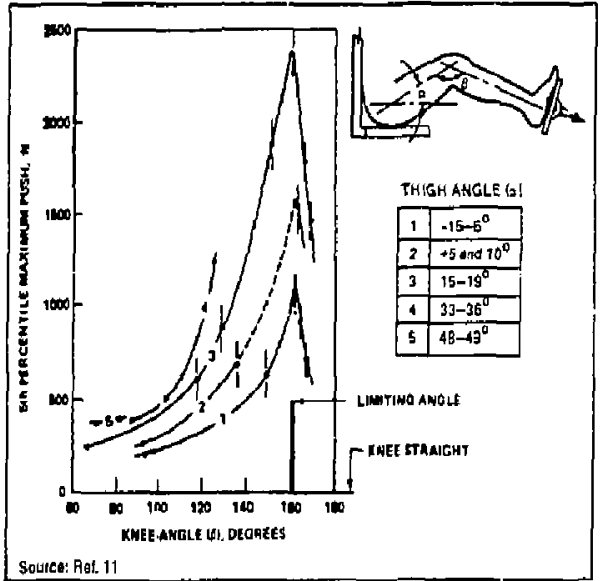

Exhibit 3.1.5 Leg Serength of Various Knee and Thigh Angles (5th Percentile, Male) 
3.0 PERSONNEL

3.2 Environmental Conditions and Constraints Affecting Maintajnability 
PERSONNEL 3.0

ENVIRONMENTAL CONDITIONS AND

CONSTRAINTS AFFECTING MAINTAINABILITY 3.2

\subsubsection{INDEX}

Page

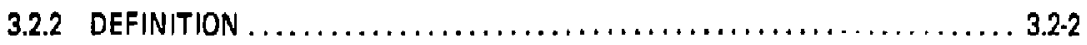

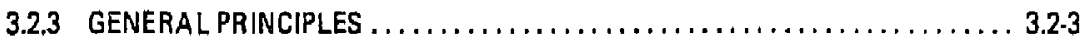

3.2.4 SPECIFIC PRINCIPLES $\ldots \ldots \ldots \ldots \ldots \ldots \ldots \ldots \ldots \ldots \ldots \ldots \ldots \ldots \ldots, \ldots, 2-4$

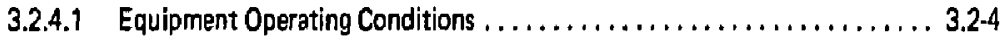

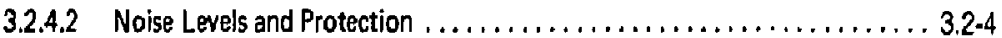

3.2 .4 .3 Vibration Levels and Protection .......................... 3.2-5

3.2.4.4 Lighting Levels and Protection ............................ 3.2-5

3.2.4.5 Temperature and Humidity Levels and Protection . . . . . . . . . . . . . 3.2-6

3.2.4.6 Nuclear Radiation Levels and Protection...................... 3.2-6 
PERSONNEL 3.0

\section{ENVIRONMENTAL CONDITIONS AND}

CONSTRAINTS AFFECTING MAINTAINABILITY 3.2

\subsubsection{DEFINITION}

Environmental conditions and constraints, as used in these guidelines, refer to certain aspects of the total system within which maintenance is performed and external to the equipment itself that can affect task performance of the technician. These conditions and constraints originate from the following sources: temperature, humidity, noise, vibration, illumination, and radiation.

\section{NOTE}

No attempt is made in these guidelines to cover all aspects of environmental factors that affect maintainability. The intent of the guidelines is to emphasize human tolerance limitations and recommended levels for environmental factors as they are significant to maintainability. 


\section{GENERAL PRINCIPLES}

32.3.' Systems should be designed to accommadate deviations from specified tolerable conditions. These deviations may ressult in:

a. The $r$ ad for using ; rotective clothing, devices, etc. which may affect the mability and weressibilify of the technician.

b. The need for increased mainteinability because of reduced equipment reliability.

c. Uts of procedures which require longer maintenance times. v. Conditions that ceuse increased errars, oversights, etc. which are detrimental to ove ll system perlormance.

3.2.3.2 In the design of systems for maintainability, the tollowing environmental influances must be taken into consideration:

a. Effects from the natural or geographic environment.

b. Specitic subsystem effects, muterials, or elem ws such as vibration sources, pressure and temperature from steam lines, toxic gas discharge, radiation, etc.

c. The cumulative, conflieting, or interseting effects of environmental influences in the final and full system configuration. 


\section{2 .4 SPECIFIC PRINCIPLES}

3.2.4.1 EOUIPMENT OPERATING CONDITIONS. Unsheltered equipment for outdoor use should be deseigned to operate to the following tolerances. (Note: These tolerances have been derived for aeronautical equipment and are meant to serve only as reference benchmari:i.)

a. TEMPERATURE

(1) Stendard area:
- Cperating:
-29 10 $52^{\circ} \mathrm{C}\left(-20\right.$ 10 $\left.125^{\circ} \mathrm{F}\right)$.

- Nonoperating; -54 to $54^{\circ} \mathrm{C}$ (-65 to $130^{\circ} \mathrm{F}$.

(2) Cold weather area:

- Operating:

$-40^{\circ} \mathrm{C}\left(-40^{\circ} \mathrm{F}\right)$ If operator is unsheiltered,

- Operating: $\quad-54^{\circ} \mathrm{C}\left(-65^{\circ} \mathrm{F}\right)$ if oporator is sheitered.

- Non-operating: $-62^{\circ} \mathrm{C}\left(-80^{\circ} \mathrm{F}\right)$ for 3 days and achieve ratad capacity after 30 minutes pre-heating and walm. up.

(3) Desert and trepical areas:

- Operatiny: $\quad 52^{\circ} \mathrm{C}\left(125^{\circ} \mathrm{F}\right)$.

- Non-operating: $71^{\circ} \mathrm{C}\left(160^{\circ} \mathrm{F}\right)$ for 4 hours per day ir,definitely. b. HUMIDITV:
(1) Operating:
Up to $100 x$ at $37^{\circ} \mathrm{C}\left(100^{\circ} \mathrm{F}\right)$ including condensation.
(2) Nonoperating: Up so $100 \%$ including conden- sation.

c. SOLAR RADIATION:

Endure a wolar intensity of 369 QTU per square ioot, per hou.r for a period of 4 hours (minimum) a. $52^{\circ} \mathrm{C}$ $\left(125^{\circ} \mathrm{F}\right)$.

d. MiND:

Withstand wind pressures up to 50 pounds per square foot of projected surface, eithe: empty or under load.

?. OTHER CONDITIONS TO BE CDNSIDERED:

(1) Salt atmosphere, as encountered in coastal regions or Jcean transport,

(2) Sand and dust, as encountered in desert regions.

(3) Insects and fungi, as encountered in the tropics.

(4) Ice and snow loads,

(5) Rutinfall.

\subsubsection{NOISE LSVELS AND PROTE:TION}

a. Noise levels should be minimized wherever practical and should never exceed the following limits:

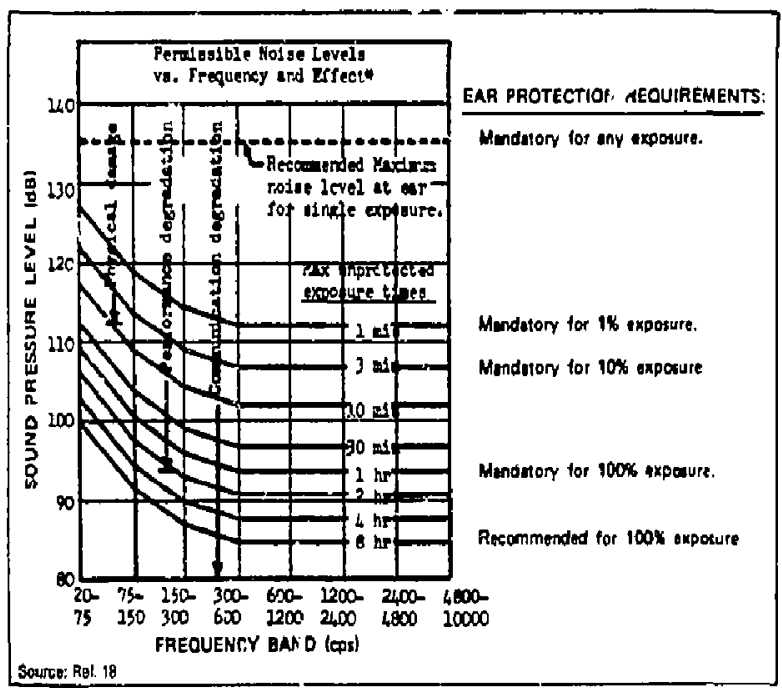

Exhibit 3.2.1 Noite Leval Limits

b. Warnings shouid be posted to prevent unprotected technicians from entering areas with noise levels above 130dt, even for short periods of time.

c. When possible, trealy moving parts which contribute to noise should be dampened or eliminated.

d. Where it is not possible to design equipment to oliminate noise production, the amount of noise trans. mitted should be reduced by:

(1) Increasing the distance between the work area and the noise wurce.

(2) Enclosing noise-producing sources.
(3) Placing noise-producing sources on mounts that reduce sibration.

(4) Soundproofing the work area 10 reduce vibration and reverberation.

(5) Designing auditory alert and warning signals to be at least 10db above maximum ambient nolse levels.

e. Where noise levels cannot be teduced by equipment or system design, technicians should be provided with suitable car protection. 


\subsubsection{VIBRATION LEVELS AND PROTECTION}

a. Vibuation should be mirimized whenever practical and should never gxcaed the lallowing limits:

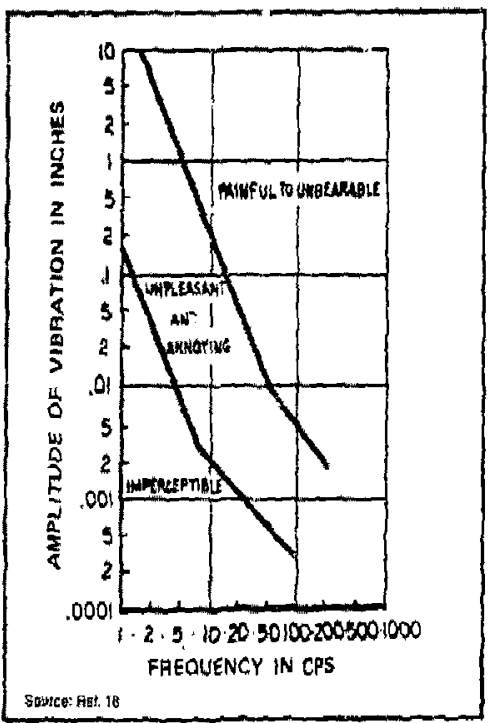

Exhibit 3,2 Vhreigan Leval Limits

b. Equipment stould be designed to resist vibration and stock or to be isolated trom such action by shook absorbers, eushioned mountings, springs, of fluid ctoutings.

c. Ho:ating equipment elements should be properly balanced.

o. Seated technicians are most a theted by vertical vi. brations; prone technieians by horizontal vibrations. Oanairg materials or cushions should be provideo for standing or seated technicians.

e. For sagted technicions, vibrations of 3-4 aps should be avoided since this is the resonant frequency for $\mathrm{B}$ person seated.

f. For critical maintenance operations which require letter of digit discrimination on disnlays mounzed on machinety that is not vibration-free, display size andior itumination should to incseased to improve reading speed and accuracy.

\subsubsection{LIEHTING LEVELS AND PROTECTION}

a. Adequate light levels should be provided for the lectho niçian to perform in all work areas. Recomintetended levals are presented below:

\begin{tabular}{|c|c|c|}
\hline Light Levet & Tuk Condtions & Type of Lighting \\
\hline 150 of more & 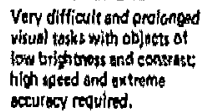 & $\begin{array}{l}\text { Supplemantery, sgocial } \\
\text { fixturts tuth By dets } \\
\text { Imons. }\end{array}$ \\
\hline 50 or mote & 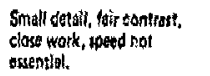 & Susplementery. \\
\hline 25 or marp & 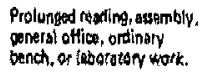 & $\begin{array}{l}\text { Locai lighting; zolling } \\
\text { ilxpures ditectly over. } \\
\text { hetos. }\end{array}$ \\
\hline 10 or mora & 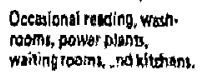 & General lighting. \\
\hline bot mort & $\begin{array}{l}\text { No dotall whion, stirwiys, } \\
\text { or eupply warchoues. }\end{array}$ & $\begin{array}{l}\text { Gonerel or wipplemantary } \\
\text { Ifghing. }\end{array}$ \\
\hline
\end{tabular}

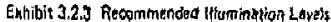
(in Foor-Cundles at the Work Point)

b. Lighting should be arranged in such s way as to provide an equal level of illumination over the ontitre work area. Tc help determing task lighting requiremenths, the following brightness ratios should not be exceeded:

\begin{tabular}{|c|c|}
\hline Ases & $\begin{array}{l}\text { Luminance } \\
\text { Ratio }\end{array}$ \\
\hline $\begin{array}{l}\text { Tagk orda varsus adjacent darker } \\
\text { omplindinge }\end{array}$ & $3: 1$ \\
\hline $\begin{array}{l}\text { Task area versus adjacant lighter } \\
\text { surreundit ; }\end{array}$ & $9: 7$ \\
\hline $\begin{array}{l}\text { Tayk arte werwus more remoty } \\
\text { torker w Whess }\end{array}$ & $10: 1$ \\
\hline $\begin{array}{l}\text { Tayk arep versus moie rethote } \\
\text { lighiof suifaces }\end{array}$ & $1: 10$ \\
\hline $\begin{array}{l}\text { Luminaties versus surtaces } \\
\text { adjacant to them }\end{array}$ & $20 \div 1$ \\
\hline $\begin{array}{l}\text { Anywhere within hormal tiold } \\
\text { of tyow }\end{array}$ & $40: 1$ \\
\hline Source: Rat. 10 & \\
\hline
\end{tabular}

Exhibie 3.2.4 Maximuin Task Ares Luminance Ratios

c. Giare, wsually due fo the presence of direct or rofiected light within the field of vision, should be avaided by:

(1) Using surfaces and paints which diffuse rather than reflect light

(2) Avoiding bright surfaces wittin the working visual field.

(3) Avoitling bright light soures within $60^{\circ}$ of the central visual tieldo

(4) Placing lights high and ditectly above the work area.

(5) Using indirect lighting wherever pasibie.

(a) Using diffusoo lighting where possible, speed high and close together. 
(7) Arrenging light sourtes to avoid equal lighting and viewing angles.

(8) Providing shis/ds, hoods, end visors to reduce or prevent glare.

(9) Using numerous low intensity sources rather than a few intense ones.
3.2,4.5 TEMPERATURE AND HUMIDITY LEVELS AND PROTECTION. The environment within which the maintenance technisian must work should not exceed the tolerance limits provided balow:

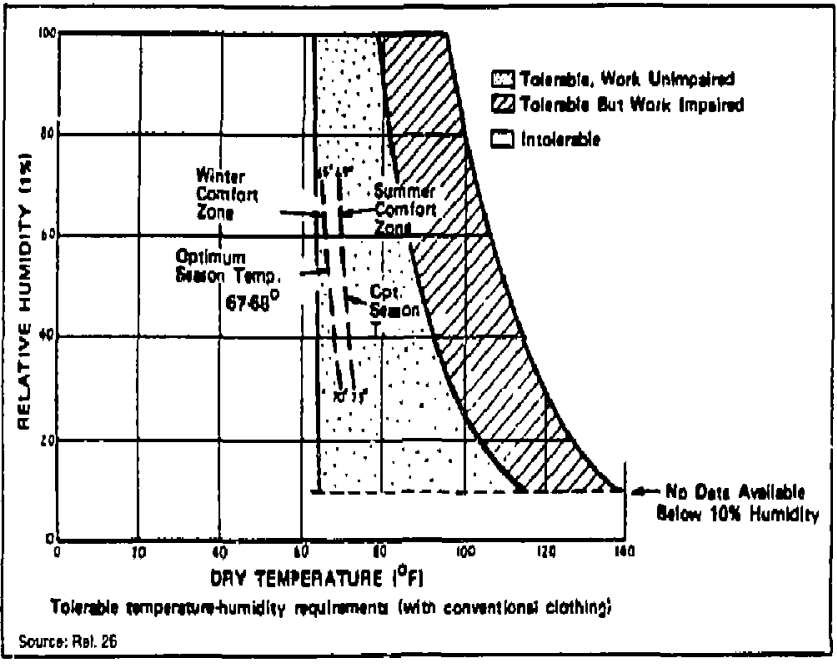

Exhibit 3.2.5 Temporuture and Humidity Tohnanse Limits

\subsubsection{NUCLEAR RADIATION LEVELS AND PROTECTION}

a. Long-hendled 10ols, remotely operated controls, and similar approaches should be used, where feasible. to separate meintenance tethnicians from soures of radiation to the maximum extent possible.

b. Equipment located in radiosetive areas should be designed to accommodate maintenance technicians wearing protective clothing.

c. Equipment located in rediogctiva work areas should be designed to allow complating maintenance work afficiontly given the rediced manual dexterity because of protective clothing.

d. The designs for facilities and equipment which are located in radioactive areas should optimize speed of maintenance operations to minimize stay times and associated exposure levels.

e. Traffic routes near radjation sources or through po. tentially radioactively contominated portions of the facility should route pretsonnel oway from radiation exposure sources as much as possible.

f. Access openings associated with equipment in radio. active areas should be sitec to allow convenien' and speedy entry and exit by technicians who span the anthropometric range while being burdened by protective clothing.

g. Permanent or fixed access provisions shculd be avgilable to auipment which is located in radioactive work areas to eliminate radiation exposure incurred by erecting tamparary accesses, e.g., scaffolding, shielding. h. Control and storage of contaminated debris, work aids, spare parts, etc. should be adequate to prevent hindrance to the mobility of personnel and vehicles.

i. Storase provisions for contaminateu equipment and stores used during outages should be adequate to prevent these items, from obstructing nomal passage. ways for personriel and vehicles.

j. Normally contaminated work areas or facilities should be sited and configured to allow ample roorn for radiation waste barrels, step-off pads, contaminated clothing collection barrels, cordon stands, ttc.

$k$. Remote viewing techniques such as closed circuit T'V should be consideresd tor coordinating mainenance ectivities with a minimum of exposure to radiotion on the part of those who support migintenence, i.e., 0.perators, OC inspectors, etc.

I. Use of viewing provisions (that block ardiation exprosure) in normally opaque shielding walls should is consijered to protect personnel who oversee maintt nance work.

7T. Protective slothing and assuciated gear shouls be designed to withstand mulri-stress environments, e.g., heat and radiation.

n. Failitit; should be available to ensure an adequate supply of clean, decontaminated protective clothing. especially during peak worklond periods $\{0,9$. laundering facilities for wasthable gear, store focilitiex icr issue of ane time use dispossble gear).

a. Pracedurs or other maintenance information sources should be readily evailable to the technician working in contominated areas. Whera procedures and forms 
must make the transition from "hot" to "clean," copies should be used so that contaminsted paper stays behind. A copy machine, strategicaliy located at the boundery of the "hot" area should also be considered. p. Both inhouse and contractor personnel assigned to wo:k In radioactive areas should receive sufficient training, including moskup rehearsals, to ensure maximum task performance and minimum stay times, 
3.0 PERSONNEL

3.3 Maintenance Information 
PERSONNEL 3.0

MAINTENANCE INFORMATION 3.3

3.3.1 INDEX

Page

3.3.2 DEFINITION $\ldots \ldots \ldots \ldots \ldots \ldots \ldots \ldots \ldots \ldots \ldots \ldots \ldots \ldots \ldots \ldots \ldots, 3.3 .2$

3.3.3 GENERAL PRINCIPLES $\ldots \ldots \ldots \ldots \ldots \ldots \ldots \ldots \ldots \ldots \ldots \ldots \ldots, \ldots \ldots .3 .3$

3.3.4 SPECIFIC PRINCIPLES $\ldots \ldots \ldots \ldots \ldots \ldots \ldots \ldots \ldots \ldots \ldots \ldots \ldots \ldots \ldots, 3.3-4$

3.3.4.1 Troubleshooting Procedures . ............................

3.3.4.2 Mainterance Manuals/Job Instructions/Procedures. . . . . . . . . . . . . 3.3-4 
PERSONNEL $\mathbf{3 . 0}$

MAINTENANCE INFORMATION 3.3

\subsection{DEFINITION}

Maintenance information, as used in these guidelines, refers to procedures, manuals, instruccions, and job aids (e.g. flow diagrams, schematics, drawings, decision trees) used by the mainte, rance technician to perform his/her job.

\section{NOTE}

No attempt is made in these guidelines to identify or summarize the numerous military and civilian specifications and guides which address the preparation of instructional materials. 


\subsubsection{GENERAL PRINCIPLES}

3.3.3.1 Ideally, every maintenance operation should be covered by a procedure(s) prepared and tested during the development of the system. Without procedures, maintenance effectiveness will be reduced because of excessive trial-and-error pettormance required by the technician.

3.3.3.2 Information contained in procedures, manuals, instructions, and job aids should not be excessively redundant among the maintenance documentation and with information the technician already possessas.

3.3.3.3 Wainienance information should be compatible with the capabilities and limitations of the perzonnel whe will be !ssing it and with the anticipated environmental conditions, s ?uipment characteristics, and task requipe. ments.

3.3.3.4 Maintenance instruction should not require the techniciarn to work near dangerous voltages or delicate components. Procedures which require work to be jet formed in areas of contamination should always specity the protective equipment and measures necessary to work sately in this environment.

3.3.55 Maintenance information should be based on a systematic analysis of the tasks which are rezuired in the performance of the maintenance activity.

3.3.3.6 Maintenance information should be prepared and/or reviewed by perso nel who are knowledgeable in technicues of instructional preparation and the technical subject covered by the information.

3.3,3.7 Maintenance information should be validated by means of fieid tests to ensure clarity, comprehensiveness, and effectiveness.

3.3.3.8 Job performance aids (JPAs) should be considered for use by maintenance technicians in highly complex tasks

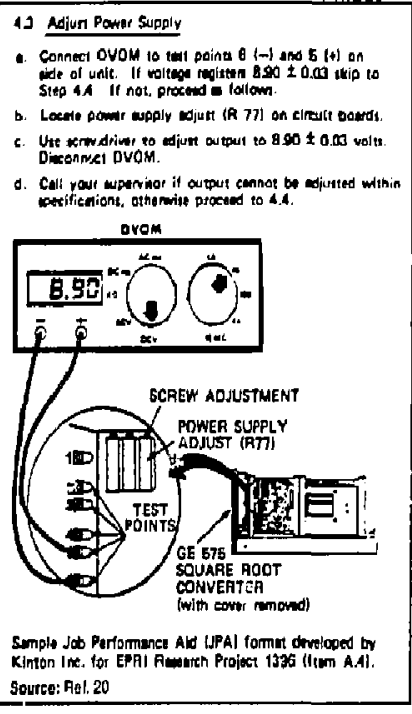

Exhibit 3.3.1 Exmplo of Jab Pertormmence Aid L."A) or major tasks with imporlant safety or availability implications.

3.3.3.9 Maintenance information should be kept current with equipment. Whenever new equipment or modifications to equipment are introduced, old maintenance information should be revised to reflect these changes.

3.3.3.10 Following are some of the more important features that apply to preparing main tenance procectures:

g. Maintenance procedures should be as brief as possible without sacrificing necessary information.

b. Procedures should provide unambiguous results.

c. Required tolerances should be realistic for the level of maintenance being performed li.e., fiets tolerances, shop or factory tolerances, new part tolerances, replacement part tolerances, in-senvice tolerances].

d. Procedures should be easy for the technician to follow. ldeas and woins should be as simple to comprehend as possible. Procedures sometimes can be simplified by designing test equipment to do some or all of the progremming or sequential operations.

e. The number of decisions required to be mare by the technician should be kept as few as reasonable and as straightforward as possible.

f. Exact, step-ty-step procedures should be used (compared to narrativesl. This form will allow inexparienced technitians to learn the procedure easily.

\begin{tabular}{|c|c|}
\hline USE THIS & NOT THIS \\
\hline Assom bling Injactor Tepping Tool & Aumbling Injoctor Topping Tool \\
\hline 1. Replace defective part. & $\begin{array}{l}\text { First, replase the defective part } \\
\text { from supply, Install nut and }\end{array}$ \\
\hline $\begin{array}{l}\text { 2. Instell nut and washer on } \\
\text { hane.tap shank. }\end{array}$ & washer on hand. Iap shank, \\
\hline 3. Install rollpin in nut. & $\begin{array}{l}\text { Next, place the rollpin in the } \\
\text { nut. Upon completion, check } \\
\text { the tapping tool lar proper }\end{array}$ \\
\hline $\begin{array}{l}\text { 4. Check tapping tool lor } \\
\text { procer operation. }\end{array}$ & performance. \\
\hline Source: Re!, & \\
\hline
\end{tabular}

Exhibit 3.32 Example of Step-oy-Step Instruction

g. Each procedure, if necessary, should explain how to start up and shut down the equipment.

h. Systematic troubleshooting procedures should always be provided for the technicien. Failure to do this may result in the technician following inefficient or even dangerous methods.

i. Pages should be numbered "__ of ___ "for recognition of missing pages of a procedure.

j. Requirentrents should be stated at the outset of a procedure for the number, level, and types of mintenance personnel required to accomplish the tasks described by the procedure.

k. All applicable documents pertaining to a procedure should be listed in the initial portions of the procedure, to include list of tools required, list of parts and materials required, safety precautions, and related reference documents (e.g., specifications, drawings).

I. Procedures shuuld be as self-contained as possible. The content and structure of procedures should muti. mize the need for con sulting other references. 
3.3.3.11 Maintenance or test suppor. functions, rests or stands on which technical orders, menuals, or procedures should be provided when required. When permitted by dessign requirements, such res:.: or stands shall be part of the basic unit, rack, or console chassis.

Maintenance or test practices, procedures, or conditions that may result in hazards or injury to personnel or damage to equipment should be presented in the form of caution statements.

Maintenance or test practices, procedures, or conditions of special interest or importance that will aid in or simplity job perior nance should be presented in the form of note statements.

Caution and note statements should:

a. Be located with the material to which it applies.

b. Stand out on a page full of other material.

c. Attract the usere's eye, but not be overpowuring.

त. Be apparent to the user no matter what method is used to access infc:mation and enter the masual.

e. Contain all necessary irrformation.

f. Be easy to read and understand,

Caution statemer ts shc, id include ihe following information, when applicable:

a. The specitic nature of the hazard.

b. The steps to be taken to avoid or minimize the hazard.

c. The iocation or source of the hazard.

d. The consequences of failing to heed the warning or caution.

e. Corrective or first-aid actions to be taken if the hazard materializes.

f. Time considerations when critical.

Maintenarce or test information which should be hrought io the user's attention.

Caution statements should prexede and appear on the same page as the text or orocedural steps to which they apply,

A note statement should always preceed a procedural statement 10 which it applies.

Caution and note statements should not contain procedural steps.

When it is necessary to precead a procedural step with both caution and a note statements, the caution statementss| shourd appers first.

General caution statement(s) should be placed at the Leginning of the procedural steps, or on a "Precautions" page at the frorit of the procedure or manual.

\subsubsection{SPECIFIC PRINCIPLES}

3.3.4.1 TROUBLESHOOTING PROCEDURES. Fault ijolation is perhaps the most demanding maintenance operation for a techniciar. to perform because it involves complex diagnostic probiems and decision processes. a. Troubleshooting procedures should follow a systematic strakegy. A troublesshoating method, common to diagnosing electronic equipment failures, is presented below in a summary form.

(1) Step i-Visual checks for clues such as smoke, 'oose connections, or missing or damaged parts.

(2) Step 2-Operational checks by evaluating readings from ineters, gauges, and other indicators. Check. lists are typically used for this step.

(3) Step 3-Intermediate checks to isolate the malfunction to a particular stage, i.e., unit, assembly. or component.

(4) Step 4-Systematic checks by an ordered inspection of, for example, circuits within a component.

Decision trees a id computer-aided techniques are other effective troubleshooting approaches.

b. When available, probability date should be used for developing troubleshooting procedures.

c. Short sentences with concise and unambigucus language should be used.

d. When applicable, special diagrams should be provided for the technician which heip in analyzing symptom pacterns by indicating which components affect each system output for each step in an operational or intermediate check.

e. Double check liets should be provided for an independent observer to check specially critical axtivities.

\subsubsection{MAINTENANCE MANUALS/ JOB IISSTRUCTIUNSTPROCEDL'AES}

a. Content should contain only job-relevant information.

b. Instructions stould be preparad specitically for each organizational level li.e., field, shop, facturyl of mainte. nance and ach skill level of maintcnance technician required to perform the work rather than for all levels being combined.

c. Nimenclatur: that is ised on the equipment should bo lised in the instructions.

d. Instructiors should contain an index with key word: the technician is likely to louk for when locating a particular item in the instructions.

e. Photographs or high-quality drowings should be used to clarify written instructions or is provide extra information that the technician may require.

f. Tables with instructions on how to use thern should be used for presenting data,

9. Diagrams to describe processes and interrelationships should be used. 
h. Components shown in data flow diagrams should be in the same selative position s'at thev are in the equipment.

i. Foldout pages should he avoided or kept to a minimum.

j. Tagging and switching instructions should be listed in the initial portions of the procedures.

k. Checklists and/or data tables should be provided for lengthy prerequisites, tests, or caleslations.

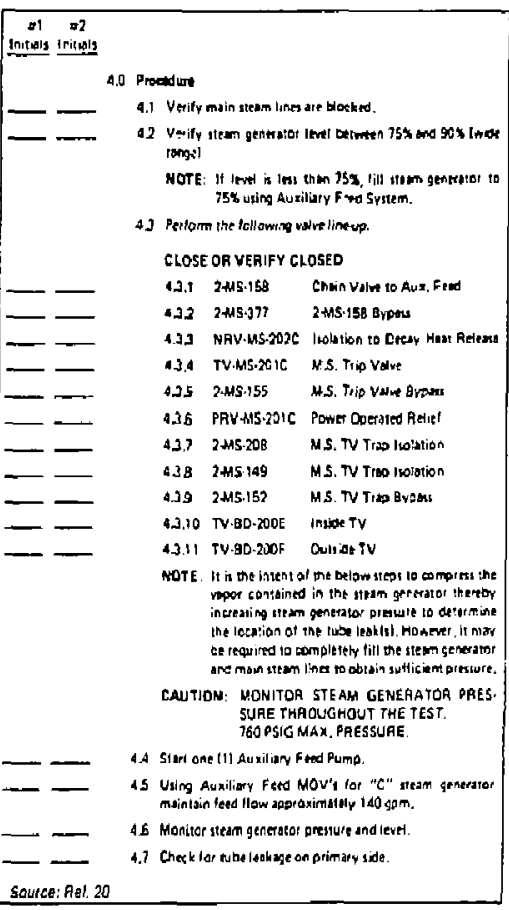

Exhibit 3.3.3 Examale of a Double Check List tor an Independent Observer

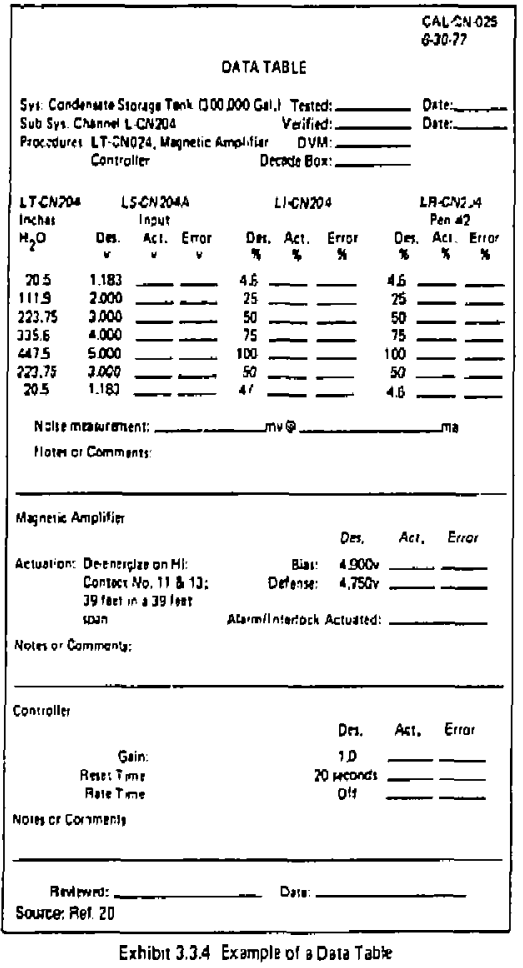

I. Procedures and insuructions should be identified by:

- Titie

- Applicability (if nac title)

- Revision date

- Approval status

- Indexing designation or code.

m. Procedures and instructions should be self-contained documents, as much as possible, to avoid the need for shitting back and forth between the procedure and other procedures or supporting documents. 


\subsection{PERSONNEL}

\subsection{Design Plan and Schedule for Maintainability}


PERSONNEL 3.0

DESIGN PLAN AND SCHEDULE FOR MAINTAINAEILITY 3.4

3.4.1 INDEX

Page

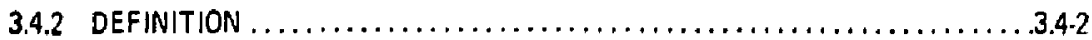

3.4.3 GENERAL PRINCIPILES $\ldots \ldots \ldots \ldots \ldots \ldots \ldots \ldots \ldots \ldots \ldots \ldots, 3,4,3$

3.4 .4 SPECIFIC PRINCIPLES $\ldots \ldots \ldots \ldots \ldots \ldots \ldots \ldots \ldots \ldots \ldots \ldots \ldots \ldots \ldots \ldots, \ldots, 4.4$ 
PERSONNEL 3.0

DESIGN PLAN AND SCHEDULE FOR MAINTAINABILITY 3.4

\subsubsection{DEFINITION}

Design plan and schedule refer to the preferred phasing or sequencing of maintainability design activities.

\section{NOTE}

Only basic principles for developing and implementing a design plan and schedule for maintainability are presented in these gujdelines. No attempt is made to detail characteristics of a design program for maintainability. 


\subsubsection{GENERAL PRINCIPLES}

3.4.3.1 Operation equipment, resembling the type being designed, should be studied by the design team. Particular attention should be paid to maintenance features of the equipment and to those features that are lacking in the equipment.

$\mathbf{3 . 4 3}$ The erit:e system (within which the equipment is to be instalied) should be reviewed to determine infor. mation such as where the equipment will se installed, access opening meàsurements, etc.

3.4.3.3 Test equipment and tools already in use on related equipment and that might 'se adapted to the equipment being designed should be determined.
3.4.3.4 Maintenance technician avoilability and required skills and level of proficiency should be determined,

3.4.3.5 Existing storage and work facilities, if any, should be determined.

34,3,6 A determination should be made of the type and quantity of maintenance information (diagrams, $m$-nuals, job aids, etc.) that will be required to maintain the equip ment, how much of ine information is available, and how much information must be developed,

3.43.7 Supply facilities should be determined which are available th provide spare parts for the equipment.

3.4.3.8 $\mathrm{Fl}$ w, diugrams, event trees, state diagrams, schedule charts, or other visual displays should be used to show maintenance or design "equences and ralations. 


\subsubsection{SPECIFICPRINCIPLES}

3.4.4.1 An overall plan for maintainability should be developed to include the following tasks to insure the design for maintainability will proceed in an vorderly and effective manner.

a. PROJECT DEF'NITION PHASE-Proposals for nEw systems shoula include quantitative maintairability objectives as an inherent porion of the periomanee objectives. A maintainability program an appropriate documentation, including the maintainability objec. tives, and a plan for achicving and evaluating objectives should be included.

b. DEVELOPMENT PROGRAM PHASE-The development program phasa should include o: provide for the following essential elements:

(1) PROGRAM PLAN-Contains maintainability objactives, plans, goals, and miestones for accomplishment and evaluation which can be demonstrated on a time basis. This plan can also serve as a guide for all design, production, and product arsurance engineers.

(2) QUANTIT+iIVE MODEL-Provides goais for maintainability, vailability, etc. to seve as a stendard for demonstrating the design ashizvet. This model can also be used in determining the maintainability staus and effectiveness of the system during all stages of design, development, and testing.

(3) SP:CIFICATION REVIEW-Emphasizes the im. portance of maintainability as part of the overall design program. As an initial effort of the program, a complete and thorough study of maintainability and other related product assurance specifications should be made.

(4) PREDICTION AND ANALYSIS-Provides preliminary maintainability predictions based an dab supplied through integrated test program.

(5) TRAINING PROGRAM-Orients to maintain ability all engineering persennel partisipating in equipment or system devalopment.

(6) HUMAN FACTORS ENGINEERING-Reviews equipment design concepss for logic, display control configurations, and operations emphasizing system maintainability.

(7) CHANGE CONTAOL-Procedure assures that design changes required for and affecting main. tainability are carefully reviewed.

(8) SCHEDULED DESIGN REVIEWS-Insures that design changes required for and affecting main. tainability are carefully ratiewed.

(9) METHODS FOR CONSIDERING DESIGN TRADEOFFS-Considers in early cevelopmerit phase, the designs which, while conforming to main tainability specificstions, do not always meet other specified requirements; i.e, operational requirements, raliability, eccnomic limitations, and periormance requirements.

(10) VENDORS INDOCTRIN.:TION PHOGRAM-PROvides subcontracturs with mintainability guidelines and specificotions.

(11) UEMONSTRATIONA ANO TASK-Conducted to obtain maintain bility dato that cannot be evaluated by analytical methods, or as required to verify that main:-inability requirements have been met.

(12) SCHEDULED EVALUATION AND IMPAOVEMENT-Evaluates data feedback fram demonstrations, tests, and fielć areas for supporting design improvement recommendatiors and for verification of maintainability pradictions.

c. PRODUCTION PHASE-During this phase, the maintainability requirements and objectives must be consistent with those established during design and develonment, i.e., with the maintenance support plan. Close survillance should be provided to assule that quality assurance requirements and mointainability specifications are met. This phase considers.

(1) OUALITY CONTROL-Maintains high quality in workmanship and manufecturing standards with respect to maintainahility. Poor quality control practice must be isolated and corsective action initiated to prestude maintainability problems in the field.

(2) MODIFICATION AND CHANGE CONTFOLEstablishes coordination procedures between design and manufacturing activities to insure that clanges or modifications to squipment desizn are agreed upon before they are initiater. In all cases the designer must concur with the changes.

d. OPERATIONAL PHASE-The final validation of mạintanability predictions is accomplished during this neriod. This phase includes:

(1) INITIAL DEVEL.OPMEN! STAGE-Based upon evaluation of data accumulated relative to design rests, engineering costs, user tests, system demonstrations, transportation, stor age assembly, emplacement and check-out. Data should be analyzed and recommendations made for product improvement for future equipment.

(2) FIELD OPERATING STAGE-Active maintenance data should be analyzed from all equipment sitas and used to validate predicied main ainability figures. Uisatisfactory Equipment Reports (UER), Equipment Improvement Reports (EIR), or equivalent nethods, should be utilized.

3.4.4.2 An example of a maintainability plan is provided in the following exhibit: 


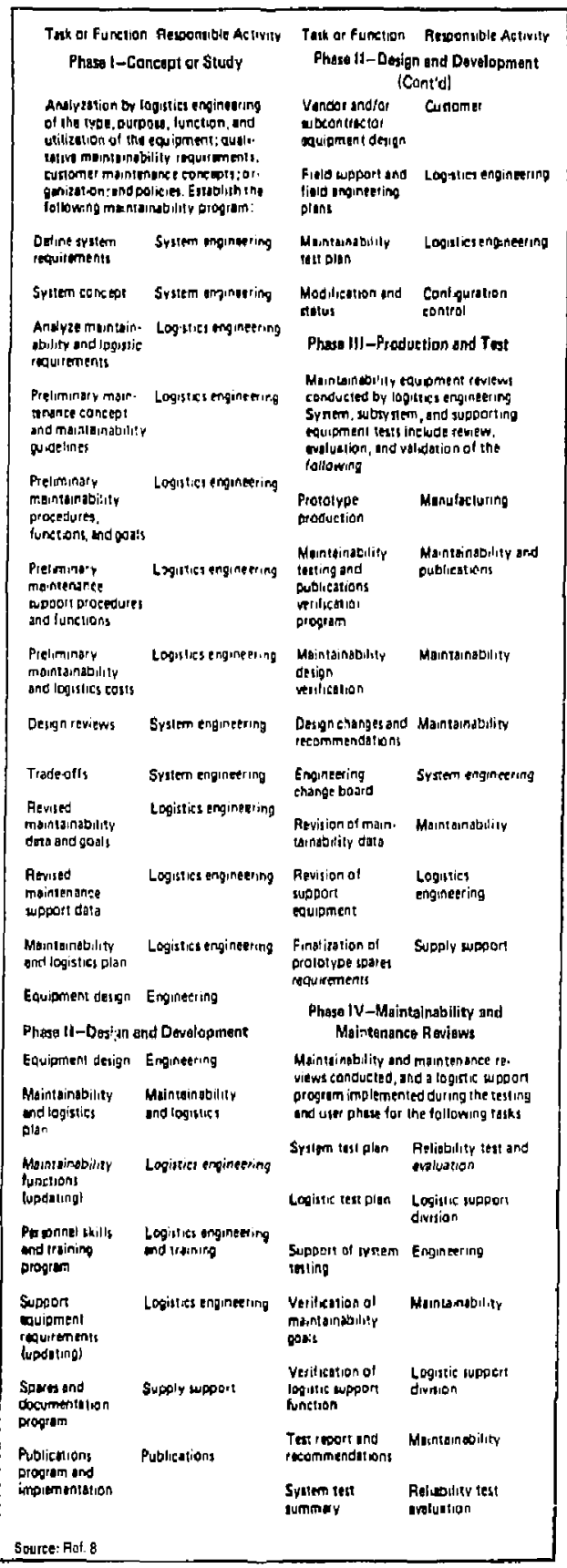

Exhibit 3,4,1 Example of Plan tar Maintainability 
3.4.4.3 To successfully implemen: a design program for maintainability, the maintainability plan should:

a. Be sufficiently flexible to permit revision and updating at any point in the program.

b. Include the various tasks and milestones, and epproximate times required to scomplish each. (This is the design schedule.) c. Show each key ovent, and the coordinated sequence of accurrences, and the interrelationship of events. (This may be shown within the design schedule.)

d. Provide valuable impetus for determining project costs and the most economical a'location of personnel.

3.4.4.4 An example of a design schedute for maintainsbility is shown in the following exhibit:

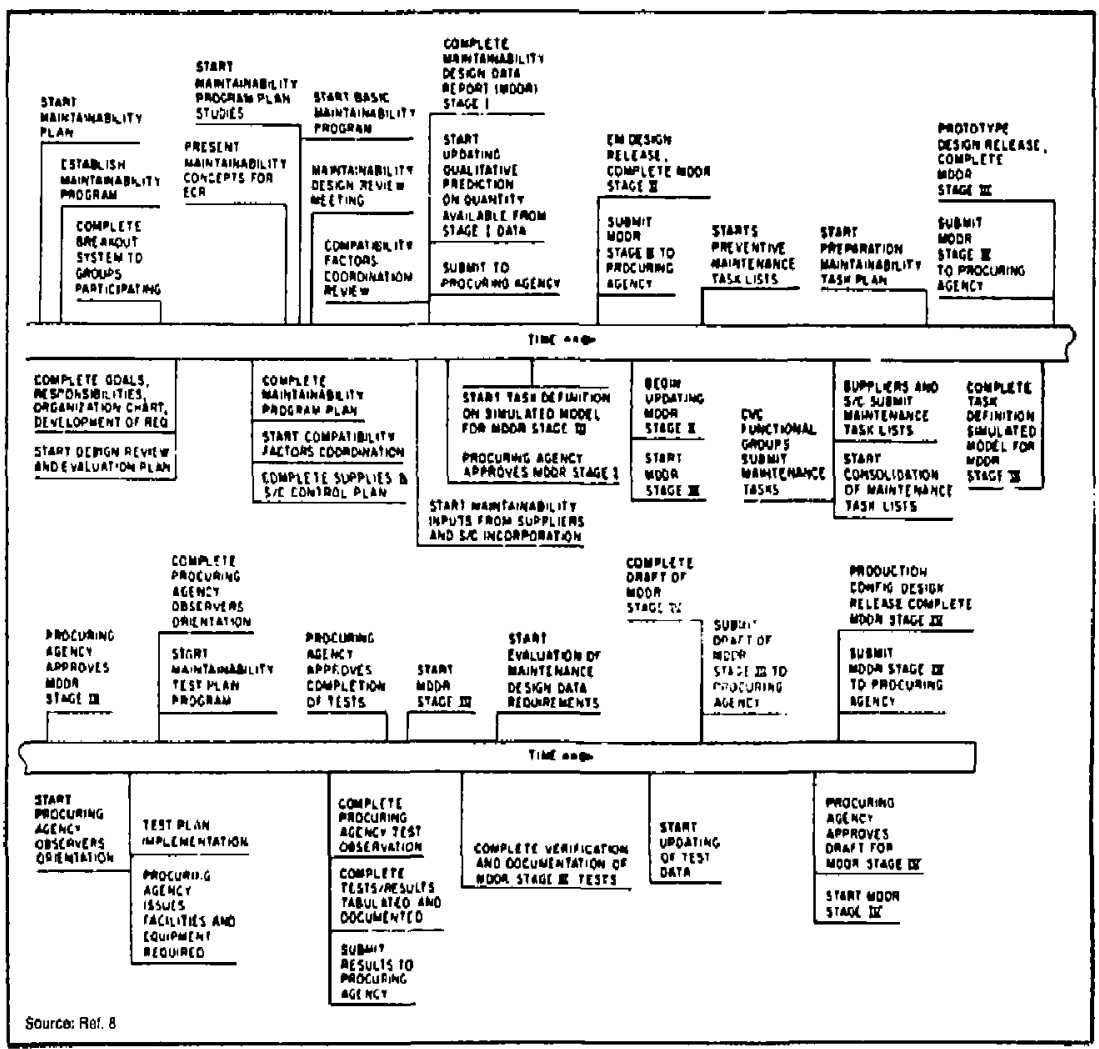

Exhibit 3.4.2. Example of Mointainability Dosign Schedule 


\section{REF SRENCES}

1. Altman, J.W., Marchese, A.C., \& Marchianda, B.W. Guide to design of mechanical equipment for maintainability (ASD Technical Report 61-381). Wright.Patterson Air Force Base, $\mathrm{OH}$, August 1961, (NT!S AD-269332)

2. Blanchard, B.S., \& Lowery, E.E. Maintainability: Principles and practices. New York: McGraw-Hill, 1969.

3. Brynda, W.J., Lobner, P.P., Powell, R.W., \& Siraker, E.A. Design guide for category II reactors light and heavy water cooled reactors. Brookhaven National Laboratory, Uptun, NY. Prepared for the U.S. Departisent of Energy, Washington, D.C., May 1978. (NTIS BNL.50831.11, UC-80)

4. Choate, L.M., Schmidt, T.R. Saridia Laboratories radiation facilitios. Kirtland Air Force Base, E. Albuquerque, NM. Reactor Development and Applications Cepartment, Sendia Laboratories, July 1979.

5. Crawford, B.M., \& Altman, J,W. Designing for mair tainability, In H.P. Van Cott and R.G. Kinkade (Eds.), Human engineering guide to equipment design. Washington, D.C.: Government Printing Office, 1372.

6. Cunningham, C.E., \& Cox, W. Applied maintainability engineering. New York: John Wiley \& Sons, 1972.

7. Designing for man's advances in control room operations. EPRI Journal, July/August 1982, pp. 6-13.

8. Engineering design handbook-maintainability guide for design (AMC Pamphlet 706-134). U.S. Army Materiel Crmmand, Washington, D.C., October 1972. (NTIS AD.754 202)

9. Folley, J.D., \& Altman, J.W. Guide to design of electronic equipment for maintainability (WADC-TR-56-218). Wright Air Development Center, Wright-Patterson Air Force Base, OH, April 1956. (NTIS AD-101-729)

10. Guidelines for control room design reviews (NUREG-0700). Division of Human Factors Safety, Office of Nuclear Reactor Regulation, U.S. Nuclear Regulatory Commission, Washington, D.C., 1981.

11. Human engineering design criteria for military systems, equipment and facilities (MIL-STD1472-C). Department of Defense, Washington, D.C., May 1981.

12. Human factors engineering design for Army materiel (MIL-HBK-759). Department of Defense, Washingtori, D.C., March 1975.

13. Maintainability program requirements (for systems and equipment) (MIL-STD-470). Department of Defense, Washington, D.C. March i勺ế6.

14. McCormick, E.J., \& Sanders, M.S. (Eds.). Human factors engineering and design (5th ed,). New York: McGraw-Hill, 1982. 
15. Morgan, C.T., Chapanis, A., Cook, J.S., III, \& Lund, M.W. (Eds.). Human engineering guide to equipment design. New York: MicGraw-Hill, 1963.

16. Paiker, J.F., Jr, \& West, V.R. (Eds.). Bioastronautics data bonk (2nd ed.). Washington, D.C.: National Aeronautics and Space Administration, 1973.

17. Pulliam, R., Price, H.E., Bongarra, J.P., Jr., Sawyer, C.R., \& Kisner, R.A. A methodology for allocating nuclear power plant control functions to human or automatic control (NUREG/CR3331) U,S. Nuclear Regulatory Commission, Washington, D.C., August 1983.

18. Rigby, L.V., \& Cooper, J1. Problems and procedures in maintainability (ASD Technical Note 61-126). Wright.Patterson Air Force Base, $\mathrm{OH}$, Behavioral Sciences Laboratory, Aerospace Meoitcal Laboratory, Aeronautical Systems Division, Air Force Systems Command, U.S. Air Force, October 1961. (NTIS AD-273-108)

19. Rigby, L.V., Cooper, J.I., \& Spickard, W.A. Guide to integrated system design for maintainability (ASD Technical Report 61-424). Wrighti-Pattersom Air Force Base, $\mathrm{OH}$, Behavioral Sciences Laboratory, Aerospace Medical Laboratory. Aeronautical Systems Division, Air Force Systems Command, U.S. Air Force, October 1961.

20. Seminara, J.L. Human factors methods for assessing and enhancing power plant maintainability (EPRI-NP-2360). Prepared by Lockheed Missiles \& Space Company, Inc., for the Electric Power Research Institute, Palo Alto, CA, May 1982.

21. Seminara, J.L., \& Parsons, S.O. Human factors review of power plant maintainability (EPRIN3.3567). Prepared by Lockheed Missiles \& Space Company, Inc., for the Electric Power Research institute, Palo Alto, CA, February 1981.

22. Seminara, J.L., Parsons, S.O., Schmidt, W.J., Gonzalez, W.R., \& Dove, L.E. Human factors review of power plant maintainability (EPRI-NP.1567SY). Prepared by Lockeed Missiles \& Space Company, Inc., for the Electric Powar Aesearch Institute, Palo Alto, CA, October 1980.

23. Seminara, J.L., Gonzalez, W.R., \& Parsons, S.O. Human factors review of nuclear power plant control room design (EPRI.NP-309). Prepared by Lockeed Missiles \& Space Company, Inc., for Electric Power Research Institute, Palo Alto, CA, March 1977.

24. Smith, O.J., \& Babb, A.H. Maintainability engineering. New York: John Wiley \& Sons, 1973.

25. Van Cott, H.P. \& Kinkade, R.G. (E.Js.). Human engineering guide to equipment design. Washington, D.C.: U.S. Gover.ment Printing Office, 1972.

26. Woodson, W.E. Human factors design handbook. New York: MicGraw. Hill, 1981.

27. Zahn, h.j. at al. Develuping maintainability for fusion power systems (Final Report). McDonnell Douglas Astronautics Company, St. Louis, MO. Prepared for the U.S. Department of Energy, Washington, D.C., Novernber 1979. (NTIS CO0.4184-8) 


\section{ADDITIONAL REFERENCES}

1. User document on requirements of DEC computers. Digital Equipment Corporation, 7700 Edgewater Drive, Oakland, CA 94621.

2. Hand Tool Design - Greenburg, L, \& Chaffin, D.B. Workers and their tools: A guide to the ergonomic design of hand tools and small presses. Ann Arbor, Mi; University of Michigan, monograph, July 1975.

3. Maintenance and Test Procedures - Brune, R.L. \& Weinstein, M. Procedures Evaluation Checklist for maintenance, test, and calibration procedures (NUREG/CR-1369, Revision 1).

Washington, D.C.: Nuclear Regulatory Commission, September 1982.

4. MIL-HDBK-6303B-1 (TM) Technical Writing Style Guide, Washington, D.C.: Department of Defense, 1 May 1977. 
SOURCE REFERENCE DOCUMENT 
Engineered Hardware 1.0

Source Reference Document

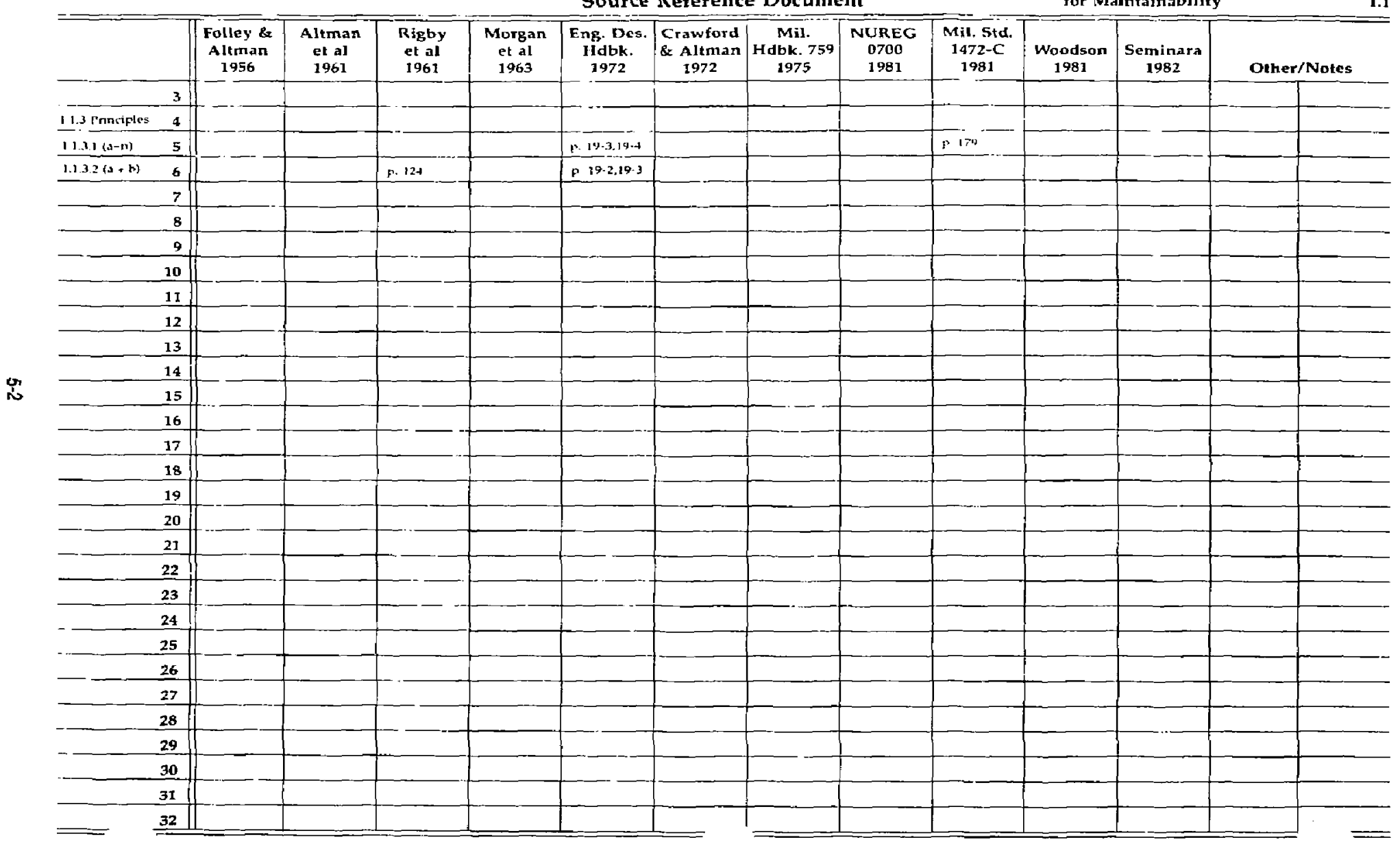


Engineered Har. e 1.0

Source Reference Document

Unit Layout, Packaging and Mounting for Maintainability

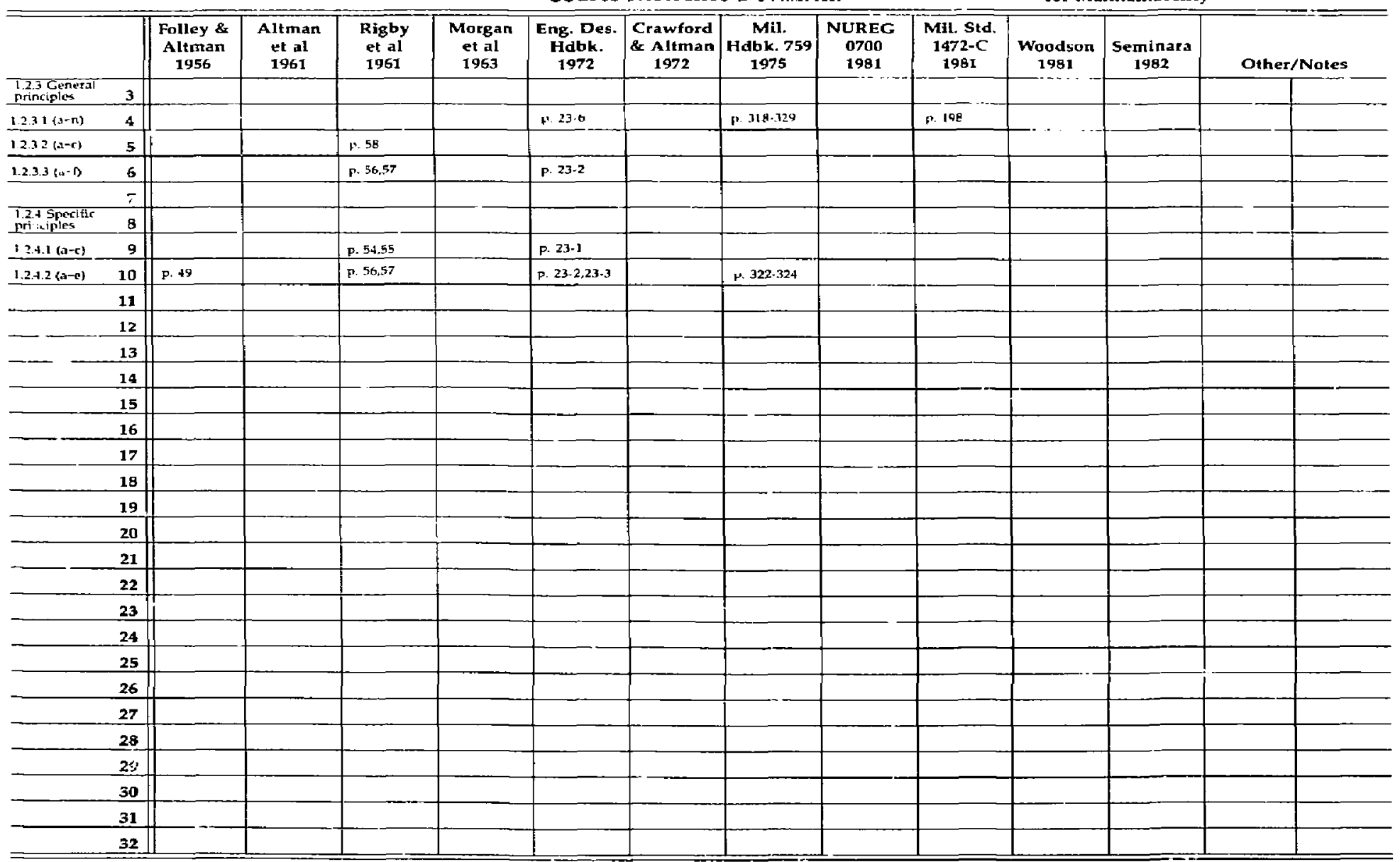


Engineered Hardware 1.c

Source Reference Dacument

Hardware Identification

for Mainlainability

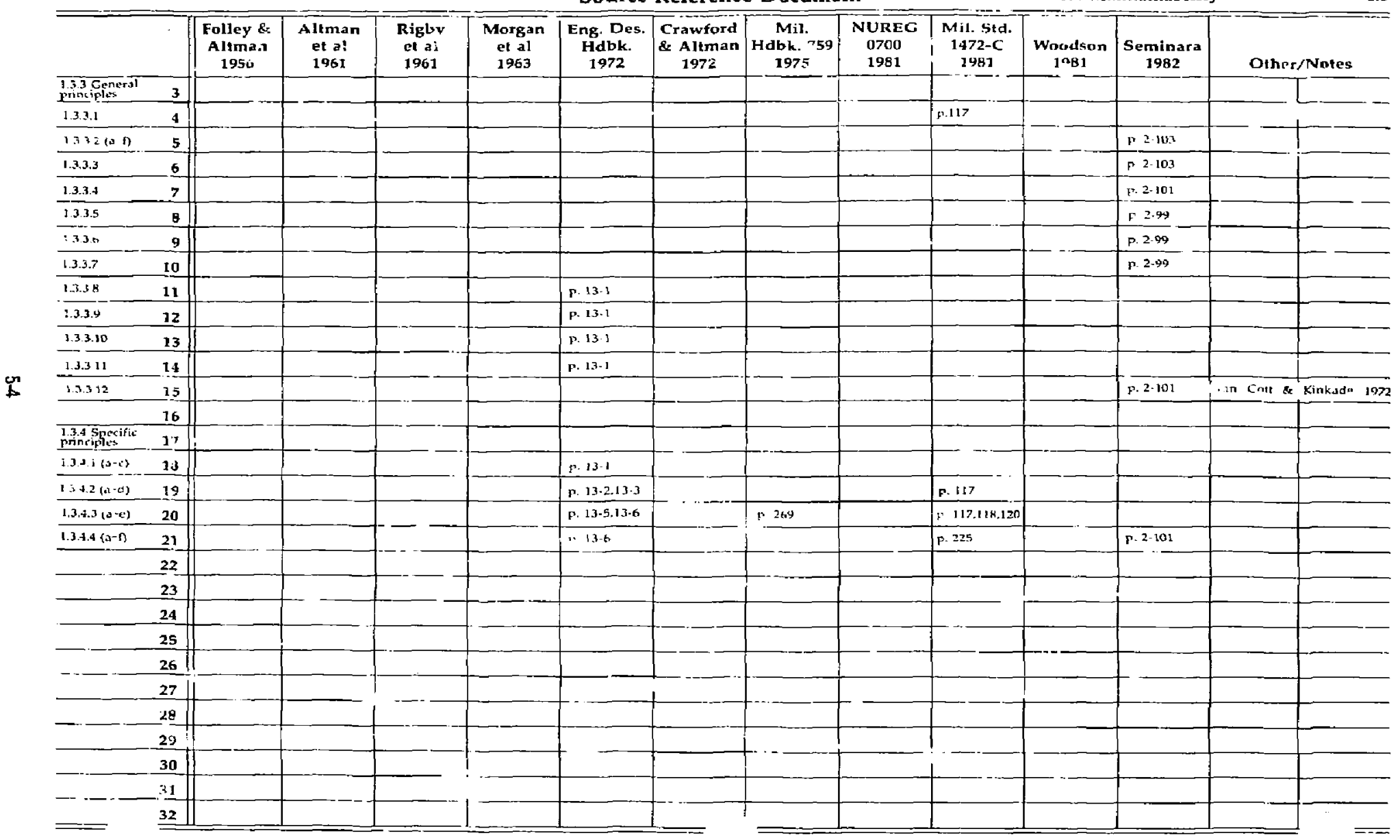


Engineered Har' 1.0

Source Reference Dacument

Equipment Accessibility

$\mathbf{1 . 4}$




Engineered Hardware 1.0

Source Reference Document

\begin{tabular}{|c|c|c|c|c|c|c|c|c|c|c|c|c|c|}
\hline \multirow{3}{*}{$\begin{array}{l} \\
153 \text { Genral } \\
\text { principles }\end{array}$} & \multirow{3}{*}{3} & \multicolumn{9}{|c|}{ Source Reference Document } & \multicolumn{2}{|c|}{ for Maintainabilit } & \multirow[b]{2}{*}{ Other/Notes } \\
\hline & & $\begin{array}{c}\text { Folley \& } \\
\text { Altman } \\
1956\end{array}$ & $\begin{array}{l}\text { Altman } \\
\text { et al } \\
1961\end{array}$ & $\begin{array}{l}\text { Rigby } \\
\text { ef al } \\
1961\end{array}$ & $\begin{array}{c}\text { Morgan } \\
\text { et al } \\
1963\end{array}$ & \begin{tabular}{|c|} 
Eng. Des. \\
Hdbk. \\
1972
\end{tabular} & $\begin{array}{c}\text { Crawford } \\
\text { \& Altman } \\
1972\end{array}$ & $\begin{array}{c}\text { Mil. } \\
\text { Hdbk. 759 } \\
1975\end{array}$ & $\begin{array}{c}\text { NUREG } \\
0700 \\
1981\end{array}$ & $\begin{array}{c}\text { Mil. Std. } \\
1472-C \\
1981\end{array}$ & $\begin{array}{c}\text { Woadson } \\
1981\end{array}$ & $\underset{1982}{\text { Seminara }}$ & \\
\hline & & & & & & & & & & & & & \\
\hline $1.5 .3 .1(2-n)$ & 4 & & p. 30.31 & & & & F. 614 & & & & & & \\
\hline \multirow[t]{2}{*}{$15.3 .2(0-8)$} & 5 & & p. $34-35$ & & & & & & & & & & \\
\hline & 6 & & & & & & & & & & & & \\
\hline \multirow{2}{*}{$\begin{array}{l}\text { 15.45perific } \\
\text { principes } \\
1.5 .10(0-c)\end{array}$} & 7 & & & & & & & & & & & & \\
\hline & 8 & & p. 33 & & & & & & & & & & \\
\hline \multirow[t]{2}{*}{$1.5 .422(0-k)$} & 9 & & p. 353 & & & & & & & & & & \\
\hline & 10 & & & & & & & & & & & & \\
\hline \multicolumn{14}{|c|}{11} \\
\hline \multicolumn{14}{|c|}{-12} \\
\hline \multicolumn{14}{|c|}{13} \\
\hline \multicolumn{14}{|c|}{14} \\
\hline \multicolumn{14}{|c|}{15} \\
\hline \multicolumn{14}{|c|}{16} \\
\hline \multicolumn{14}{|c|}{17} \\
\hline \multicolumn{14}{|c|}{18} \\
\hline \multicolumn{14}{|c|}{19} \\
\hline \multicolumn{14}{|c|}{20} \\
\hline \multicolumn{14}{|c|}{21} \\
\hline \multicolumn{14}{|c|}{22} \\
\hline \multicolumn{14}{|c|}{23} \\
\hline \multicolumn{14}{|c|}{24} \\
\hline \multicolumn{14}{|c|}{25} \\
\hline \multicolumn{14}{|c|}{26} \\
\hline \multicolumn{14}{|c|}{27} \\
\hline \multicolumn{14}{|c|}{28} \\
\hline & 29 & & & & & & & & & & & & \\
\hline & 30 & & & & & & & & & & & & \\
\hline & 31 & 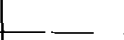 & & & & & & & & & & & \\
\hline$\underline{-}$ & 32 & & & & & & & & & & & & \\
\hline
\end{tabular}


Source Reference Document

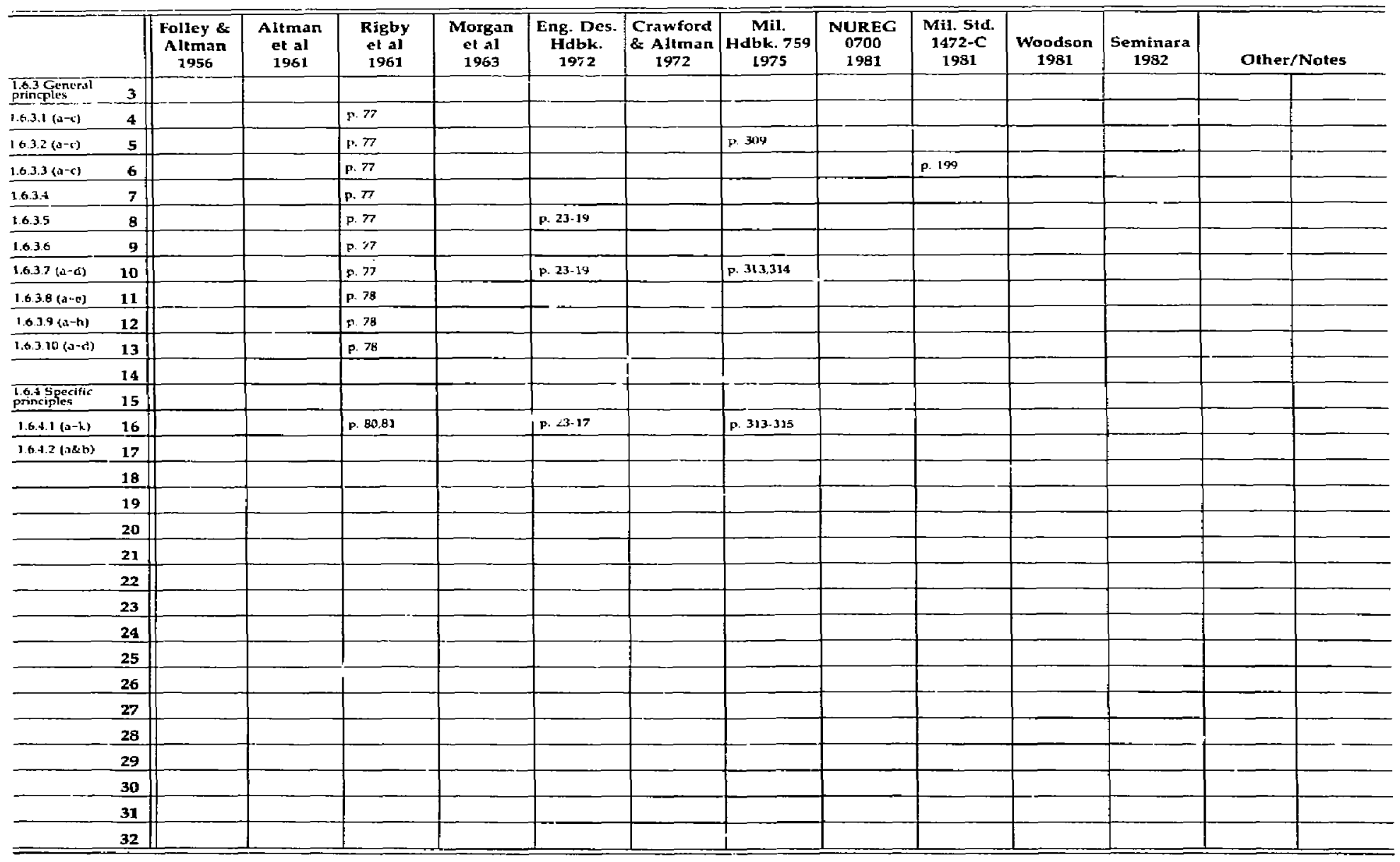


Engincered Hardware 1.0

Test and Service Point Design

Source Reference Document

\begin{tabular}{|c|c|c|c|c|c|c|c|c|c|c|c|c|c|}
\hline & & & & \multicolumn{5}{|c|}{ source Reference } & \multicolumn{3}{|r|}{ ntamation } & \\
\hline & & $\begin{array}{c}\text { Folley \& } \\
\text { Altman } \\
1956\end{array}$ & $\begin{array}{l}\text { Altman } \\
\text { et al } \\
1961\end{array}$ & $\begin{array}{l}\text { Rigby } \\
\text { ef al } \\
1961\end{array}$ & $\begin{array}{c}\text { Morgan } \\
\text { et al } \\
1963\end{array}$ & $\begin{array}{l}\text { Eng Des. } \\
\text { ldabk. } \\
1972\end{array}$ & $\begin{array}{l}\text { Crawford } \\
8 \text { Altman } \\
1972\end{array}$ & $\begin{array}{c}\text { Mil. } \\
\text { Hdbk. } 759 \\
1975\end{array}$ & $\begin{array}{l}\text { NUREG } \\
\text { O7U0 } \\
1981\end{array}$ & $\begin{array}{c}\text { Mil. Std. } \\
1472-C \\
1981\end{array}$ & \multirow[t]{2}{*}{$\begin{array}{c}\text { Woodsion } \\
1981\end{array}$} & \multirow[t]{2}{*}{$\begin{array}{c}\text { Seminara } \\
1982\end{array}$} & Other/Notes \\
\hline \multicolumn{12}{|l|}{$\begin{array}{l}1.3 \text { General } \\
\text { prifusiples }\end{array}$} & & \\
\hline 1.7 .3 .1 & 4 & & & p. 87 & & & & & & & & & \\
\hline 1.7.3.2. & 5 & & & F. 67 & & & & & & & & & \\
\hline 1.7 .3 .3 & 6 & & p. 122 & P. 67 & & & & & & & & & \\
\hline 1.7.3.4 (a\&\&b) & 7 & & & p. 87 & & & & & & & & & \\
\hline 1.7 .3 .5 & 6 & & & p.87 & & & & & & & & & \\
\hline $1.7 .3 .6(\mathrm{a}-\mathrm{e})$ & 9 & & & P. $B x$ & & & & p. 333 & & & & & 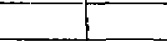 \\
\hline 1.7 .3 .7 & 10 & & F. 122 & P. BR & & & & p. 333 & & & & & \\
\hline 1.7 .3 .8 & 11 & & & p. 88 & & & & & & & & & \\
\hline 1.7 .3 .9 & 12 & & p. 122 & F. 88 & & & & & & & & & \\
\hline $1.7 . x .10$ & 13 & & & P.BH & & & & & & & & & \\
\hline $17.3 .11(\mathrm{a}-1)$ & 14 & & v. 123 & 1. Ba & & & & & & & & & \\
\hline 1.7 .312 & 15 & & 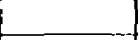 & 1. 89 & & & & p. 331 & & & & & \\
\hline 1.7 .3 .13 & 16 & & p. 1.3 & & & & & & & & & & \\
\hline 1.7 .3 .14 & 17 & & & p. $8 B$ & & & & & & & & & \\
\hline \multirow[t]{2}{*}{$1,7.315$} & 18 & & P. 122 & & & & & & & & & & \\
\hline & 19 & & & & & & & & & & & & \\
\hline \multicolumn{14}{|c|}{$\begin{array}{l}1.74 \text { specific } \\
\text { primciples }\end{array}$} \\
\hline $1.7+1(a-\mathrm{d})$ & 21 & & p. $75,123,125$ & F. 27-27 & & p. $23-28$ & & P. 334-336 & & & & & \\
\hline \multirow[t]{5}{*}{$1.7 .4 .2(\mathrm{a}-\mathrm{e})$} & 22 & & p. $126 \quad 128$ & p. 92 & & p. $16 \cdot 3$ & & & & & & & \\
\hline & 23 & & & & & & & & & & & & \\
\hline & 24 & & & & & & & & & & & & \\
\hline & 25 & & & & & & & & & & & & \\
\hline & 36 & & & & & & & & & & & & \\
\hline \multicolumn{14}{|c|}{27} \\
\hline \multicolumn{14}{|c|}{28} \\
\hline \multicolumn{14}{|c|}{29} \\
\hline \multicolumn{14}{|c|}{30} \\
\hline \multicolumn{14}{|c|}{31} \\
\hline 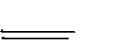 & 32 & & & & & & & & & & & & \\
\hline
\end{tabular}


Source Reference Dacument

\begin{tabular}{|c|c|c|c|c|c|c|c|c|c|}
\hline & & $\begin{array}{c}\text { Folley \& } \\
\text { Altman } \\
1956\end{array}$ & $\begin{array}{l}\text { Allman } \\
\text { et al } \\
1961\end{array}$ & $\begin{array}{l}\text { Richy } \\
\text { et al } \\
1961\end{array}$ & $\begin{array}{c}\text { Morgan } \\
\text { :t al } \\
1963\end{array}$ & $\begin{array}{c}\text { Eng. De. } \\
\text { Hdbk. } \\
1972\end{array}$ & $\begin{array}{c}\text { Crawford } \\
\text { \& Altman } \\
1972\end{array}$ & $\begin{array}{c}\text { Mil. } \\
\text { Hdbk. 759 } \\
1975\end{array}$ & $\begin{array}{c}\text { NUREG } \\
0700 \\
1981\end{array}$ \\
\hline $\begin{array}{l}1.83 \text { General } \\
\text { frinciples }\end{array}$ & 3 & & & & & & & & \\
\hline
\end{tabular}

$1.8 .32(\mathrm{~d}-\mathrm{h}) \quad 5$

1.8.75pecific
principies $\frac{6}{7}$

$1.3 .4 .1(a-c) \quad 8$

1.R.A $2(a-\mathrm{j}) \quad 9$

$1.8+3(a-c) \quad 10$

12

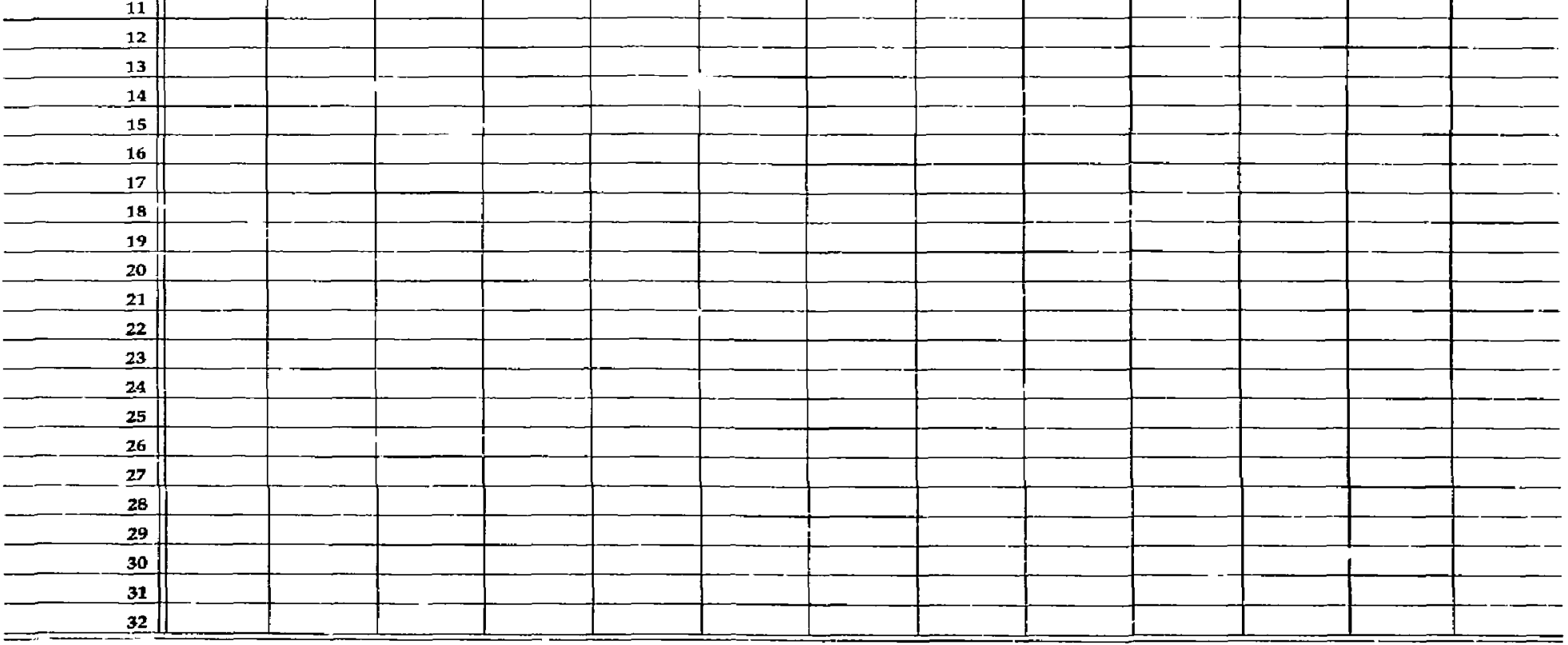


Engineered Hardware 1.0

Source Reference Document

Connector Design

Maintainability

1.9

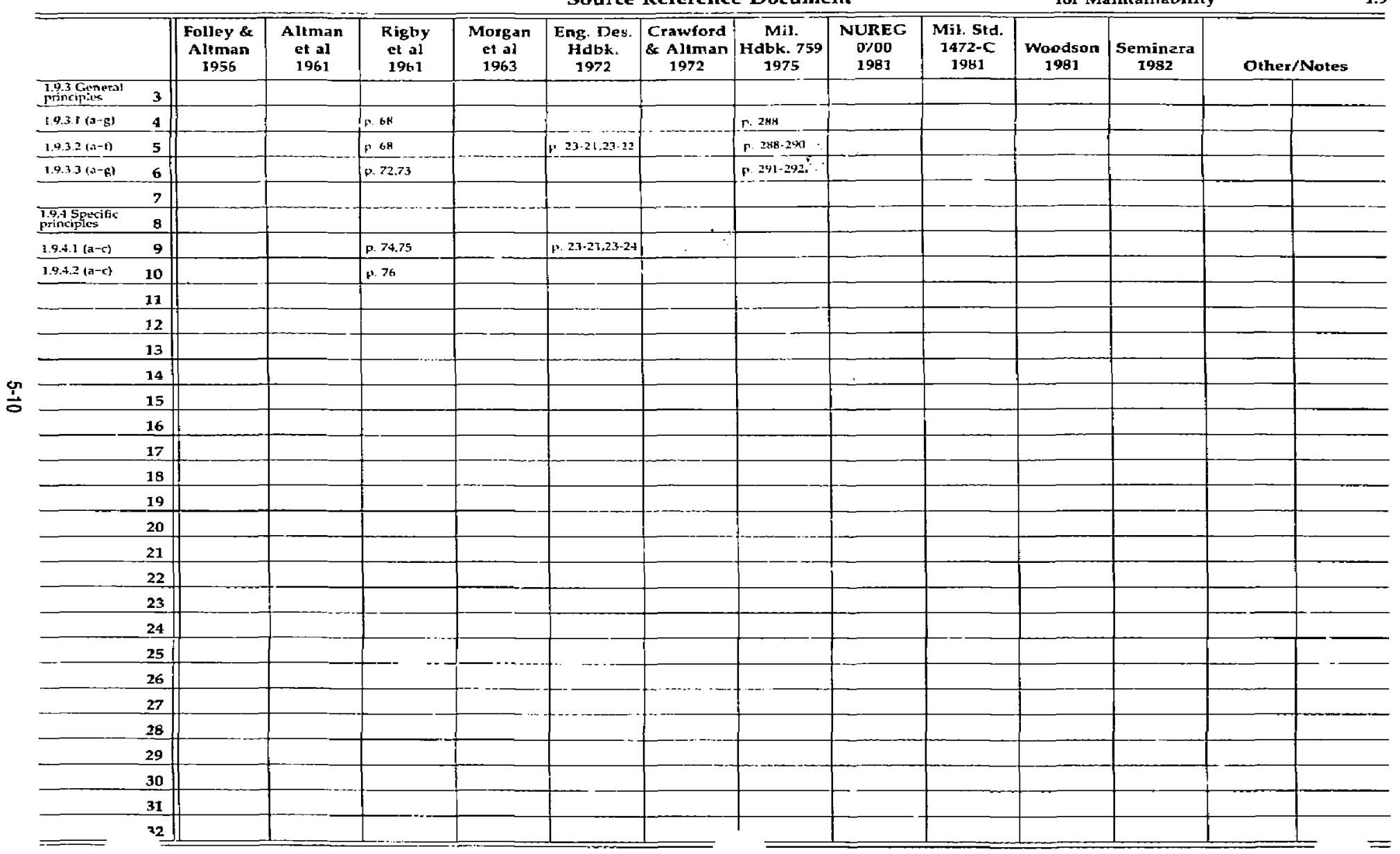


Engineered Hardw:

Source Reference Document

Cover, Case and Shield Design for Maintalnability

\begin{tabular}{|c|c|c|c|c|c|c|c|c|c|c|c|c|c|}
\hline & & $\begin{array}{c}\text { Folley \& } \\
\text { Altman } \\
1956\end{array}$ & $\begin{array}{c}\text { Altman } \\
\text { et al } \\
1961\end{array}$ & $\begin{array}{l}\text { Rigby } \\
\text { et al } \\
1961 \\
\end{array}$ & $\begin{array}{c}\text { Morgan } \\
\text { et al } \\
1963\end{array}$ & \begin{tabular}{|c|} 
Eng. Des. \\
Hdbk. \\
1972
\end{tabular} & $\begin{array}{c}\text { Crawford } \\
\& \text { Altman } \\
1972\end{array}$ & $\begin{array}{c}\text { Mil. } \\
\text { Hdbk. } 759 \\
1975\end{array}$ & $\begin{array}{c}\text { NURFG } \\
0700 \\
1981 \\
\end{array}$ & $\begin{array}{c}\text { Mil. Std. } \\
\text { 1472-C } \\
109_{1}\end{array}$ & $\begin{array}{c}\text { Woodson } \\
1981 \\
\end{array}$ & $\begin{array}{c}\text { Seminara } \\
1982\end{array}$ & Other/Notes \\
\hline \multicolumn{14}{|c|}{$\begin{array}{l}1.103 \text { Generis } \\
\text { finciples }\end{array}$} \\
\hline t.10.3.1 & 4 & & & p. $\mathrm{Hz}$ & & F. 3.13 & & f. 292 & & & & & \\
\hline $\left.1.10 .3 .2+.1-p_{0}\right)$ & 5 & F. 52 & & p. 82 & & & & p. 295 & & & & & \\
\hline $1.10 .3 .3(3-0)$ & 6 & & & p. 82 & & & & & & & & & \\
\hline $1.10 .3 . x(a-g)$ & 7 & & p. 52 & p. 63 & & & & & & & & & \\
\hline $1.103 .5(a-f)$ & $\mathbf{8}$ & & p. 52 & p. 83 & & & & & & & & & \\
\hline $1.10 .3 .6[(\pi-1)$ & 9 & & F. 87,88 & 5.83 & & & & p. 247 & & & & & \\
\hline \multirow[t]{2}{*}{$1.10 .3 .7(\mathrm{~d} \cdot \mathrm{d})$} & 10 & & & f. 85.86 & & & & & & & & & \\
\hline & 11 & & & & & & & & & & & & \\
\hline \multicolumn{14}{|c|}{ 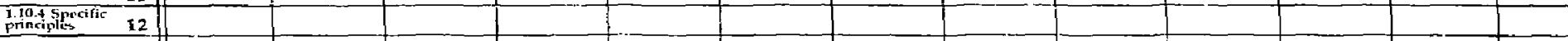 } \\
\hline 1. $10.2 .1(\mathrm{n}-\mathrm{e})$ & 13 & & & p. 85 & & p. 23.14 & & & & & & & \\
\hline $1.10 .4 .2(0-\mathrm{d})$ & 14 & & & P. Ro & & f. 23.15 & & & & & & & \\
\hline $1.107 .3(0-6)$ & 15 & & p. 53 & r.86 & & & & & & & & & \\
\hline $1.10 .4 .7(\mathrm{~d}-\mathrm{e})$ & 16 & & & P. B6 & & & & & & & & & \\
\hline $1.10 .4 .5(x-8)$ & 17 & & p. 51 & & & p. 3.13 & & p. 294 & & & & & \\
\hline \multirow[t]{3}{*}{$1.10 .4 .6(a-g)$} & 18 & & & p. 85 & & & & & & & & & \\
\hline & 19 & & & & & & & & & & & & \\
\hline & 20 & & & & & & & & & & & & \\
\hline & $2 \mathrm{I}$ & & & & & & & & & & & & \\
\hline & 22 & & & & & & & & & & & & \\
\hline & 23 & & & & & & & & & & & & \\
\hline & 24 & & & & & & & & & & & & \\
\hline & 25 & & & & & & & & & & & & \\
\hline & 26 & & & & & & & & & & & & \\
\hline & 27 & & & & & & & & & & & & \\
\hline & 28 & & & & & & & & & & & & \\
\hline & 29 & & & & & & & & & & & & \\
\hline & 30 & & & & & & & & & & & & \\
\hline & $3 I$ & & & & & & & & & & & & \\
\hline & 32 & & & & & & & & & & & & \\
\hline
\end{tabular}


Engineered Hardware 1.0

Source Reference Document

Fastener Design and Afplication

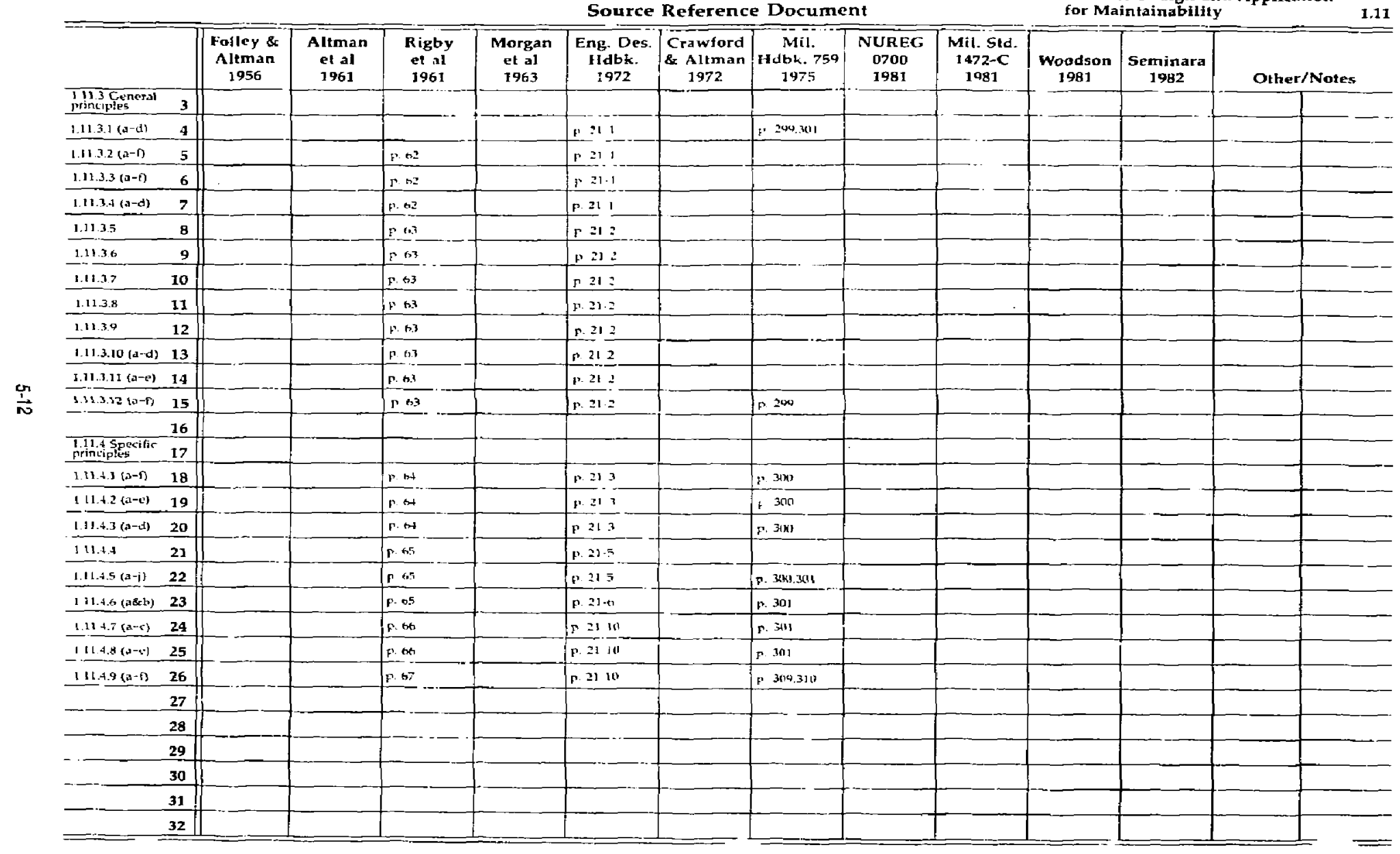




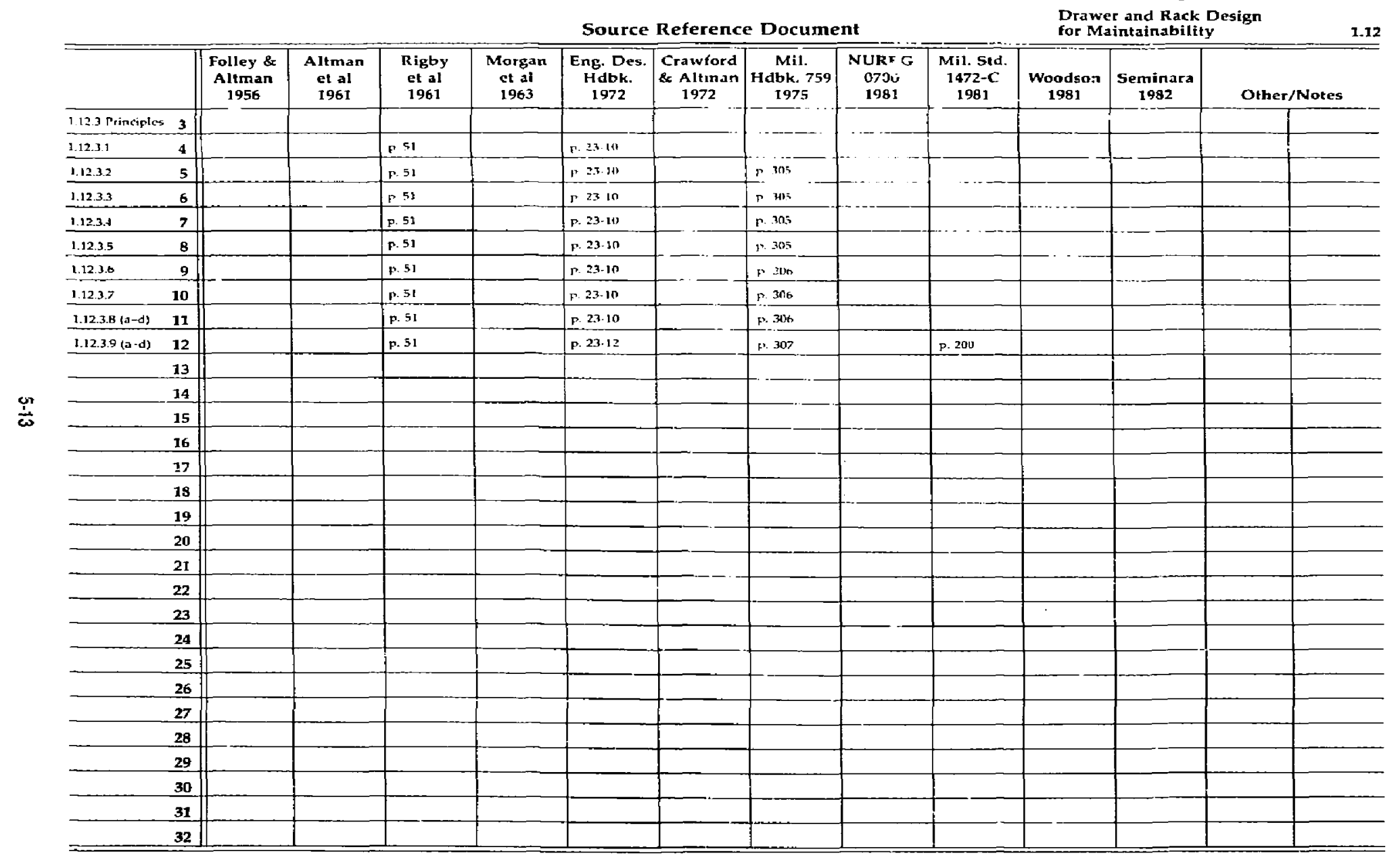


Engineered Mardware 1.0

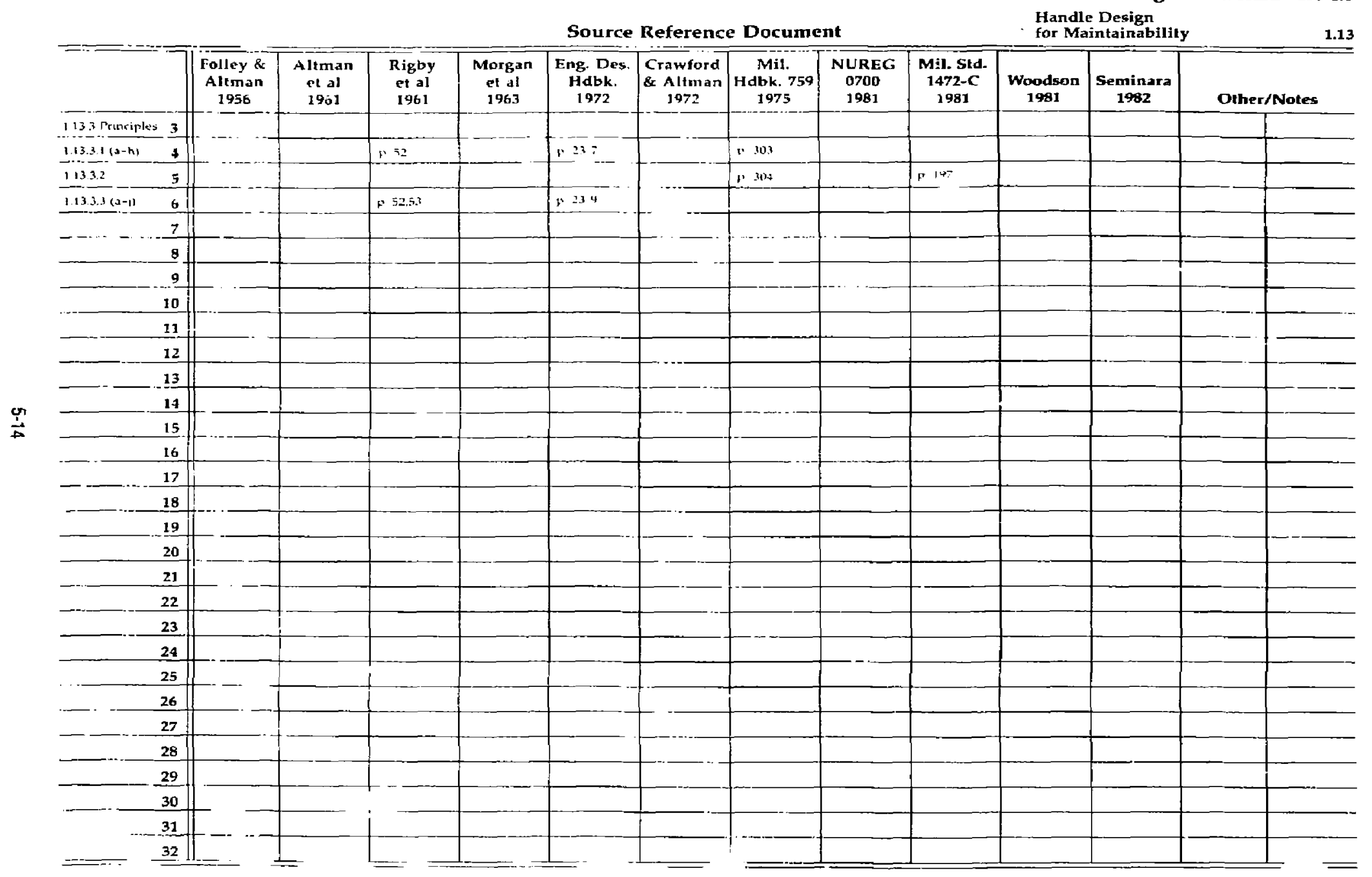


Facility SL, , 2.0

Source Reference Document

Workspace, Storage Repair Facility

Design for Maintainability

\begin{tabular}{|c|c|c|c|c|c|c|c|c|c|c|c|c|c|}
\hline & & $\begin{array}{c}\text { Folley \& } \\
\text { Altman } \\
1956\end{array}$ & $\begin{array}{c}\text { Altman } \\
\text { et al } \\
1961\end{array}$ & $\begin{array}{c}\text { Rigby } \\
\text { 101 al } \\
1961 \\
\end{array}$ & $\begin{array}{c}\text { Morgan } \\
\text { et al } \\
1963 \\
\end{array}$ & $\begin{array}{c}\text { Eng. Des. } \\
\text { Hdbk. } \\
1972\end{array}$ & $\begin{array}{c}\text { Crawford } \\
\& \text { Airman } \\
1972 \\
\end{array}$ & $\begin{array}{c}\text { Mil. } \\
\text { Hdbk. } 759 \\
1975\end{array}$ & \begin{tabular}{|c|} 
NUREG \\
O700 \\
1981
\end{tabular} & $\begin{array}{c}\text { Mil. Std. } \\
1472-C \\
1981\end{array}$ & $\begin{array}{c}\text { Woodson } \\
1981\end{array}$ & $\begin{array}{c}\text { Seminara } \\
1982\end{array}$ & Other/Notes \\
\hline $\begin{array}{l}213 \text { General } \\
\text { princeples }\end{array}$ & 3. & & & & & & & & & & & & \\
\hline 2131 & 4 & & & & F. $4:$ & & & & & & & & \\
\hline $213.2(d-d)$ & 5 & & & & $F=$ & & & & & & & & \\
\hline \multirow[t]{2}{*}{2.1 .3 .3} & 6 & & & & F 17 & & & & & & & & \\
\hline & 7 & & & & & & & & & & & & \\
\hline $\begin{array}{l}2.1 .4 \text { Sgecifie } \\
\text { principles }\end{array}$ & 8 & & & & & & & & & & & & \\
\hline 2.741 rashs) & 9 & & & & $p+k$ & & & f. 174 & & & & & \\
\hline 2.14 .2 & 10 & & & & 5.50 & & & F. $369-173$ & $F$ 61-32.61.36 & p. 142-145 & & & \\
\hline 2.1 .43 & 11 & & & & (1, 5) & & & & & & F. 390 & $2-5,2-11$ & \\
\hline $2.1 .4 .4(\mathrm{a}-\mathrm{v})$ & 12 & & & & & & & F. 175 & & & & p. 2-21 & \\
\hline $2.1 .45(\mathrm{a}-1)$ & 13 & & & & & & & & & & & p. $2-9$ & \\
\hline \multirow[t]{7}{*}{$2,1,4,6(9-5)$} & 14 & & & & & & & & & & & & \\
\hline & 15 & & & & & & & & & & & & \\
\hline & 16 & & & & & & & & & & & & \\
\hline & 17 & & & & & & & & & & & & \\
\hline & 18 & & -1. & & & & & & & & & & \\
\hline & 19 & & & & - & & & & & & & & \\
\hline & 20 & & & & & & & & & & & & \\
\hline \multicolumn{14}{|c|}{21} \\
\hline \multicolumn{14}{|c|}{-22} \\
\hline \multicolumn{14}{|c|}{$\begin{array}{r}23 \\
-\ldots .\end{array}$} \\
\hline \multicolumn{14}{|c|}{24} \\
\hline \multicolumn{14}{|c|}{25} \\
\hline \multicolumn{14}{|c|}{26} \\
\hline \multicolumn{14}{|c|}{27} \\
\hline \multicolumn{14}{|c|}{$\begin{array}{r}28 \\
\end{array}$} \\
\hline \multicolumn{14}{|c|}{$\begin{array}{r}29 \\
\end{array}$} \\
\hline \multicolumn{14}{|c|}{$\begin{array}{r}30 \\
\end{array}$} \\
\hline & 31 & & & & & & & & & & & & \\
\hline & 32 & & & & & & & & & & & & \\
\hline
\end{tabular}


Facility Support $\mathbf{2 . 0}$

c re Reference Document

Maintenance Suppor ${ }^{7}$

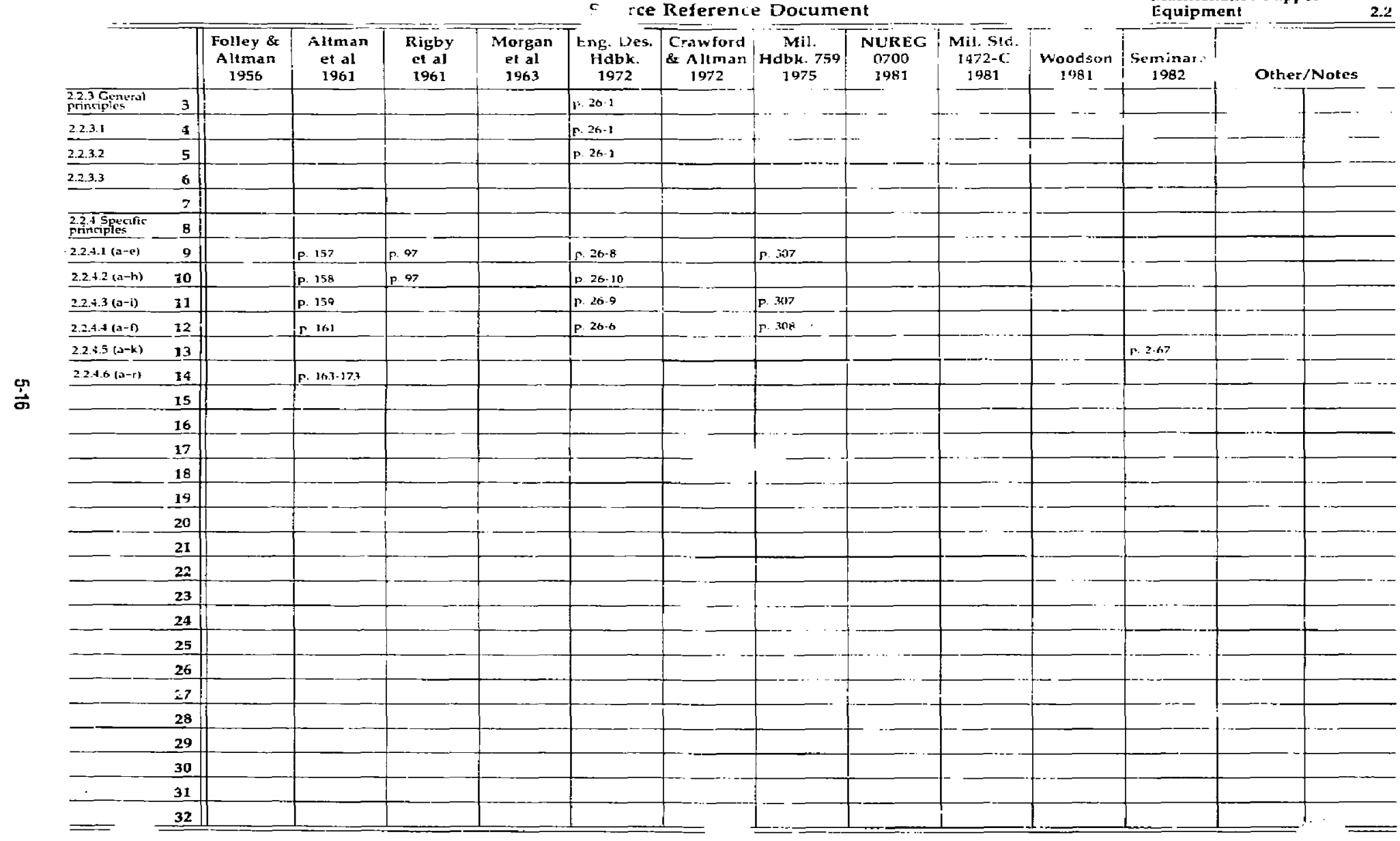


Facility si., oft 2.0

Source Reference Document

Hand Tool Design

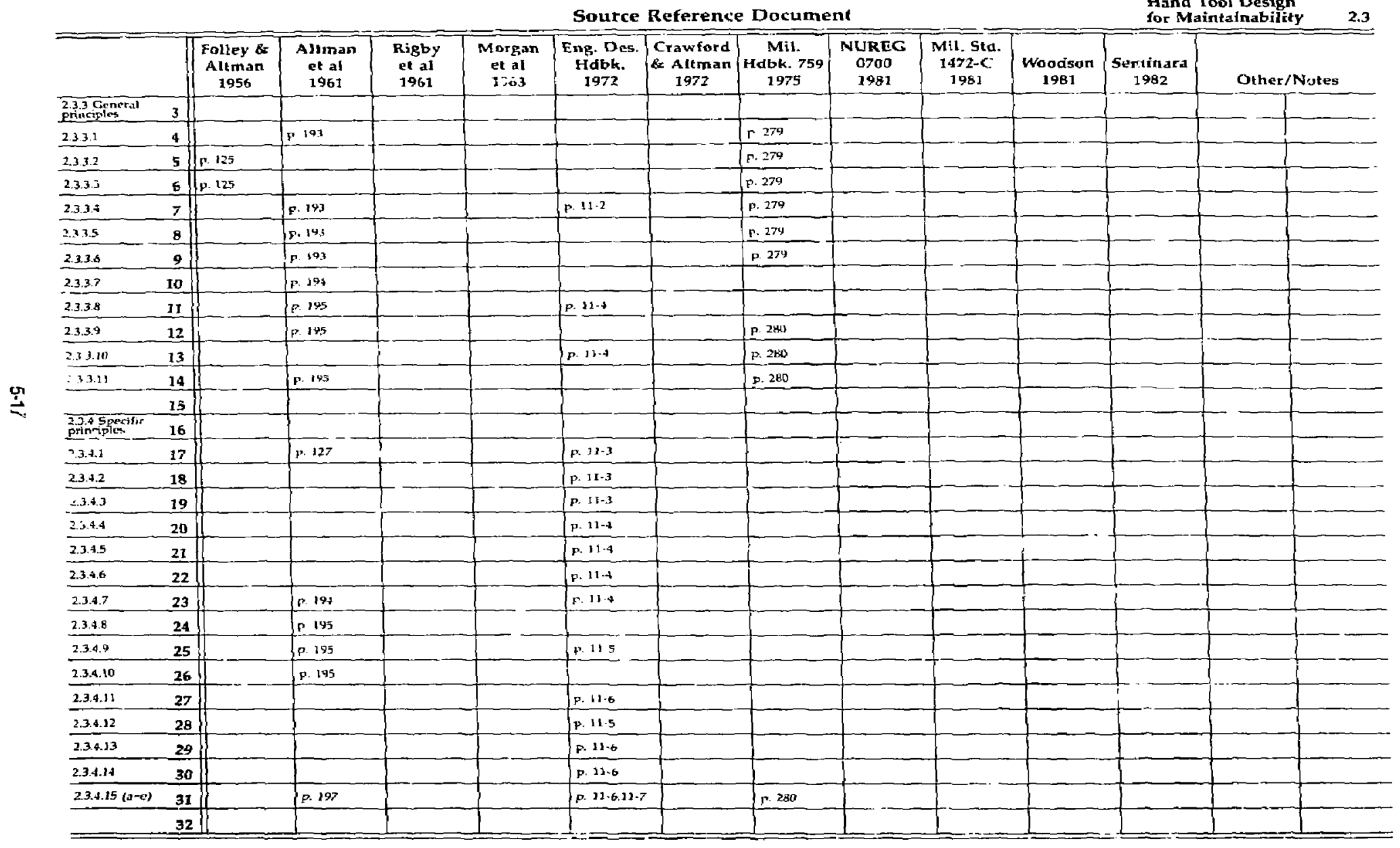


Faciliiy Suppoit 2.ú

Source Reference: Document

Stair, Ladder and Ramp Design

for Mairatainability

2.4

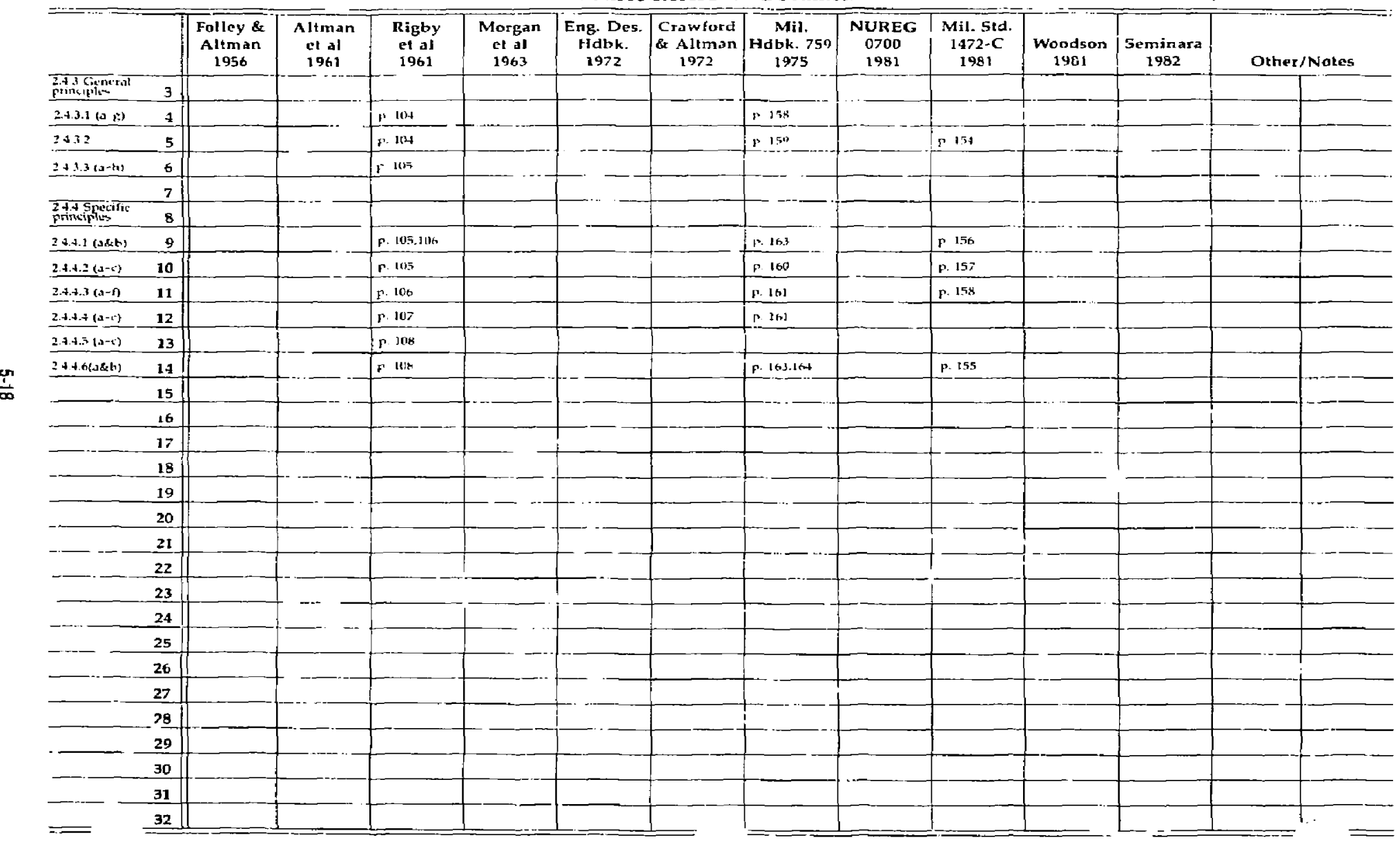


Facility $\$$. ., 2.0

Gource Reference Document

Platform and Shelter Design for Maintainability 2.5

\begin{tabular}{|c|c|c|c|c|c|c|c|c|c|c|c|c|c|}
\hline & & $\begin{array}{c}\text { Folley \& } \\
\text { Altman } \\
1956\end{array}$ & $\begin{array}{l}\text { Altman } \\
\text { et al } \\
\text { 1961 }\end{array}$ & $\begin{array}{l}\text { Rigby } \\
\text { et al } \\
1961\end{array}$ & $\begin{array}{c}\text { Morgan } \\
\text { et al } \\
1963\end{array}$ & $\begin{array}{c}\text { Eng. Des. } \\
\text { Hdbk. } \\
1972\end{array}$ & $\begin{array}{c}\text { Crawford } \\
\text { \&c.Altman } \\
1972\end{array}$ & $\begin{array}{c}\text { Mil. } \\
\text { Hdbk. } 759 \\
1975\end{array}$ & $\begin{array}{l}\text { NIJREG } \\
\text { C700 } \\
1981\end{array}$ & $\begin{array}{c}\text { Mil. Std, } \\
1 \neq i / 2-C \\
1981\end{array}$ & $\begin{array}{c}\text { Woodson } \\
19811\end{array}$ & $\begin{array}{c}\text { Seminara } \\
1982\end{array}$ & Other/Nates \\
\hline $\begin{array}{l}5 \text { inguneral } \\
\text { rincipins }\end{array}$ & 3 & & & & & & & & & & & & \\
\hline $2.5 .3 .1(2-1)$ & 4 & & & P 100 & & & & $F \quad 16\rangle$ & & $\therefore 159$ & & & \\
\hline $2.5 .3 .2(20 \mathrm{D})$ & 5 & & & $F$ InI & & & & & & & & & \\
\hline $2.5 .3 .3(\mathrm{~s}-\mathrm{d})$ & 6 & & & r. 101 & & & & & & & & & \\
\hline $2.5 .3 .4(a-d)$ & 7 & & & p. 101 & & & & & & & & & \\
\hline & 8 & & & & & & & & & & & & \\
\hline $\begin{array}{l}2.545 \text { focific } \\
\text { principles }\end{array}$ & 3 & & & & & & & & & & & & \\
\hline $2.5 .4 .1(a-n)$ & 10 & & & & & p. $26-12$ & & p. 168 & & & & & \\
\hline $2.5 .4 .2(\mathrm{~s}-\mathrm{i})$ & 11 & & & p. 203 & & & & & & & & & \\
\hline 2.5 .4 .3 (a\&b) & 12 & & & & & & & p. 168 & & & & & \\
\hline & 13 & & & & & & & & & & & & - \\
\hline & 14 & & & & & & & & & & & & 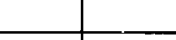 \\
\hline & 15 & & & & & & & & & & & & 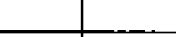 \\
\hline & 16 & & & & & & & & & & & & \\
\hline & 17 & & & & & & & & & & & & \\
\hline & 18. & & & & & & & & & & & & - \\
\hline & 19 & & & & & & & & & & & & \\
\hline & 20 & & & & & & & & & & & & \\
\hline & 21 & & & & & & & & & & & & \\
\hline & 22 & & & & & & & & & & & & \\
\hline 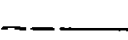 & 23 & & & & & & & & & & & & \\
\hline & 24 & & & & & & & & & & & & \\
\hline & 25 & & & & & & & & & & & & \\
\hline & 26 & & & & & & & & & & & & \\
\hline & 27 & & & & & & & & & & & & \\
\hline & 28 & & & & & & & & & & & & \\
\hline & 29 & & & & & & & & & & & & \\
\hline & 30 & & & & & & & & & & & & \\
\hline & 31 & & & & & & & & & & & & \\
\hline & 32 & & & & & & & & & & & & \\
\hline
\end{tabular}


Facility Support 2.0

Source Reference Document

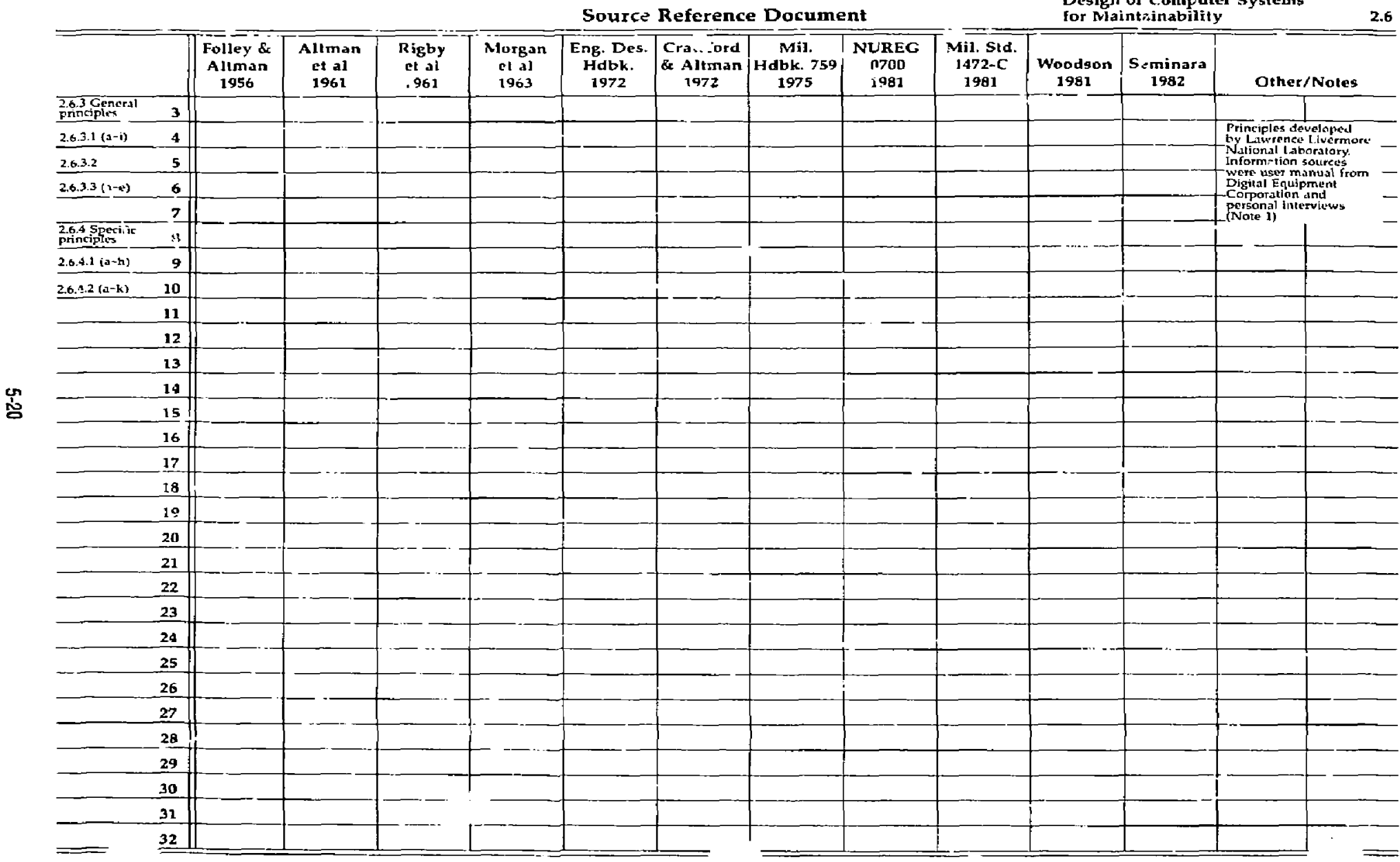


Per:- il 3.0

Source Reference Document
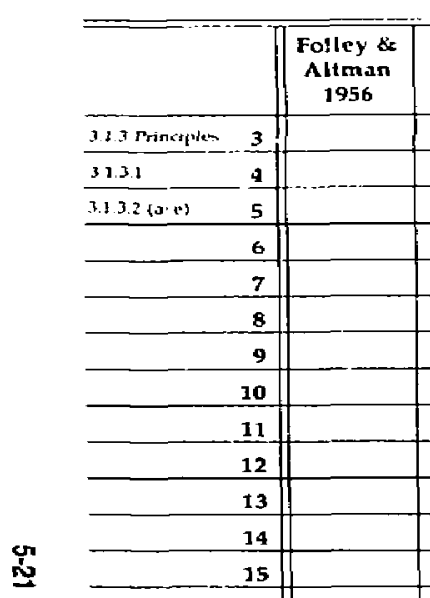

3.3 Prinativer

313.1

$3.13 .26 \cdot 3$

$+2$

Folley \&

Aliman

Morgan

1956

j9b]

et al

et al

Eng. Des. Crawford

\begin{tabular}{l|l|c|c|c} 
ng. Des. & Crawfor & Mil. & NUREG & Mil. Std \\
Hith
\end{tabular}

1972

\begin{tabular}{c|c} 
Altm_: & Habk.75 \\
1972 & 1975
\end{tabular}

NURE

0700
1981

\begin{tabular}{l|l|l|l|l|l|} 
& & 1963 & 1972 & 1975 & 1961 \\
\hline
\end{tabular}

$1472-C$ 1981

3
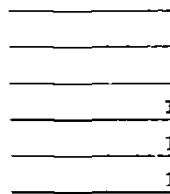

1. 145.14

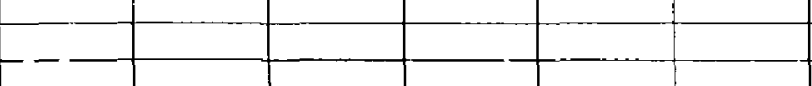

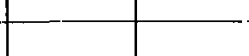

10

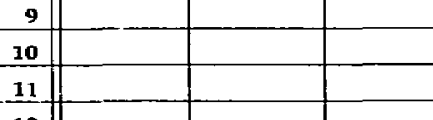

12

\begin{tabular}{l|l|l|l|l}
- & & & \\
& & & & \\
\hline
\end{tabular}

-

$1-$

\begin{tabular}{r|r|r}
\hline \\
\hline
\end{tabular}

p. 1 135.1454

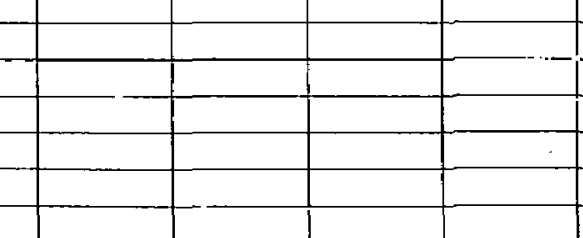

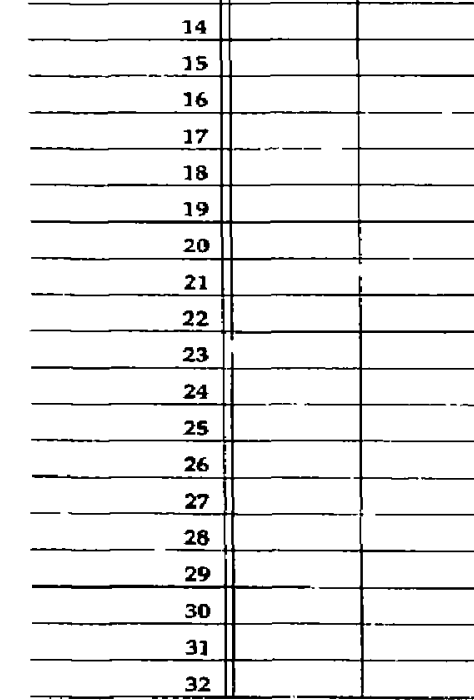

32
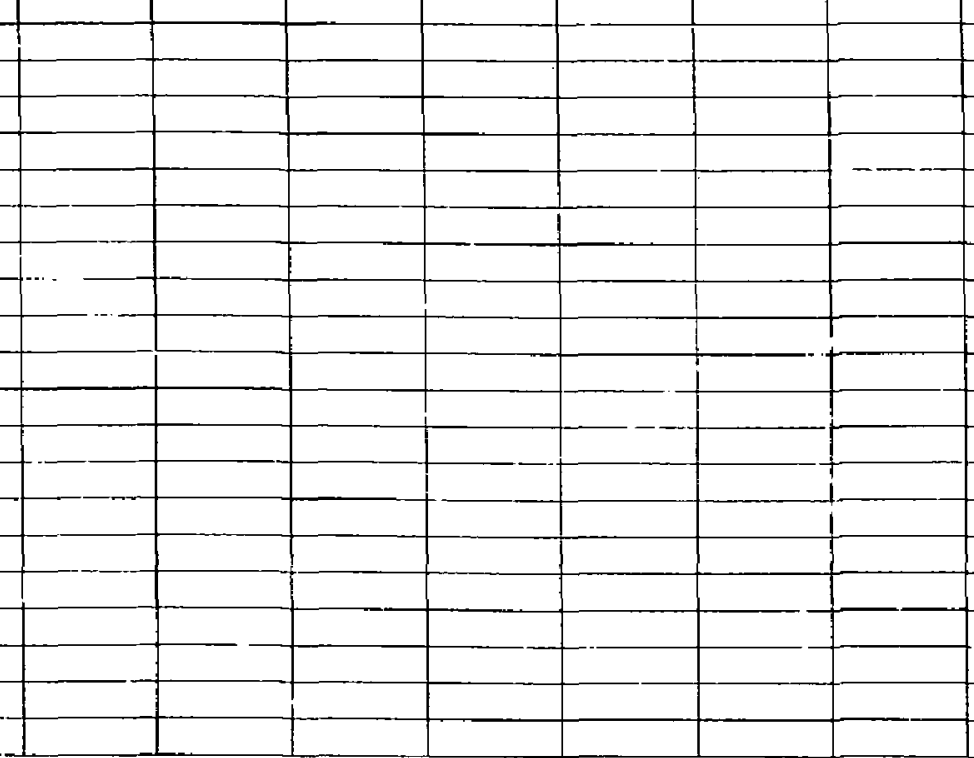

Engineeriug Anthropometry in the
Design for Maintainability

Woodson Seminara

1981 Seminara

1981

1982 .

Other/Notes

$-$

$-1$

\begin{tabular}{l|l|l} 
& & \\
\hline ?.80 & & \\
\hline $2-91$ & & \\
\hline
\end{tabular}

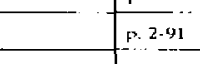
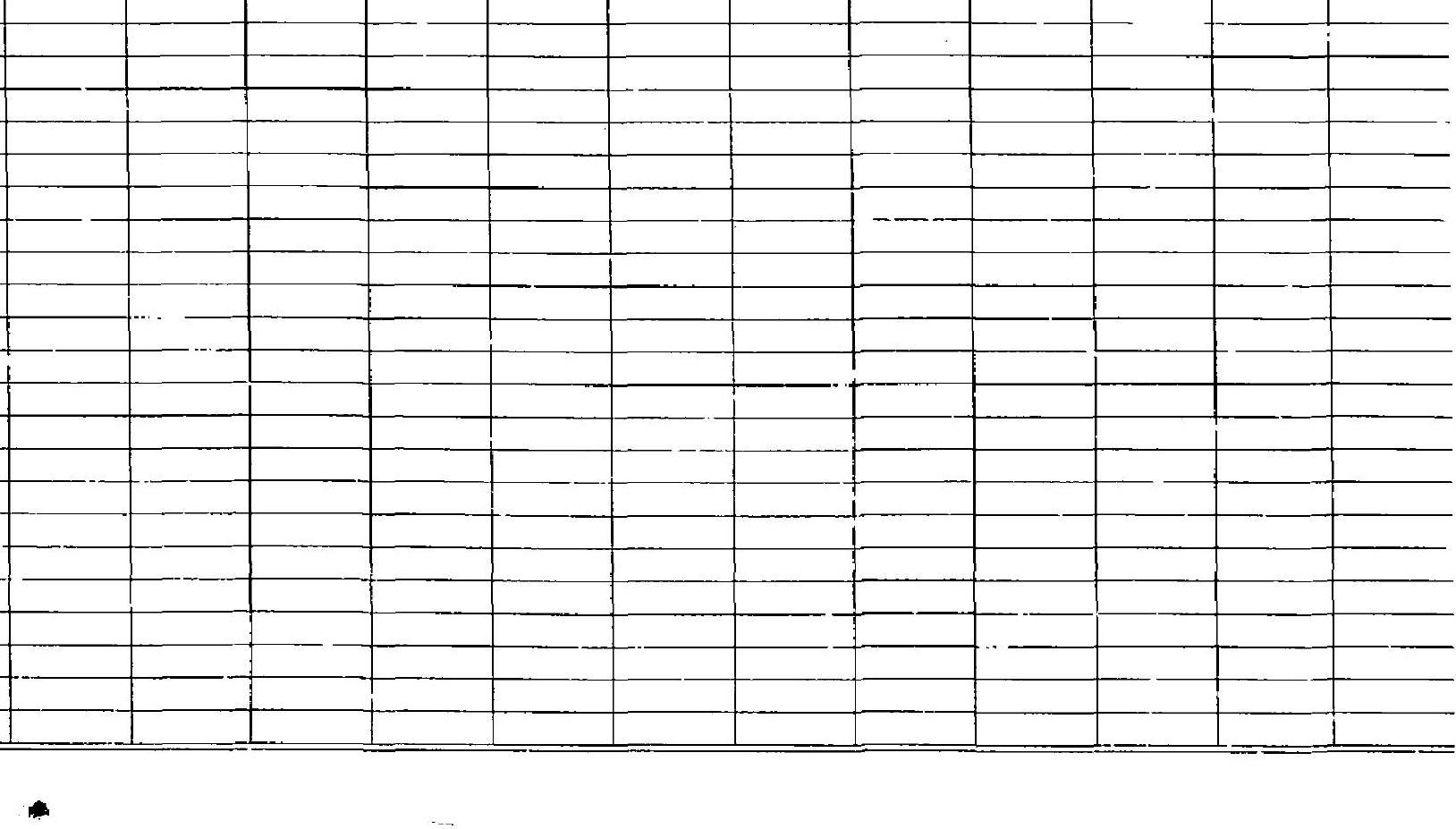
Personnel 3.0

Source Reference Document

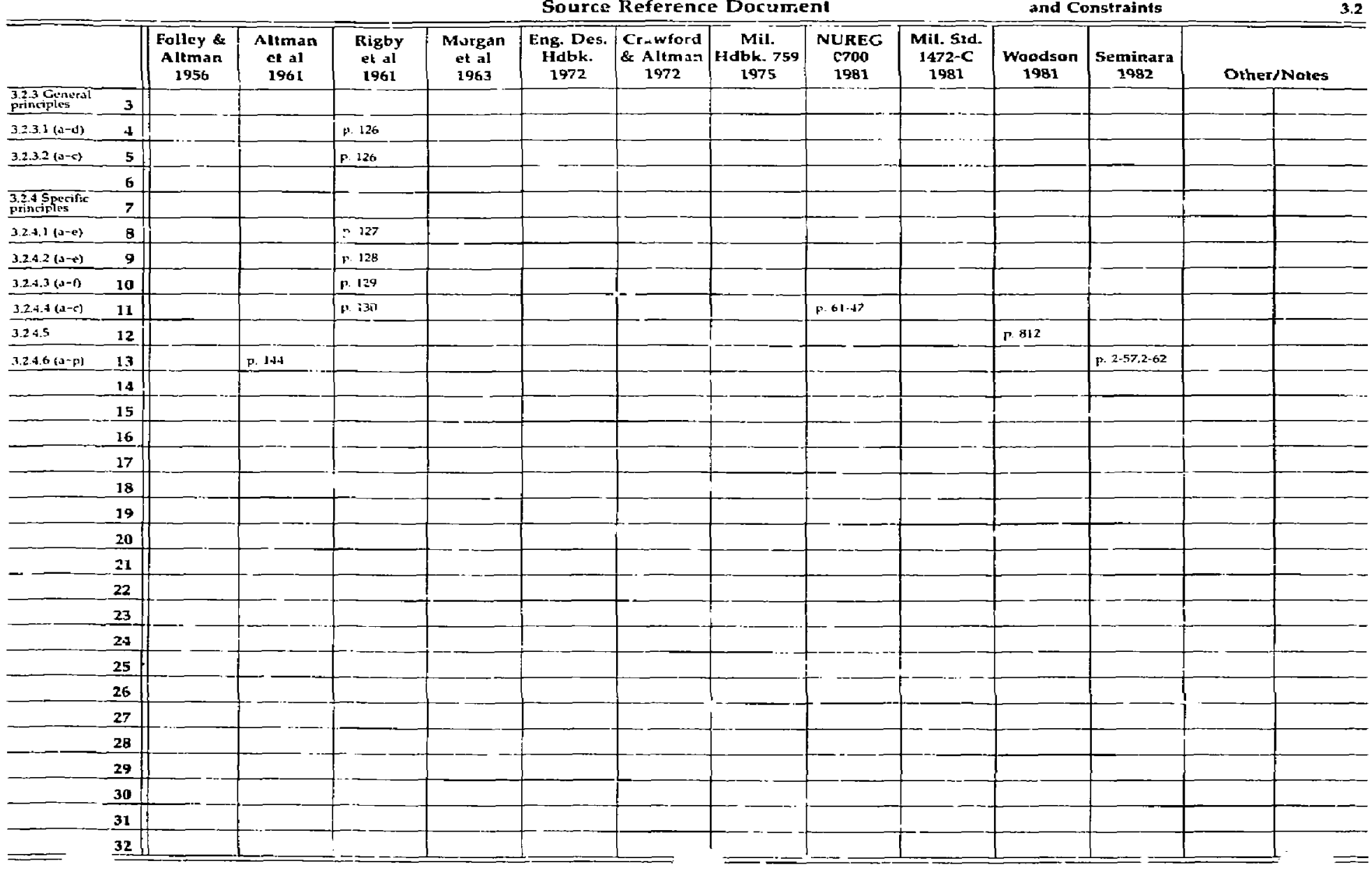


Pers 3.0

Source Reference Document

Maintainance Information 3.3

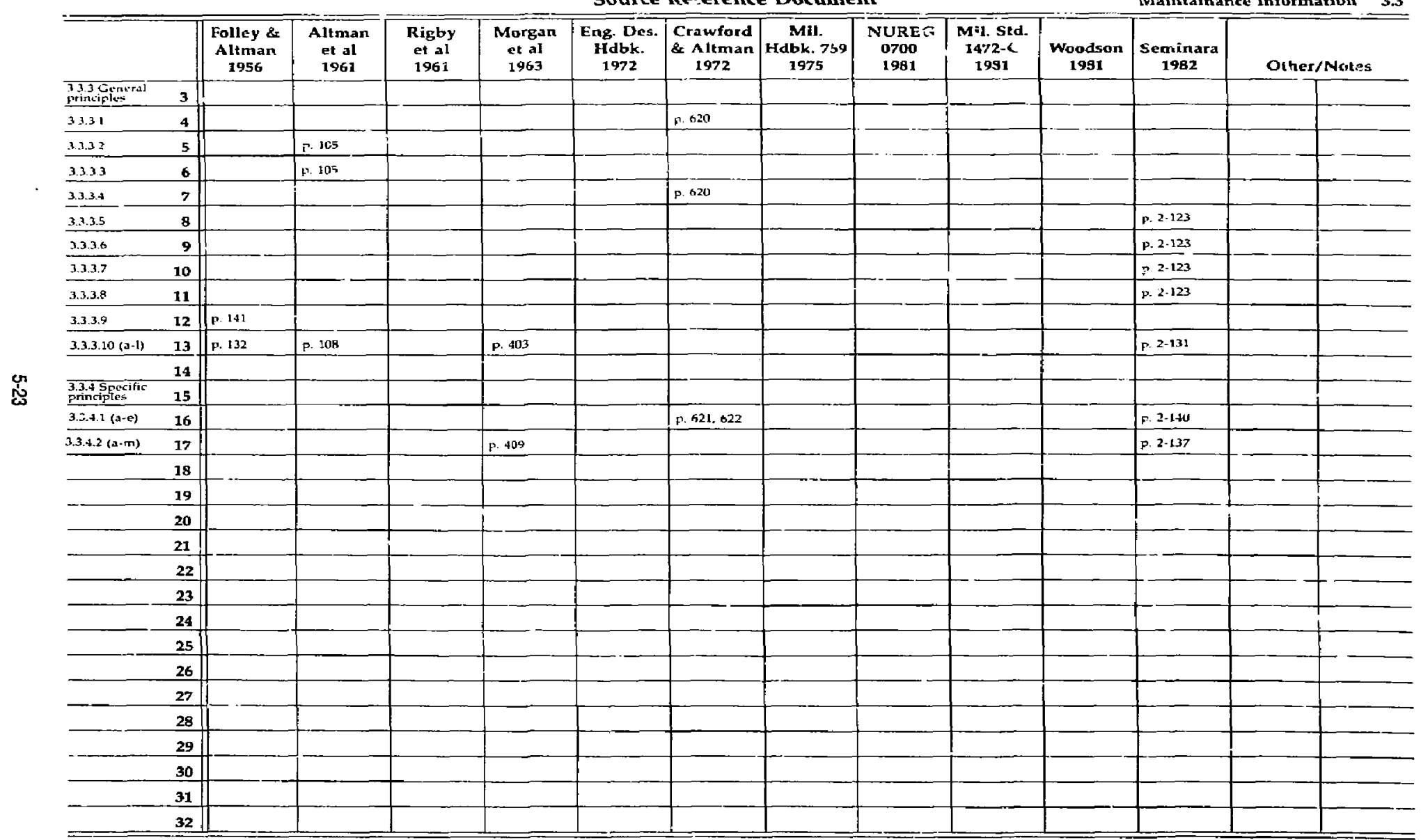


Personnel 3.0

Source Reference Document

Design Plan and Schedule

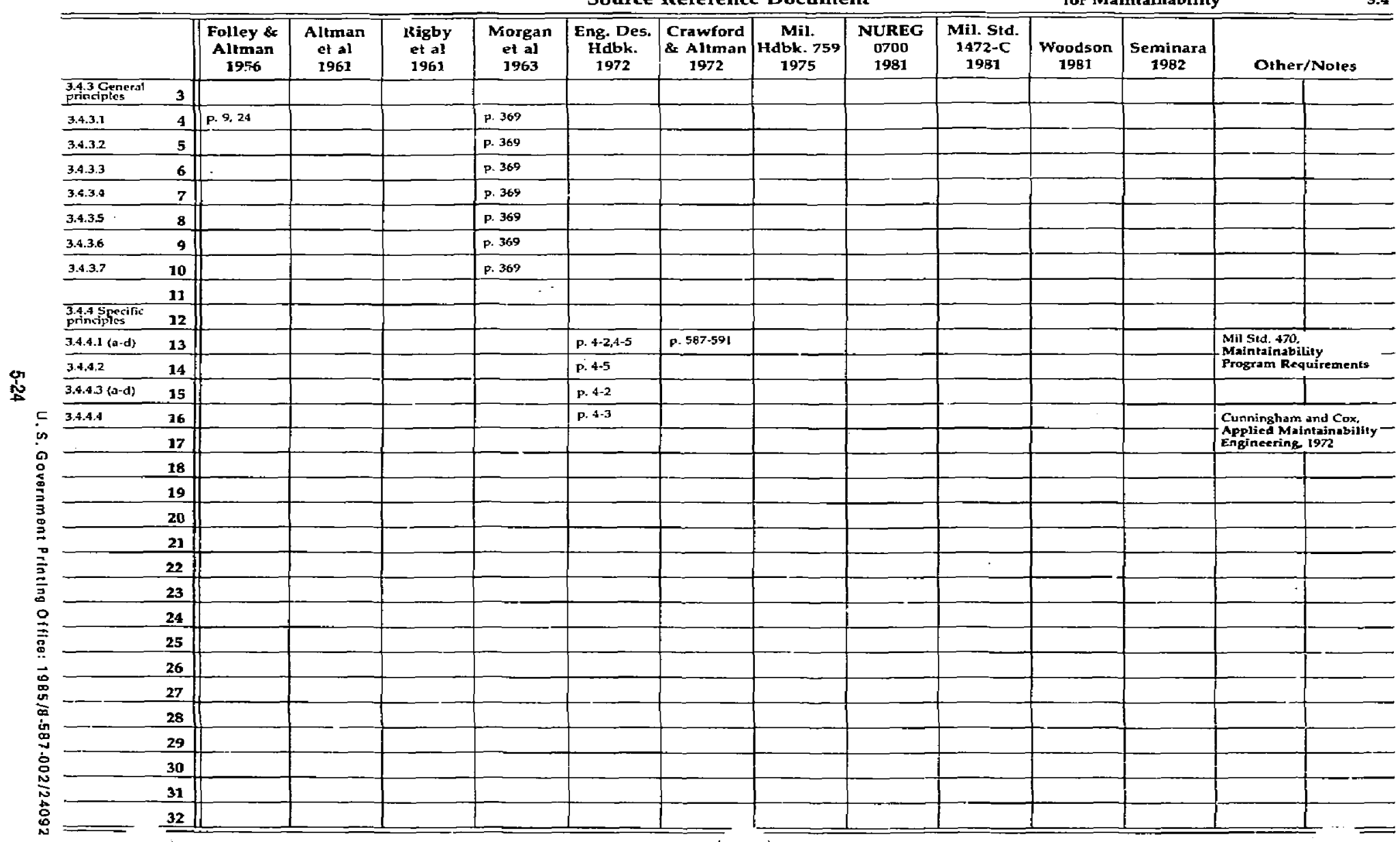

